\title{
Investigation of Injector System and Gas Generator Propellant For Aft-Injected Hybrid Propulsion
}

\author{
by \\ Bryan Pilon, B. Eng. \\ A thesis submitted to the Faculty of Graduate Studies and Research in partial \\ fulfillment of the requirements for the degree of

\section{Master of Applied Science} \\ Ottawa-Carleton Institute for Mechanical and Aerospace Engineering \\ Department of Mechanical and Aerospace Engineering \\ Carleton University \\ Ottawa, Ontario, Canada
}

November 22, 2006 


$\begin{array}{ll}\begin{array}{l}\text { Library and } \\ \text { Archives Canada }\end{array} & \begin{array}{l}\text { Bibliothèque et } \\ \text { Archives Canada }\end{array} \\ \begin{array}{l}\text { Published Heritage } \\ \text { Branch }\end{array} & \begin{array}{l}\text { Direction du } \\ \text { Patrimoine de l'édition }\end{array} \\ \begin{array}{l}\text { 395 Wellington Street } \\ \text { Ottawa ON K1A ON4 }\end{array} & \begin{array}{l}\text { 395, rue Wellington } \\ \text { Ottawa ON K1A ON4 } \\ \text { Canada }\end{array}\end{array}$

Your file Votre référence ISBN: 978-0-494-23344-3 Our file Notre référence ISBN: $978-0-494-23344-3$

NOTICE:

The author has granted a nonexclusive license allowing Library and Archives Canada to reproduce, publish, archive, preserve, conserve, communicate to the public by telecommunication or on the Internet, loan, distribute and sell theses worldwide, for commercial or noncommercial purposes, in microform, paper, electronic and/or any other formats.

The author retains copyright ownership and moral rights in this thesis. Neither the thesis nor substantial extracts from it may be printed or otherwise reproduced without the author's permission.
AVIS:

L'auteur a accordé une licence non exclusive permettant à la Bibliothèque et Archives Canada de reproduire, publier, archiver, sauvegarder, conserver, transmettre au public par télécommunication ou par l'Internet, prêter, distribuer et vendre des thèses partout dans le monde, à des fins commerciales ou autres, sur support microforme, papier, électronique et/ou autres formats.

L'auteur conserve la propriété du droit d'auteur et des droits moraux qui protège cette thèse. $\mathrm{Ni}$ la thèse ni des extraits substantiels de celle-ci ne doivent être imprimés ou autrement reproduits sans son autorisation.
In compliance with the Canadian

Privacy Act some supporting forms may have been removed from this thesis.

While these forms may be included in the document page count, their removal does not represent any loss of content from the thesis.
Conformément à la loi canadienne sur la protection de la vie privée, quelques formulaires secondaires ont été enlevés de cette thèse.

Bien que ces formulaires aient inclus dans la pagination, il n'y aura aucun contenu manquant.

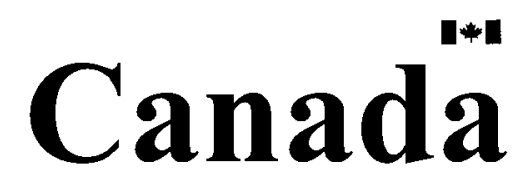




\section{Abstract}

This research consisted of investigate a novel aft-injected hybrid (AIH) rocket propulsion system. An AIH motor operates with the use of a fuel-rich solid propellant (gas generator) which is then mixed in a post combustion chamber with additional oxidizer. The first portion of this dissertation was focused on the development of the gas generator propellant. This included propellant ingredient selection through use of theoretical chemical equilibrium analysis. This was supplemented with mixing of propellant batches and hot-fire testing to obtain ballistic data. The final gas generator propellant used ammonium perchlorate as the oxidizer, HTPB, as the binder, and polyethylene as the fuel. It was discovered that below approximately 400-550 psi the gas generator propellant would self-extinguish, thereby providing the required safety aspects under ambient conditions. Three larger propellant batches with slight ingredient changes were mixed and casted so 4" diameter BATES grains could be hot-fire tested. The final selected propellant batch achieved a burn rate of $6.5 \mathrm{~mm} / \mathrm{s}$ at 800 psi and was used for experimental injector testing in the sub-scale aft-injected motor. The second portion of this research was focused on the fabrication and experimental testing of a sub-scale aft-injected motor, specifically aimed at investigating the injector. This sub-scale motor used water as a substitute oxidizer in order to obtain temperature measurements in the post combustion chamber due to the cooler temperatures $\left(\approx 890^{\circ} \mathrm{C}\right)$. This motor demonstrated the feasibility of the aft-injected concept, and six different injectors were tested. With this it was shown that the momentum ratio plays a significant role in determining how efficient the injector mixes the liquid and gas. To further supplement the injector research a numerical model was developed and presented. 


\section{Acknowledgments}

First and foremost I would like to thank my parents for their loving support throughout my academic life. Without them inscribing in me a strong work ethic, intelligence, and well roundedness, I never would have made it this far. I would also like to thank my Aunt Rose-Ann for her kind heart in allowing this adventure to be less of a burden.

There are also a few people which I would like to recognize in being instrumental to allow my passion for propulsion research to take place. I would like to sincerely thank my supervising Professor Tarik Kaya, for his support and insight during my graduate studies. With the majority of this research taking place at CTI, I would like to acknowledge Dr. Fred Cristy in helping to initiate this collaboration and Anthony Cesarnoi for allowing this wonderful experience to occur. Over the year spent at CTI it was a tremendous pleasure and honor to learn from my co-supervisor Dr Jeroen Louwers. His wisdom and knowledge are undeniably vast and being lucky enough to both work and learn from him is an experience of a life time, and for that I am truly thankful.

Finally I would like to show my great appreciation for my Nagymama and Nagypapa for everything they have provide. Without their sacrifice and hard work over many decades to provide our family with a better life none of this would have been possible.

BRYAN PILON

\section{Carleton University}

November 22, 2006 


\section{Contents}

$\begin{array}{ll}\text { Abstract } & \text { iii }\end{array}$

Acknowledgments iv

List of Tables $\quad \mathbf{x}$

List of Figures $\quad$ xii

Nomenclature $\quad$ xix

Abbreviations $\quad$ xxii

$\begin{array}{lll}\text { Chapter } 1 & \text { Introduction } & 1\end{array}$

1.1 Types of Propulsion Systems $\ldots \ldots \ldots \ldots \ldots$

1.2 Forward and Aft Injected Hybrids . . . . . . . . . . 5

1.3 Thesis Outline $\ldots \ldots \ldots \ldots \ldots \ldots$

1.4 Literature Review . . . . . . . . . . . . . . . . . . . . 10 
1.4.1 Aft-Injected Hybrid Studies . . . . . . . . . . . 10

$\begin{array}{lll}\text { Chapter } 2 & \text { Gas Generator Propellant } & 16\end{array}$

2.1 Goals of Gas Generator Propellant . . . . . . . . . . . . . . 18

2.2 Chemical Equilibrium Analysis . . . . . . . . . . . . 20

2.2 .1 Solid Fuel Oxidizer . . . . . . . . . . . . . . . . 22

$2.2 .2 \quad$ Binder . . . . . . . . . . . . . . . . 24

$2.2 .3 \quad$ Fuel Additives $\ldots \ldots \ldots \ldots \ldots \ldots$

2.3 Propellant Baseline Samples . . . . . . . . . . . . . . . . . . . . . . 31

2.3.1 Step Motor Test Apparatus . . . . . . . . . . . . . . . 33

2.4 Results . . . . . . . . . . . . . . . . . . . 38

$2.4 .1 \quad$ Particle Size Distribution . . . . . . . . . . . . . 40

2.4.2 Combustion Termination $\ldots \ldots \ldots \ldots \ldots$

2.4.3 Selected Gas Generator Propellant . . . . . . . . . . . . . 50

Chapter 3 Trajectory Simulation $\quad 55$

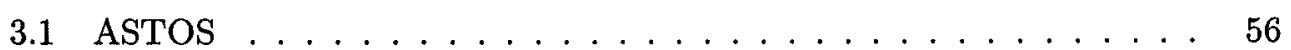

3.2 Launch Vehicle Requirements . . . . . . . . . . . . . . 57

3.3 Input Data $\ldots \ldots \ldots \ldots \ldots \ldots \ldots \ldots$

3.3.1 Propulsion Input $\ldots \ldots \ldots \ldots \ldots \ldots$

3.3.2 Phase Configuration . . . . . . . . . . . 59

vi 
3.3 .3 Constraints . . . . . . . . . . . . . 60

3.4 Results. . . . . . . . . . . . . . . . . 61

3.4.1 Baseline Vehicle Derivative . . . . . . . . . . . 64

$\begin{array}{lll}\text { Chapter } 4 & \text { Injector Selection } & 67\end{array}$

4.1 Injector Initial Sizing $\ldots \ldots \ldots \ldots \ldots$

4.2 Gas Generator / Water Injector . . . . . . . . . . 76

$\begin{array}{lll}\text { Chapter } 5 & \text { Sub-Scale Test Motor } & 79\end{array}$

5.1 Gas Generator Grains . . . . . . . . . . . . . . . . . 83

5.1 .1 BATES Grain . . . . . . . . . . . 85

5.2 Injector $\ldots \ldots \ldots \ldots \ldots \ldots \ldots \ldots \ldots$

$5.3 \quad$ Oxidizer Pressurization $\ldots \ldots \ldots \ldots$

5.4 Combustion Chamber \& Nozzle . . . . . . . . . . . . . . 93

5.5 Data Acquisition . . . . . . . . . . . . . . . . 97

5.5 .1 Temperature ................... 98

5.6 Test Procedure . . . . . . . . . . . . . . . . . . . 102

5.7 BATES Grain Results . . . . . . . . . . . . . . . . . . . 104

5.7.1 Single Grain Experimental Tests . . . . . . . . . . . 106

5.7 .2 Three Grain Experimental Tests . . . . . . . . . . 111

5.8 Aft-Injected Hybrid Motor Results . . . . . . . . . . . . . . 116

vii 
$5.8 .1 \quad$ Startup Transient $\ldots \ldots \ldots \ldots \ldots$

5.8 .2 Data Reduction . . . . . . . . . . . . . . . . . 120

$5.8 .3 \quad$ Uncertainty Analysis . . . . . . . . . . . . . . . . 126

5.8 .4 Injector Evaluation $\ldots \ldots \ldots \ldots \ldots \ldots$

$\begin{array}{lll}\text { Chapter } 6 & \text { CFD Injector Modeling } & 138\end{array}$

6.1 CFD Software . . . . . . . . . . . . . 141

6.2 Numerical Discretization . . . . . . . . . . . . . . . . 141

6.3 Modeling Geometry Simplification . . . . . . . . . . . . . 142

6.4 GG/Water Domain . . . . . . . . . . . . . . . . . 142

6.4 .1 Working Fluid . . . . . . . . . . . . . 145

6.5 Governing Equations . . . . . . . . . . . . . . . 148

6.5.1 Turbulence Model . . . . . . . . . . . . . . . . . 153

6.5.2 Phase Change Model . . . . . . . . . . . . . . . . 158

6.6 Boundary Conditions . . . . . . . . . . . . . . . 160

6.7 Wall Functions . . . . . . . . . . . . . . . . . . . . . . 162

$6.8 \mathrm{Mesh} \ldots \ldots \ldots \ldots \ldots \ldots \ldots \ldots$

6.8 .1 Mesh Analysis . . . . . . . . . . . . . . 167

6.9 Results . . . . . . . . . . . . . . . . . . 170

6.9 .1 Velocity Profile . . . . . . . . . . . . . . . . 172

viii 
6.9 .2 Volume Fraction $\ldots \ldots \ldots \ldots \ldots \ldots \ldots$

6.9 .3 Temperature Profile . . . . . . . . . . 178

$\begin{array}{lll}\text { Chapter } 7 & \text { Conclusions } & 186\end{array}$

7.1 Recommendations . . . . . . . . . . . . . . 189

7.1 .1 Gas Generator Propellant . . . . . . . . . . . . 190

$7.1 .2 \quad$ Sub-Scale Motor . . . . . . . . . . . . . 190

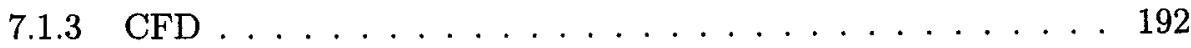

$\begin{array}{lr}\text { Bibliography } & 194\end{array}$

Appendix A Chemical Equilibrium Analysis (CEA) Output 203

$\begin{array}{lll}\text { Appendix B Polynomial Coefficients In NASA Format } & \mathbf{2 1 1}\end{array}$

$\mathrm{ix}$ 


\section{List of Tables}

2.1 Compositions of Gas Generator Propellants (NOTE: normalized based on baseline composition) $\ldots \ldots \ldots \ldots \ldots \ldots \ldots$

2.2 Additives used in propellant batches . . . . . . . . . . . . 33

2.3 Particle Size of Components in Gas Generator Propellents(NOTE:

Additive 1 was a range in particle size) $\ldots \ldots \ldots \ldots$

2.4 Burn Rate Test Results of Gas Generator Propellents . . . . . . . . 52

2.5 CEA output for GG propellant CSLV22 . . . . . . . . . . 53

3.1 First and Second Stage propulsion ASTOS input parameters . . . 59

3.2 Relevant data from simulated trajectory using ASTOS . . . . . 62

3.3 Effect of a choked and unchoked gas generator system . . . . . . 64

4.1 Parameters used for injector dimension sizing . . . . . . . . 73

4.2 Injector Dimensions and Flow Conditions . . . . . . . . . 78

5.1 Sub-Scale Test Motor Components . . . . . . . . . . . . . 96 
5.2 Dimensions of GG BATES Grains . . . . . . . . . . 106

5.3 Comparison of combustion species of propellant formulations . . . 112

5.4 Comparison of thermodynamic properties of propellant formulations 112

5.5 Comparison of thermodynamic properties of propellant formulations 114

5.6 Thermocouple temperature data of injector testing . . . . . . 123

5.7 Parameter used and their associated bias errors. . . . . . . . 127

5.8 Precision error associated with instruments $\ldots \ldots \ldots \ldots 127$

5.9 Uncertainty estimate of key parameters . . . . . . . . . 127

6.1 Gas Generator/Water Injector Dimensions . . . . . . . . . . 145

6.2 CEA Output For Gas Generator . . . . . . . . . . . . 147

6.3 Values For Constants Used In Turbulence Models _ . . . . . . . . . 157

6.4 CFD boundary conditions $\ldots \ldots \ldots \ldots 2 \ldots \ldots \ldots$

6.5 First Node Spacing . . . . . . . . . . . . . . . 164

6.6 GG/Water model specifications used For ANSYS mesh generator 167

1 CEA Output For Gas Generator . . . . . . . . . . . . . 211

$\mathrm{xi}$ 


\section{List of Figures}

1.1 Comparison of solid (LEFT) and liquid (RIGHT) propulsion systems 3

1.2 Comparison of hybrid propulsion systems: (LEFT) aft-injected (RIGHT)

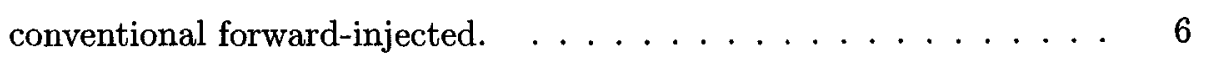

2.1 Chemical equilibrium calculations of ammonium perchlorate with HTPB acting as the fuel-rich gas generator propellant mixed with LOX. . . 23

2.2 Chemical equilibrium calculations of ammonium nitrate with HTPB acting as the fuel-rich gas generator propellant mixed with LOX. . . 23

2.3 Variation in aluminium content of $50 \%$ ammonium perchlorate oxidizer and HTPB binder combined with LOX. . . . . . . . 26

2.4 Variation in polystyrene content of $50 \%$ ammonium perchlorate oxidizer and HTPB binder combined with LOX. . . . . . . . . 27

2.5 Variation in Regalrez content of $50 \%$ ammonium perchlorate oxidizer and HTPB binder combined with LOX. . . . . . . . . 28

xii 
2.6 Variation in axido carbonamide content of $50 \%$ ammonium perchlorate, Regalrez, and HTPB binder combined with LOX. . . . . . . 28

2.7 Variation in polyethylene content of $50 \%$ ammonium perchlorate oxidizer and HTPB binder combined with LOX. . . . . . . . . . 29

2.8 Variation in wax MS 5714 content of $50 \%$ ammonium perchlorate oxidizer and HTPB binder combined with LOX. . . . . . . . . 30

2.9 CAD drawing of step motor tester $[24] \ldots \ldots \ldots$

2.10 Step-Motor on experimental test stand $\ldots \ldots \ldots \ldots$

2.11 Example chamber pressure trace for a step motor test (CSLV-10) . 36

2.12 Effect of smaller oxidizer particle (blue circles) relative to larger courser

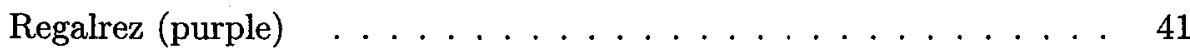

2.13 Unburnt fuel surface grain in a step-cup (left) compared to a grain that had extinguished (right \& top) $\ldots \ldots \ldots \ldots \ldots \ldots$

2.14 Comparison of sudden change in burning behavior of the GG propellant below a certain chamber pressure level . . . . . . . . . . 48

2.15 Comparison of regression rate of Polyethylene and Regalrez as AP

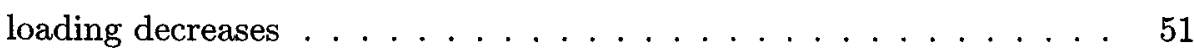

2.16 Effect on Isp with change in $\mathrm{O} / \mathrm{F}$ ratio for final propellant formulation

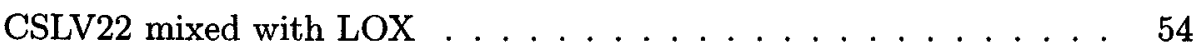

3.1 ASTOS simulated trajectory profile. . . . . . . . . . . 61 xiii 
3.2 Plot of ASTOS trajectory over a flat earth map. . . . . . . . . 65

3.3 Payload capabilities of the baseline launch vehicle. . . . . . . . 66

4.1 (LEFT) liquid center/gas annulus injector configuration (RIGHT) gas center/liquid annulus injector configuration . . . . . 74

4.2 Drawing of bypass ports for gas center/LOX annulus injector. (LEFT) a single injector on 4" diameter motor (RIGHT) multiple injectors used on a 12 " sub-scale motor $\ldots \ldots \ldots \ldots \ldots$

5.1 Sub-scale motor on experimental test stand identifying the four major components ..................... 81

5.2 Cross sectional view of sub-scale motor with labeled components . . 82

5.3 BATES grains and starter grains used for AIH motor (three individual grains and 2 starter grains per test) $\ldots \ldots \ldots \ldots 6$

5.4 (TOP LEFT) Assembled water and GG element in manifold (TOP RIGHT) Water element unassembled with GG element assembled in manifold (BOTTOM) Cross section of entire injector assembly (manifold, water and GG element) $\ldots \ldots \ldots \ldots$

5.5 (LEFT) Oxidizer tank hanging from load cell (RIGHT) Nitrogen pressurization $\operatorname{tank} \ldots \ldots \ldots \ldots \ldots \ldots$

5.6 Oxidizer pressurization schematic $\ldots \ldots \ldots 9 . \ldots . \ldots 9$

xiv 
5.7 (TOP) Combustion chamber assembled with AIH motor (BOTTOM) Inside view of the combustion chamber, with thermocouples extended through the chamber wall . . . . . . . . . . 95

5.8 Control room with data acquisitions systems $\ldots \ldots \ldots$. . . . 97

5.9 Location of thermocouples in post combustion chamber (NOTE two radial locations at thermocouple $\# 3$ and $\# 9) \ldots \ldots \ldots 9$

5.10 (LEFT) Raw circuit board layout (RIGHT) A single fully assembled amplifier .................... 100

5.11 Thermocouple amplifiers $(12$ units $) \ldots \ldots \ldots 10 . \ldots \ldots$

5.12 Test of full AIH sub-scale motor (both GG and water) $\ldots \ldots . .103$

5.13 Comparison of experimental test for single GG BATES grains . . . . 105

5.14 Adjusted theoretically BATES grain for regressive profile $\ldots \ldots . .110$

5.15 Test results from hot fire test using three BATES grain of the GG

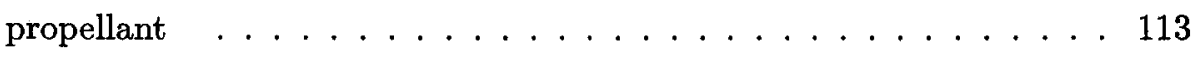

5.16 Mass flow of final GG propellant using 3 BATES grains . . . . . . 115

5.17 Sequence of full AIH sub-scale motor firing (TOP MIDDLE) ignition (TOP RIGHT) full GG operation (BOTTOM LEFT) opening water valve (BOTTOM MIDDLE) full water \& GG steady state operation (BOTTOM RIGHT) burn out $\ldots \ldots \ldots \ldots \ldots \ldots$

5.18 Pressure trace for hot fire test of injector(RC1) with water . . . . 119 $\mathrm{xv}$ 
5.19 Pressure and thrust trace data for injectors RC1 . . . . . . . . . 124

5.20 Venturi pressure and water tank discharge data for injectors RC1 . . 124

5.21 Temperature profile for injector $\mathrm{RC} 1$ test (TOP) Axially at $\mathrm{r}=6 \mathrm{~mm}$ (MIDDLE) Radial at $\mathrm{x}=64 \mathrm{~mm}$ (BOTTOM) Radial at $\mathrm{x}=140 \mathrm{~mm} \quad \cdot 125$

5.22 Change in time constant with increase in sheath diameter for air [35] 129

5.23 Temperature measurements in post combustion chamber when just GG propellant is ignited i.e. no water injection (for thermocouple \# locations refer to Figure 5.9$) \quad \ldots \ldots \ldots \ldots \ldots \ldots$

5.24 Comparison of injectors using $\eta_{c^{*}} \ldots \ldots \ldots \ldots \ldots \ldots$

5.25 Comparison of injectors using $\eta_{\Delta T} \ldots \ldots \ldots \ldots \ldots$

5.26 Effect of velocity ratio on injector efficiency . . . . . . . . . . 137

6.1 GG/LOX domain dimensions $\ldots \ldots \ldots$. . . . . . . . . 143

6.2 (TOP) Reference dimensions for the injectors investigated (BOTTOM) Modeling domain dimensions. . . . . . . . . . . . . . 144

6.3 Location of inlet (left) and outlet (right) boundary conditions . . . . 161

6.4 Unstructured mesh geometry for injector RC1 (Top) full domain view (Bottom) refined nodes in injector region $\ldots \ldots \ldots 165$

6.5 Depiction of how inflated layers are used in the near wall region to allow a semi-structured mesh $\ldots \ldots \ldots \ldots \ldots$

6.6 RC1 GG volume fraction profile at $\mathrm{r}=6 \mathrm{~mm}$ for different mesh densities 169 xvi 
6.7 Comparison of mesh density based on $\%$ difference from finest mesh for injector RC1 using GG volume fraction profile at $\mathrm{r}=6 \mathrm{~mm} \ldots . \quad 170$

6.8 Velocity vector plot for injector $\mathrm{RC} 1 \ldots \ldots \ldots \ldots$

6.9 Water volume fraction: (TOP) RC1 injector (MIDDLE) RC2 injector (BOTTOM) RC3 injector . . . . . . . . . . . . . . 173

6.10 Water volume fraction: (TOP) RC4 injector (MIDDLE) RC5 injector (BOTTOM) RC6 injector . . . . . . . . . . . . . . 174

6.11 Water volume fraction: (TOP) RC1 injector (MIDDLE) RC2 injector (BOTTOM) RC3 injector . . . . . . . . . . . . 175

6.12 Water volume fraction: (TOP) RC4 injector (MIDDLE) RC5 injector (BOTTOM) RC6 injector . . . . . . . . . . . . 176

6.13 Water volume fraction of all six injectors along center axis (TOP LEFT) full length plot (TOP RIGHT) Zoomed view $\ldots \ldots \ldots$. . . 177

6.14 Resultant water volume $\%$ at $100 \mathrm{~mm}$ axial location $\ldots \ldots \ldots$. . . 178

6.15 $\mathrm{RC} 1$ injector numerical results for global temperature profile at $\mathrm{r}=8 \mathrm{~mm}$ 180

$6.16 \mathrm{RC} 2$ injector numerical results for global temperature profile at $\mathrm{r}=8 \mathrm{~mm}$ 180

6.17 RC3 injector numerical results for global temperature profile at $\mathrm{r}=8 \mathrm{~mm}$ 181

xvii 
6.18 RC4 injector numerical results for global temperature profile at $\mathbf{r}=8 \mathrm{~mm}$ 181

6.19 RC5 injector numerical results for global temperature profile at $\mathrm{r}=8 \mathrm{~mm}$ 182

6.20 RC6 injector numerical results for global temperature profile at $\mathrm{r}=8 \mathrm{~mm}$ 182

6.21 Comparison of temperature profile of all six injectors $\ldots \ldots \ldots$. . . 184

xviii 


\title{
Nomenclature
}

\author{
$A \quad$ area \\ a burn rate coefficient \\ $C p \quad$ heat capacity \\ $C c \quad$ venturi contraction coefficient \\ $c^{*} \quad$ characteristic velocity \\ D kinematic diffusivity \\ $F \quad$ force \\ $g \quad$ gravitational acceleration \\ $h \quad$ enthalpy \\ Isp specific impulse \\ $L^{*} \quad$ combustion chamber characteristic length \\ $\dot{m} \quad$ mass flow \\ $M \quad$ mass \\ n burn rate exponent \\ $N_{C} \quad$ number of chemical species \\ $\mathrm{Nu} \quad$ nusselt number \\ $\operatorname{Pr} \quad$ prandtl number \\ $P, p \quad$ pressure \\ $q \quad$ heat flux \\ $Q \quad$ total heat flux \\ $\dot{r} \quad$ regression rate \\ $r \quad$ radial distance from Earth's center
}

xix 


\begin{tabular}{|c|c|}
\hline$R$ & gas constant \\
\hline$R e$ & Reynolds number \\
\hline$s$ & entropy \\
\hline$S_{m}$ & momentum sources \\
\hline$S_{e}$ & energy sources \\
\hline$t_{b}$ & propellant burn time \\
\hline$t$ & time \\
\hline$T$ & temperature \\
\hline$u$ & velocity component \\
\hline$U$ & velocity vector \\
\hline$v$ & velocity \\
\hline$V$ & volume \\
\hline$Y$ & mass fraction \\
\hline$\alpha$ & thermal diffusivity \\
\hline$\delta$ & identity matrix \\
\hline$\epsilon$ & turbulent eddy dissipation \\
\hline$\zeta$ & bulk viscosity \\
\hline$\gamma$ & ratio of specific heats \\
\hline$\Gamma$ & dynamic diffusivity \\
\hline$\kappa$ & turbulent kinetic energy \\
\hline$\lambda$ & thermal conductivity \\
\hline$\rho$ & density \\
\hline$\Upsilon$ & mass fraction \\
\hline$\eta$ & efficiency \\
\hline$\sigma$ & turbulence model constant \\
\hline
\end{tabular}

$\mathrm{xx}$ 


$\begin{array}{ll}\tau & \text { shear stress } \\ \phi & \text { longitude } \\ \mu & \text { viscosity } \\ \psi & \text { latitude } \\ \omega & \text { turbulent frequency }\end{array}$

\section{Subscript}

$\begin{array}{ll}\text { atm } & \text { atmospheric } \\ \alpha & \text { phase alpha } \\ \beta & \text { phase beta } \\ b & \text { burn surface } \\ c & \text { combustion chamber } \\ \text { eff } & \text { effective } \\ \text { exp } & \text { experimental } \\ G G & \text { gas generator propellant } \\ \kappa & \text { turbulent kinetic energy } \\ \text { prop } & \text { propellant } \\ r e f & \text { reference } \\ \text { stat } & \text { static } \\ t & \text { throat } \\ \text { tot } & \text { total } \\ v & \text { vapour } \\ w & \text { wall }\end{array}$




\title{
Abbreviations
}

\author{
LOX Liquid Oxygen \\ H2 Hydrogen Gas \\ GG Gas Generator \\ AIH Aft-Injected Hybrid \\ LEO Low Earth Orbit \\ Isp Specific Impulse \\ O/F Oxidizer-to-Fuel Ratio \\ $\mathrm{AzC} \quad$ Azido Carbonamide \\ HTPB Hydroxyl Terminated Polybutadiene \\ RG Regalrez \\ PS Polystyrene \\ PE Polyethylene \\ AL Aluminium \\ AP Ammonium Perchlorate \\ AN Ammonium Nitrate \\ ASTOS Aerospace Trajectory Optimization Software \\ CSLV Canadian Small Launch Vehicle \\ CEA Chemical Equilibrium Analysis \\ DAQ Data Acquisition \\ CTI Cesaroni Technology Inc. \\ CFD Computational Fluid Dynamics
}

xxii 


\section{Chapter 1}

\section{Introduction}

In today's launch vehicle world there seems to be two directions which designers are pushing towards. One is to design a launch vehicle that will provide the highest performance to get the maximum payload into orbit. This often involves using leading edge technology in materials, processing, and design. However going in this direction requires extremely high budgets and is usually government sponsored programs exclusively. The other approach is to try and design a vehicle that will reduce the overall price of the entire launch vehicle program. This often means sacrifices in certain areas (such as maximum performance or low weight) for overall cost savings. It also means that considerations of manufacturing processes, safety, transportation, all play a key role in keeping overall development costs low. 
Due to the very nature which makes conventional propellants suitable to provide the sufficient performance to reach orbit, makes them extremely volatile and dangerous. This is perhaps one of the largest costs associated with any propulsion system. Safe handling of the chemicals is paramount and this entails having to use special procedures and equipment for the manufacturing, transportation, and use of these rockets or propulsion system. This translates into major costs associated with the special hardware and operating procedures.

\subsection{Types of Propulsion Systems}

Throughout the 20th century rocket propulsion has been completely dominated by either liquid or solid propulsion. Other types of propulsion systems have been investigated, but for the most part all practical launch systems have been powered by either one or a combination of these two types. However, with current technology advancements the use of hybrid propulsion has started to become a feasible option.

What liquid propulsion entails is as the name implies, a propellant that is a liquid oxidizer mixed with a liquid fuel. These two are injected into a combustion chamber were they are mixed and ignited. The hot gases produced are then expanded and expelled through a convergent-divergent nozzle creating thrust by the 
change in momentum from the high exit velocity of the gases. With liquid propulsion there is a need for some form of pumping or pressurization system, as well as a injection system to mix the oxidizer and fuel. This makes a liquid propulsion system much more complex with several moving parts. This drives the requirement for highly reliable components which ultimately makes this system much more expensive. However the advantage which this system has is that it is capable of achieving much higher performance (Isp of 290-330 s). It also allows the engine to be throttled and shut down if required. This translates into more flexibility in the trajectory and mission profile.

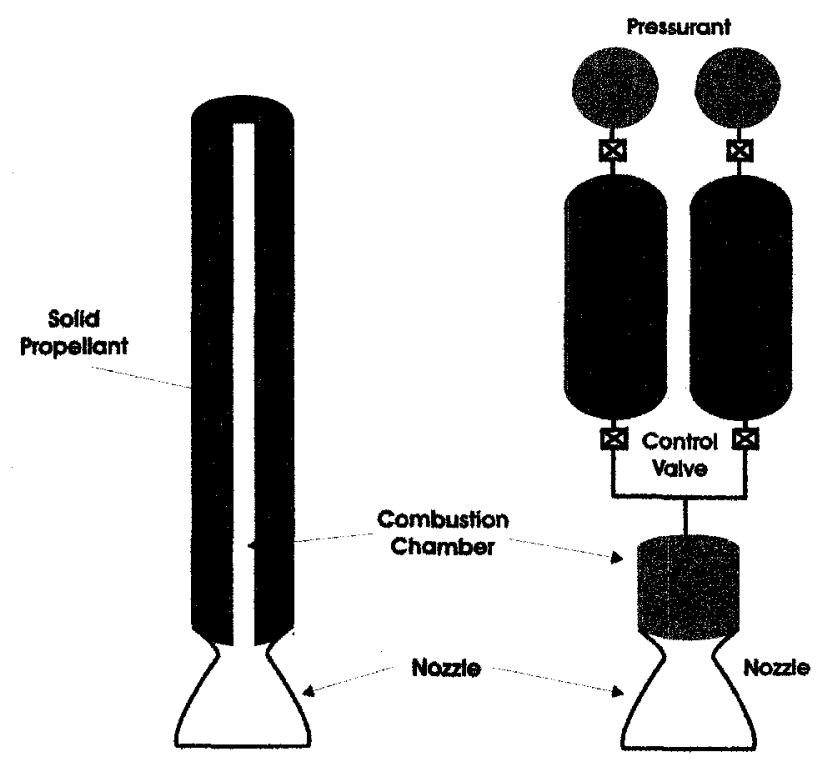

Figure 1.1: Comparison of solid (LEFT) and liquid (RIGHT) propulsion systems 
Solid propulsion operates under the same principle as liquid except that its propellant is a mixture of solid oxidizer and solid fuel. These two are mixed in a slurry and casted and allowed to cure into a solid grain. Typically there is a port (hole) down the center of the grain, which acts as the combustion chamber. The hot gases generated are expanded and expelled out the nozzle in the same fashion as liquid propulsion. The advantage of solid propulsion is that it is a much simpler system with little or no moving parts. It is much cheaper to operate, however it does not have the same performance capabilities of a liquid (Isp of 240-290 s). It also has the major disadvantage of traditionally not being able to be throttled or shut down after ignition.

One option that bridges the gap between solid and liquid propulsion is the use of hybrid propulsion. This type of system combines some of the benefits of both these system and is an area that always seems to appear when the subject of reduced cost comes into play.

Hybrid technology shows many advantages to traditional solid or liquid propulsion. It offers comparatively high performance capabilities with a liquid system, and the capability to be throttled as desired. It is a much simpler system then liquid because it only requires pressurization or pumping of the oxidizer and not the 
fuel. This greatly reduces the risk of failure of the vehicle, since one of the major failure modes of any vehicle revolves around its pumping or pressurization system. Also, the cost is obviously reduced since only one pressurization and injection system (oxidizer) is required. Hybrids also have the major benefit over both liquid and solid in that they are inherently safer. The reason for this is that since the oxidizer and the fuel are separated from each other, they posses less risk. Due to the separation of the oxidizer and fuel this means that during transporting the two can be shipped separately from one another. This results in obvious safety benefits since generally neither the oxidizer nor the fuel can be detonated on their own. Another safety advantage of hybrids is that they are not susceptible to catastrophic failure from cracks within the grain were solid propellants lack.

\subsection{Forward and Aft Injected Hybrids}

Almost all hybrid propulsion systems operate with a liquid (or gas) oxidizer and a solid fuel grain. There are, however, a few hybrids that operate in an opposite manner, with a solid oxidizer and liquid fuel. This is referred to as reverse hybrids. Since little has been done with reverse hybrids due to them being larger because of propellant properties, the focus will be on conventional hybrids.

Traditionally, hybrid motors have been situated with a solid fuel grain with 
a port (hole) down the center, where liquid (or gaseous) oxidizer is injected down. This is known as a forward injected hybrid as shown on the left of Figure 1.2. These have been generally used because of the complete isolation of the oxidizer from the fuel. They only require one injector at the top of the motor enclosure where the oxidizer is sprayed down the port.
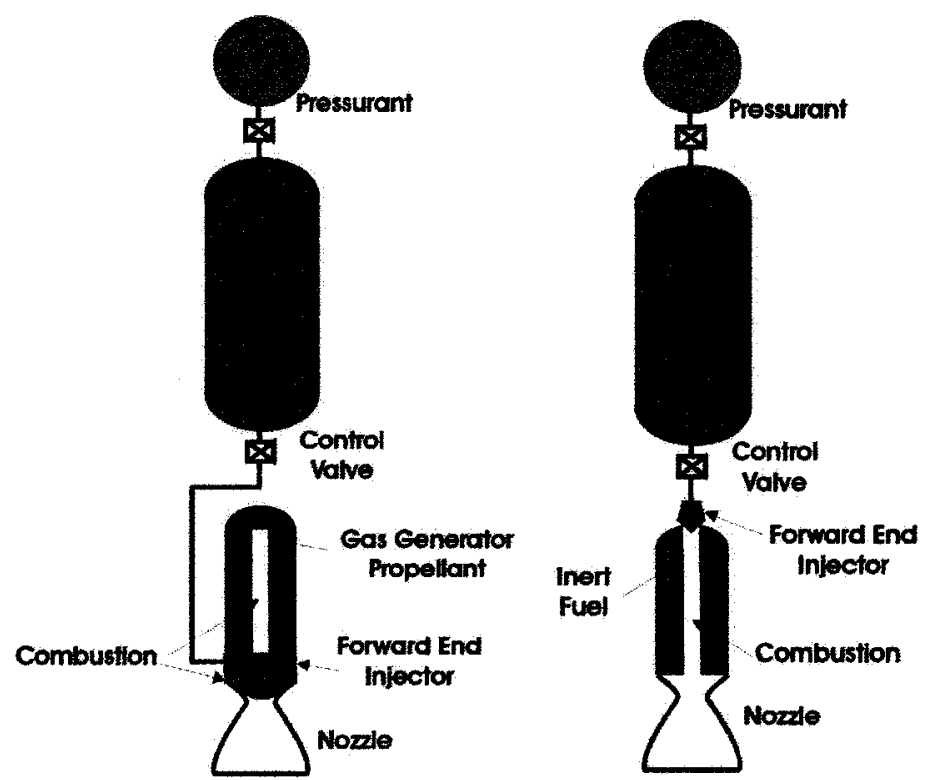

Figure 1.2: Comparison of hybrid propulsion systems: (LEFT) aft-injected (RIGHT) conventional forward-injected.

A new novel alternative is the aft injection (gas generator) hybrid shown on the left of Figure 1.2. This motor operates by having a fuel grain, which is actually a fuel-rich solid propellant, known as a gas generator. The propellant burns 
to create a gas mixture that is highly fuel rich. This gas is then combined in an aft combustion chamber with additional liquid oxidizer. The additional oxidizer and fuel-rich gas are then ignited and expanded through a nozzle like any conventional rocket.

The largest problems associated with a forward injected hybrid for large scale hybrid rocket boosters is that they have low regression rate. In smaller motors (hobby rockets, and small sounding rockets) this is not a major factor. However with larger launch vehicles the low regression rates cause the web thickness (distance the propellant burns) to become very small for a typical burn time to reach orbit. Therefore, in order to get the required propellant into the stage for a successful launch trajectory, this means that a multi-port system must be used. This leads to low volumetric load fractions, and complex grain geometries. Often, additional structures must be added to the grain in order for the propellant to maintain its structural integrity when the web becomes thin at the end of the burn. This means extra weight to the vehicle, which is obviously very detrimental. Also with this type of multi-port system the residual propellant (slivers) left over after the burn is greater, and these slivers can become dislodged and clog the nozzle throat leading to instant over-pressurization and motor failure. Slivers also constitute "dead" mass, which the vehicle carried throughout its flight with no contribution to the system. It 
is for these reasons why large-scale hybrids have not played a larger role in current launch vehicles.

Another problem associated with the traditional hybrid is that there is a shift in the $\mathrm{O} / \mathrm{F}$ ratio (Oxidizer/Fuel) throughout the length of the fuel grain. This is because the oxidizer at the top part of the grain is used for combustion and is no longer present for the portion of the bottom part of the grain. What this means is that there is a larger percentage of left over fuel grain at the bottom of the port then the top at burnout. The advantage traditional hybrids have is the fuel grain is total incombustible without oxidizer so it receives a reduced hazardous safety designation. They also have the advantage in that the combustion process is fairly well understood and is generally dictated by the heat transfer, heterogeneous fuel decomposition, and fuel/oxidizer mixing process in the boundary layer diffusion flame [36].

In the case of the aft injected hybrid the problems of slow regression rates as in traditional hybrids is no longer encountered because a modified solid fuel is used. With a solid fuel, the burn rates are much higher so the propellent can be put into a volume that does not require several ports. Also the shift in the $\mathrm{O} / \mathrm{F}$ ratio along the length of the fuel grain is no longer present because all the fuel-rich gas is mixed with the appropriate oxidizer ratio with the injectors. The major disadvantage of 
the aft injected hybrid is that the fuel grain actually contains oxidizer within it and therefore not entirely inert as in the case of traditional hybrids. It must undergo more scrutiny when classifying it as a safer hybrid system. There is also much more stringent requirements requirement on the injector system to properly atomize and disperse the oxidizer with the gas flow from the fuel-rich propellent.

\subsection{Thesis Outline}

The focus for this dissertation will be on the development of a solid propellant gas generator grain and on the design and testing of a single injector element for an new aft-injected hybrid motor. In doing so it will look at the following;

- Development of solid propellant composition for the gas generator.

- Trajectory simulation to prove that the aft-injected propulsion system is capable of placing a payload into orbit with this propellant.

- Selection of the type of injector to be used.

- Design of a 4" sub-scale aft-injected motor

- Testing of different injectors using water as the oxidizer to obtain temperature measurements and validation of CFD.

- A computational fluid dynamics analysis of the injector using the gas generator fuel and water. 


\subsection{Literature Review}

Aft-injected hybrid propulsion is a relatively new concept. Due to this, the amount of previous work done using this system is very limited. A summary of the aftinjected hybrid propulsion work that has been previously investigated is reviewed here. This work includes studies using both liquid oxygen and hydrogen peroxide as an oxidizer.

\subsubsection{Aft-Injected Hybrid Studies}

\section{Markopoulos \& Abel [28]}

This work consisted primarily of experimental testing of two motors (11" and 24" diameter) using a AIH motor system. The oxidizer used was $90 \%$ hydrogen peroxide together with end burn fuel rich gas generator grain. Three different ammonium perchlorate (AP) based fuel grains were tested. Fuel screening looked at AP loading from 40 to $70 \%$, along with particles sizes of 20 and $200 \mu \mathrm{m}$. The fuel grains were also able to achieve a DoT Class 1.4c hazard rating. The planned operating chamber pressure for the motors was 200 psi. The motor utilized a catalyst pack for the $\mathrm{H} 202$, and an annular injector that directed the oxidizer stream onto the face of the end burn grain with a $15^{\circ}$ swirl. For each motor both a high and low characteristic length $\left(\mathrm{L}^{*}\right)$ were tested. The tests conducted showed the AIH mo- 
tor was capable of stable combustion, with multiple restart capability. Some after burning was shown, but the motor demonstrated extinguishment when the oxidizer was cut-off. It was found that the low $L^{*}$ motor had slightly higher regression rates and chamber pressure, which is likely due to the injectors being closer to the fuel grain face. The lower $\mathrm{L}^{*}$ motors also exhibited shorter startup transients then the high $\mathrm{L}^{*}$ tests. The larger 24 " motor showed improved ballistic performance and high combustion efficiency (98\%) over the 11" motor. Motor scale up between the 11" and 24" motor was shown to be successful.

\section{Culver \& Mueggenburg [14]}

Here they investigated the vaned type injector system using LOX and a fuelrich solid propellant gas generator. This type of system was first developed and hot fire tested by the Advanced Rocket Engine Storable (ARES) of the U.S. Air Force. The vaned injector is a gas/liquid injector where the vanes contain liquid propellant. At the trailing edge of the vane has self-impinging elements that are mixed with the passing hot gas from the fuel-rich propellant. The vanes are aligned parallel to each other thereby ensuring uniform mixing. The trailing edge of the vanes is chamfered to reduce surface area since they are exposed to the high heat flux of combustion. The trailing edge is also regenerative cooled by high velocity oxidizer. The advantages this injector provides is the vanes are free to expand and 
contract thermally, which provide uniform mixing and control of the combustion chamber boundary layer mixing. The other advantage is the short cycle time to fabricate an injector because of the process used. The vanes are mass produced and made from machined platelets from photo-etching using CAD system and laser plotter. The plates are stacked and diffusion bonded together. This process reduces development time, but the required infrastructure is expensive. For the injector the overall diameter was 30 inches. The author found that the impinging fan streams must be spaced one inch or less, and a 0.12 " orifice for the LOX was used.

\section{Lund, Starrett, \& Jensen [26]}

The purpose of this work was to formulate a propellant that would provide a specific impulse of 310 s, low cost, low hazard ratings, and a moderate regression rate. Both an aft injected end burn and a traditional center perforated (CP) fuel configuration was examined. The fuel consisted of a ammonium perchlorate (AP) as the oxidizer and either HTPB or polyether (PPG) binders. PPG had higher pressure deflagration limit, but HTPB provided higher Isp and optimum $\mathrm{O} / \mathrm{F}$, but did produced large amounts of soot. Therefore a combination of the two binders was used. For both CP and aft injected configurations the two main oxidizers looked at were $90 \%$ hydrogen peroxide and gaseous oxygen. It was discovered that combustion chamber $\mathrm{L} / \mathrm{D}$ ratio had a significant effect on aft injected performance with higher 
values causing a decrease in chamber pressure. However smaller size AP resulted in more stable combustion. Regression rate was slightly higher with $\mathrm{H} 2 \mathrm{O} 2$ then GOX, but was due to the operational point being closer to the optimum $\mathrm{O} / \mathrm{F}$ ratio of $\mathrm{H} 2 \mathrm{O} 2$. There was an increase in regression rate with impinging flow direction of the injector nozzle, showing that the fuel is sensitive to flow flux. The final fuel formulation was given a hazard classification of DOT class $1.4 \mathrm{c}$.

\section{Atlantic Research Corporation [1]}

The most extensive amount of work done with an AIH system came out of the Hybrid Propulsion Demonstration Program initiated in March 1995. This program was funded by NASA and included all the major propulsion companies in the US. The goal of this program was to identify necessary technology and demonstrate large sub-scale systems for using hybrid propulsion in manned and unmanned launch vehicles. Most of the companies for this program developed conventional hybrids. Atlantic Research Corporation (ARC) investigated both a conventional hybrid and an AIH system. They selected the AIH system because it offers all operational advantages as liquid propulsion, lower life cycle cost, and its scalability attributes which conventional hybrids lack. This report consisted of 314 pages and obviously cannot be totally summarized here. Furthermore the size of the vehicle that was being investigated is an order of magnitude larger than the research for this disser- 
tation (563 $269 \mathrm{~kg}$ vs. $13213 \mathrm{~kg}$ ) and looked at both pressurization and turbopump scenario. Only the key aspects that are relevant to this thesis research are presented from ARC study. The reader can see reference [1] for more details.

There were eight different gas generator fuel grains evaluated. Oxidizers looked at were both $\mathrm{H} 202$ and LOX, of which the latter was selected. The requirements of the fuel grain was to extinguish below 300 psi, have a burn rate of 7.6 to $12.7 \mathrm{~mm} / \mathrm{s}$ at $1000 \mathrm{psi}$, and to produce less than $1 \% \mathrm{HCL}$. One metallized fuel using aluminum was investigated and showed $9.6 \%$ lower Isp and a higher flame temperature which made it incompatible for this design. Two other variants were investigated ARCADENE: 399 (37\% AP, 34\% polystyrene, 25\% binder (CTPB), $4 \%$ iron oxide) and ARCADENE 246 (69.5\%AP, 25.6\% binder/fuel (PBAN), 0.4\% iron oxide, and $4.5 \%$ curative). Derivative of each of these were investigated, which included replacing some AP with sodium nitrate to act as a scavenger to get rid of the harmful emission HCL. The final fuel grain selected was the scavenged version of ARCADENE 399. The size of the fuel grain was $386 \mathrm{~cm}$ in diameter and $1625 \mathrm{~cm}$ long requiring $209911 \mathrm{~kg}$ of propellant. The fuel grain was center perforated with different sections of slots 4 and 8 ). The slots were overcasted HTPB/AP propellant to aid in ignition. This allowed the initial pressurization of the gas generator and introduction of oxidizer. 
The injector is an impingement type, with the gas generator chamber being unchoked. For the gas flow from the fuel grain, 500 tubes with a diameter of $39 \mathrm{~mm}$ are used. Around these tubes 8 pairs of self impinging oxidizer ports with diameters of $3.3 \mathrm{~mm}$ each are space equally. Each pair is angled to self imping on each other and in addition they are angled inward towards the gas stream. The fuel tubes around the outer perimeter do not have oxidizer ports, allowing the gas $(\asymp 1278 \mathrm{~K}$ ) which is relatively cool to act as a film cooling method of the chamber walls. The injector is fabricated of stainless steel. 


\section{Chapter 2}

\section{Gas Generator Propellant}

The composition of the propellant will dictate particle species, size, velocity, etc. and these will drastically effect the functionality of the injector. The velocity of the inlet gas being mixed with the injector will have a dramatic effect on the mixing properties, turbulence, atomization, etc. of the oxidizer and the gas flow [4],[13].

The final GG solid propellant formulation that would be used for the launch vehicle would have to undergo extreme evaluation and testing. Many minor ingredient adjustments would have to be made to achieve the precise characteristics required of the solid grain for performance, mechanical properties, casting viscosity, aging, etc. However, for injector design/testing a rough derivative of the propellant should be sufficient for characterizing the important properties such as temperature, velocity, particle size and species. Therefore in order to develop the injector system 
of an aft-injected hybrid propulsion system an appropriate gas generator propellant must first be developed.

A composite style propellant was selected for the GG solid propellant as this is the most abundantly used today due to its increase performance capabilities and significantly safer to handle then a double based propellant (nitrocellulose/nitroglycerine). Using a composite meant that there is separate oxidizer crystals, fuel powder, binder, and additives.

To initially narrow down the selection of different GG propellant compositions to investigate, chemical equilibrium analysis (CEA code)was used. Once the field of different compositions was narrowed down, small propellant batches $(1.4 \mathrm{~kg})$ were mixed and hot fire tested (using a step motor apparatus) to determine burn rate and pressure characteristics. Using these small propellant batches also allowed the combustion termination point to be determined. Larger batches $(24 \mathrm{~kg})$ of the selected GG propellant were also mixed and tested but are discussed later in Section 5.1 as they were dictated by both the geometry and performance requirements of the sub-scale motor. 


\subsection{Goals of Gas Generator Propellant}

In developing the gas generator solid propellant there were 4 goals that were sought after for this type of low cost launch vehicle discussed earlier.

\section{Safety:}

One of the major costs associated with a launch vehicle is the safe handling and storage of the propellants used for combustion. Due to the very nature of the propellants that make it well suited for combustion is the same reason why special handling procedures and storage containers must be used. Propellants hazardous properties have a rating system that designates the propellant based on it combustion capabilities. If a propellant could be tailored to provide sufficient combustion at specified conditions during operation, but not experience these conditions under normal handling or storage processes, then the propellant can be given a lower safety class rating. This is the idea behind using a gas generator propellant. One of the goals of developing a gas generator (GG) propellant is to have the propellant undergo combustion at an elevated pressure, but it would not be able to sustain combustion below a set pressure level (approximately $<500$ psi). Since this pressure environment would never be experienced during normal handling or storage this would allow the gas generator to be given a lower hazardous safety rating (Class 1.4). 
This translates into immense savings of the overall launch vehicle program.

\section{Performance:}

An obvious goal of any rocket propellant is to provide high performance. In rocket terms the performance is dictated by the specific impulse (Isp). The goal is to achieve the highest Isp while still maintaining all the other goals. Of course the, performance of the propellant must still being able to achieve orbit (outlined in Section 3.

\section{Low Flame Temperature:}

This is desired so that the components that are exposed to the hot gas could be made of cheaper material and reduces the parts susceptibility to failure. If exotic materials or special thermal barrier coatings (like iridium-radium) can be replaced by stainless steel this translated into enormous cost savings. The flame temperature should be kept in the range that conventional gas turbines operate under $\left(\max .1500^{\circ} \mathrm{C}\right)$ since the materials they utilize undergo thousands of operating hours at a relatively low price. It would be desirable to have the temperature of the gas low enough that standard stainless steel can be used. Another advantage that can be utilized with a relatively warm gas is that it allows for simpler and cheaper design of the thrust vectoring (TVC) system of the vehicle. Since pivoting must occur for a TVC system it places stringent 
criteria on seals, and joints where this occurs. With conventional vehicles these joints are experiencing temperatures in excess of $3000^{\circ} \mathrm{C}$, which makes the seals very complicated and costly. Obtaining a warm gas less than 1000 ${ }^{\circ} \mathrm{C}$ would significantly reduce the cost, complexity, and increase reliability.

\section{High Burn Rate:}

The final goal of the gas generator propellant is to obtain a reasonable burn rate in order to aid in the volumetric loading of the propellant. This way it will not suffer the same problems associated with hybrids, as discussed in Section 1.2. Typically, a burn rate of $2.5 \mathrm{~mm} / \mathrm{s}$ or higher should be sufficient for efficient volumetric loading of a vehicle this size.

\subsection{Chemical Equilibrium Analysis}

In developing the gas generator solid propellant theoretical chemical equilibrium, calculation were performed to determine which compositions would provide the highest performance. This was done with the use of the widely accepted NASA Lewis Research Center's Chemical Equilibrium with Applications (CEA) computer program. This program was created by Gordon and McBride in 1994 and allows the chemical equilibrium compositions of complex mixtures with several different applications one of which is rocket problems. In determining chemical equilibrium Gibbs minimization of free energy method is used by CEA since temperature and 
pressure are used to characterize the thermodynamic states of the compositions being considered [30].

The performance parameters of the different propellant composition and the species from the products were obtained through CEA. The burn rate, mechanical properties, and external considerations (such as castablitiy, end of burn residual fuel, etc) for the propellant could only be examined with actual propellant batch tests.

The input into CEA was a reaction of fuel and oxidizer. The fuel was the different GG composition and the oxidizer was liquid oxygen to model a hybrid motor. LOX was used as the oxidizer as it will be the likely oxidizer to be used for an actual launch vehicle and it gives an equal comparison throughout for all GG compositions. 


\subsubsection{Solid Fuel Oxidizer}

In developing a baseline solid fuel of the gas generator there are two types of crystalline oxidizers that were examined; ammonium perchlorate (AP) and ammonium nitrate (AN). The reason for the current limitation of AP and AN oxidizers is twofold. First, these are the two oxidizers which are commercially available. Second, these are the two most commonly used oxidizers for gas generator applications $[13],[32],[12]$.

As seen by both Figure 2.1 and 2.2, as the oxidizer content (AP or AN) of the gas generator propellant increases, the maximum performance at the optimum oxidizer-to-fuel ratio $(\mathrm{O} / \mathrm{F})$ decreases. This would be expected since the hot gases produced by the fuel-rich propellant are further mixed with LOX in the combustion chamber and ignited to produce the vehicles thrust. Therefore at the absolute maximum, no oxidizer in the fuel rich propellant would be required since all oxidizer could come from the LOX injection, which is a better oxidizer then either AP or AN. In the case of no oxidizer this would simply become a traditional hybrid (100\% HTPB).

Ideally, one would like to have as little oxidizer (either AP or AN) as possible. The problem that arises is that the gas generator propellant must be able to sustain independent combustion as a fuel-rich solid propellant. Without sufficient 


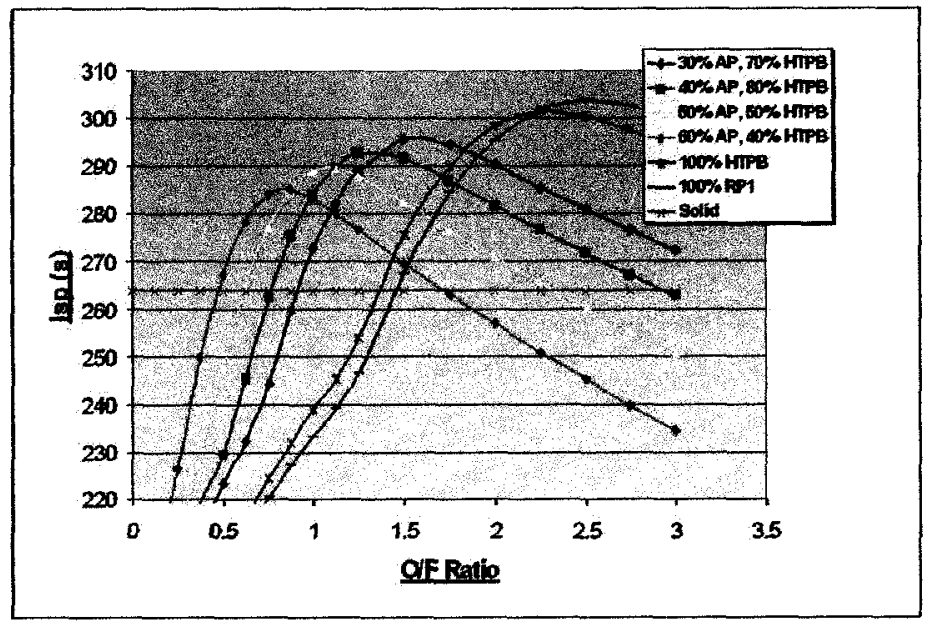

Figure 2.1: Chemical equilibrium calculations of ammonium perchlorate with HTPB acting as the fuel-rich gas generator propellant mixed with LOX.

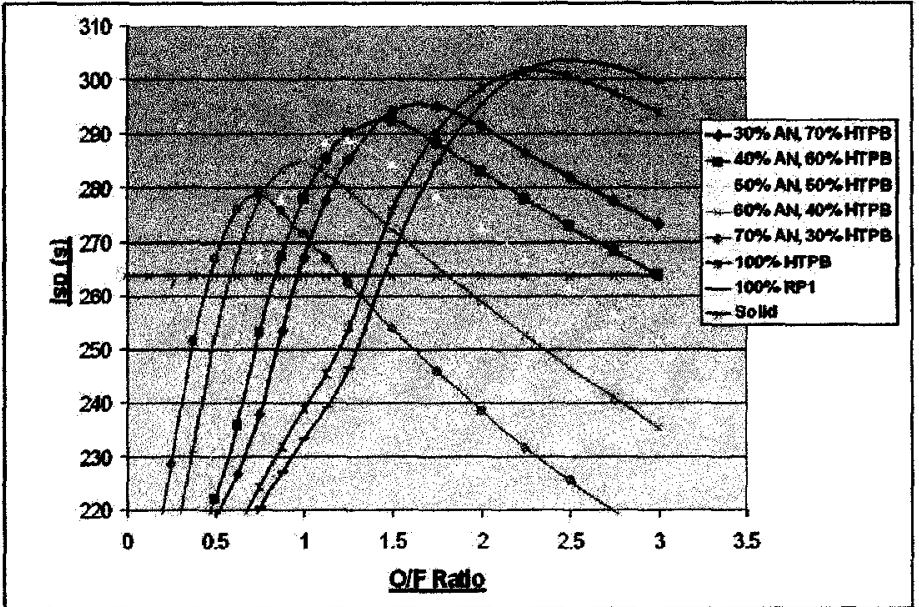

Figure 2.2: Chemical equilibrium calculations of ammonium nitrate with HTPB acting as the fuel-rich gas generator propellant mixed with LOX. 
oxidizer the solid propellant will not be able to maintain combustion from the lack of oxygen. However, this ties in nicely with the goal to only have the GG propellant being able to sustain combustion at elevated pressures (discussed later in Section 2.4.2).

Therefore, in developing the gas generator propellant, it must first be determined at what oxidizer level the solid fuel will no longer sustain combustion. An initial base-line experimental batch was tested with low AP \% (compared to traditional solid propellant). Once it was established that this AP \% will ignite properly the oxidizer content was reduced until the point at which combustion can no longer be sustained.

In direct comparison of AP and AN (Figures 2.1 and 2.2) it is shown that there is a significant advantage using AP over AN (approximately 2 second Isp difference). Therefore emphasis was placed on using AP if possible over AN.

\subsubsection{Binder}

As mentioned above, with this being a composite propellant, a binder is required to hold the mixture of crystals and powders together. The obvious choice which is almost exclusively used for this type of solid propellant application was hydroxyl terminated polybutadiene (HTPB). 


\subsubsection{Fuel Additives}

The next step in setting up the baseline propellant was the addition of a solid fuel material to the composition to make up the remaining volume. HTPB by itself is a fuel, so the composition could just consist of oxidizer crystals and a high $\%$ of binder. However, since the oxidizer content is going to be significantly reduced compared to traditional solid propellants, this additional volume can be occupied by a fuel additive which is more hydrocarbon rich than HTPB to improve performance. The inital products looked at were; aluminum, regalrez, polystyrene, polyethylene, wax, and a blowing agent.

Aluminium is widely used in traditional solid propellants, so it was considered first. Aluminium is desirable because it oxidizes into aluminium oxide under combustion and agglomerate into larger particles. Overall aluminium increases the heat of combustion, flame temperature, and density.

As shown in Figure 2.3 the addition of aluminum causes a significant decrease in performance. The fact that aluminum does not have to be added to the propellant is a great benefit since aluminum is a very abrasive species and increases erosion of the motor components substantially (especially the injector and nozzle 
throat). Since aluminum is so widely used in most solid propellants and it may be required for combustion stability, one of the base line samples was mixed and tested with a $5 \%$ aluminum content for verification.

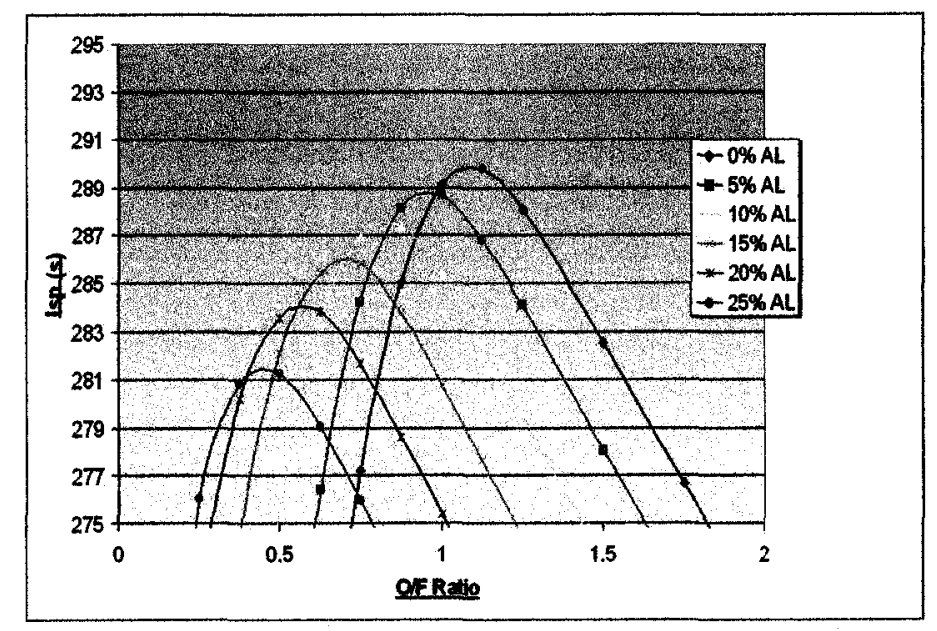

Figure 2.3: Variation in aluminium content of $50 \%$ ammonium perchlorate oxidizer and HTPB binder combined with LOX.

The next substance investigated was the use of polystyrene. As shown in Figure 2.4, the addition of polystyrene actually resulted in a slight decrease in performance. With $10 \%$ polystyrene it resulted in a system reduction in Isp of approximately 1 second. Therefore the addition polystyrene was not considered for the gas generator propellant. 


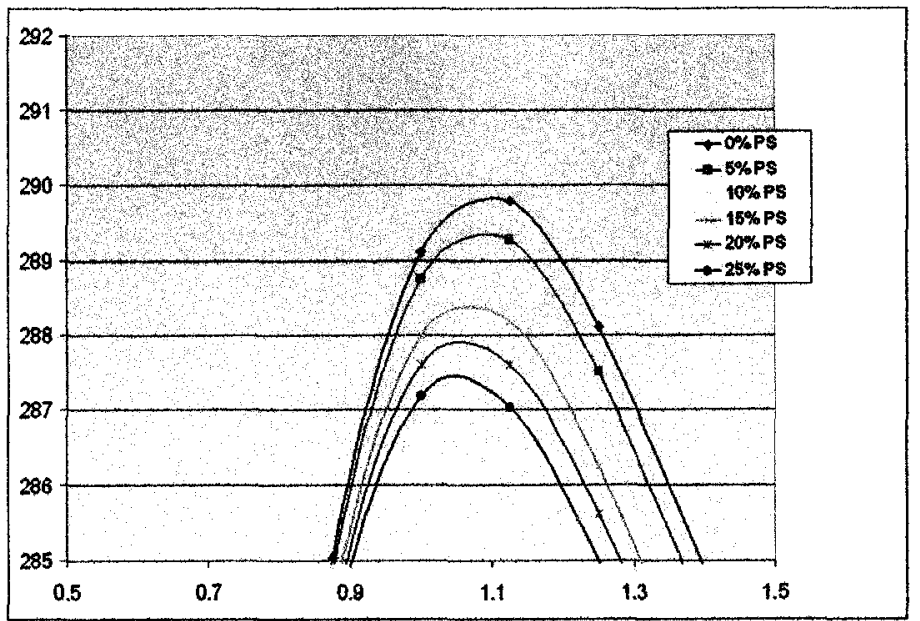

Figure 2.4: Variation in polystyrene content of $50 \%$ ammonium perchlorate oxidizer and HTPB binder combined with LOX.

Another substance considered was Regalrez. This is a polymer like substance, with a low density $(0.99 \mathrm{~kg} / \mathrm{L})$ and a low melting temperature $\left(94^{\circ} \mathrm{C}\right)$. As shown in Figure 2.5 the addition of Regalrez (RG) resulted in an increase in performance. It shows extremely good mechanical properties for a solid propellant.

A blowing agent was also investigated to see if the this would help reduce the thickness of the melt layer on the fuel surface to help improve the heat transfer to the surface. It was thought that in turn this would increase the regression rate of the fuel. The blowing agent that was looked at was Azido Carbonamide $(\mathrm{AzC})$. As shown in Figure 2.6, the addition of AzC causes a reduction in performance. However since there may be an increase in the regression rate it was still considered. 


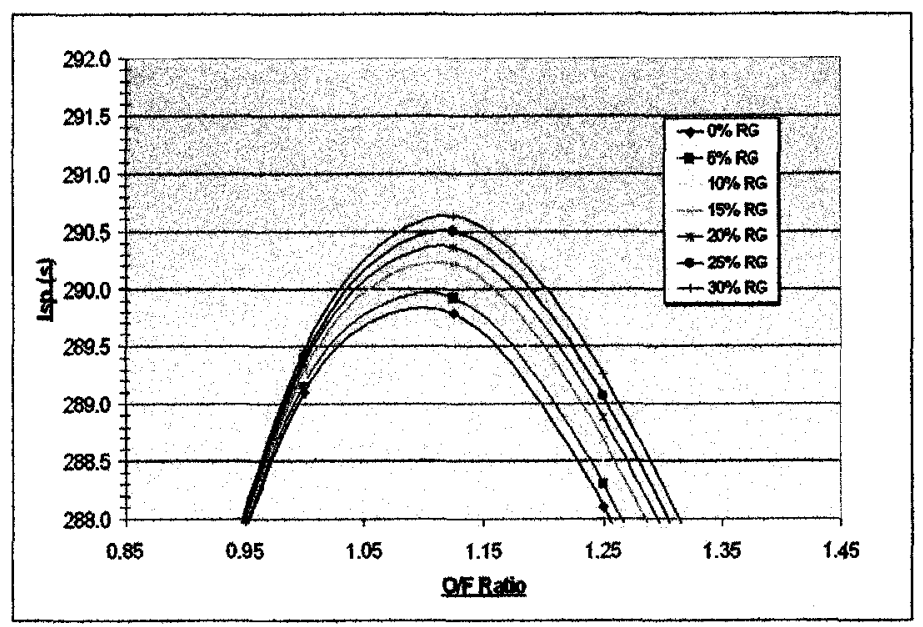

Figure 2.5: Variation in Regalrez content of $50 \%$ ammonium perchlorate oxidizer and HTPB binder combined with LOX.

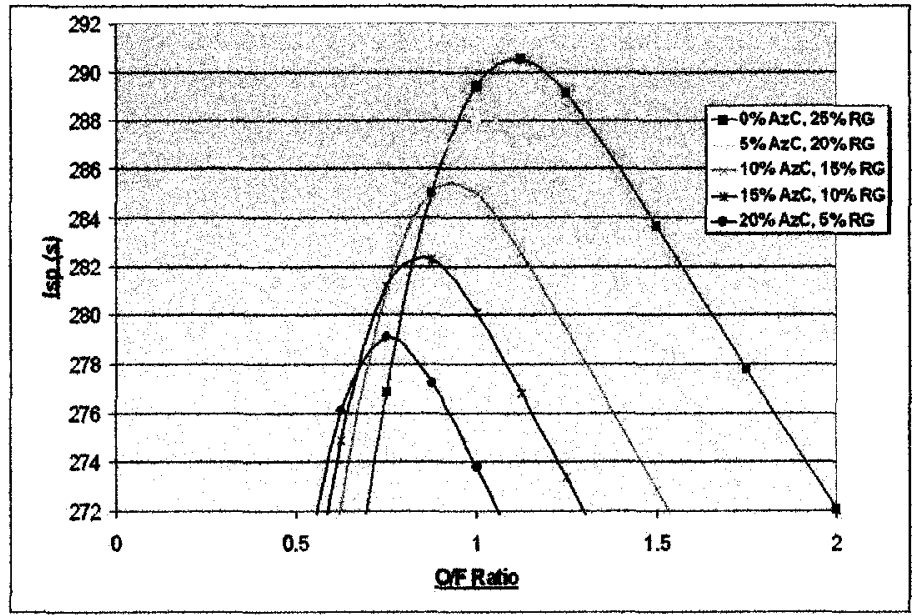

Figure 2.6: Variation in axido carbonamide content of $50 \%$ ammonium perchlorate, Regalrez, and HTPB binder combined with LOX. 
Polyethylene was also looked at as an additive. As shown in Figure 2.7 there is a fairly significant improvement in performance with the addition of PE. In comparing Figures 2.5 and 2.7 , it is seen that polyethylene gives an even higher performance than Regalrez for the same quantity (approx. 1 second difference).

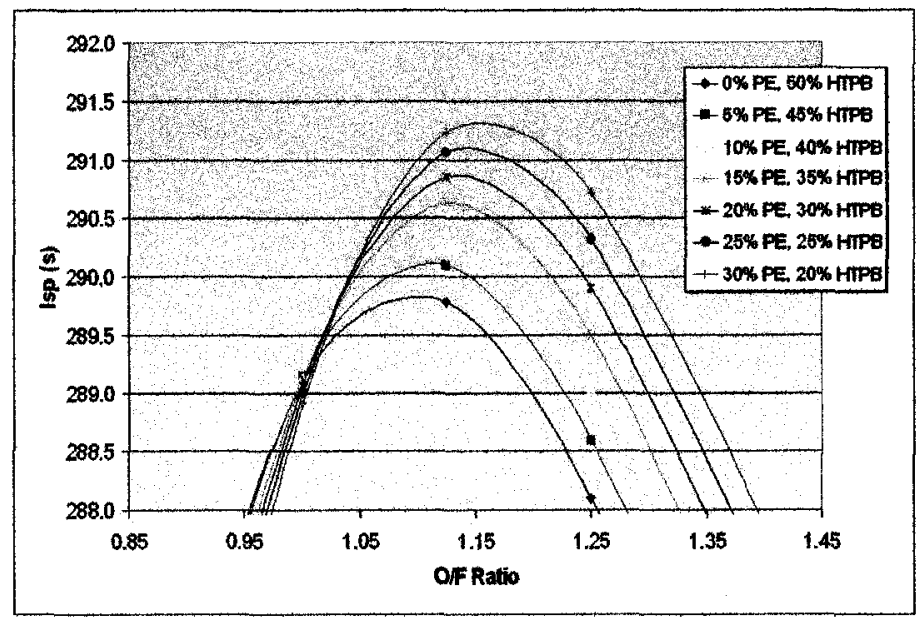

Figure 2.7: Variation in polyethylene content of $50 \%$ ammonium perchlorate oxidizer and HTPB binder combined with LOX.

The final additive that was investigated was using a wax (MS 5714). From literature there has been some experiments done using wax as a fuel in hybrids, however it has not been used in full scale motors to date. Looking at Figure 2.8 it is seen that there is an increase in performance with the addition of the wax. In comparison to Polyethylene there is even a very small advantage. However some 


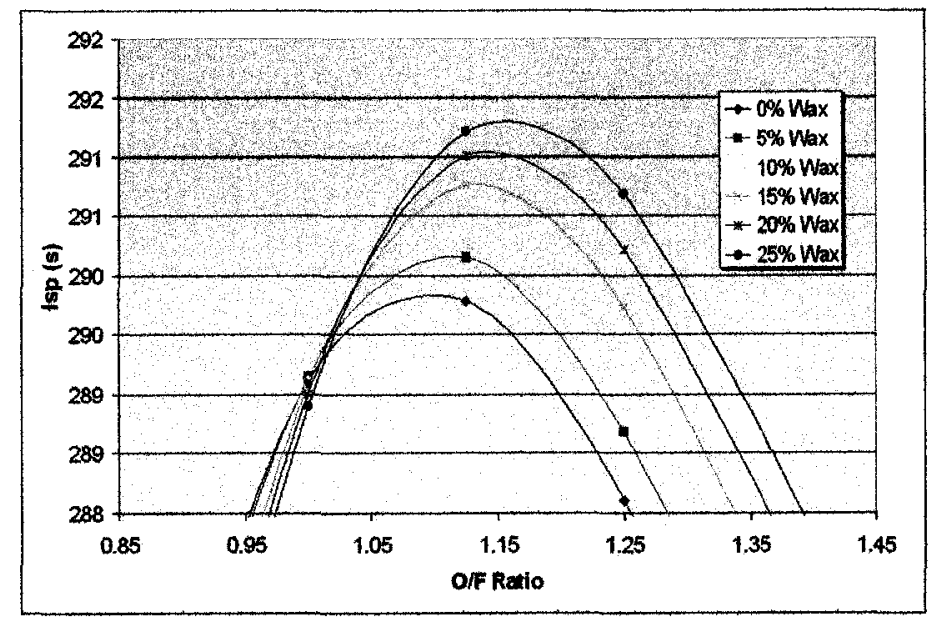

Figure 2.8: Variation in wax MS 5714 content of $50 \%$ ammonium perchlorate oxidizer and HTPB binder combined with LOX.

problems arose when attempting to mix the wax as a propellant. Trials showed that only a maximum of $10 \%$ wax could possible be added to the mix before it lost all its viscosity. Also due to its low melt point it became tricky in regulating the temperature during the mixing process. The overall mixing process became extremely difficult. Also once the propellant cured and it went through post-machining on the lathe, the tip of the machine bit would re-melt the wax and it could not be machined to precise dimensions as the other propellants. 


\subsection{Propellant Baseline Samples}

The chemical equilibrium analysis discussed in the previous section allowed for the possible candidates for the GG propellant to be narrowed down to the ones presented (AL,PE,AzC,RG), based on their performance characteristics. Several other compositions were investigated but showed extremely poor qualities and were not perused further. These different candidates were then mixed in $1.4 \mathrm{~kg}$ sample propellant batches using CTI's vacuum mixer. They were then casted into "step motor cups" (discussed below). Curing time for these propellant batches took between 1-2 weeks. Hot-fire testing was conducted on these propellant batches to experimentally determine the burn rate characteristics of the propellant. These small propellant batches also allowed external properties that will effect the entire development process to be observed. These were examined qualitatively and include things like the mechanical properties, viscosity of the propellant for castings, curing time, etc. Table 2.1 shows all the propellant batches that were examined and the important variations between the main ingredients. Table 2.2 list all the minor additives and their purposes used with the GG propellant. 
Table 2.1: Compositions of Gas Generator Propellants (NOTE: normalized based on baseline composition)

\begin{tabular}{|c|c|c|c|c|c|c|c|}
\hline $\begin{array}{c}\text { Batch } \\
\text { \# }\end{array}$ & $\begin{array}{c}\text { AP } \\
\mathbf{\%}\end{array}$ & $\begin{array}{c}\text { HTPB } \\
\mathbf{\%}\end{array}$ & $\begin{array}{c}\text { Additive 1 } \\
\text { Type }\end{array}$ & $\mathbf{\%}$ & $\begin{array}{c}\text { Additive 2 } \\
\text { Type }\end{array}$ & $\begin{array}{c}\text { Iron Oxide } \\
\mathbf{\%}\end{array}$ \\
\hline \hline CSLV-1 & $100 \%$ & $100 \%$ & Regalrez & $100 \%$ & n/a & - & $\mathbf{1 0 0 \%}$ \\
\hline CSLV-2 & $100 \%$ & $100 \%$ & Regalrez & $80 \%$ & AzC & $10 \%$ & $100 \%$ \\
\hline CSLV-3 & $100 \%$ & $100 \%$ & Regalrez & $80 \%$ & Aluminium & $10 \%$ & $100 \%$ \\
\hline CSLV-4 & $100 \%$ & $100 \%$ & Polystyrene & $100 \%$ & n/a & - & $100 \%$ \\
\hline CSLV-5 & $100 \%$ & $100 \%$ & Regalrez & $100 \%$ & n/a & - & $100 \%$ \\
\hline CSLV-6 & $90 \%$ & $104 \%$ & Regalrez & $116 \%$ & n/a & - & $100 \%$ \\
\hline CSLV-7 & $80 \%$ & $106 \%$ & Regalrez & $134 \%$ & n/a & - & $100 \%$ \\
\hline CSLV-8 & $90 \%$ & $104 \%$ & Regalrez & $117 \%$ & n/a & - & $0 \%$ \\
\hline CSLV-9 & $90 \%$ & $104 \%$ & Regalrez & $76 \%$ & Wax MS5714 & $20 \%$ & $100 \%$ \\
\hline CSLV-10 & $102 \%$ & $104 \%$ & Polyethylene & $116 \%$ & n/a & - & $100 \%$ \\
\hline CSLV-11 & $94 \%$ & $116 \%$ & Polyethylene & $104 \%$ & n/a & - & $100 \%$ \\
\hline CSLV-12 & $90 \%$ & $128 \%$ & Polyethylene & $92 \%$ & n/a & - & $100 \%$ \\
\hline CSLV-13 & $90 \%$ & $104 \%$ & Regalrez & $116 \%$ & n/a & - & $100 \%$ \\
\hline CSLV-14 & $90 \%$ & $128 \%$ & Polyethylene & $92 \%$ & n/a & - & $100 \%$ \\
\hline CSLV-15 & $85 \%$ & $128 \%$ & Polyethylene & $102 \%$ & n/a & - & $100 \%$ \\
\hline CSLV-16 & $90 \%$ & $128 \%$ & Polyethylene & $92 \%$ & n/a & - & $100 \%$ \\
\hline CSLV-17 & $80 \%$ & $138 \%$ & Polyethylene & $102 \%$ & n/a & - & $100 \%$ \\
\hline CSLV-18 & $75 \%$ & $148 \%$ & Polyethylene & $102 \%$ & n/a & - & $100 \%$ \\
\hline CSLV-19 & $90 \%$ & $128 \%$ & Polyethylene & $92 \%$ & n/a & - & $100 \%$ \\
\hline CSLV-20 & $90 \%$ & $128 \%$ & Polyethylene & $92 \%$ & n/a & - & $40 \%$ \\
\hline CSLV-21 & $70 \%$ & $128 \%$ & Polyethylene & $92 \%$ & AN & 0.2 & $100 \%$ \\
\hline CSLV-22 & $80 \%$ & $139 \%$ & Polyethylene & $102 \%$ & n/a & - & $40 \%$ \\
\hline CSLV-23 & $90 \%$ & $129 \%$ & Polyethylene & $92 \%$ & n/a & - & $100 \%$ \\
\hline CSLV-24 & $70 \%$ & $140 \%$ & Polyethylene & $101 \%$ & $200 \mu \mathrm{m}$ AP & 0.1 & $40 \%$ \\
\hline CSLV-25 & $60 \%$ & $140 \%$ & Polyethylene & $101 \%$ & $200 \mu \mathrm{m}$ AP & 0.2 & $40 \%$ \\
\hline CSLV-26 & $78 \%$ & $142 \%$ & Polyethylene & $104 \%$ & n/a & - & $40 \%$ \\
\hline CSLV-27 & $76 \%$ & $138 \%$ & Polyethylene & $104 \%$ & n/a & - & $40 \%$ \\
\hline CSLV-28 & $80 \%$ & $139 \%$ & Polyethylene & $102 \%$ & n/a & - & $40 \%$ \\
\hline & & & & & & & \\
\hline
\end{tabular}


Table 2.2: Additives used in propellant batches

\begin{tabular}{|l|c|c|}
\hline Additive & Chemical Name & Purpose \\
\hline \hline Poly BD R45HT & $\begin{array}{c}\text { Hydroxy-Terminated } \\
\text { Polybutadine }\end{array}$ & Binder \\
\hline Ralox 46 & $\begin{array}{c}2,2^{\prime} \text {-Methylenebis } \\
\text { 6-t-butyl-4-methylphenol }\end{array}$ & Antioxidant \\
\hline $\mathrm{HX}-752$ & $\begin{array}{c}1,1^{\prime}-(1,3-\text { Phenylenedicarbonyl }) \\
\text { Bis 2-Methyl-Aziridine }\end{array}$ & Bonding Agent \\
\hline Desmodur W & $\begin{array}{c}\text { Dicyclohexylmethane } \\
\text { Diisocyanate }\end{array}$ & Curing Agent \\
\hline Antifoam & - & - \\
\hline $\mathrm{DBTDL}_{\text {in solution of DOA }}$ & Dibutyltin Dilaurate & Curiative Catalyst \\
\hline $\mathrm{Fe}_{2} \mathrm{O}_{3}$ & Iron Oxide & Burn Rate Catalyst \\
\hline
\end{tabular}

\subsubsection{Step Motor Test Apparatus}

The samples were casted into individually phenolic cup (step motor cups). These cups contained 7 steps (see Figure 2.9), each of which has a reduction in diameter of 0.25 inches. The propellent burns as a cigarette or end burn, so the burn surface area is the equivalent circular surface area of the cup at each step. With each step a reduced burn surface area is achieved which implies a different chamber pressure by Equation 2.1

$$
P_{c}=\dot{r} \rho c^{*}\left(\frac{A_{b}}{A_{t}}\right)
$$


The following assumptions were made in order to have the different pressures at each step;

- insignificant nozzle erosion, therefore constant throat area

- constant c star (exhaust velocity)

- approximately constant burn rate throughout one pressure step

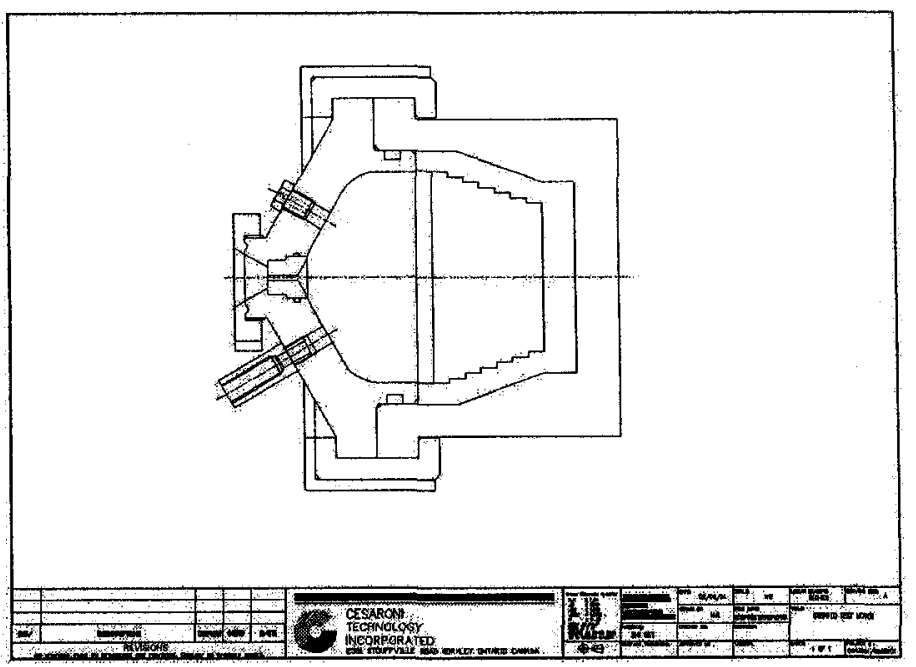

Figure 2.9: CAD drawing of step motor tester [24] 


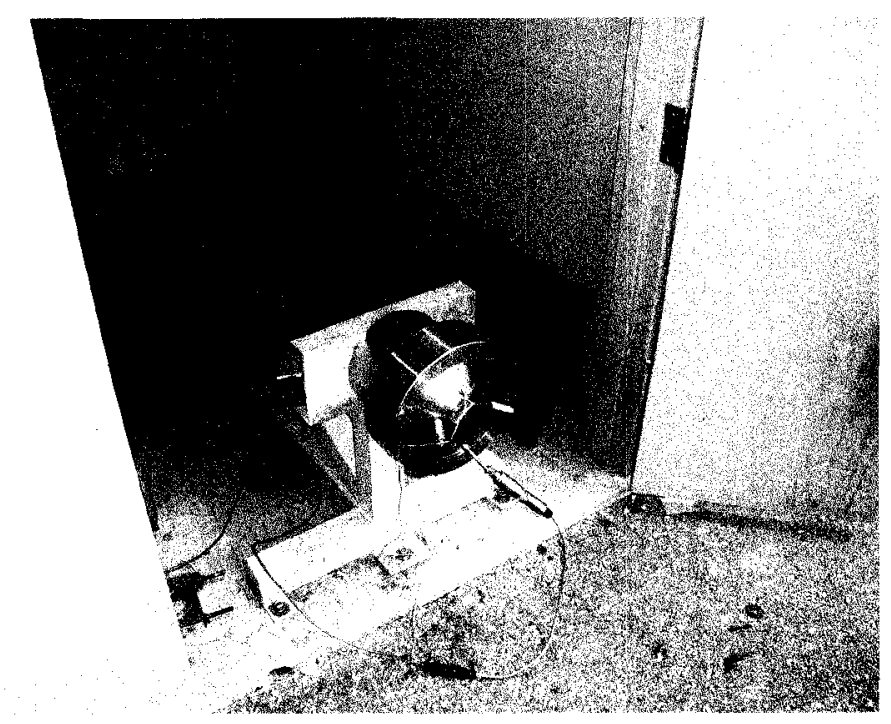

Figure 2.10: Step-Motor on experimental test stand

The advantage of a step motor is that with one firing it can operate at 7 different chamber pressures (see Figure 2.11). With the distance of each step known $\left(3 / 8^{\prime \prime}\right)$, the burn rate can be determined at several operating pressure, allowing the burn rate coefficient and burn rate exponent to be determined all in one test. This allows the propellant characteristics (specifically regression rate) to be determine all with one motor firing, unlike traditional testing which requires a motor firing for each pressure regime to generate the appropriate data. 


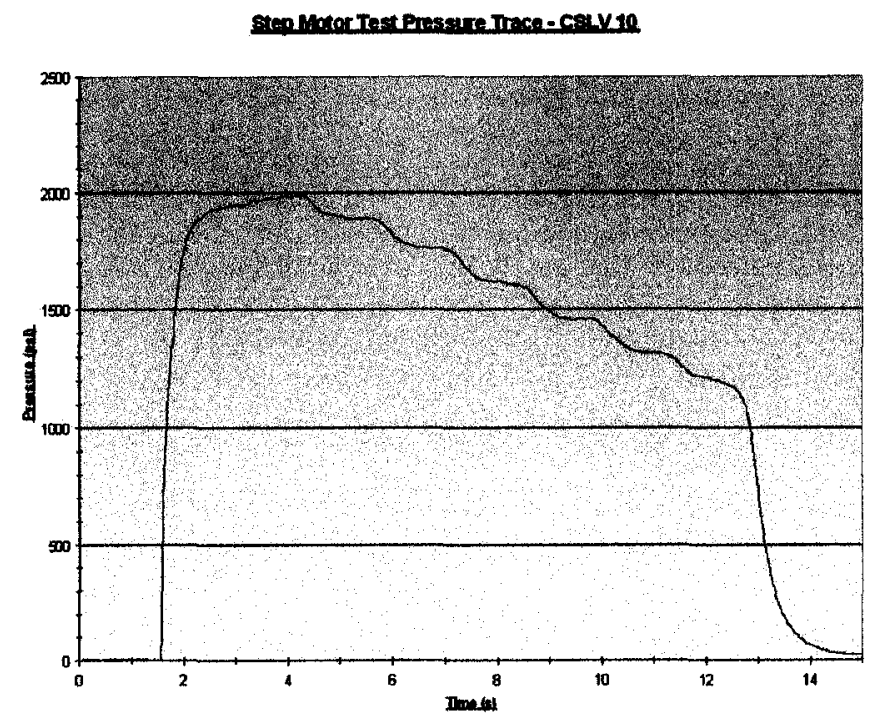

Figure 2.11: Example chamber pressure trace for a step motor test (CSLV-10)

\section{Ignition Process}

One of the most important goals of the GG propellant (Section 2.1) is safety and to make it act as any inert hybrid grain. This is accomplished in two ways. The first is with the propellant not being able to be sustain combustion under ambient conditions (1 atm pressure). The second is to make the propellant extremely difficult to ignite. In order to get the motor up to operational pressure a burst disk is used that seals the nozzle exit. Therefore the propellant is allowed to burn until the chamber pressure reaches operational pressure. Making the propellant hard to ignite is done with the low AP \%. For operational purposes the step motor ignition is assisted with a BKNO3 pellet and by coating the surface of the GG propellant 
with a thin layer of normal type of solid propellant paste (non-cured propellant from the CTI ProX hobby motors) 


\subsection{Results}

As mentioned earlier AP is a better oxidizer than AN, so the emphasis was on using AP for the test batches. A propellant batch was mixed with $\mathrm{AN}$ to verify that there is no significant increase in burn rate or external properties. There were no significant improvements with regards to production of the propellant (castibility, curing, etc.). The hot fire test actually resulted in the propellant extinguishing indicated either significant problems with ignitability of the propellant or a much lower burn rate (since nozzle size was constant). Therefore the use of AN as an oxidizer was not investigated further and all subsequent formulations utilized AP as the oxidizer.

For the first few propellant test batches, the fuel used was Regalrez as previous experience at CTI had been gained working with it on conventional hybrids. The very first step motor test (CSLV-1) was conducted and resulted in extremely slow burn rate. The burn rate was actually so slow that the duration of the test exceeded the allotted time for the data acquisition cycle time. The data for only the first three steps was captured by the DAQ, but showed an approximate burn time of $0.8 \mathrm{~mm} / \mathrm{s}$ with an initial chamber pressure of approximately 480 psi for the first step. For baseline samples CSLV-2, and CSLV-3 they showed similar results with very low burn rates as shown in Table 2.4 (note the maximum time of the DAQ was extended for these tests) 
The problem with these low burn rates is the same as outlined in Section 1.1. With a low burn rate implies that the web (distance the propellent burns) is very small. For larger propellent masses (launch vehicles) the use of a end burn is impossible, and for a single port grain, this causes an extremely high $\mathrm{L} / \mathrm{D}$ ratio. With a high $\mathrm{L} / \mathrm{D}$ ratio there are numerous problems (erosive burning, increased structural mass, vehicle stability, etc) that are encountered. Therefore if the propellent has a lower burn rate, a multiple port configuration is required, like a traditional hybrid which defeats the purpose of the AIH motor. The burn rate of the GG propellant should only be a little lower than a traditional solid propellants in order to make this system feasible.

Based on preliminary vehicle sizing (presented later in Section 3), the propellant formulation should give a higher burn rate in the proximity of $3 \mathrm{~mm} / \mathrm{s}$. Investigation into using the blowing agent and aluminum both did not significantly increase the burn rate to the required level. 


\subsubsection{Particle Size Distribution}

The next concept that was investigated to increase the burn rate was altering the particle sizes of the Regalrez and AP (oxidizer). Initial for CSLV 1-4 a uniform "medium" AP particle was used with the Regalrez particles ranging anywhere from "extra-fine" to "coarse". The next test was to try and reduce the particle size of the AP, but maintain only large particles of Regalrez. The idea was if the particles of the Regalrez are large in comparison to the particles of the AP, then the AP content will be greater in localized regions (see Figure 2.12), compared to the overall propellent percentage. This will allow the propellent in these localized region to burn similar to a normal solid propellent (oxidizer percentage $>70 \%$ ). Although the overall oxidizer content of the propellent still remains the same, these microscopic localized regions will burn quicker. This means that the overall burn surface will increase because the localized regions are burning quicker (see bottom of Figure 2.12). 

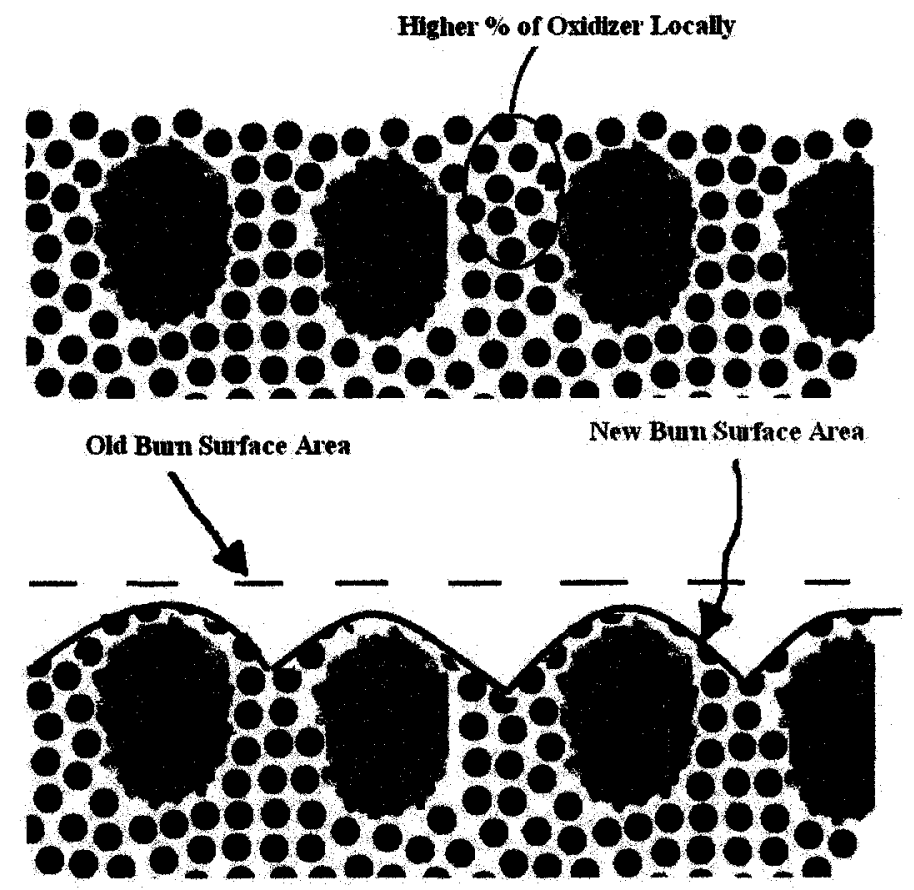

Figure 2.12: Effect of smaller oxidizer particle (blue circles) relative to larger courser Regalrez (purple) 
From well determined propellent burn laws (Equation 2.4.1), by increasing the burn surface this dictates the burn rate will increase, since propellent density and mass flow relatively are constant.

$$
\dot{m}=\dot{r} A_{b} \rho_{\text {prop }}
$$

Obviously, there is a delicate balance between the ratio of particle sizes. If the coarse Regalrez particles got so large that the mixture would become heterogeneous then the propellent would consist of isolated pockets of fuel and oxidizer, where combustion would only occur along their interface. This would result in a very poor propellant

Therefore, the next propellant formulations which were investigated was to reduce the AP particle size to "fine" and restrict the Regalrez particle size between "coarse" and "extra-coarse". This resulted in a dramatic increase in the burn rate from approximately $0.8 \mathrm{~mm} / \mathrm{s}$ to $4.8 \mathrm{~mm} / \mathrm{s}$ (see Table 2.4 ).

This particle size distribution was also investigated further by reducing the overall particle size but maintaining the same ratio. The AP particles were reduced to "extra-fine" and the Regalrez particles were kept between "medium" and "large." 
Table 2.3: Particle Size of Components in Gas Generator Propellents(NOTE: Additive 1 was a range in particle size)

\begin{tabular}{|c|c|c|c|}
\hline $\begin{array}{c}\text { Batch } \\
\#\end{array}$ & $\begin{array}{c}\text { AP } \\
\mathbf{\%}\end{array}$ & $\begin{array}{c}\text { Additive 1 } \\
\text { Lower Size }\end{array}$ & $\begin{array}{c}\text { Additive 1 } \\
\text { Upper Size }\end{array}$ \\
\hline \hline CSLV-1 & Medium & Extra-Fine & Large \\
\hline CSLV-2 & Medium & Extra-Fine & Large \\
\hline CSLV-3 & Medium & Extra-Fine & Large \\
\hline CSLV-4 & Medium & Extra-Fine & Large \\
\hline CSLV-5 & Fine & Large & Extra-Coarse \\
\hline CSLV-6 & Fine & Large & Extra-Coarse \\
\hline CSLV-7 & Fine & Large & Extra-Coarse \\
\hline CSLV-8 & Fine & Large & Extra-Coarse \\
\hline CSLV-9 & Fine & Large & Extra-Coarse \\
\hline CSLV-10 & Fine & Large & Coarse \\
\hline CSLV-11 & Fine & Large & Coarse \\
\hline CSLV-12 & Fine & Large & Coarse \\
\hline CSLV-13 & Extra-Fine & Medium & Large \\
\hline CSLV-14 & Extra-Fine & Medium & Large \\
\hline CSLV-15 & Fine & Large & Coarse \\
\hline CSLV-16 & Extra-Fine & Medium & Large \\
\hline CSLV-17 & Fine & Large & Coarse \\
\hline CSLV-18 & Fine & Large & Coarse \\
\hline CSLV-19 & Extra-Fine & Medium & Large \\
\hline CSLV-20 & Fine & Large & Coarse \\
\hline CSLV-21 & Fine & Large & Coarse \\
\hline CSLV-22 & Fine & Large & Coarse \\
\hline CSLV-23 & Fine & Large & Coarse \\
\hline CSLV-24 & Fine & Large & Coarse \\
\hline CSLV-25 & Fine & Large & Coarse \\
\hline CSLV-26 & Fine & Large & Coarse \\
\hline CSLV-27 & Fine & Large & Coarse \\
\hline CSLV-28 & Fine & Large & Coarse \\
\hline & & & \\
\hline
\end{tabular}


The results from this actually resulted in a slower burn rate, and the propellant did not maintaining a constant pressure throughout the steps. In post inspection, the propellant had waffer like residuals, where it was quite evident that the pockets of AP were consumed, but not all the fuel was burnt. A possible explanation for this phenomenon is with the AP particles allowed to be "extra-fine" they can actually self-sustained combustion (its given a DoT 1.1 classification). Therefore, it does not require as much additional fuel (Regalrez or Polyethylene) to complete combustion. With the smaller particles it allowed a much tighter localized volume of the AP particles in the propellant mixture so they could burn independently from the fuel (RG).

Therefore it was concluded that the GG propellant should retain a particle size distribution of "fine" for the AP and a range of "coarse" to "extra-coarse" for the PE or Regalrez. With this particle size ratio the regression rates are quick enough to achieve the fourth goal outlined in Section 2.1 .

\subsubsection{Combustion Termination}

The next aspect to be determined for the formulation was the amount of AP loading in the propellant. As shown in Section 2.2.1 GG propellant should have as little AP oxidizer in the formulation as possible. However in order for it be capable of self-sustained combustion, a set amount of AP needs to be added. Hot fire testing 
was conducted on propellant batches with reducing amounts of AP, until it could no longer sustain combustion on its own. It was discovered that once the AP was reduced to $75 \%$ (CSLV-18) of the baseline batch, that the propellant would not sustain independent combustion. The surface of the grain was partially burnt, but it was quite evident that the pockets of oxidizer were consumed without the entire surface burning (see Figure 2.13).

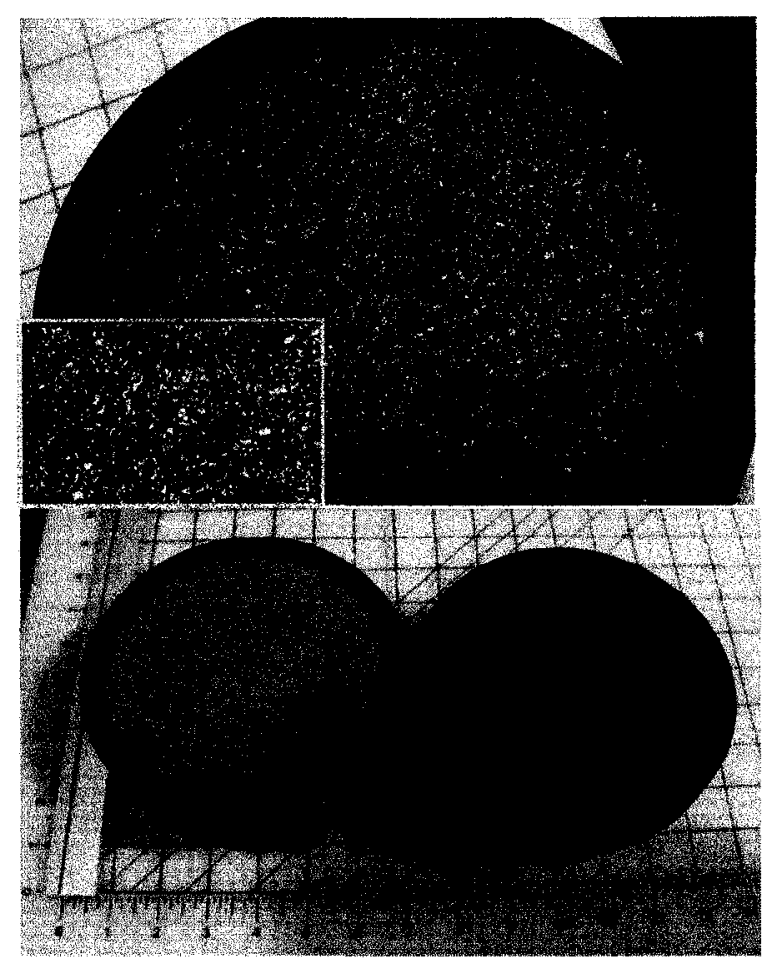

Figure 2.13: Unburnt fuel surface grain in a step-cup (left) compared to a grain that had extinguished (right \& top) 
Reducing the amount of AP also assisted in achieving the first goal of the GG propellant. In order to make the propellant safe like a conventional hybrid (which uses an inert fuel grain), the propellant must not be able to undergo combustion at ambient conditions. This was achieved by only having the propellant being able to sustain continuous combustion at elevated pressures. The way in which this is achieved is due to a balancing act of how AP-based composite propellant undergo combustion

First, an understanding of the combustion process of AP is to be understood. It begins with raising the temperature at or just below the surface to the point where decomposition of the binder/fuel, and AP particles occurs. This forms a thin melt layer (also called a solid-phase or condensed-phase reactive zone). The decomposed products emitted from the condensed-phase diffuse into each other to form diffusion flame streams [22]. This generates heat and forms a flame zone raising the temperature to its maximum value. The gases then flow away from the surface (downstream out the nozzle). The heat generated is fed back to the surface to continue the decomposition process and obtain stable combustion.

By having a fuel-rich, low AP\% propellant formulation entails that there is significantly more binder and fuel than conventional solids. With more binder 
means that the melt layer becomes substantially thicker. This makes the heat feedback through this layer become more important in the decomposition process. It has been well proven that there is a strong relationship between both the thickness of the condensed-phase and the flame stand off distance. As the operating pressure of a solid decrease the surface and the melt layer becomes thicker and the flame grows farther away from the surface [22]. The self-extinguishing pressure dependency is obtained by having the propellant operate under normal conditions at a pressure where the heat feedback to the surface is just enough to cause decomposition to occur. When the pressure is reduced, the flame stand off distance increases and the melt layer becomes thicker. This causes the generated heat feedback to the surface to be lowered. Since the condensed phase is significantly thicker and the flame temperature much lower with the GG propellant, their effect is much more influential. It is actually reduces the temperature low enough that the generated heat to the surface is not enough to allow decomposition of the AP, PE, HTPB to occur, resulting in the motor extinguishing.

In comparison to normal solid propellant, the condensed phase is significantly thinner and the flame temperature is approximately three times higher so the continuous decomposing of the oxidizer/binder is still accomplished with changes in pressure. However there are still ramification on the burn rate (like the GG propellant). 
Using the step motor allowed a range in pressure within a single test to be examined. It was discovered that below a chamber pressure of approximately 400550 psi the propellant would no longer sustain combustion. As can be seen in Figure 2.14 , there is a drastic change in the combustion process below this pressure level.

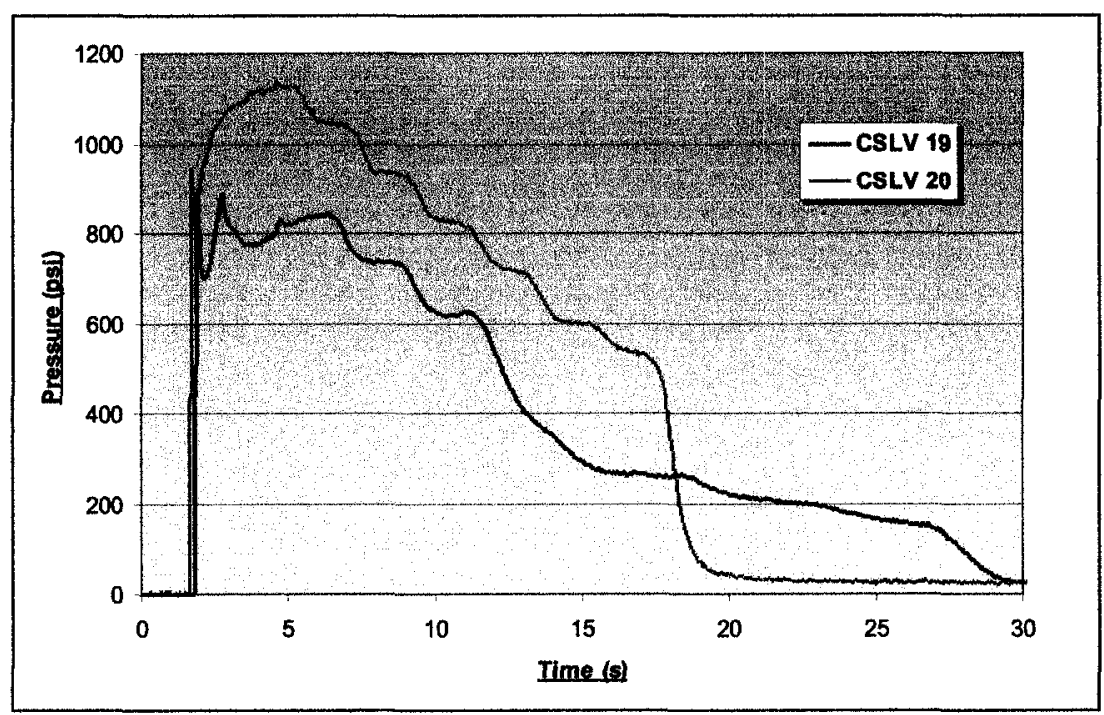

Figure 2.14: Comparison of sudden change in burning behavior of the GG propellant below a certain chamber pressure level

The propellant does continue to burn at approximately $200 \mathrm{psi}$. This can be explained due to the the aft-closure of the step motor. The aft-closure is designed to act as a heat sink and therefore after the pressure drops below the self-extinguishing level the heat absorbed by the aft closure is still available to be conducted back into the propellant. The propellant likely is able to obtain enough heat to continue to 
smolder away. With larger motors this heat sink source would not be available and the motor would completely extinguish. This was confirmed when estimating the throat diameter for the three-grain GG propellant testing (Section 5.7.2). When the nozzle throat was too large (i.e. pressure was lower than $500 \mathrm{psi}$ ) it caused the motor to completely extinguish.

The lack of ignitability was also qualitatively examined under ambient conditions with left over propellant from the mixing process. A propane touch was held over the surface of the propellant for several seconds. The propellant appeared to undergo combustion with direct contact with the heat source (torch), but once removed it stopped. It continued to smolder and melt, but again was similar any other standard inert plastic exposed under the same conditions. To further this conclusion, it was noted that the plastic container in which the propellant was placed in for these tests exhibited identical burning characteristics once the torch was removed. When the torch was reapplied there was a clear difference.

Under these characteristics, it would be assumed that it would get the improved safety class rating. To actually obtain this safety rating requires a large number of tests under specified government regulations and the cost are significant. Since obtaining the specific hazardous class rating is not the specific goal of this 
dissertation, it was assumed that if the CSLV project warrants the time and cost necessary to obtain this safety rating from a manufacturing/transportation stand point it can be easily achieved later on in development. Furthermore minor ingredient changes would still have to be adjusted and examined for the curing and storage properties. Therefore obtained the hazardous class rating should not be done until the absolute final propellant formulation is complete.

\subsubsection{Selected Gas Generator Propellant}

The final aspect to be determined is whether the fuel should be composed of polyethylene or Regalrez. Figure 2.15 shows the regression rate for polyethylene and Reglrez from the step motor tests conducted. Polyethylene exhibits a substantially higher burn rate than Regalrez. There is also an improvement in performance when using PE over RG as was shown in Section 2.2.3. Therefore the obvious choice for the fuel selection was polyethylene. 


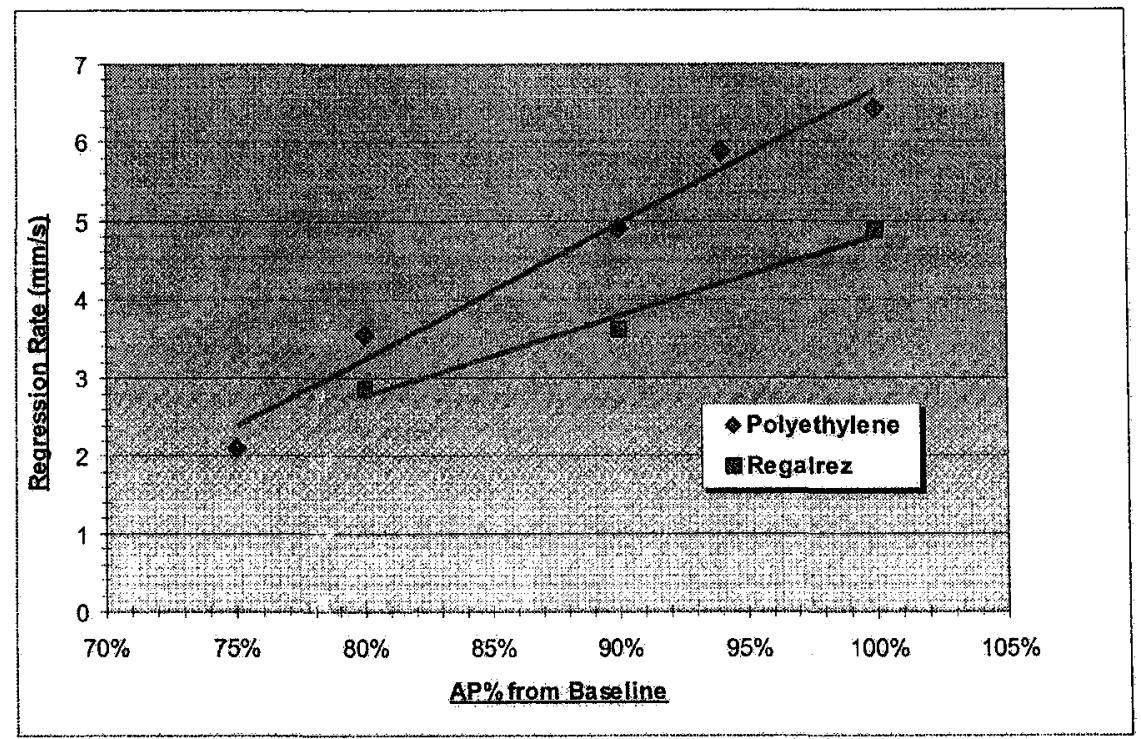

Figure 2.15: Comparison of regression rate of Polyethylene and Regalrez as AP loading decreases

Since it was shown that below $75 \%$ AP loading from the baseline the propellant will no longer sustain combustion, the selected GG propellant will have $80 \% \mathrm{AP}$ from the baseline composition. As was outlined earlier the AP size should be "Fine" and the fuel particles should be maintained between "Large" and "Coarse." Therefore, the final GG propellant formulation selected was CSLV-22. The step motor test conducted showed a burn rate of $3.55 \mathrm{~mm} / \mathrm{s}$ (shown in Table 2.4). This burn rate is high enough to meet the fourth goal discussed earlier(making the GG propellant attractive for use in a launch vehicle). Based on what has been presented propellant formulation CSLV-22 will meet all four goals outline in Section 2.1. 
Table 2.4: Burn Rate Test Results of Gas Generator Propellents

\begin{tabular}{|c|c|c|}
\hline $\begin{array}{c}\text { Batch } \\
\#\end{array}$ & $\begin{array}{c}\text { Regression Rate } \\
\text { (mm/s) }\end{array}$ & $\begin{array}{c}\text { Chamber } \\
\text { Pressure (Psi) }\end{array}$ \\
\hline \hline CSLV-1 & 0.88 & $500-200$ \\
\hline CSLV-2 & 0.83 & $510-200$ \\
\hline CSLV-3 & 0.8 (approx.) & 480 \\
\hline CSLV-4 & Extinguished & - \\
\hline CSLV-5 & 4.88 & $2250-1800$ \\
\hline CSLV-6 & 3.619 & $1750-1450$ \\
\hline CSLV-7 & 2.862 & $1050-800$ \\
\hline CSLV-8 & 0 & $2200-850$ \\
\hline CSLV-9 & 1.841 & $630-1000-630$ \\
\hline CSLV-10 & 6.436 & $2000-1150$ \\
\hline CSLV-11 & 5.89 & $1550-800$ \\
\hline CSLV-12 & 3.78 & $1800-700-150$ \\
\hline CSLV-13 & 0.21 & $650-280-130$ \\
\hline CSLV-14 & 2.2 & 300 \\
\hline CSLV-15 & 4.01 & $1000-650$ \\
\hline CSLV-16 & Extinguished & 250 \\
\hline CSLV-17 & 3.49 & 760 \\
\hline CSLV-18 & 2.1 & $825-675$ \\
\hline CSLV-19 & 4.14 & 730610 \\
\hline CSLV-20 & 4.89 & $1000-500$ \\
\hline CSLV-21 & Extinguished & - \\
\hline CSLV-22 & 3.55 & $750-390$ \\
\hline CSLV-23 & 4.82 & $1400-900$ \\
\hline CSLV-24 & 4.41 & $750-400$ \\
\hline CSLV-25 & Extinguished & - \\
\hline CSLV-26 & 3.65 & $1140-640$ \\
\hline CSLV-27 & Extinguished & - \\
\hline CSLV-27 & Extinguished & - \\
\hline CSLV-28 & 6.5 & 780 \\
\hline & & \\
\hline
\end{tabular}


This final propellant formulation was then recalculated in CEA for three separate conditions to gather pertinent parameters. The first case is the GG propellant by itself (i.e. $\mathrm{O} / \mathrm{F}=0$ ) since this information is required in estimating the GG propellant grain dimensions (Section 5.7) and expected flame temperature. The second case is with the GG propellant mixed with LOX. This would be the scenario used for the full size launch vehicle using an AIH motor (Section 3), and is also needed to determine the $\mathrm{O} / \mathrm{F}$ for the injector. The third case looked at was when the GG propellant is mixed with water under the same $O / F$ ratio that was used for the GG/LOX case. Experimental injector testing and analysis is done (Section 5 using water instead of LOX for obvious safety/simplicity reasons and in order to acquire temperature measurements. The results for all three cases are shown in Table 2.5.

Table 2.5: CEA output for GG propellant CSLV22

\begin{tabular}{|l|c|c|c|}
\hline & GG Propellant & Water/GG & LOX/GG \\
\hline \hline O/F Ratio & 0 (only GG) & 1.45 & 1.45 \\
\hline Density $\left[\mathrm{kg} / \mathrm{m}^{3}\right]$ & 15.88 & 54.38 & 5.66 \\
\hline c $[\mathrm{m} / \mathrm{s}]$ & 1037.9 & 572.9 & 1738.3 \\
\hline Isp (vacuum) $[\mathrm{s}]$ & 190.1 & 106.5 & 317.6 \\
\hline Isp (sea-level) $[\mathrm{s}]$ & 174.0 & 97.0 & 291.0 \\
\hline Flame Temperature [K] & 1169 & 537 & 3625 \\
\hline
\end{tabular}


The $\mathrm{O} / \mathrm{F}$ ratio was set based on the optimum value for the GG/LOX case. This was done since the real AIH motor would most likely use the GG propellant mixed with LOX as the oxidizer and therefore the injector needs to be evaluated at that particular optimum $\mathrm{O} / \mathrm{F}$ ratio. It was found that the optimum $\mathrm{O} / \mathrm{F}$ ratio for the GG/LOX scenario is 1.45 as shown in Figure 2.16.

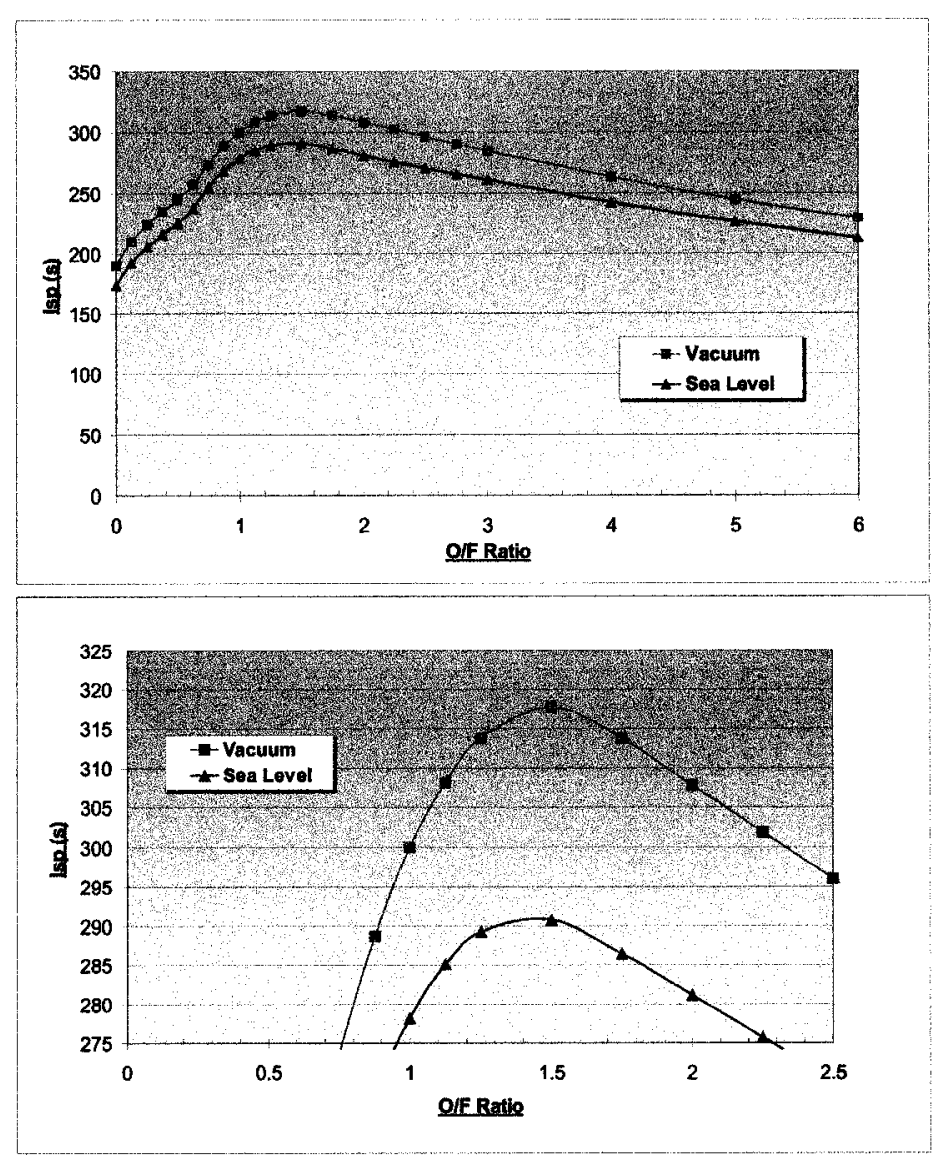

Figure 2.16: Effect on Isp with change in $\mathrm{O} / \mathrm{F}$ ratio for final propellant formulation CSLV22 mixed with LOX 


\section{Chapter 3}

\section{Trajectory Simulation}

As mentioned in Section 1.2 an aft-injected hybrid is a relatively new concept which is still in the development stages for launch vehicles. In order to develop a realistic aft-injected hybrid motor the details of the overall vehicles propulsion system need to be known or obtain a reasonable estimate of them. Specifically the performance of the gas generator solid propellant that was developed (Section 2) needs to be capable of placing a payload into orbit, otherwise this entire exercise is futile. Also the mass flow rate required for the injectors will be dictated by the thrust of the launch vehicle to reach orbit. In order to obtain a reasonable estimate for this pertinent information, a trajectory simulation was performed for a typical mission that would utilize an aft-injected hybrid. 


\section{$3.1 \quad$ ASTOS}

The trajectory software used was Aerospace Trajectory Optimization Software (ASTOS). It was produced by the Institute of Flight Mechanics and Control at the University of Stuttgart, in conjuction with the European Space Agency who partially funded its development. ASTOS allows the optimization of 3-DOF launch trajectories for a wide range of scenarios. It has the capabilities of 6-DOF re-entery, orbit transfers, and emergency aborts, however for this application only the conventional launcher trajectories were used. Like any trajectory simulation, the equations of motion are derived from Newton's second law, which is shown below in spherical coordinates for completeness.

$$
\begin{gathered}
\frac{\partial^{2} r}{\partial t^{2}}-r\left[\left(\frac{\partial \phi}{\partial t}\right)^{2} \cos ^{2} \psi+\left(\frac{\partial \psi}{\partial t}\right)^{2}\right]=\frac{\Sigma F}{m}-g \\
\frac{2}{\partial t^{2}}+\frac{\partial r}{r} \frac{\partial \phi}{\partial t} \frac{\partial \phi}{\partial t}-2 \frac{\partial \phi}{\partial \phi} \frac{\partial \psi}{\partial t} \frac{\partial \psi}{\partial t} \tan \psi=\frac{\Sigma F}{m} \\
\frac{\partial^{2} \psi}{\partial t^{2}}+\frac{2}{r} \frac{\partial r}{\partial t} \frac{\partial \psi}{\partial t}+\left(\frac{\partial \phi}{\partial t}\right)^{2} \sin \psi \cos \psi=\frac{\Sigma F}{m}
\end{gathered}
$$


where $\mathbf{r}$ is the radial distance from the earths center, $\phi$ is the longitude, and $\psi$ is the latitude. The term $\Sigma F$ is the sum of all the forces acting on the vehicle such as thrust, aerodynamic drag, wind, coriolis/centrifugal effect, etc.

ASTOS uses a second software GESOP to perform the actual optimization for the complex, multi-phase control problems. For details on the specifics of how GESOP optimize operates refer to [3]. ASTOS provides a graphical interface for the user to input all data for the desired mission, without having to worry about the optimizing algorithms details. The overall mission is broken down into four areas; mission definition, model definition, phase configuration, and mission constraints. Within each of these, input parameters are required depending on the type of mission and scenario that the user desires.

\subsection{Launch Vehicle Requirements}

To simulate a realistic type of mission that would be used by an aft-injected hybrid motor the following mission was defined.

- $100 \mathrm{~kg}$ payload (+15 $\mathrm{kg}$ adaptor)

- LEO orbit to $700 \mathrm{~km}$.

- Typical 3 stage launch vehicle.

- Stage 1 had three motors (each motor is one individual unit as described in Section 1) 
- Stage 2 has one motor

- Stage 3 is to be a small relatively cheap, simple solid motor.

- Propellant data based on selected GG propellant Section 2.4.3

- Propellant mass fraction of 0.82

- Canadian launch site (Churchill: LAT $=58.75$, LONG $=-94.07$ )

\subsection{Input Data}

When setting up the ASTOS simulation, it can be arranged in a variety of different circumstances depending on the users requirements. For this model the concept was to have a set payload $(115 \mathrm{~kg})$ and optimize the vehicle to have the lowest gross lift-off weight (GLOW). This is what the cost function was set for in the mission definition. Also in the mission definition, the planet model used was a standard J2 oblate earth, with no wind, and Vandenberg atmospheric conditions.

\subsubsection{Propulsion Input}

The model definition in ASTOS requires propulsion input. The $1^{\text {st }} \& 2^{\text {nd }}$ was dictated by the results from the CEA performance of the selected GG propellant (Section 2.4.3). This was inputed in table format with the exhaust velocity performance (from CEA) at specified expansion ratios (1 to 150). Other important parameters that were required are shown in Table 3.1. The $3^{\text {rd }}$ stage was done in a similar manner with CEA results for a typical solid propellant composition ( $70 \% \mathrm{AP}, 16 \%$ 
AL, 14\% HTPB). The expansion ratio for the 1st stage was optimized, while the $2^{\text {nd }} \& 3^{\text {rd }}$ stage were limited to 50 and 60 respectively. This was implemented since the optimizer would idealiy try to go off to infinity since these stages are in vacuum. Both the throat area and the propellant tank mass were allowed to be optimized.

Table 3.1: First and Second Stage propulsion ASTOS input parameters

\begin{tabular}{|l|c|}
\hline Parameter & Value \\
\hline \hline Characteristic Velocity (m/s) & 1728.4 \\
\hline Chamber Pressure (psi) & 800 \\
\hline O/F Ratio & 1.5 \\
\hline Isp Efficiency & $94 \%$ \\
\hline
\end{tabular}

\subsubsection{Phase Configuration}

The trajectory was broken down into 8 different phases;

1. Vertical Ascent

2. Pitch Over

3. Pitch Constant

4. $1^{\text {st }}$ Stage Burn: acting with gravity turn

5. $2^{\text {rd }}$ Stage Burn With Fairing

6. $2^{\text {rd }}$ Stage Burn Without Fairing

7. Coast Arc

8. $3^{\text {rd }}$ Stage Burn: ending with orbital insertion

Within each of these phases the time duration was allowed to be optimized unless additional constraints were needed (discussed below). 


\subsubsection{Constraints}

Constraints were imposed within the trajectory simulation in order to ensure that the optimizer would define the trajectory based on the desired mission. The goal of the optimizer was to make the vehicle as light as possible (cost function $=$ minimize GLOW). Without forcing it to adhere to certain criteria it would define a vehicle that would over minimize GLOW, and not be representative of the mission at hand. There are also constraints place in order to ensure that logical parameters can be achieved (such as the realistic burn time of a solid motor). Constraints were also imposed due to the commonality between Stages 1 and 2 .

To achieve some overall constraint, multiple mutually inclusive constraints had to be used (such as perigee and apogee altitude to achieve circular orbit altitude). The key constraints used are listed below.

- Circular orbit $=700 \mathrm{~km}$

- Stage 1 Burn Time = Stage 2 Burn Time

- Stage 1 Throat Area $=$ Stage 2 Throat Area

- Maximum Heat Flux $=1035 \frac{W}{m^{2}}$

- Orbital Inclination $=98.3^{\circ}$ (for SSO trajectory)

- Maximum Stage 3 Burn Time $=40 \mathrm{~s}$ 


\subsection{Results}

In using ASTOS a wealth of information is provided for the simulated trajectory. In this application a significant portion of this data is not needed, but ASTOS must still calculate and provide it to accurately simulate the trajectory. Table 3.2 shows some of the relevant results acquired from ASTOS. The most important aspect of this entire exercise is the fact that it shows given the GG propellant developed in Chapter 2, a useful circular orbit of $680 \mathrm{~km}$ can be achieved. This is all accomplished with a reasonable GLOW of $13213 \mathrm{~kg}$ typical, which is typical of a small launch vehicle such as this.

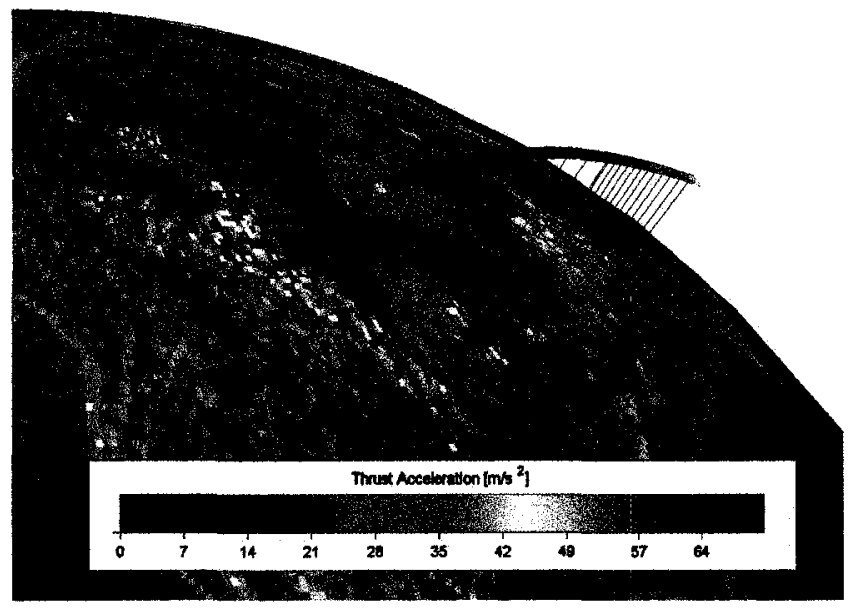

Figure 3.1: ASTOS simulated trajectory profile. 
Table 3.2: Relevant data from simulated trajectory using ASTOS

\begin{tabular}{|l|c|}
\hline Stage 1 & \\
\hline \hline GG Mass & $3234 \mathrm{~kg}$ \\
\hline LOX Mass & $4851 \mathrm{~kg}$ \\
\hline Burn Time & $1 \mathrm{~min} 53.2 \mathrm{sec}$ \\
\hline Mass Flow & $71.45 \mathrm{~kg} / \mathrm{s}$ \\
\hline Thrust - Vacuum & $203.92 \mathrm{kN}$ \\
\hline Stage 2 & \\
\hline \hline GG Mass & $1078 \mathrm{~kg}$ \\
\hline LOX Mass & $1617 \mathrm{~kg}$ \\
\hline Burn Time & $1 \mathrm{~min} 53.2 \mathrm{sec}$ \\
\hline Mass Flow & $23.82 \mathrm{~kg} / \mathrm{s}$ \\
\hline Thrust - Vacuum & $75.56 \mathrm{kN}$ \\
\hline \hline Stage 3 & \\
\hline \hline Propellant Mass & $309.74 \mathrm{~kg}$ \\
\hline Burn Time & $40 \mathrm{sec}$ \\
\hline Mass Flow & $7.74 \mathrm{~kg} / \mathrm{s}$ \\
\hline Thrist - Vacuum & $21.51 \mathrm{kN}$ \\
\hline Total Vehicle & \\
\hline \hline Total Mass (GLOW) & $13213 \mathrm{~kg}$ \\
\hline Total Flight Time & $11 \mathrm{~min} 24 \mathrm{sec}$ \\
\hline Circular Orbit Achieved & $680.3 \mathrm{~km}$ \\
\hline Inclination & $60.4^{\circ}$ \\
\hline
\end{tabular}

This mass sizing from the trajectory simulation was required to get preliminary estimates of the overall launch vehicle size. The vast majority of the vehicle sizing is not applicable to this particular research, however one important relevant result from this sizing was whether the gas generator should operate as a choked or unchoked system. A choked system is desirable so that the pressure at which the gas generator operates at is unaffected from any fluctuations in the down stream post combustion 
chamber. It is also very desirable since it allows precise determination of the mass flow of the warm gas from the GG propellant. However in order to operate as a choked system the GG propellant would have to operate at a pressure adleast 1.78 times that of the post combustion chamber (based on the propellants specific heat ratio). At this higher pressure the gas generator case thickness must be significantly larger. As shown in Table 3.3 by having a unchoked system results in a mass savings of $1.5 \%$ over the entire vehicle. This was based on a composite GG case and only included the mass due to the larger thickness of the case. It does not include any additional components that may need to be heavier for the higher pressures such as piping, valves, etc. Although at first glance 1.5\% does not seem like much this is a significant weight savings on the entire vehicle since it is only allotted $18 \%$ for total structural mass (0.82 mass fraction). Therefore it was clearly decided that the gas generator propellant would operate unchoked despite the convenience of using a choked system. 
Table 3.3: Effect of a choked and unchoked gas generator system

\begin{tabular}{|l|c|c|}
\hline & Choked & Unchoked \\
\hline \hline Thickness & $4.7 \mathrm{~mm}$ & $8.9 \mathrm{~mm}$ \\
\hline Mass & $53 \mathrm{~kg}$ & $101.3 \mathrm{~kg}$ \\
\hline & & \\
\hline \hline Mass Savings Per GG Case & $48.3 \mathrm{~kg}$ & \\
\hline Total Mass Savings & $193.2 \mathrm{~kg}$ & \\
\hline Total Vehicle Mass & $13213 \mathrm{~kg}$ & \\
\hline \% Vehicle Mass Savings & $1.46 \%$ & \\
\hline
\end{tabular}

\subsubsection{Baseline Vehicle Derivative}

As part of an additional study conducted outside this particular research, the vehicle trajectory simulated was also compared for different derivatives of this vehicle. As an aft-injected system is still a new technology yet to be proven the derivatives of these vehicles are shown here for completeness and to give a sense of the flexibility that this propulsion system would be able to achieve. 


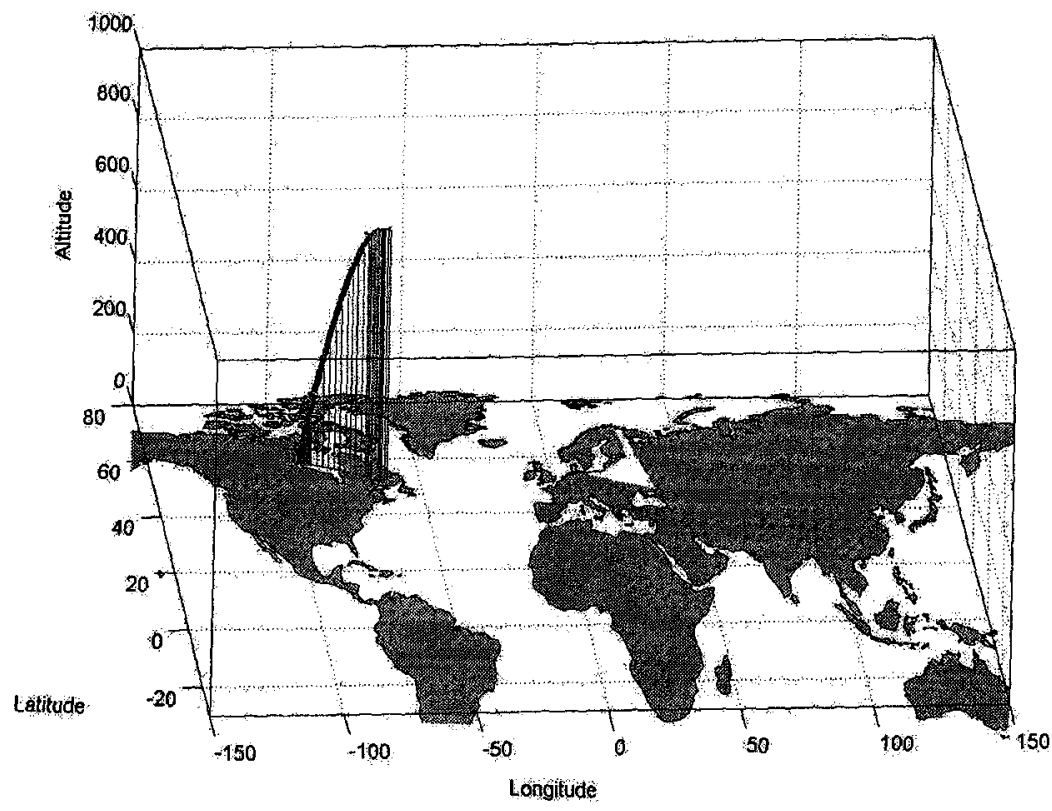

Figure 3.2: Plot of ASTOS trajectory over a flat earth map. 
The baseline vehicle was the one described above $(100 \mathrm{~kg}$ payload to $700 \mathrm{~km}$ orbit flexible inclination). Using the identical vehicle (same GLOW, propellant mass, burn times, etc) with changes only to phase durations and control maneuvers, two different derivatives were looked at. These were an air-launch scenario from 9 $\mathrm{km}$ altitude and a sun-synchronous orbit mission. The payload capabilities of this baseline vehicle are shown in Figure 3.3.

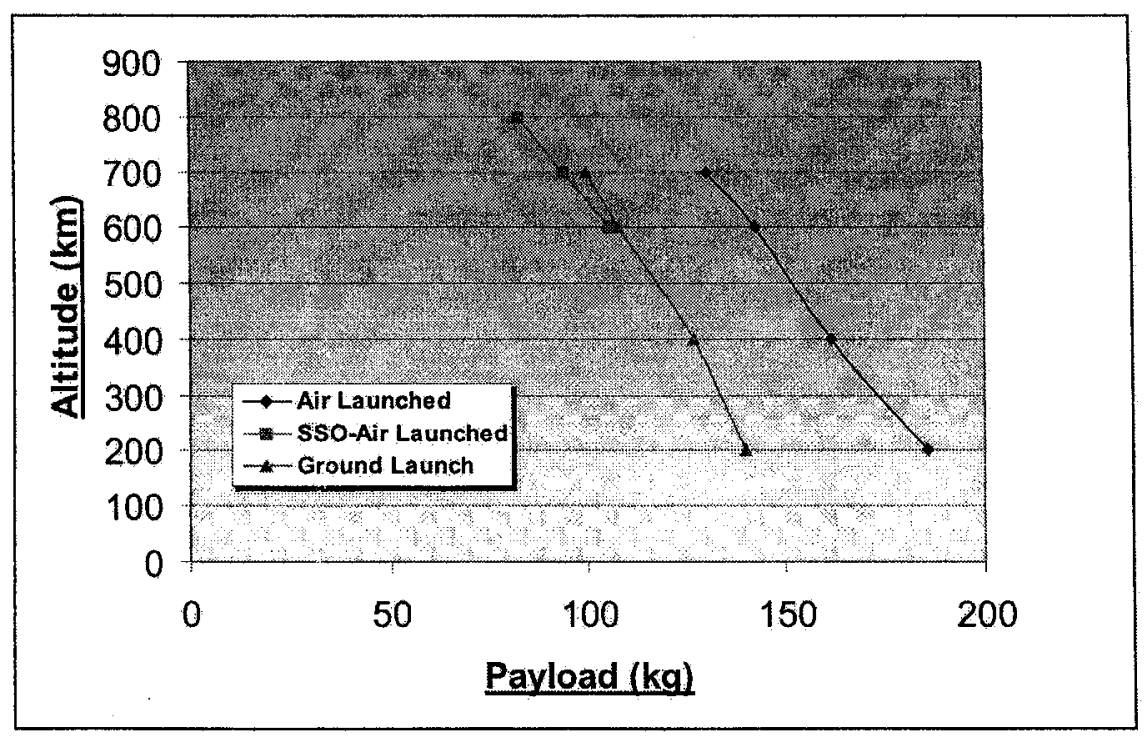

Figure 3.3: Payload capabilities of the baseline launch vehicle. 


\section{Chapter 4}

\section{Injector Selection}

Based on the literature reviewed and an examination of propulsion systems currently used for launch vehicles a coaxial injector is the preferred choice for this type of system. The reasoning for this is that it has a reputation of being a high performance, stable injector [20]. Perhaps the largest driving factor for a coaxial injector is with an aft-injected hybrid (AIH) motor there is already a gaseous fuel mixed with a liquid oxidizer (LOX). The different phases are required with a coaxial injector since it principle operation occurs with the interaction and transfer of momentum between the liquid and gas. Many large launch vehicles (such as the space shuttle, Ariane-5, H-II, etc) go through a lot of effort and cost to gasify one of the propellants in order to use a coaxial injector. Since the AIH motor already operates in this manner it makes it ideally suited for the coaxial injector. It also has some advantages in terms of its simplicity for manufacturing. Since everything is aligned concentrically the 
coaxial injector can be fabricated on a standard lathe.

In comparison to other injectors, the use of an impingement type has a disadvantage due to the gaseous fuel and liquid oxidizer. It is also more difficult to manufacture due to the tight tolerance on the precise angles necessary for the injection ports. The impingement injector is more susceptible to lower performance with slight changes in off-design operation such as throttling. The reason for this is the angle at which the injection streams of fuel and oxidizer collide with one another is critical for good mixing and atomization. Since the gas generator propellant is to operate as an unchoked system (discussed in Section 3.4) it will likely endure some slight fluctuations in the mass flow, injection velocity, and pressure, all of which would have dramatic effects on the injection efficiency when using a impingement injector.

Other injectors such as the showerhead was ruled out early due to extremely poor atomization and mixing, and is why they have not been actively used since the early days of rocketry. A concept that was developed for an AIH motor was the use of a platelet or vane injector. This was developed by the Advanced Rocket Engine Storable (ARES) in 1967 for the U.S. Air Force. An advanced version was even proposed and demonstrated for the space shuttle main engines (SSME), but 
lost out to the coaxial configuration. The manufacturing of a platlet injector is extremely difficult (and nearly impossible) without using an etching process for the fabrication. In addition there are significant issues with the platelets themselves effecting the flow. Therefore the platlet injector was ruled out as a possible injector for this system.

\subsection{Injector Initial Sizing}

As mentioned in Section 1.3, injector testing will be done both experimentally and numerically. Testing of these injectors will occur with different dimension in order to provide different flow characteristics. However, it should be first determined what the dimensions should be based on what has previously been done and on fluid mechanics.

Obviously, one of the key parameters to any injector is the mass flow. The first thing that was done was to look at previous work that has been performed on coaxial injectors and any propulsion systems that use coaxial injectors. A data base of oxidizer and fuel dimensions, velocities, mass flows, number of injectors, and propellant types was created. From this it was quickly discovered that the vast majority of information, testing, and experimentation was accomplished on LOX 
and gaseous hydrogen. This was obviously due in part to H2/LOX providing the highest performance, and being used on the majority of larger launch vehicles.

The problem that this posed was that the $\mathrm{O} / \mathrm{F}$ ratio used for $\mathrm{GH}_{2} / \mathrm{LOX}$ combination is higher compared to this gas generator hybrid motor of 1.5 (Section 3 ). Also the density and chemical reaction is quite different between the warm gas from the decomposed solid propellant and hydrogen. This meant that the mass flow for both the oxidizer and fuel, and precise dimensions for coaxial injector from previous work could not be used as a starting point. The AIH propulsion is a new concept, with the only research completed on it discussed in Section 1.4 (which used either an annual injector in the reverse flow or a impingement type of injector), therefore there is no real comparison for a coaxial configuration. The next thing which was looked at was the mass flow per injector. The reasoning behind this, is that for a relatively large rocket such as the $\mathrm{AIH}$ motor there will obviously be more than one injector. Obviously, it would be ideal to have as many small injectors (holes) as possible to improve mixing and atomization. However as the hole get smaller and smaller other problems arise such a blockage from particles, manufacturing tolerances/reproducibility, and cost. There is also a lower limit on the physics of the shear interface. Therefore even though some of the parameters are different for other coaxial injectors from previous work an approximation of total mass flow per injec- 
tor will still show what is reasonable to achieve. For this, information was gathered from both coaxial injectors used in actual operating propulsion systems and from coaxial injectors used in research/experiments. The later included cold fire, hot fire, and numerical work performed, with empathize on hot fire conditions. From this it was shown that the average total mass flow per injector for propulsion systems currently used in industry was $0.71 \mathrm{~kg} / \mathrm{s}$ and the average for research experiments performed was $0.54 \mathrm{~kg} / \mathrm{s}$ respectively. Therefore it was decided to use a value of $0.61 \mathrm{~kg} / \mathrm{s}$ per injector element for the $\mathrm{AIH}$.

One parameter that is shared between the AIH motor and the LOX/GH2 is the velocity at which the gas and liquid are injected. From the literature it was strongly shown that the ratio of the gas velocity to the liquid velocity plays a significant role in governing the atomization of the liquid [17],[23],[38],[33] . This is due to the momentum transfer causing the shearing action between the liquid and gas. Therefore the velocity of the oxidizer and fuel from research performed in the past was investigated. Based on information from [20] it was expected that the liquid would be around $33 \mathrm{~m} / \mathrm{s}$ and a gas velocity of $330 \mathrm{~m} / \mathrm{s}$, for a ratio of 10:1. Based on the data base of information collected, it was shown that the average oxidizer and fuel velocity were $41 \mathrm{~m} / \mathrm{s}$ and $312 \mathrm{~m} / \mathrm{s}$ respectively. This resulted in a velocity fuel-to-oxidizer ratio of 7.6. As part of this research the goal is to examine the effects 
that this velocity ratio plays on the efficiency of the injector. Therefore different injectors will have varying velocities to achieve this.

The next aspect of the coaxial injector which was investigated was its orientation. It had to be decided whether to have the liquid oxidizer in the center post with the gas in the outer annulus or to arrange the gas in the center post and liquid in the outer annulus. Based on all books and research papers reviewed of coaxial injectors the vast majority had a liquid center, gas annulus configuration. However since this specific injector is not using hydrogen as the gas, but the gas from the solid propellant, this may not be the best suited and was therefore investigated. Initially the idea was to have gas in the center post because it was very attractive for ease of manufacturing. This is much easier to manufacture since it is only a matter of drilling the appropriate diameter hole for the gas in the injector face, and then have the liquid (LOX) manifold pipe in through an annulus. This would eliminate the need for an elaborate manifold system to get the LOX in the center stream of the gas, and the turbulent effects this manifold piping would have on the fluid flow would be eliminated.

To compare these two scenarios a reasonable fixed value for the oxidizer and fuel velocity was established as $30 \mathrm{~m} / \mathrm{s}$ and $300 \mathrm{~m} / \mathrm{s}$ respectively. From Chapter 
Table 4.1: Parameters used for injector dimension sizing

\begin{tabular}{|l|c|c|}
\hline Parameter & Value & Units \\
\hline \hline O/F Ratio & 1.45 & - \\
\hline Gas Generator Density (gaseous) & 15.88 & $\mathrm{~kg} / \mathrm{m}^{3}$ \\
\hline Oxidizer Density (LOX) & 1137 & $\mathrm{~kg} / \mathrm{m}^{3}$ \\
\hline Water Density & 998 & $\mathrm{~kg} / \mathrm{m}^{3}$ \\
\hline Total Injector Mass Flow & 0.61 & $\mathrm{~kg} / \mathrm{s}$ \\
\hline Gas Mass Flow & 0.25 & $\mathrm{~kg} / \mathrm{s}$ \\
\hline Oxidizer Mass Flow & 0.36 & $\mathrm{~kg} / \mathrm{s}$ \\
\hline
\end{tabular}

2.4.3, the density and $\mathrm{O} / \mathrm{F}$ ratio are know of the gas generator with LOX using CEA (see Table 4.1). Usirig these values the area of the injector can be determined from the continuity equation.

$$
A=\frac{\dot{m}}{\rho v}
$$

For the case of the gas center/liquid annulus configuration, it resulted in a very small annulus gap for the liquid (see right side of Figure 4.1). The actual inside diameter of the post for the solid fuel gases was $8.22 \mathrm{~mm}$. A $2 \mathrm{~mm}$ splitter plate (outer diameter is $12.22 \mathrm{~mm}$ ) was used between in both cases, as this is what was typically seen from the database of experimental injectors discussed above. This resulted in the LOX (liquid) annulus gap only being a minuscule $0.27 \mathrm{~mm}$. The reason for this tiny gap was due to the differences in density between the phases of liquid and gas. Obviously, this type of injector would be very difficult to fabricate, with high demand in tolerances during manufacturing and assembly. Although at- 
omization of the LOX would be good, this would lead to extremely poor mixing. It would be nearly impossible for the center portion of the gas to be penetrated, which results in very inefficient mixing.
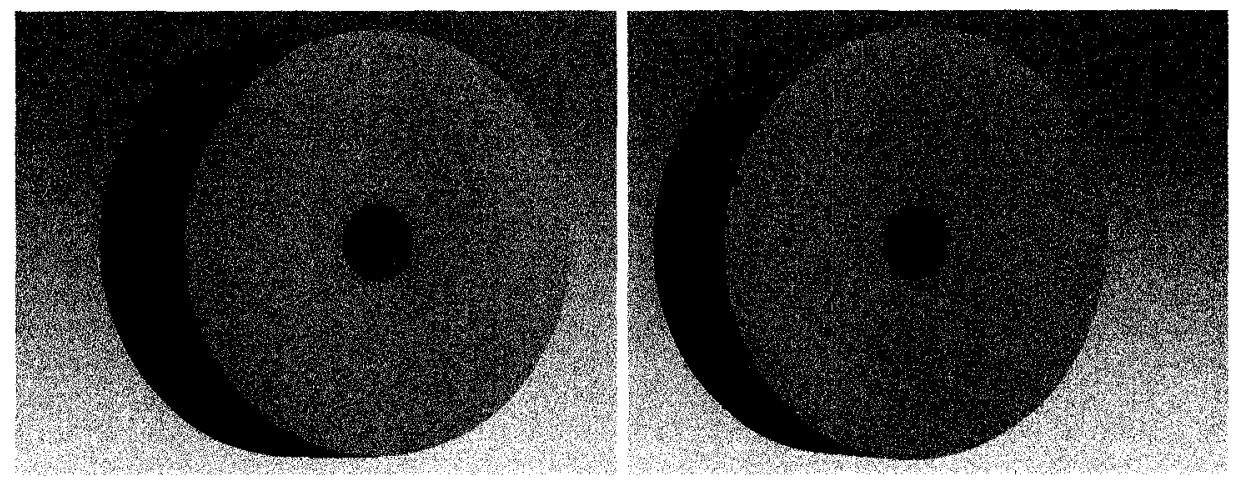

Figure 4.1: (LEFT) liquid center/gas annulus injector configuration (RIGHT) gas center/liquid annulus injector configuration

Another concept that was looked at was to bleed of a portion of the gas into straight posts without a liquid annulus and have a single center post that would have the liquid annulus. However after analysis it was shown that in order to have enough by pass gas posts, the injector starts to become more of a showerhead configuration instead of a coaxial (left side of Figure 4.2). This is only amplified when the multiple injectors are used for the full scale motor that requires a mass flow of $13.4 \mathrm{~kg} / \mathrm{s}$. Even for the sub-scaled AIH motor (12 inch motor) this becomes quite evident with nine injectors, as shown on the left in Figure 4.2. Therefore the advan- 
tages of mixing and atomization with a coaxial injector are become less effective. A second gas annulus was not investigated because this would lead to even more complex geometry for plumbing/manufacturing of the manifold then simply having the liquid center, gas annulus injector.
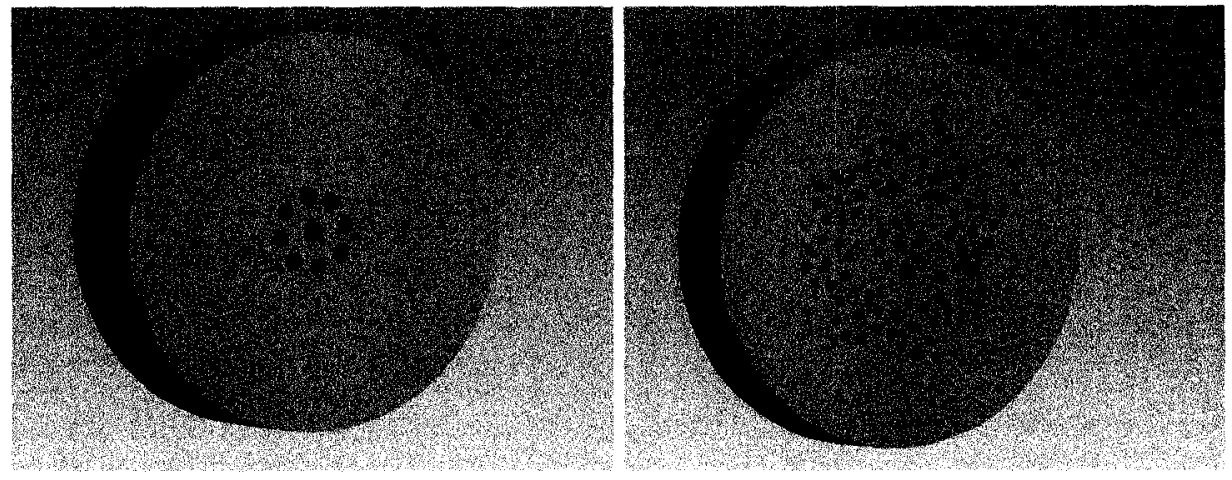

Figure 4.2: Drawing of bypass ports for gas center/LOX annulus injector. (LEFT) a single injector on 4" diameter motor (RIGHT) multiple injectors used on a 12" sub-scale motor

The nominal configuration of a liquid center/gas annulus injector was finally investigated. In this scenario when using the same oxidizer/fuel velocity and the same parameters from Table 4.1 the resulting injector was much more reasonable (see left side of Figure 4.1). The corresponding injector had an liquid post inner diameter of $3.70 \mathrm{~mm}$, outer diameter of $7.70 \mathrm{~mm}(2 \mathrm{~mm}$ splitter plate), and an annulus gap of $1.79 \mathrm{~mm}$. Therefore it was clearly decided that a liquid center/gas annulus injector configuration will be used. 


\subsection{Gas Generator / Water Injector}

There are three major difficulties when experimenting with LOX. The first is the fact that it is highly reactive with many different substances. This means much care must be taken when designing, and assembling any components that are in contact with LOX. Secondly is the fact that LOX is a cryogenic, so many component must be specified or modified to be capable of handling the extreme temperature differences. The final problem is with the high flame temperatures that result with a combination with the fuel-rich solid propellant. These high flame temperatures are desired within a propulsion system since this is the principle operation to convert thermal energy into kinetic energy. However, with the high flame temperatures ( $3000 \mathrm{~K}$ ) gaining data becomes very difficult and extremely costly. The simple application of thermocouple can not be used since they are not able to withstand these extreme environment.

Therefore, injector testing was first done using water instead of LOX. This significantly reduced the flame temperature $(\approx 1170 \mathrm{~K})$, well within the operating range of thermocouples. This also allowed much simpler, more reliable, and "off the shelf" components to be used first to prove out the sub-scale motor before introducing it to the complexity of cryogenics. 
Since the atomization process is dependent on the momentum transfer (shearing of the liquid-gas interface), the mass flow ratio $(\mathrm{O} / \mathrm{F})$ should be maintained. Also the velocity ratio between the liquid and gas must also be maintained. Therefore the cross-sectional area of the injector inlet is modified due to the change in density between LOX and water. Based on the initial injector parameters for LOX/GG from CEA (Table 4.1) but using water density instead the injector dimensions can be established.

As mentioned earlier the goal of this research is to investigate the effect the velocity ratio plays on the efficiency of the injector. Since fabrication and testing of these injectors is very expensive, the number of injectors tested will be limited to six. A baseline injector is established at a velocity ratio of 7.0 representative of the average from the database looked at. Two injectors with lower velocity ratios, and two with higher were investigated. The final injector will have the same velocity ratio as the baseline injector but the magnitude of the gas and oxidizer velocity will be lower to observe what this effect has. 
Initially, the baseline injector was sized have an oxidizer velocity of $30 \mathrm{~m} / \mathrm{s}$ with a gas velocity of $210 \mathrm{~m} / \mathrm{s}$, to provide a ratio of 7.0. However, fabrication constraints also came into consideration with the injector sizes. Specifically, since the inner post diameter was so small and a boring bar could not be used, the diameter had to fall into standard remer sizes so that the contours of the wall could be machined properly. The outer diameter and the annulus diameter was not a fact and could be to any specified size. Due to this the velocities are slightly different and are shown in Table 4.2. Dimensions for all injectors are also shown.

Table 4.2: Injector Dimensions and Flow Conditions

\begin{tabular}{|l|c|c|c|c|c|c|}
\hline Injector & $\begin{array}{c}\mathbf{D}_{\text {inner }} \\
{[\mathbf{m m}]}\end{array}$ & $\begin{array}{c}\mathbf{D}_{\text {outer }} \\
{[\mathbf{m m}]}\end{array}$ & $\begin{array}{c}\mathbf{D}_{\text {annulus }} \\
{[\mathbf{m m}]}\end{array}$ & $\begin{array}{c}\text { Water Velocity } \\
{[\mathbf{m} / \mathbf{s}]}\end{array}$ & $\begin{array}{c}\text { GG Velocity } \\
{[\mathbf{m} / \mathbf{s}]}\end{array}$ & Ratio \\
\hline RC1 & 5.00 & 9.00 & 13.50 & 18.4 & 198.1 & 10.8 \\
\hline RC2 & 4.37 & 8.37 & 12.70 & 24.1 & 219.6 & 9.1 \\
\hline RC3 & 3.97 & 7.97 & 13.50 & 29.2 & 168.8 & 5.8 \\
\hline RC4 & 5.00 & 9.00 & 15.47 & 18.4 & 126.4 & 6.9 \\
\hline RC5 & 3.97 & 7.97 & 15.47 & 29.2 & 113.5 & 3.9 \\
\hline RC6 & 3.97 & 7.97 & 12.70 & 29.2 & 205.0 & 7.0 \\
\hline
\end{tabular}




\section{Chapter 5}

\section{Sub-Scale Test Motor}

As mentioned previously, an aft-injected hybrid rocket motor is a relatively new concept. To fully prove out the new technology, a sub-scale test motor was designed and built. This sub-scale motor was designed for testing purposes, and is not a flight ready motor i.e. it did not use light-weight components in all aspects. The aim for this sub-scale motor was for three fold. First, additional testing of the new GG propellant (developed in Chapter 2) was completed with a new grain shape. Secondly this test motor provide proof that the aft-injected concept is functional with stable operation and startup procedure. Finally, the an analysis on the injector was completed with investigation into the effect the momentum ratio (velocity ratio) plays on the efficiency of the injector. 
This test motor utilized a single full scale injector element using the relevant dimensions and parameters outlined in Section 4. This injector element would be equivalent to the one used in the full size launch vehicle based on results from ASTOS trajectory simulation (Chapter 3). In order to keep costs down and reducing the time for fabrication, the test motor was designed around existing hardware where ever possible.

The existing hardware was based on the Pro-98 hobby solid motor series developed and produced at CTI. The same outer diameter (4") was used so that liners, retainer rings, forward closures, insulators, nozzle, etc could all be used. The overall sub-scale test motor can be divided up into four main components; the solid propellant GG grains, injector, post combustion chamber/nozzle, and oxidizer pressurization/plumbing. 


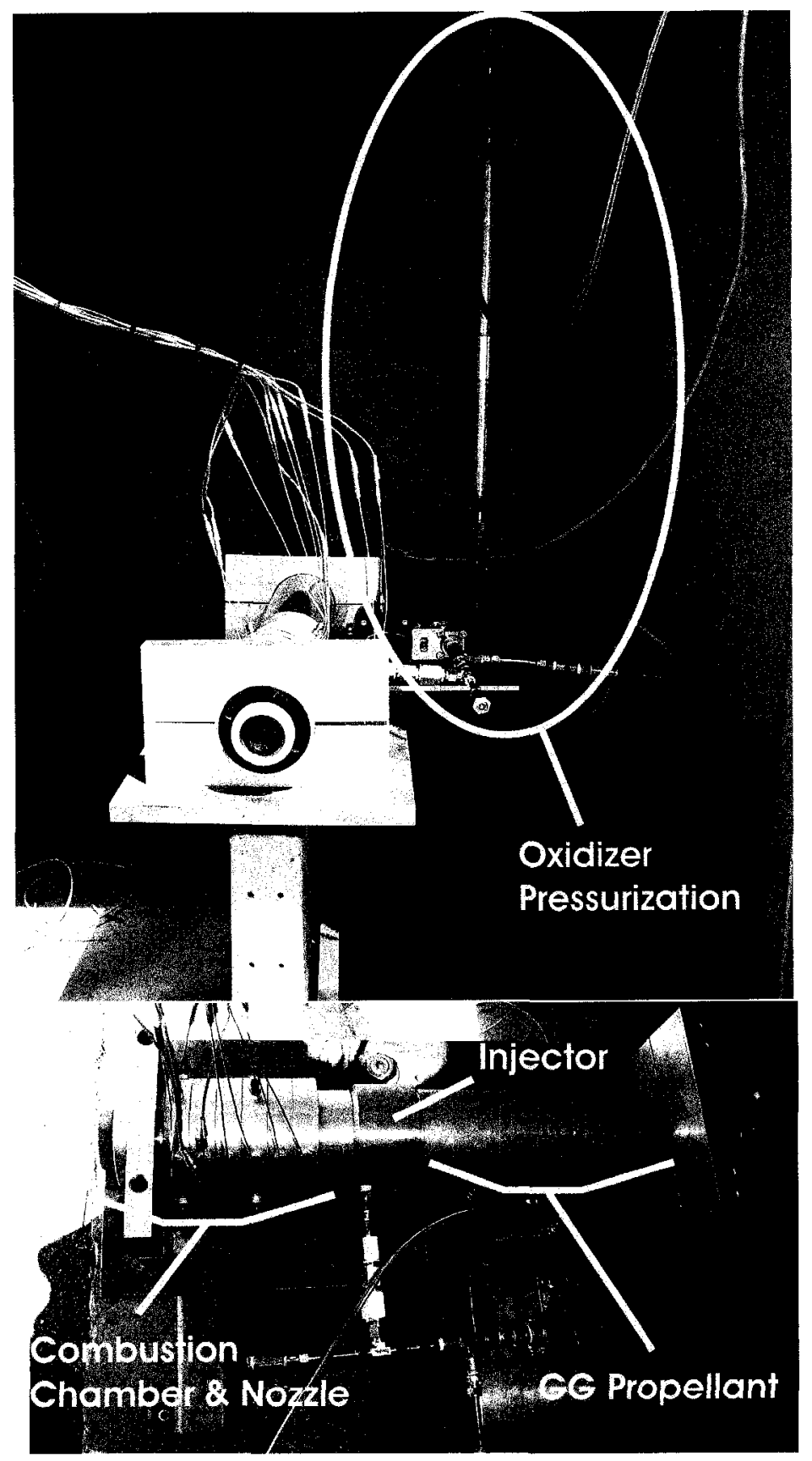

Figure 5.1: Sub-scale motor on experimental test stand identifying the four major components 


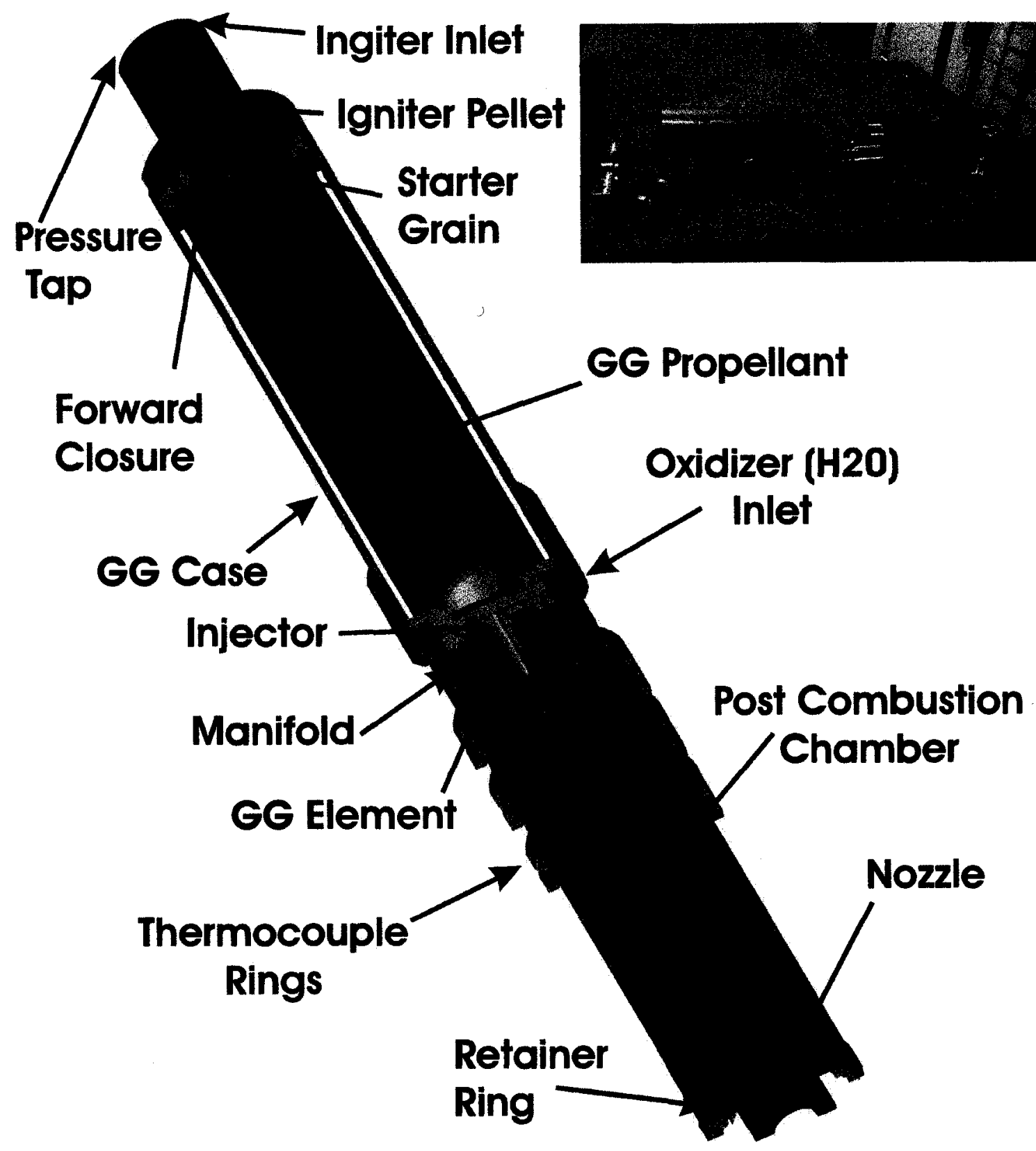

Figure 5.2: Cross sectional view of sub-scale motor with labeled componenets 82 


\subsection{Gas Generator Grains}

This sub-scale aft-injected hybrid motor used a cartridge loaded gas generator solid fuel grain. The grains were cartridge loaded to help in reducing the time required for casting and assembly of the test motor. Three separate propellant batches $(24 \mathrm{~kg})$ using propellant formulation CSLV22, CSLV26, and CSLV27 (Table 2.1 in Section 2 were made for testing these grains. The final grain used for the injector testing was based on propellant formulation CSLV22 for reasons discussed later Section 5.7.

The propellant grains were casted into cardboard tubes (same as Pro-98), and were post machined specifically to provide the desired mass flow characteristics (discussed below). The grains, along with a Pro-98 liner, were inserted into a casing that could be attached to the upstream side of the injector manifold. The casing was a derivative of the Pro-98 casing with the difference being it had an outside screw thread for attachment to the injector.

Due to the inherit safety of these grains (a prerequisite as outlined in Section 2.1 and 2.4.2), it makes them incredible hard to ignite and sustain combustion. The ignition of the grains is accomplished through a three step process. A standard hobby motor electrical igniter is used to start the ignition sequence, which then ignites a BKNO3 pellet. This pellet then produces enough hot gases to ignite a 
starter grain. This starter grain is a high burn rate version of the Pro38 hobby solid propellant motors. This modified Pro38 (38mm diameter) grain is simply a grain with a $1 / 2$ " port, and a shorter length of $3 / 4 "$ " Two of these grains are used to start the GG solid propellant. They were placed in the Pro-98 forward closure which was also modified. It had a hole drilled through to allow the gas from the pellet to enter and a NPT thread put on the outside for the igniter body holder to attach to.

For the actual GG grain, as outlined in Section 4.1 the mass flow desired for the solid fuel gas generator was $0.250 \mathrm{~kg} / \mathrm{s}$. For the injector, it is also required to have a fairly constant mass flow. This is desirable so that combustion occurs at the optimum $\mathrm{O} / \mathrm{F}$ ratio, thereby providing the maximum performance (Isp) as shown in all Figures within Section 2.2. Also the optimum liquid-to-gas velocity ratio should be maintained to provide good atomization of the liquid oxidizer. In order to achieve a relatively constant mass flow the propellant grain must be shaped and designed accordingly. For a small sub-scale motor, such as this, there are basically two different possibilities for the grain design; a star or BATES (BAllistic Evaluation TESt Motor). Due to the additional cost of manufacturing a unique star shaped mandrel, a BATES grain was selected for this sub-scale motor. 


\subsubsection{BATES Grain}

A BATES grain is essentially a center perforated grain (circular hole or port down the center of the grain) with uninhibited ends. By carefully matching the inner diameter to the outer diameter and controlling the length, the burn surface area (which is directly proportional to the mass flow) can be kept relatively constant. This is accomplished by having the progressive burn of the center port (which burn radially outward), offset by the regressive burn of the ends of the grain (which burns axially reducing the port length). If a larger mass flow is required multiple BATES grains are used to sum to the total mass flow.

Based on the Pro-98 series motor, the outer diameter of the propellant grain is restricted to $83 \mathrm{~mm}$. Therefore the flexibility with the grain is with the port diameter, length, and number of grains. The dimensions of the BATES grain went through a few iterations and required some critiquing after hot fire experimental tests. The details of this are discussed in depth in Section 5.1. 


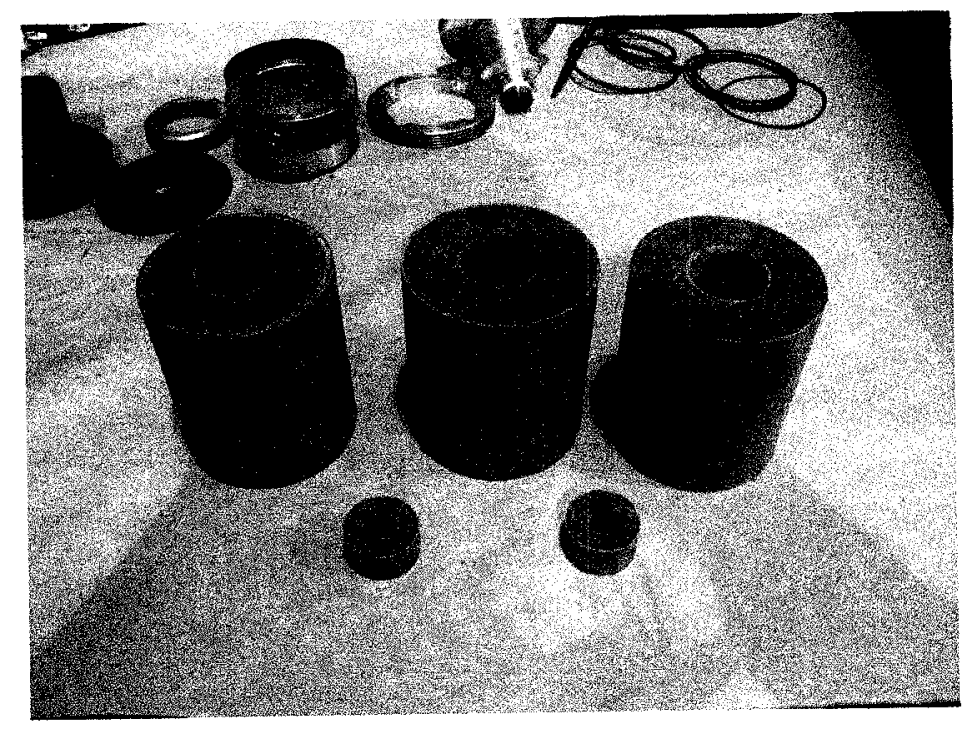

Figure 5.3: BATES grains and starter grains used for AIH motor (three individual grains and 2 starter grains per test) 


\section{$5.2 \quad$ Injector}

The injector used was a coaxial as discussed in Chapter 4. For this sub-scale motor, the injector manifold, water element, and gas generator (GG) element were all uniquely fabricated. This motor was designed so that the water element and the GG element could both be interchanged easily to allow different injector dimensions to be tested (thereby changing the injection parameters). This also allowed the testing of both water/GG injector and LOX/GG in later development from the same hardware.

Sealing of the water element was done with face sealing o-rings. Face seals were used so that the manifold can be used with LOX in the future and the seal gaps were made to fit cryogenic OmniSeal-103A series seals. The GG element used a radial o-ring seal since it only experiences the warm gases produced from the GG solid propellant. The injector that were tested are shown in Table 4.2. 

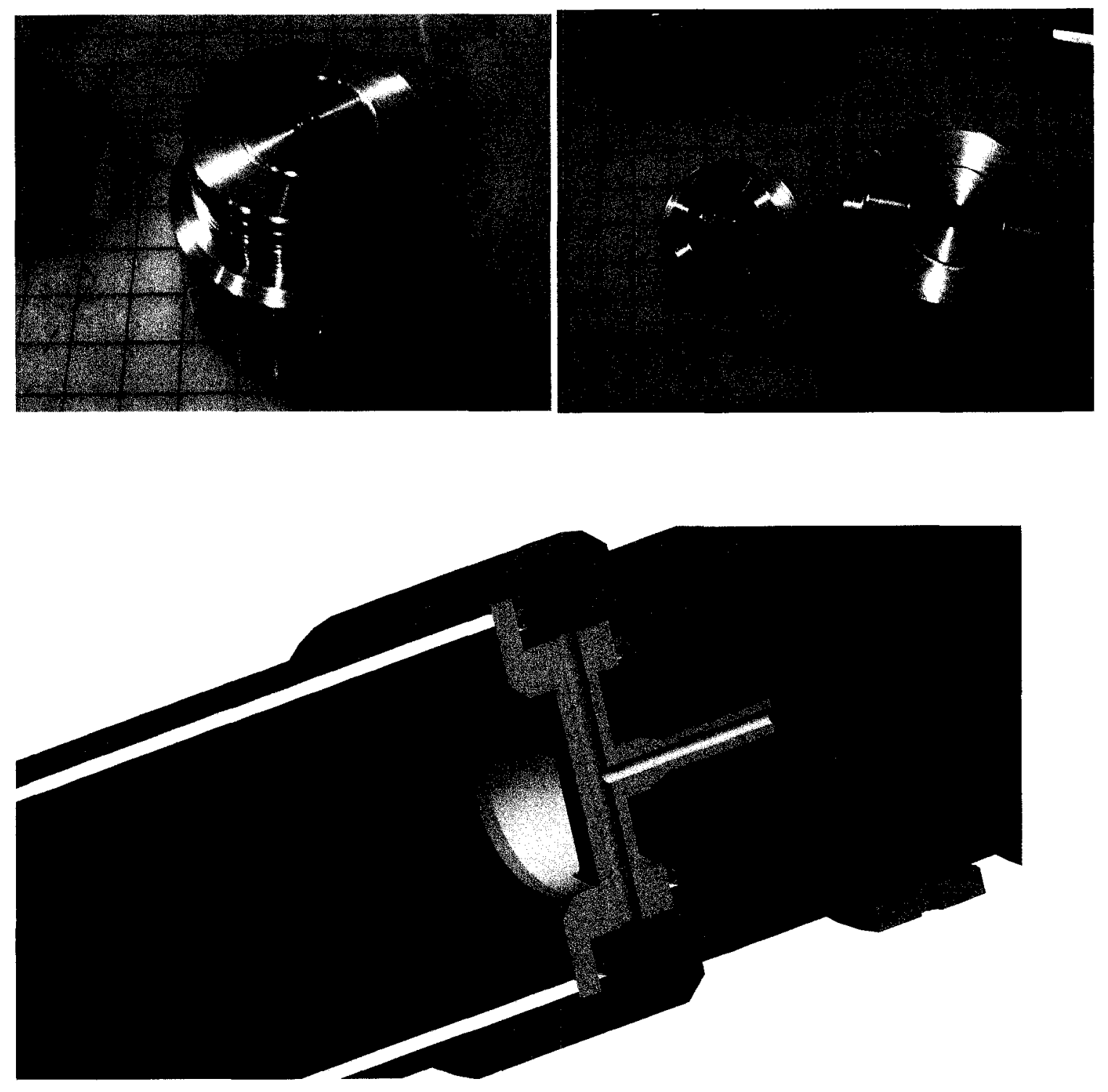

Figure 5.4: (TOP LEFT) Assembled water and GG element in manifold (TOP RIGHT) Water element unassembled with GG element assembled in manifold (BOTTOM) Cross section of entire injector assembly (manifold, water and GG element) 


\subsection{Oxidizer Pressurization}

For the injector testing the oxidizer was simulated using water instead of LOX for obvious safety and simplification reasons. As discussed in Chapter 4 the inlet pressure to the injector for the water is to be 805 psi at a mass flow of $0.375 \mathrm{~kg} / \mathrm{s}$. The oxidizer (water) tank used was a 4.6L HyperTEK tank produced by CTI for the hybrid hobby motors. These tanks are used for nitrous oxide (N20) and due this oxidizer being self pressurized, the tank only has one opening. The HyperTEK tank was modified to provide an inlet at the top of the tank, and use the existing opening for the outlet of the oxidizer (water). The new inlet at the top consisted of a unique adapter that was welded in place (see Figure 5.5). This adapter allowed three attachment points; nitrogen inlet, pressure relief valve, and water fill point. The adapter allowed for an increase opening for the water inlet so the filling time of the tank was reduced. It also allowed the option for a fill stem to be added when using the tank for LOX in future applications.

To measure the mass flow of the oxidizer the tank was hung from a $60 \mathrm{lbs}$. load cell that was mounted to the ceiling. A hanging bracket was fabricated to hold the tank to the load cell, as seen if Figure 5.5. 


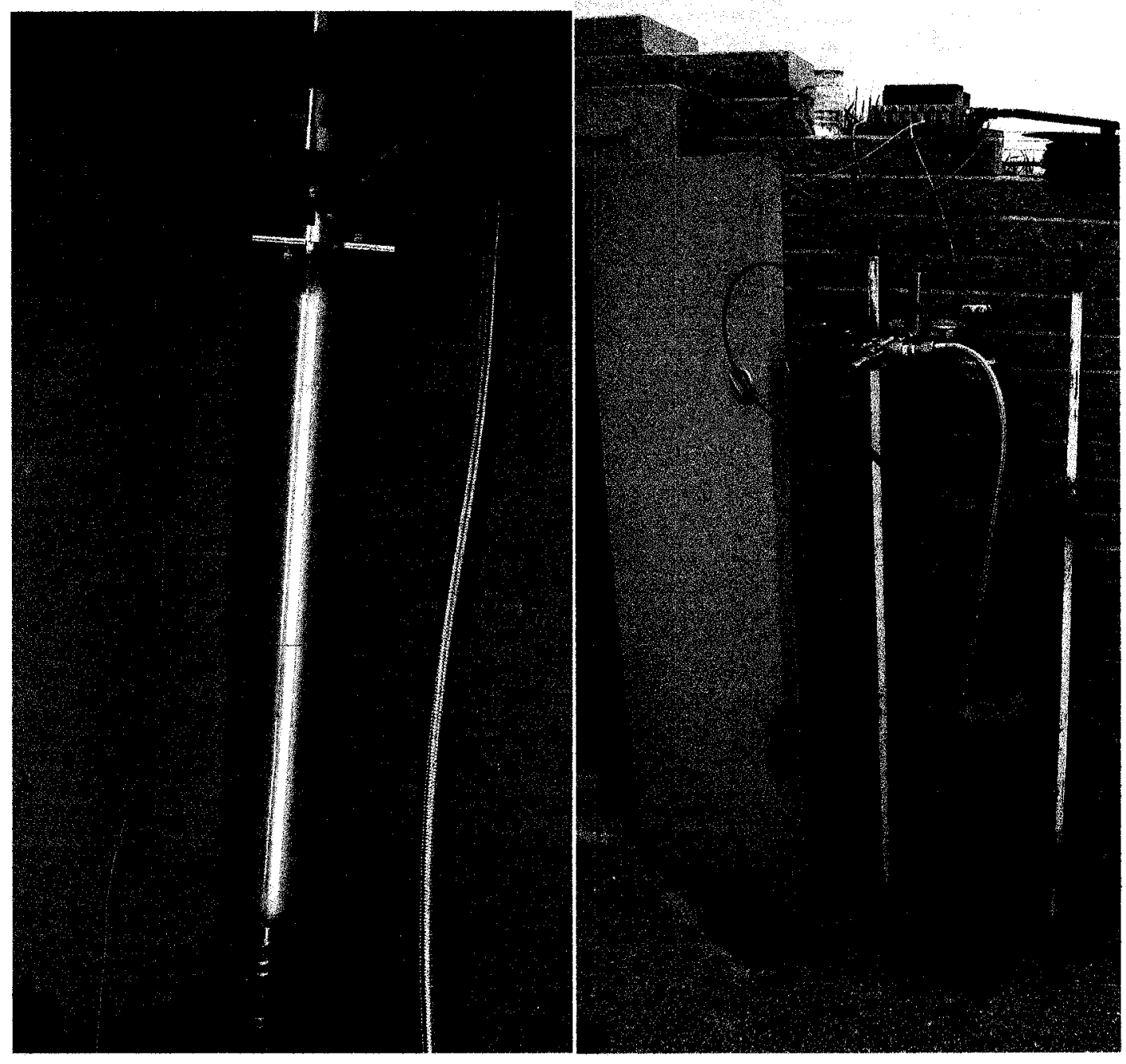

Figure 5.5: (LEFT) Oxidizer tank hanging from load cell (RIGHT) Nitrogen pressurization tank 
To pressurize the water a high pressure nitrogen tank is used as a blow down system. The nitrogen pressure level is set through a standard high pressure regulator, and is fed into the top of the oxidizer (water) tank through the adapter. Both the nitrogen valve and the main oxidizer valve were pneumatically actuated and were opened using a bank of solenoids seen above the nitrogen tank in Figure 5.5. The overall system was hydrostatic pressure tested to $2200 \mathrm{psi}$.

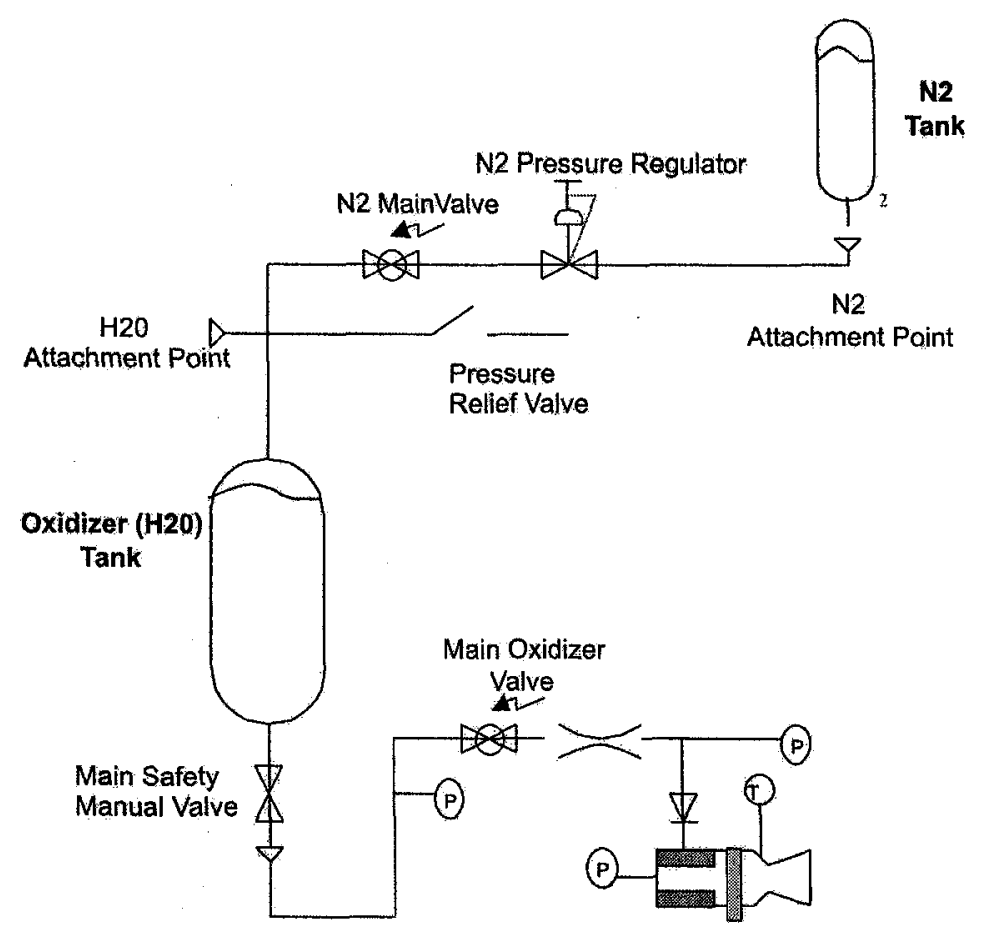

Figure 5.6: Oxidizer pressurization schematic 


\section{Venturi}

To control the mass flow of water and decouple any combustion chamber fluctuations a venturi was used just upstream of the inlet to the injector manifold. The venturi was assumed to be cavitating with a large pressure $(\approx 600 \mathrm{psi})$. The venturi also served as a second method of measuring the mass flow. The mass flow of a cavitating venturi can be determined by measuring the pressure just upstream of the venturi and the following equation;

$$
\dot{m}=\sqrt{2 \rho \frac{\left(P_{\text {upstream }}-P_{a t m}\right)-P_{v a p}}{\frac{1}{C_{c}^{2} A_{\text {throat }}^{2}}+\frac{1}{A_{\text {pipe }}^{2}}}}
$$

The area of the pipe is known $\left(3 / 8^{\prime \prime}\right)$, for water the vapour pressure $\left(\mathrm{P}_{v a p}\right)$ and density are $2339 \mathrm{~Pa}$ and $998 \mathrm{~kg} / \mathrm{m}^{3}$ respectively. The venturi had a sharp edge radius from the method in which it was machined using a standard drill bit. Therefore the contraction coefficient $\left(\mathrm{C}_{c}\right)$ shows the reduced throat area due to the vena contracta and accounts for any additional losses. Its value was experimentally determine to be 0.65 with the use of the load cell and measuring the instanteous mass over a given time interval. 


\subsection{Combustion Chamber \& Nozzle}

The post combustion chamber is where the water and the warm gas mixing occurs. The combustion chamber used was a "1 Grain" Pro-98 case and accompanying liner. This allowed for standard Pro98 nozzle, retainer rings, and nozzle holder to all be used. The attachment to the injector manifold used the same ACME thread interface as any Pro-98 casing.

For the sub-scale testing of the GG/Water injector, temperature measurements were to be obtained. Temperature data was required in order to characterize the mixing process of the injector and to be used to validate the CFD models outlined in Section 6. Thermocouple probes were placed through the casing/liner and into the combustion chamber. Sealing was accomplished with OMEGA male tube adapter (using a ferrule to seal around the probe) which was then threaded into aluminium rings on the outside of the Pro98 case. These rings had two silicon o-rings on either side of the tube adapter to seal the ring to the Pro98 case. Hydrostatic pressure tests showed that sealing of these thermocouple were capable of withstanding up to 2200psi.

Eleven thermocouple were used in all, and were located at specific axial and radial locations. Refereing to Figure 5.7 , six thermocouples were placed at a $5 \mathrm{~mm}$ 
radial distance from the center line and were equally spaced $25.4 \mathrm{~mm}$ (1") apart from the injector face in the axial direction. At two of these locations (4" and 6" axially from the faceplate) there were three additional thermocouples ( 4 in total), to get radial temperature measurements. However two of these radial thermocouples were damaged during testing. Both these thermocouples were located at the center line $(R=0 \mathrm{~mm})$, and were probably damaged from the direct impact of the high pressure water stream at the end of the test before the main valve could be shut off. They were replaced but the new thermocouples were also damaged during testing and were not replaced again for cost reasons.

The nozzle used was a standard Pro-98 nozzle with a graphite insert. This is a simple phenolic, convergent-divergent, conical nozzle. Even though the propellant does not contain aluminium and the temperature is significantly colder then traditional solid propellants, a graphite insert was used to ensure no nozzle erosion especially since the same nozzle will be used for each test. The convergence angle was $120^{\circ}$ and the divergence angle was set to $18^{\circ}$. The nozzle throat diameter could be adjusted to give the desired chamber pressure by simply drilling it out. For the injector testing the final nozzle throat diameter was set to $9.922 \mathrm{~mm}(25 / 64$ drill bit $\left.=0.3906^{\prime \prime}\right)$. 


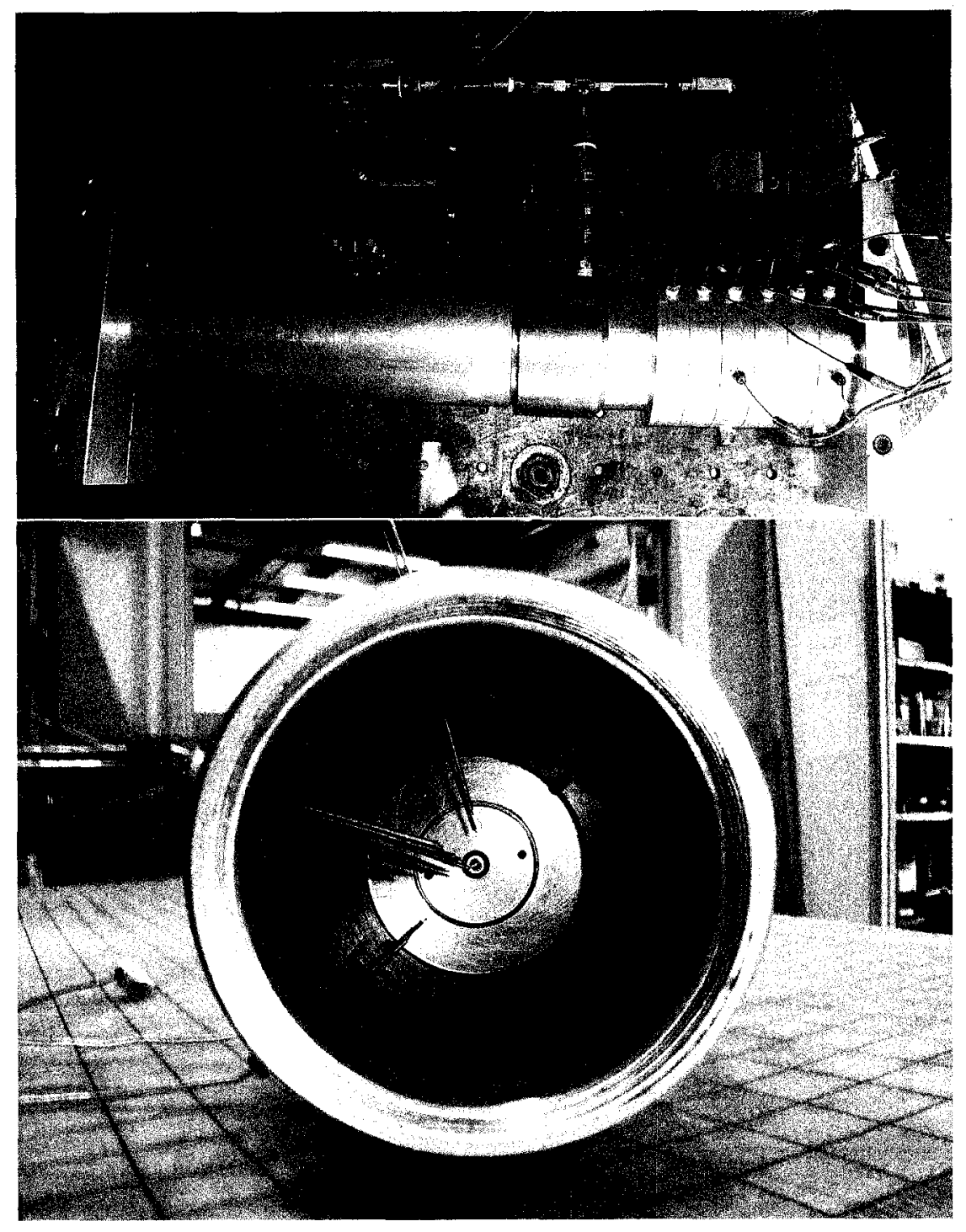

Figure 5.7: (TOP) Combustion chamber assembled with AIH motor (BOTTOM) Inside view of the combustion chamber, with thermocouples extended through the chamber wall 
Table 5.1: Sub-Scale Test Motor Components

\begin{tabular}{|l|c|}
\hline Pro 98 Components & Material \\
\hline \hline 2 Grain Case & 6061 Aluminium \\
\hline Retainer Ring (x2) & 6061 Aluminium \\
\hline Nozzle & Molded Silica Phenolic \\
\hline Nozzle Holder & 6061 Aluminium \\
\hline Forward Insulator (x3) & Phenolic \\
\hline Case Liner & Paper Phenolic \\
\hline O-ring (x6) & Silicon \\
\hline Pro-38 Propellant Grain & Solid Propellant \\
\hline Pro-38 Insulator & Paper Phenolic \\
\hline & \\
\hline AIH Motor Components & 316 Stainless Steel \\
\hline \hline Injector Housing & 316 Stainless Steel \\
\hline LOX (Water) Injector Element & 316 Stainless Steel \\
\hline GG Element & 60616061 Aluminium \\
\hline GG Case & 316 Stainless Steel \\
\hline Igniter Assembly & BKNO Propellant \\
\hline Igniter Pellet & - \\
\hline Igniter & Paper Phenolic \\
\hline Case Liner & Silicon \\
\hline O-ring (10 units) & \\
\hline - 8 different sizes & Stainless Steel \\
\hline Oxidizer Pressurization & - \\
\hline \hline Oxidizer Tank (4.6 L HyperTEK) & Stainless Steel \& Brass \\
\hline 3/8 Hydraulic Line & Stainless Steel \& Brass \\
\hline Swagelok 3/8 Braided Line & - \\
\hline 1/2" Swagelok Ball Valve (x3) & Stainless \\
\hline Swagelok Pnematic Actuator (x2) & \\
\hline Standard Pipe Fittings (Elbows, Tees, Couplers, etc) & \\
\hline Nitrogen Tank (4500 psi) & Stuminum \\
\hline Swagelok Pressure Relief \& Check Valves & \\
\hline
\end{tabular}




\subsection{Data Acquisition}

The test stand and control room at Cesaroni Technology Inc. was already equipped to obtain motor performance data for chamber pressure and thrust. This is achieved with the their in-house data acquisition software program DATACAD, and a PCIDAS6013 card, and a computer. The card has 16 channels available with two sample rate options of $250 \mathrm{~Hz}$ and $1000 \mathrm{~Hz}$, for maximum burn times of $128 \mathrm{~s}$ and $32 \mathrm{~s}$ respectively. The card has 16 bit per channel and does not filter the data. All 16 channels were used for each test; 11 channels were used for the thermocouples, 2 channels for the load cells (motor thrust \& water tank mass), and 3 channels for pressure transducers (GG combustion chamber, post combustion chamber \& upstream venturi pressure).

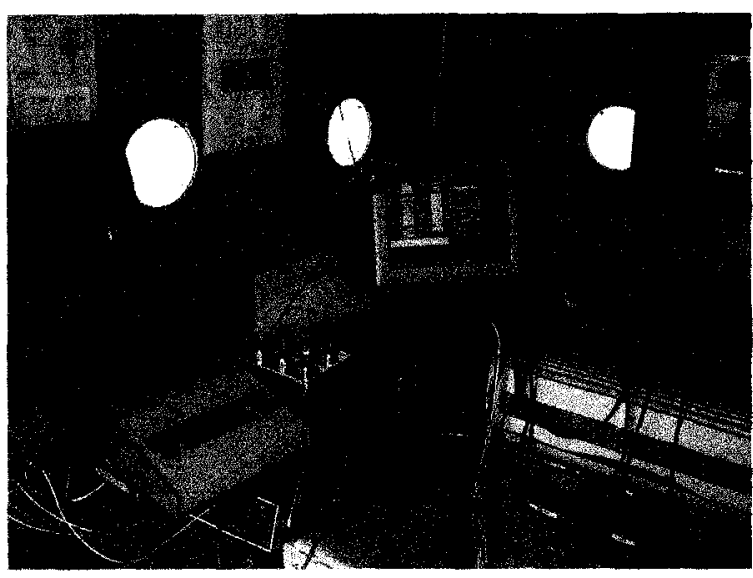

Figure 5.8: Control room with data acquisitions systems 
As indicated earlier two of the thermocouples were damaged so only 10 channels were used for the temperature data. In later tests, with the availability of an extra channel a 3rd pressure transducer was installed for in the post combustion chamber as a verification. There was one 5000psi pressure transducer used for the gas generator chamber, and two 2500 psi pressure transducers used for the venturi and post combustion charaber pressure. A 300lb load cell was used on the test stand to measure the motors thrust, and a $60 \mathrm{lb}$ load cell was mounted to the ceiling to measure the oxidizer/water tank weight.

\subsubsection{Temperature}

As mentioned above temperature measurement were taken with the use of thermocouples. The flame temperature of the warm gas from the GG propellant is predicted at $1169 \mathrm{~K}$, therefore a K-type thermocouple was selected allowing an operating temperature range of $-200^{\circ} \mathrm{C}$ to $1250^{\circ} \mathrm{C}$. The $\mathrm{K}$-type thermocouples used were transition probes, using a $1 / 16$ th diameter sheath, and an exposed junction. This small diameter was selected in order to obtain a smaller time constant as well as to ensure their presence within the combustion chamber will have minimal effect on the flow of gas. 

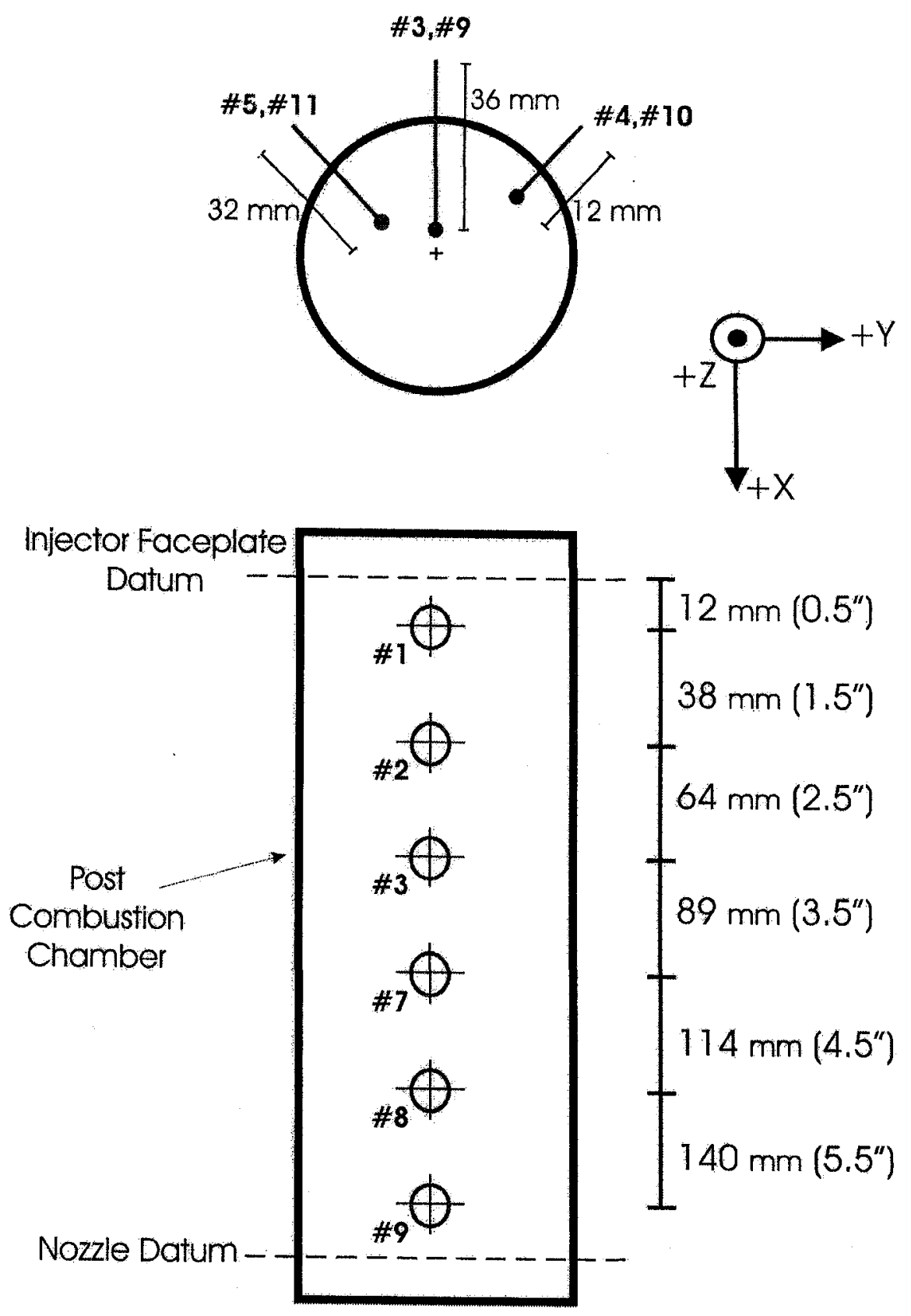

Figure 5.9: Location of thermocouples in post combustion chamber (NOTE two radial locations at thermocouple \#3 and \#9) 
Since CTI was not equipped with this data acquisition equipment for the thermocouples it had to be developed and built. In keeping the cost down the thermocouple amplifiers were all made based on a circuit board design [2]. The raw circuit boards were sent out to be manufactured by Network Circuits Inc. (Figure 5.10), and the assembly of all components was done in-house.
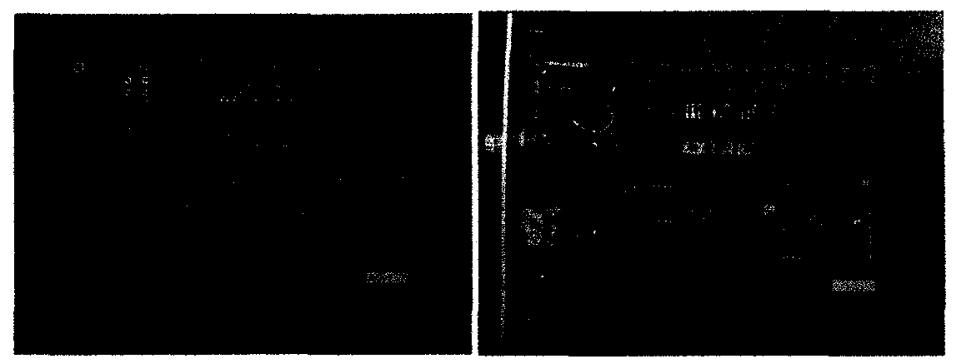

Figure 5.10: (LEFT) Raw circuit board layout (RIGHT) A single fully assembled amplifier

All together, twelve thermocouple amplifiers were made and associated hardware, panels/casing, and connectors (Figure 5.11). The amplifiers have a cold junction compensation $\left(0-50^{\circ} \mathrm{C}\right)$ with several different filtering options (filter capacitor, grounding the thermocouple, and limiting the bandwidth to $120 \mathrm{~Hz}$ were all utilized). They are equipped with error connection alarms and output to the PCI-DAS6013 card is through $\mathrm{BNC}$ connectors with $50 \Omega$ impedance. The output can be set for four different ranges and the $0-5 \mathrm{~V}$ range was used to be compatible with the PCI-DAS6013 card. 


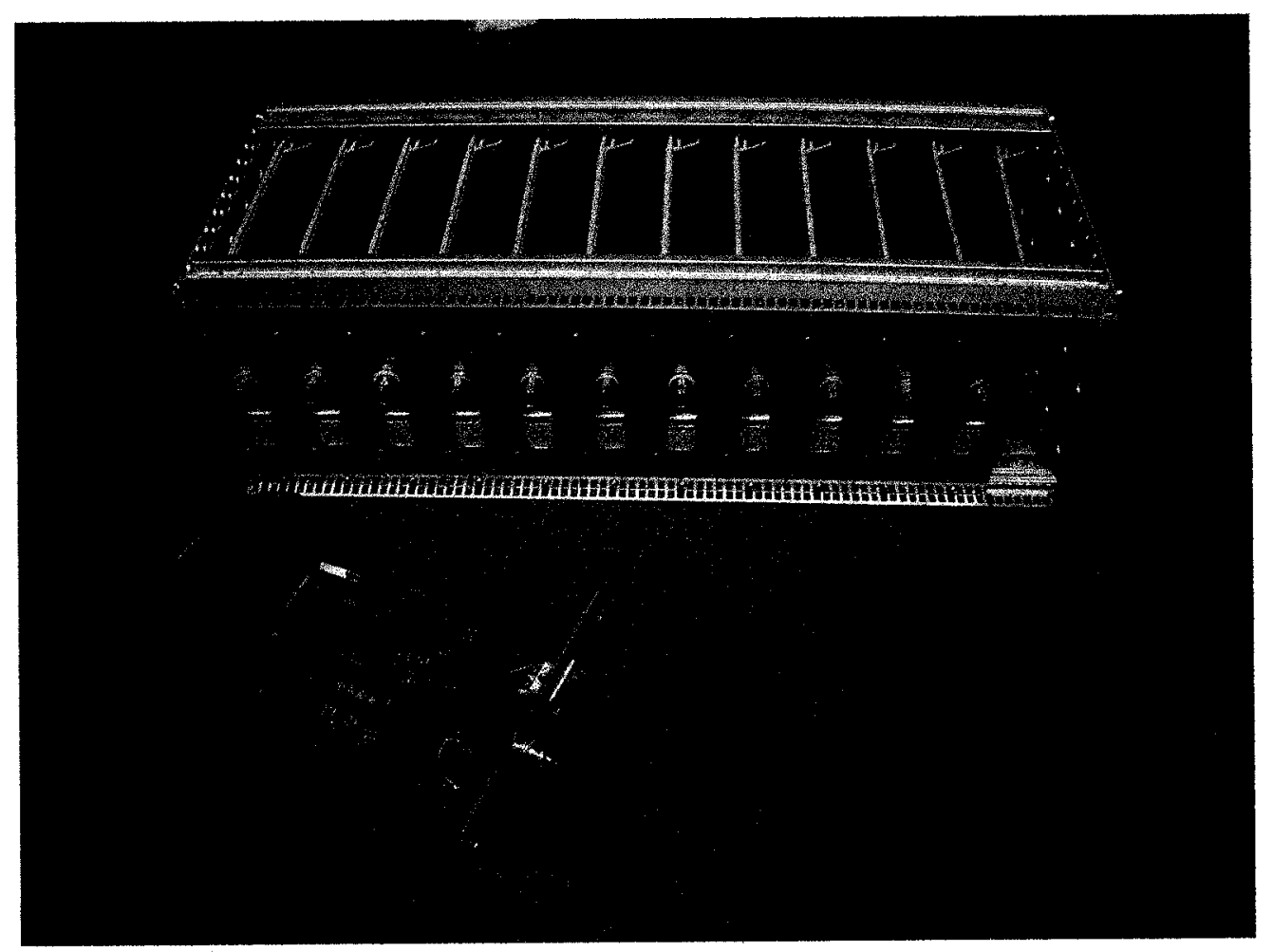

Figure 5.11: Thermocouple amplifiers (12 units) 


\subsection{Test Procedure}

1. Fully assemble motor with appropriate injector elements, GG grains, starter propellant/BKNO3 pellet and connect to the oxidizer/water plumbing.

2. Fill oxidizer tank with distilled water and insert plug seal.

3. Connect flexible nitrogen hose to top of tank and flexible water hose to the bottom.

4. Ensure all DAQ connections and thermocouples are functioning properly and all solenoid valves are closed.

5. Install igniter and open manual safety valve.

6. Open nitrogen tank main valve (manual).

7. Pressurize oxidizer/water tank by activating the nitrogen solenoid valve to open.

8. Activate high speed capture of DAQ

9. Press ignition button, followed immediately by activating the oxidizer/water solenoid valve to open

10. Turn off all valves after testing. 
Before testing could occur with the AIH motor the GG propellant BATES grains had to be tested and critiqued in order to characterize their exact performance and burn rate parameters. The grains were modified to give the desired criteria. Once this was established the full AIH sub-scale motor was hot fire tested using these grains and water as a substitute for the oxidizer in order to test the different injectors.

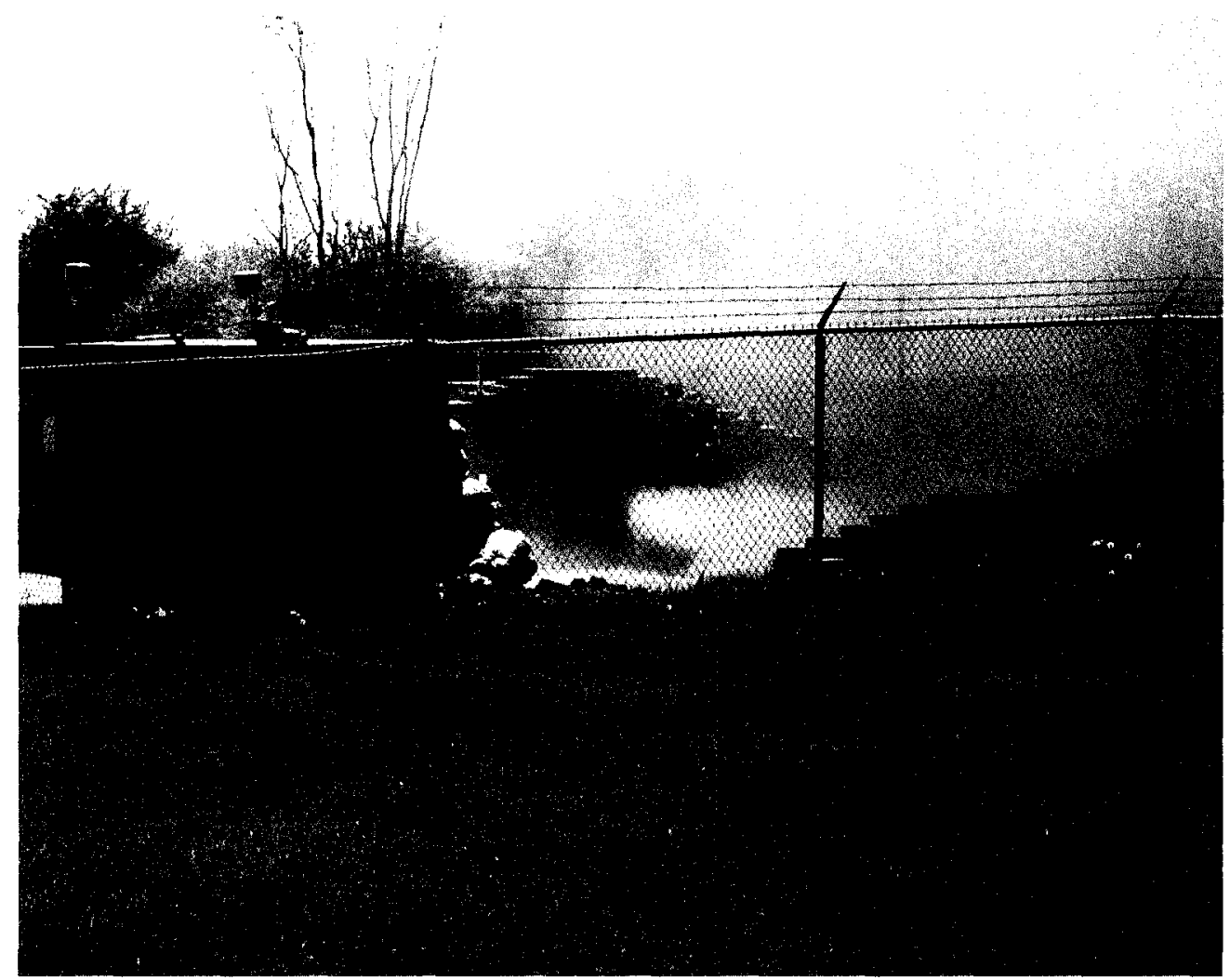

Figure 5.12: Test of full AIH sub-scale motor (both GG and water) 


\subsection{BATES Grain Results}

As discussed previously a. BATES grain design was used for the GG propellant to give a relatively neutral burn profile. Initially the grain dimensions were estimated theoretically using equation (2.1) and

$$
\dot{r}=a P^{n}
$$

When sizing the dimension of the BATES grain it was already known that a single GG propellant grain would not provide the desired $0.25 \mathrm{~kg} / \mathrm{s}$ mass flow. As such when deciding on the grain dimensions it was ensured that the mass flow provided from one grain would be an even multiple of the full mass flow desired $(0.25 \mathrm{~kg} / \mathrm{s})$. Using a time step approach and solving analytically for the burn surface area $\left(\mathrm{Kn}_{\text {avg }}=968\right)$, the pressure trace and mass flow was theoretically determined. The results from this analytical approach were verified using a commercial software package Grain Design Program (GDP). Based on this and the propellant data from the step motor test the initial grain (GG-003) dimensions could be determine and are shown in Table 5.2 . 


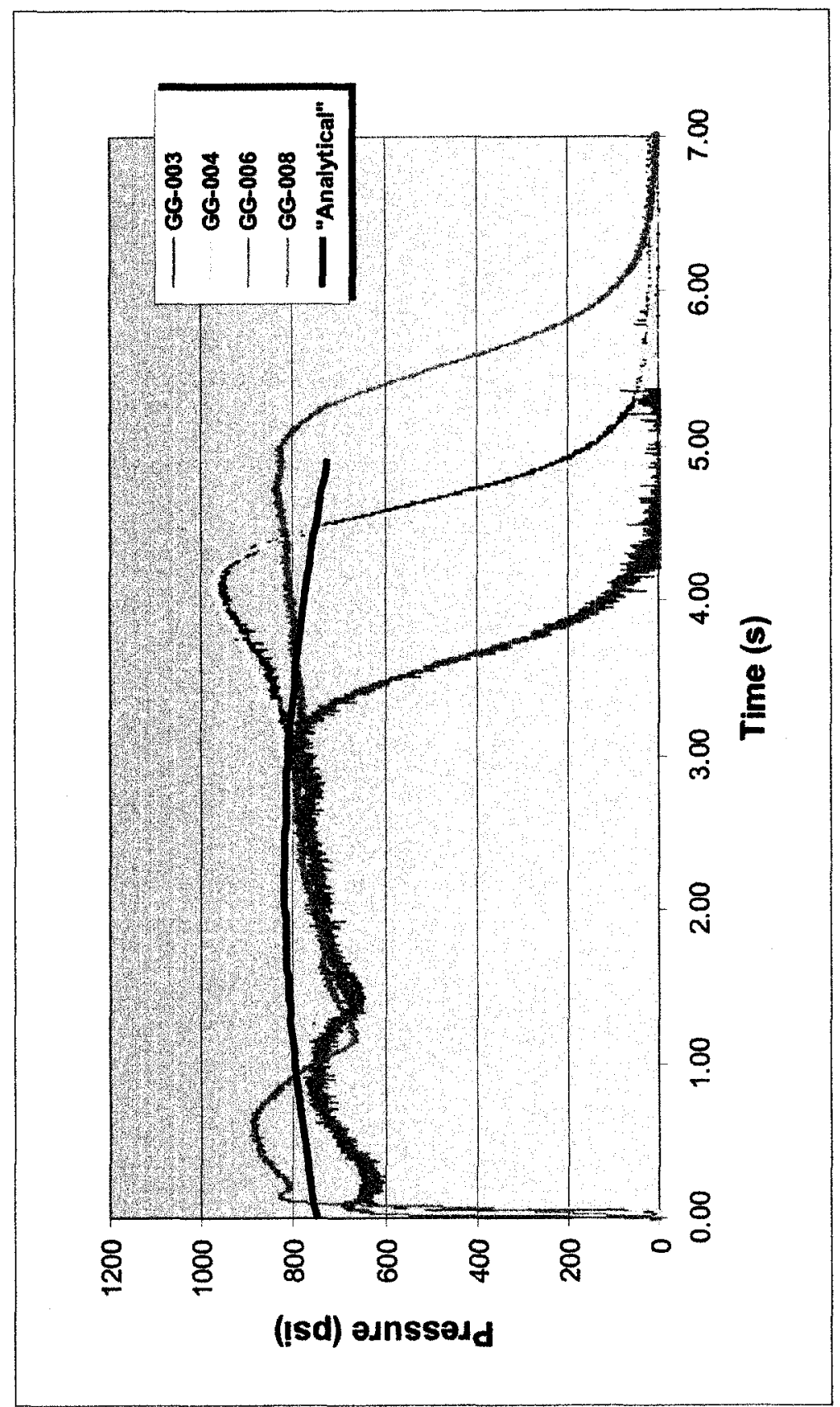

Figure 5.13: Comparison of experimental test for single GG BATES grains 
Table 5.2: Dimensions of GG BATES Grains

\begin{tabular}{|c|c|c|c|}
\hline $\begin{array}{c}\text { Grain } \\
\#\end{array}$ & $\begin{array}{c}\text { Port Diameter } \\
{[\mathbf{m m}]}\end{array}$ & $\begin{array}{c}\text { Length } \\
{[\mathbf{m m}]}\end{array}$ & $\begin{array}{c}\# \\
\text { of Grains }\end{array}$ \\
\hline GG-003 & 46 & 120 & 2 \\
\hline GG-004 & 46 & 120 & 2 \\
\hline GG-006 & 53 & 120 & 2 \\
\hline GG-007 & 35 & 101 & 3 \\
\hline
\end{tabular}

\subsubsection{Single Grain Experimental Tests}

Once the dimensions were determined for the initial BATES grain, hot fire tests conducted on single grains based on propellant formulation CSLV26. The results from the initial grain GG-003 showed a significant progressive burn profile (see Figure 5.13). Initial it was thought that end faces of the grain may not be burning during startup, so the test was repeated with a thin layer of additional fast burning solid propellant smeared on the end surfaces to ensure that they would be ignited at startup. This made no difference, and the pressure trace (GG-004) was identical to that of the initial test. The other possible cause of the progressiveness could be due to a phenomenally know as the "BARF" effect. This phenomenons occurs during the casting process and has to do with the flow shearing action between the mandrel and the fluid propellant[42]. In order to determine if this was the root cause, the port was drilled out to a larger diameter to see if there was a shift in the curve. By drilling the port out to a larger diameter, the propellant near the mandrel location that would be effected by this shearing phenomenon is effectively removed. Com- 
paring GG-003 and GG-006 in Figure 5.13, the initial startup was very similar and there is still the progressive burn. The burn time was obviously shorter due to the reduced web thickness (larger port), and therefore the overall progressive pressure increase is not as severe. From this its clear that the progressive burn is not caused by the "BARF" effect.

Another aspect noticed about all this pressure traces from Figure 5.13 was the initial startup transient. There is a clear hump over approximately the first second where the pressure rises and decreases until the steady state pressure is reached. This start up tread was seen in every BATES grain tested. This trend can be explained by a combination of two factors. The first is due to using a the small solid propellant starter grain for igniting the propellant (discussed in Section 5.1). From ballistics data of the starter grain it would be consumed within approximately 0.6 seconds, which explains the up slope of the pressure hump. The down slope and build to steady state pressure can be explained with the second contributor to this startup transient which is the burning mechanism of the propellant itself.

The burning mechanism of solid propellants in general is of much debate. Attempting to gather definitive proof of the burning process for this particular GG propellant is well beyond the scope of this dissertation, and would be the subject of 
an entire research area onto itself. However with the variety of test firings conducted and from research done on the burning mechanism of AP based propellants done [19], [22], [42], an educated hypothesis of the burning mechanism can be concluded.

As presented in Section 2.4.1 the particle size of the ammonium perchlorate $(\mathrm{AP})$ and polyethylene (PE) play a significant role on the burning properties of the propellant. It was demonstrated that the ratio of particle size between the fuel and oxidizer had a dramatic effect on the burn rate. For the GG propellant the PE particles size were limited to be no smaller than "Large" and no bigger than "Coarse". While the AP particles were limited to only be "Fine." This resulted in the AP particles being approximately an entire order of magnitude smaller that PE. Due to this fact, the time it takes for AP to decompose into its gaseous products is much quicker than the PE. Therefore at the beginning of the GG propellant burning process, the AP decomposes quickly into it gaseous products (NH3 and $\mathrm{HClO} 4$ ), but there is a lack of gaseous fuel in the diffusion layer. This would lead to a reduced mass flow (i.e. lower pressure) momentarily as the larger PE take time to decompose. In addition to this because there is a lack of gaseous fuel in the diffusion layer, the feedback heat to the surface would also be lower resulting in even a longer time for the large PE particles to decompose then normally seen in solid propellants. With substantially more fuel (PE) in this GG propellant compared to traditional solid 
propellants, this time delay would have a significant effect at startup. This explains the drop in pressure after the starter grain burns out $(0.6 \mathrm{~s})$ and then the slow rise back up to its steady state value as the PE on the surface fully gasifies.

This conclusion is supported when examining the propellant after it extinguished during startup (Figure 2.13 in Section 2.4 .2 ). It was clearly seen that all the AP particles were consumed while the large PE particles remain on the surface. In addition, to support this argument when looking at propellant batch CSLV-19 it showed the same startup phenomena. This propellant formulation used smaller particles of both $\mathrm{AP}$ and $\mathrm{PE}$, but the ratio between the particle size was preserved. The AP particles were still an order of magnitude smaller than the PE, thereby indicating that the rate of decomposition for the AP would still be faster than the PE.

Due to the new burning phenomenon, the transient for the start up of the GG propellant completely changes the theoretical steady state grain dimensions of a BATES grain. This is caused from the progressive port and regressive face ends not burning at the same regression rate throughout the first second and a half, which leads to them being mismatched throughout the entire burn.

To overcome this problem the BATES grain shape was re-sized theoretically 
in order to give an overall regressive profile to match the overall progressive profile seen experimentally. From the initial grain CSLV26-003 its seen that throughout the steady state portion the pressure rises approximately $250 \mathrm{psi}$, therefore a BATES grain was tailed to provide a regressive profile of 250 psi. The dimensions for this new grain (GG-008) are shown in Table 5.2.

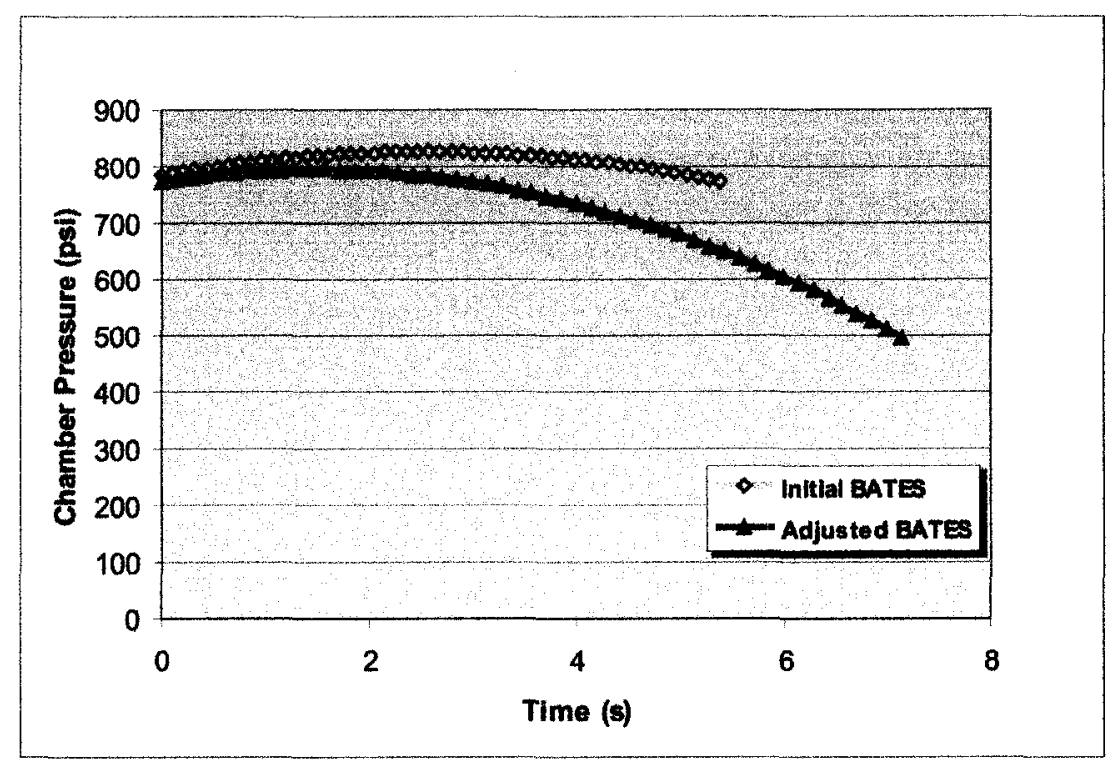

Figure 5.14: Adjusted theoretically BATES grain for regressive profile

As can be seen in Figure 5.13, the new adjusted BATES grain (GG-008) gives a much more neutral profile. The pressure only varies slightly in the steady state region of approximately $50 \mathrm{psi}$, which should have minimal effect on the mass flow. The burn time is also increased due to the web being thicker with a smaller 
port. This longer burn time is more appealing since for the sub-scale AIH the GG propellant will have to be ignited and then have water introduced, all of which will take a few seconds. Having a longer burn time for the GG grain allows more time for the steady state of the sub-scale AIH injector testing to be analyzed.

\subsubsection{Three Grain Experimental Tests}

As mentioned above more then one grain is required for the desired $0.25 \mathrm{~kg} / \mathrm{s}$. For the neutral GG-008 dimension it requires a total of three grains. Hot fire tests were conducted using all three grains to ensure that the burn profile remained neutral and to determine the overall mass flow.

Test were conducted for all three propellant batches (CSLV22, 26, 27). As can be seen in Figure 5.15, all three show a relatively neutral profile. Propellant batch CSLV27 appears to shows a slightly more progressive profile. However since burn time is longer the appearance of the progressive profile is amplified. The burn time difference between the grains can be attributed to the AP \% between the grains. CSLV26 and CSLV 27 have $1 \%$ and $2 \%$ AP less respectively than CSLV22. However CSLV27 is just on the breaking point of being able to sustain combustion as outlined in Section 2.4.2. This batch was quite difficult to ignite and with the step motor this propellant would not ignite at all even after several attempts. The burn time with 
CSLV22 ( $\approx 5$ seconds) will be sufficient for the testing of the injector. It was decided to use CSLV22 propellant for all injector testing since introducing the water with an unchoked system may cause significant fluctuations in chamber pressure making it even more difficult to get the aft-injected motor ignited. The propellant properties that will effect the injector mixing (flame temperature, enthalpy, etc) between these batches will not deviate significantly. This was verified with CEA calculations for the three propellant formulations and are compared in Tables 5.3 and 5.4.

Table 5.3: Comparison of combustion species of propellant formulations

\begin{tabular}{|l|c|c|c|}
\hline \hline Batch & CSLV 22 & CSLV 26 & CSLV 27 \\
\hline \hline CH4 & $15.3 \%$ & $15.8 \%$ & $16.4 \%$ \\
\hline${ }^{*} \mathrm{CO}$ & $15.5 \%$ & $14.6 \%$ & $13.7 \%$ \\
\hline${ }^{*} \mathrm{CO} 2$ & $6.1 \%$ & $6.0 \%$ & $5.8 \%$ \\
\hline $\mathrm{HCL}$ & $12.4 \%$ & $12.1 \%$ & $11.8 \%$ \\
\hline${ }^{*} \mathrm{H} 2$ & $3.5 \%$ & $3.5 \%$ & $3.4 \%$ \\
\hline $\mathrm{H} 2 \mathrm{O}$ & $10.0 \%$ & $10.1 \%$ & $10.2 \%$ \\
\hline${ }^{*} \mathrm{~N} 2$ & $4.7 \%$ & $4.6 \%$ & $4.5 \%$ \\
\hline $\mathrm{C}(\mathrm{gr})$ & $32.5 \%$ & $33.4 \%$ & $34.3 \%$ \\
\hline
\end{tabular}

Table 5.4: Comparison of thermodynamic properties of propellant formulations

\begin{tabular}{|l|c|c|c|}
\hline Batch & CSLV 22 & CSLV 26 & CSLV 27 \\
\hline \hline Flame Temperature $[\mathrm{K}]$ & 1169 & 1163 & 1157 \\
\hline Enthalpy $[\mathrm{kg} / \mathrm{kJ} \mathrm{K}]$ & -1620.6 & -1606.9 & -1593.1 \\
\hline Entropy $[\mathrm{kg} / \mathrm{kJ} \mathrm{K}]$ & 9.4848 & 9.4425 & 9.3998 \\
\hline Density $\left[\mathrm{kg} / \mathrm{m}^{3}\right]$ & 15.888 & 16.088 & 16.292 \\
\hline
\end{tabular}




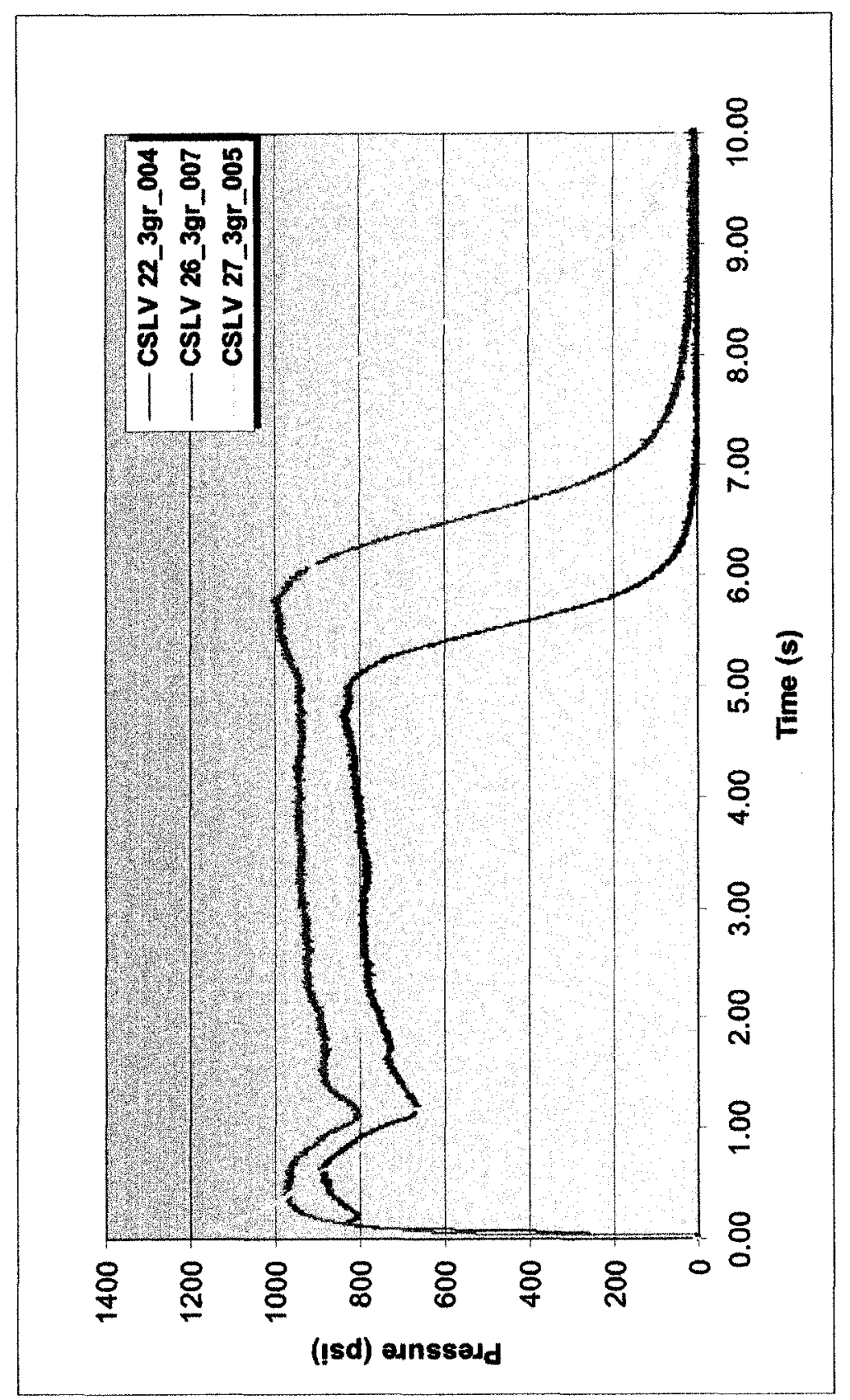

Figure 5.15: Test results from hot fire test using three BATES grain of the GG propellant 
The characteristic velocity $\left(c^{*}\right)$ for CSLV-22 was experimentally determined and compared to the theoretical $\mathrm{c}^{*}$ of 1037.9 from CEA (previously shown in Table 2.5). To determine the experimental $\mathrm{c}^{*}$ equation 2.1 was rearranged into the following format,

$$
c^{*}=\frac{A_{t}}{M_{G G}} \int_{t=0}^{t_{b}} P_{c} d t
$$

The mass of the GG propellant is know from measurement before and after the test. The the assumption is that the mass flow is equivalent to the total mass of the GG propellant over the burn time. Integration of the pressure is done numerically with a differential time steps of 0.001 (same as the sample rate). The results are shown in Table 5.5 .

Table 5.5: Comparison of thermodynamic properties of propellant formulations

\begin{tabular}{|l|c|}
\hline & Experimental \\
\hline \hline Throat Area $\left[\mathrm{m}^{2}\right]$ & $4.71 \times 10^{-5}$ \\
\hline Total GG Mass $[\mathrm{kg}]$ & 1.41 \\
\hline $\mathrm{c}[\mathrm{m} / \mathrm{s}]$ & 1007 \\
\hline$\%$ error & $2.97 \%$ \\
\hline
\end{tabular}


With the $c^{*}$ and the throat area known, the mass flow can be determine (Figure $5.16)$.

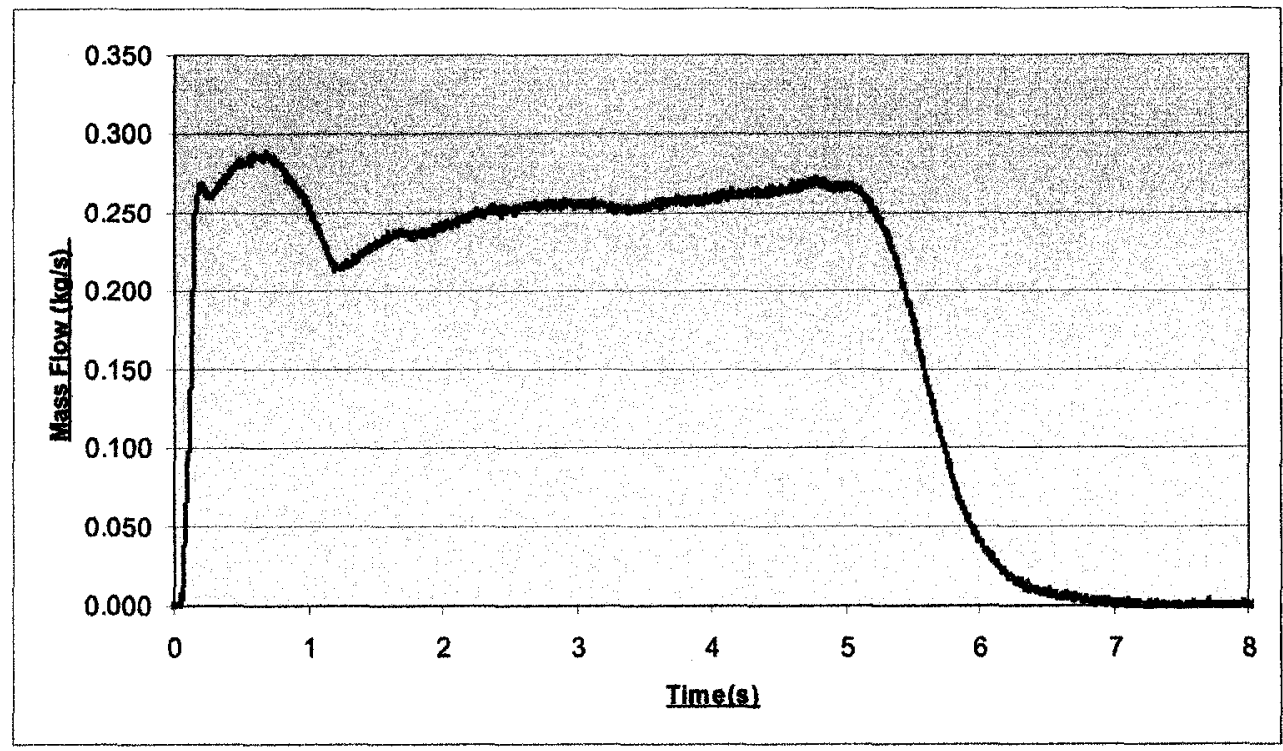

Figure 5.16: Mass flow of final GG propellant using 3 BATES grains 


\subsection{Aft-Injected Hybrid Motor Results}

Once the BATES grains characteristic were clearly defined the full AIH sub-scale motor could be tested. As mentioned previously the goal of this sub-scale motor was to first prove out the feasibility of the novel aft-injected hybrid system and secondly to investigate the injector. The tests conducted showed stable combustion with independent ignition of the GG propellant and the subsequent mixing of a secondary liquid oxidizer (water). These tests clearly demonstrated successful operation of the new AIH motor system and proved its a feasible propulsion system.

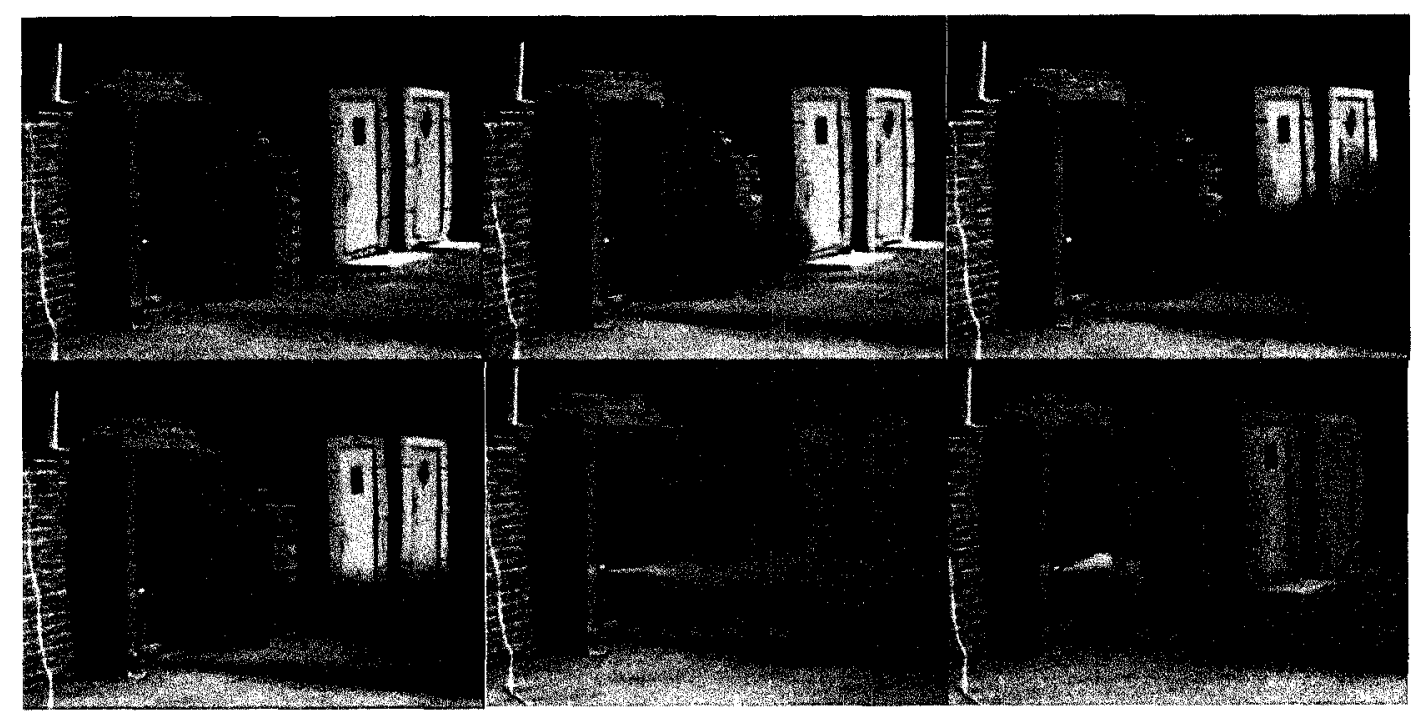

Figure 5.17: Sequence of full AIH sub-scale motor firing (TOP MIDDLE) ignition (TOP RIGHT) full GG operation (BOTTOM LEFT) opening water valve (BOTTOM MIDDLE) full water \& GG steady state operation (BOTTOM RIGHT) burn out 
In order to obtain temperature measurement in the post combustion chamber for injector evaluation, water was substituted for the oxidizer. Since the motor was proved to be operational using water as a oxidizer, the introduction of a real liquid oxidizer (such as LOX or H202) should be relatively easy as they obviously more reactive. The additional complications of introducing a real oxidizer would be in ensuring the materials used are capable of withstanding the higher heat loads. Since the materials used for this sub-scale motor are the same as ones used for solid rocket motors (ProX series) this should not be difficult to achieve.

Investigating the injector was under steady state conditions. The start up transient is discussed first so that the steady state point is clearly defined and there is no confusion with the results presented.

117 


\subsubsection{Startup Transient}

As already discussed, the startup process of this AIH motor is rather complicated. First as outlined in Chapter 2 by design, if the operating pressure of the GG propellant drops below $500 \mathrm{psi}$, the propellant will self-extinguish. In order to allow the pressure to build up while the GG propellant is ignited, the exit plane of the nozzle is sealed with an acrylic plate using o-ring so it acts as a burst disk. To complicate issues, the nozzle has to be sized for the mass flow of both the water and GG propellant. Therefore until the water is introduced the GG propellant will see a reduced pressure (due to the larger throat for both mass flows). Secondly, as discussed above a high burn rate starter grain is used to ignite the GG propellant within the first few tens of a second which adds another complete set of variables. Third, the burning mechanism of the fuel rich propellant itself leads to an abnormal ignition transient over the first second and half (as discussed in Section 5.7.1). Finally, once the GG propellant is ignited, a split second later, the water is injected into the post combustion chamber bringing mass flow up to its full value. All of this leads to a complicated startup transient.

All four of these startup variables can be seen within the first two seconds of the pressure traces of all tests. Looking at the results from injector RC1 (Figure 5.18) one can see that there is the initial ramp up in the GG combustion chamber 
from the starter grain which ends at approximately 0.6 seconds. As expected there is a slight difference in pressure between the GG and post combustion chamber during this time as expected since no water is injected in the post combustion chamber and the GG propellant is still building up pressure. Also note the slight time lag between the ramp up pressure between the two. This is also expected since it takes fractions of a second to fill the volume of the post combustion chamber (located downstream).

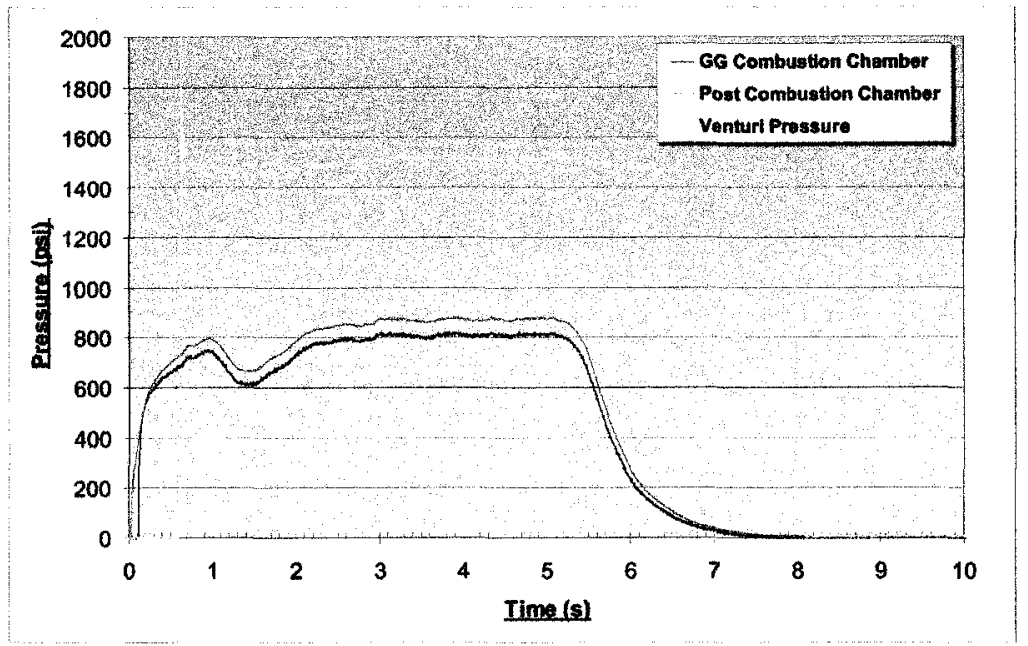

Figure 5.18: Pressure trace for hot fire test of injector(RC1) with water

The water injection is started at approximately the same time as the starter grain burns out. This is noted by the instant rise in pressure at 0.6 seconds. The effect upon the introduction of water is noticed by both the GG and post combustion just afterwards with a small ripple. Once the water is injected one can see that the 
pressure trace for both the GG chamber and the post combustion chamber follow exactly the same path with an offset between the two. This offset is due to the pressure drop across the GG element, insulator, and water element cross section, as the warm gas flow is injected from the GG combustion chamber into the post combustion chamber. The characteristic hump of the GG propellant itself is still clearly seen when testing with water.

This entire startup transient was also clearly noticed when observing the motor firing. All six injectors tested exhibited the same basic startup process. In defining the steady state region of the tests, it is clearly seen with Figure 5.18 that steady state starts at approximately 2.3 seconds and ends at 5.1 seconds.

\subsubsection{Data Reduction}

All together there were $14 \mathrm{AIH}$ motor sub-scale tests conducted. Six of these tests were used for injector evaluation (the others were used for proving the operation of the AIH motor and critiquing the startup sequence).

Calibration of the two load cells, three pressure transducers, and the thermocouple amplifiers was performed and incorporated into DATACAD directly. In 
addition to the previous calibrations, each thermocouple itself showed significant variations, therefore in the post analysis an offset was applied. The ambient temperature at the time of the test was recorded and the variation from this value for each thermocouple was applied as the offset.

Time average reduction was conducted for all data based on the action time of the motor in post analysis using Excel software. The action time was defined as the interval between initial and final $10 \%$ chamber pressure. The start of the burn time for this particular experiment occurs when the igniter propellant was consumed and the GG propellant started to ramp up. This was defined as the first positive increase in slope on the pressure trace after the initial hump from the starter grain (as discussed in Section 5.8.1). The burn out time was defined using the arc tangent bisector [42]. For the average chamber pressure, thrust, and venturi pressure they were all evaluated over the steady state region (burn time). Each thermocouple temperature measured was also averaged over this steady state time for use with injector efficiencies.

The characteristic velocity, $\mathrm{c}^{*}$, was determine in a similar manner as for just the gas generator (Section 5.7.2) with the addition of the water mass flow. 


$$
\begin{aligned}
c^{*}= & \frac{P_{c} A_{t}}{\dot{m}} \\
& \frac{A_{t}}{M_{G G}} \int_{t=0}^{t_{b}} \frac{P_{c}}{M_{H 2_{0}}} \partial t
\end{aligned}
$$

For each of the six injector tests conducted there was two load cells, three pressure transducers, and eleven thermocouples all operating at $1000 \mathrm{~Hz}$, and as such there was an enormous amount of data. In order not to confuse the reader, the data for a single injector test is presented in its entirety and data for all other injector test is presented in an Appendix C.A summary of all six injector test conducted is shown in Table 5.6. 
Table 5.6: Thermocouple temperature data of injector testing

\begin{tabular}{|l|cccccc|}
\hline & RC1 & RC2 & RC3 & RC4 & RC5 & RC6 \\
\hline \hline Avg. Pressure (psi) & 824 & 810 & 814 & 740 & 797 & 813 \\
\hline Water Mass Flow (kg/s) & 0.36 & 0.36 & 0.328 & 0.376 & 0.344 & 0.36 \\
\hline GG Mass Flow (kg/s) & 0.25 & 0.25 & 0.25 & 0.25 & 0.25 & 0.25 \\
\hline O/F & 1.44 & 1.44 & 1.31 & 1.50 & 1.38 & 1.44 \\
\hline c* $^{*}$ (m/s) & 467.7 & 471 & 450 & 471 & 461.2 & 455.7 \\
\hline Avg. Venturi Pressure (psi) & 1437 & 1445 & 1440 & 1470 & 1468 & 1465 \\
\hline Total Water Mass (kg) & 2.146 & 2.165 & 1.548 & 2.486 & 1.825 & 2.317 \\
\hline Total GG Mass (kg) & 1.27 & 1.27 & 1.27 & 1.27 & 1.27 & 1.27 \\
\hline Avg Thrust (lbf) & 83.35 & 78.3 & - & 70.87 & 84.68 & 77.0 \\
\hline Max. Thrust (lbf) & 85.94 & 82.4 & - & 76.71 & 86.94 & 83.9 \\
\hline Burn Time (s) & 6.5 & 6.8 & 5.6 & 6.6 & 6.5 & 6.8 \\
\hline \hline Thermocouple & & & & & & \\
Temperature ( ${ }^{\circ}$ C) & & & & & & \\
\hline \hline$\# 1$ & - & - & - & 125 & - & - \\
\hline$\# 2$ & 195 & 152 & - & 218 & 272 & 150 \\
\hline$\# 3$ & 217 & 210 & - & - & - & 207 \\
\hline$\# 4$ & 195 & 209 & 199 & 172 & 188 & 201 \\
\hline$\# 5$ & - & - & - & 141 & 177 & 211 \\
\hline$\# 7$ & 234 & 251 & 213 & 279 & 265 & 253 \\
\hline$\# 8$ & 225 & 263 & 240 & 252 & 223 & 237 \\
\hline$\# 9$ & 250 & 232 & 264 & 191 & 202 & 227 \\
\hline$\# 10$ & 233 & 237 & 283 & 215 & 310 & 239 \\
\hline$\# 11$ & 199 & 192 & 229 & 187 & 223 & 194 \\
\hline
\end{tabular}




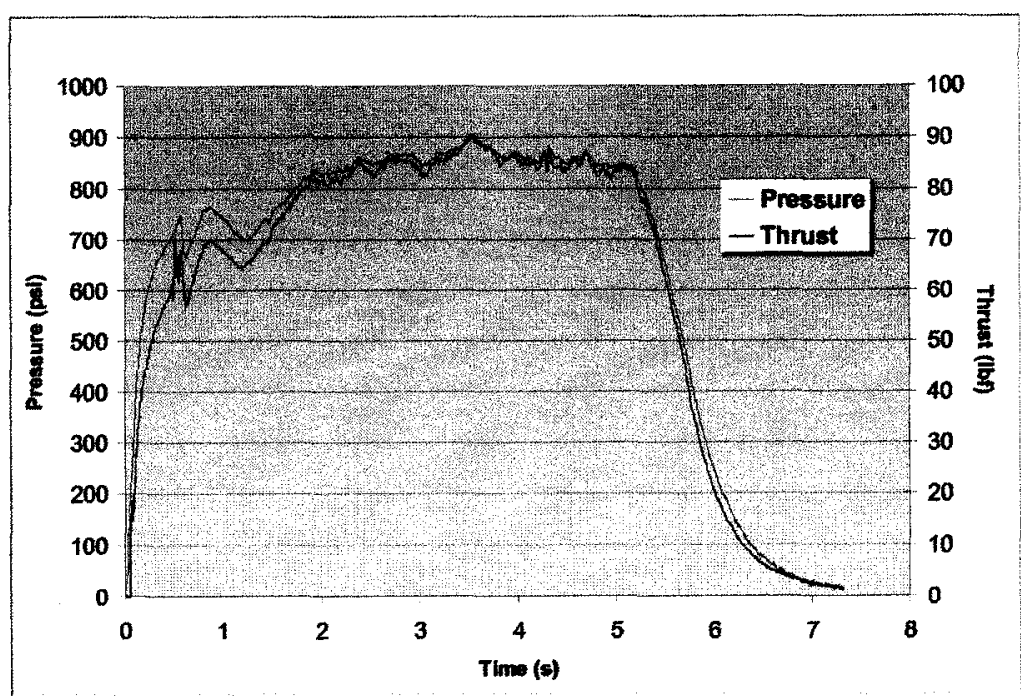

Figure 5.19: Pressure and thrust trace data for injectors RC1

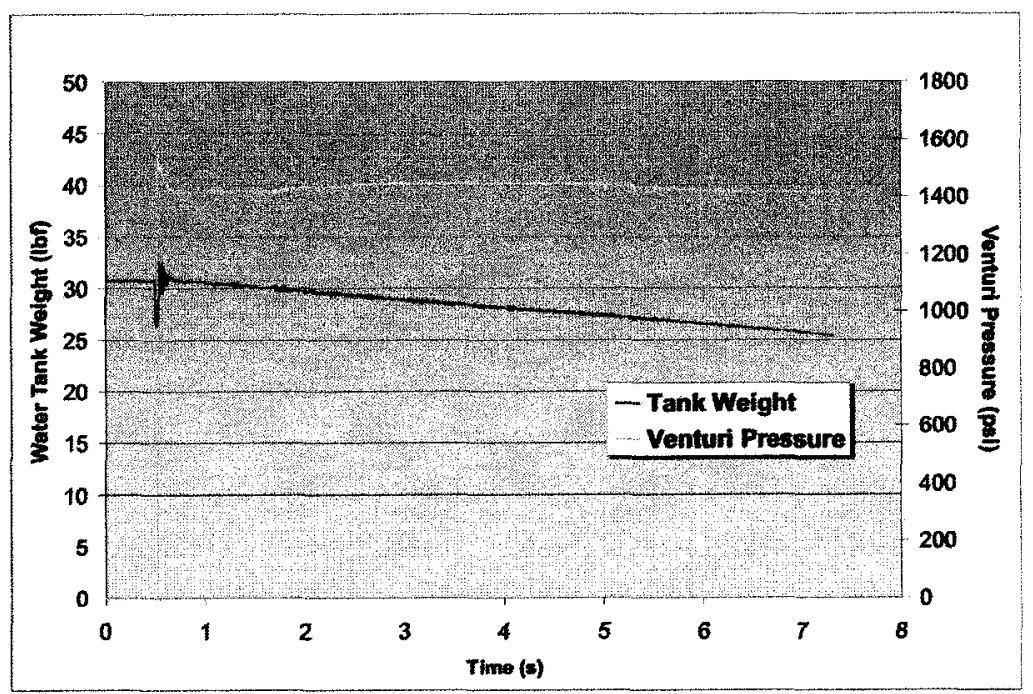

Figure 5.20: Venturi pressure and water tank discharge data for injectors RC1 

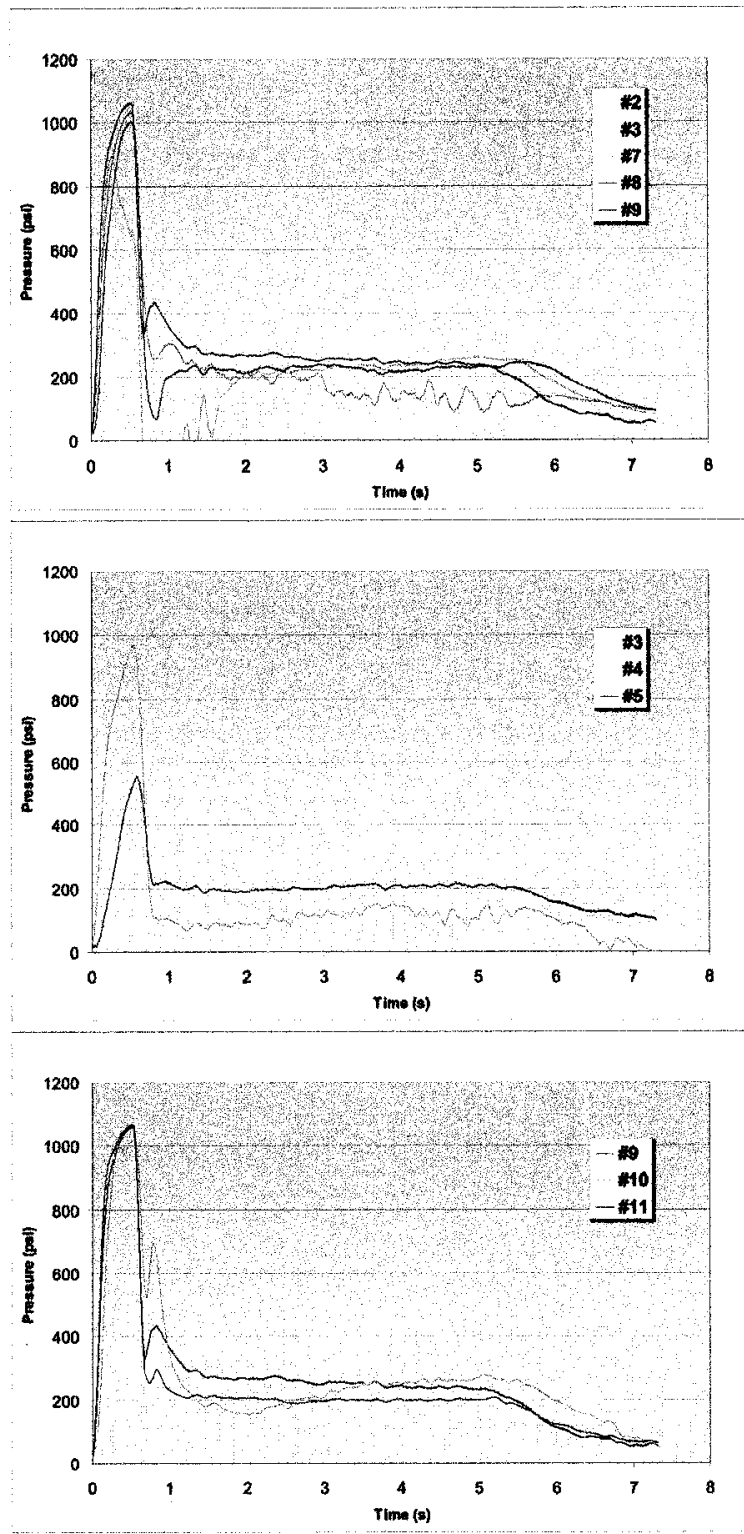

Figure 5.21: Temperature profile for injector $\mathrm{RC} 1$ test (TOP) Axially at $\mathrm{r}=6 \mathrm{~mm}$ (MIDDLE) Radial at $\mathrm{x}=64 \mathrm{~mm}$ (BOTTOM) Radial at $\mathrm{x}=140 \mathrm{~mm}$ 


\subsubsection{Uncertainty Analysis}

As with any experimental testing an uncertainty analysis was performed. The key parameter of interest from the experiential tests conducted were $c^{*}$, temperature, and burn rate for both the step motor and BATES grains. The approach taken follows the method outlined in [40] and [44].

The uncertainty is a due to both the bias and precision error. The bias error for the parameter of interest is function of several variable or directly measure quantities. The total bias error is root sum square of all partial derivative of the nominal with respect to the variable.

$\begin{aligned} \text { Bias Error } & =\sqrt{\sum_{k=1}^{n}\left(\frac{\partial r_{k}}{\partial x} \Delta x\right)^{2}} \\ \text { The total uncertaBias Error } & =\sqrt{\sum_{k=1}^{n}\left(\frac{\partial r_{k}}{\partial x} \Delta x\right)^{2}} \text { the precision error and the }\end{aligned}$ bias error

$$
\% \text { Uncertainty }=\sqrt{B_{i}^{2}+P_{r}^{2}}
$$

The parameter associated with the four key aspects investigated are shown in Table 5.7 and the total uncertainty shown is displayed in Table 5.9. 
Table 5.7: Parameter used and their associated bias errors.

\begin{tabular}{|l|r|r|c|}
\hline Bias Error & Nominal &.$+/-$ & Source \\
\hline \hline Thermocouple & $240 \mathrm{C}$ & $35 \mathrm{C}$ & Estimated error due to slag \\
\hline Thermocouple (Axial) & $150 \mathrm{~mm}$ & $1 \mathrm{~mm}$ & Error estimate of alignment \\
\hline Thermocouple (Radial) & $43 \mathrm{~mm}$ & $1 \mathrm{~mm}$ & Error estimate of alignment \\
\hline Port Diameter & $34.925 \mathrm{~mm}$ & $0.0508 \mathrm{~mm}$ & Caliper tolerance \\
\hline Grain Length & $98.425 \mathrm{~mm}$ & $0.0508 \mathrm{~mm}$ & Caliper tolerance \\
\hline Grain OD & $84.204 \mathrm{~mm}$ & $0.0127 \mathrm{~mm}$ & Cardboard tube tolerance \\
\hline Grain Mass & $1270 \mathrm{~g}$ & $0.2 \mathrm{~g}$ & Scale resolution (x2) \\
\hline Water Mass Flow & $0.36 \mathrm{~kg} / \mathrm{s}$ & $0.02 \mathrm{~kg} / \mathrm{s}$ & Estimated RMS fluctuation \\
\hline Throat Area & $8.052 \mathrm{~mm}$ & $0.0025 \mathrm{~mm}$ & Drill bit tolerance \\
\hline Water Injection Start & $1.4 \mathrm{~s}$ & $0.02 \mathrm{~s}$ & Estimated RMS fluctuation \\
\hline Pressure & $800 \mathrm{psi}$ & $6 \mathrm{psi}$ & Pressure transducer error \\
\hline Burn Time & $4 \mathrm{~s}$ & $0.05 \mathrm{~s}$ & Estimated error \\
\hline Step Distance & $9.525 \mathrm{~mm}$ & $0.0127 \mathrm{~mm}$ & Mould tolerances \\
\hline
\end{tabular}

Table 5.8: Precision error associated with instruments

\begin{tabular}{|l|c|}
\hline Precision Error & Error \\
\hline \hline Thermocouple & $0.40 \%$ \\
\hline Amplifiers & $0.24 \%$ \\
\hline Weight Scale & $0.10 \%$ \\
\hline Pressure Transducer & $0.25 \%$ \\
\hline Load Cell & $0.11 \%$ \\
\hline
\end{tabular}

Table 5.9: Uncertainty estimate of key parameters

\begin{tabular}{|l|c|}
\hline Parameter & \% Uncertainty \\
\hline \hline Temperature & $14.80 \%$ \\
\hline c star & $5.93 \%$ \\
\hline Mass Flow & $1.47 \%$ \\
\hline Burn Rate (step motor) & $1.26 \%$ \\
\hline
\end{tabular}




\section{Thermocouple Anomalies}

As can be seen in Table 5.6 (and later in Figure 5.23), there were a some thermocouples that did not take accurate readings. This was a problem encountered with all of the tests. All thermocouples were inspected prior to testing with a calibrator to ensure that they were working properly. However each test showed some thermocouples going off line at ignition. This anomaly was not specific to a particular thermocouple, but would vary randomly between tests. It was determined after post inspection of the thermocouples that this problem was likely caused by the an electrical short due to the leads of the probe bending over and making contact with the metal sheath of the thermocouple probe. The leads being bent over was caused by the impact of the water and GG propellant streams and was to be expected, however in some cases they were over extended which allowed them to make contact. This also explains why the thermocouples that generally went off-line were the ones closest to the inject faceplate, since they would see the hardest impact.

The only solution to rectify this problem would be to use grounded thermocouple instead of exposed thermocouples so the sheath would cover the entire junction. However the time constant for these grounded thermocouples are approximately 40 times longer as shown in Figure 5.22. Unfortunately having to use the exposed thermocouple resulted in a few data point(s) lost within each test. 

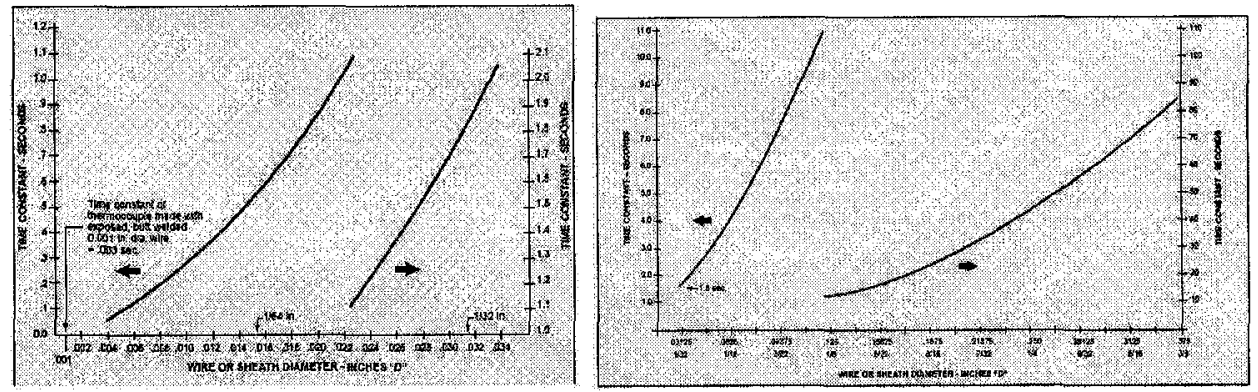

Figure 5.22: Change in time constant with increase in sheath diameter for air [35]

It should also be noted that injector \#6 and \#12 do not appear. This is because in the earlier tests, not used for the injector analysis, these thermocouples were damaged/destoryed on two separate occasions. This occurred due to the location of these two thermocouple, as they extended all the way to the centerline of the combustion chamber (i.e. $\mathrm{r}=0 \mathrm{~mm}$ ). When the $\mathrm{GG}$ propellant burns out the water stream is still injected for a short duration afterwards (approximately 2 seconds), so the water impinges on these two thermocouples under its full force at $800 \mathrm{psi}$. 


\subsubsection{Injector Evaluation}

Typically in rocket motor firings the temperatures are in excess of what can be measured with standard equipment. Injector efficiencies are normally measured based on characteristic velocity efficiencies $\left(\eta_{c^{*}}\right)$.

$$
\eta_{c^{*}}=\frac{c_{e x p}^{*}}{c_{t h e o r y}^{*}}
$$

where the experimentally measured $c^{*}$ is determine as shown with equation

5.3 and the theoretical $\mathrm{c}^{*}$ is determined based on propellant characteristics,

$$
c^{*}=\frac{\sqrt{\gamma R T}}{\gamma \sqrt{\left(\frac{2}{\gamma+1}\right)^{\frac{\gamma+1}{\gamma-1}}}}
$$

However the method for measuring the $\mathrm{c}_{e x p}^{*}$ is not always accurate and due to the nature of this propulsion system it is very sensitive to selecting when motor burn out happens. Fortunately, this experiment differs in that the warm gas is much cooler than a typical rocket motor and is therefore closer to research done in ducted rockets. With ramjet research, combustion efficiencies can still be determined through $\eta_{c^{*}}$, but due to the lower temperatures the efficiency can also be based on a temperature change, $\eta_{\Delta T}[41]$. 
As temperature measurements were obtained within the post combustion chamber, $\eta_{\Delta T}$ could be determined. Measurement of the injector efficiency was based on the change in temperature of the warm gas. Normally for ramjet (or rockets) a measure of how efficient the injector/combustion process is can be attributed to the rise in chamber temperature since better mixing would release more energy. With this experiment since water is substituted for the oxidizer there is no chemical reaction effects so a measure of the injection efficiency would be the drop in temperature of the warm gas. Efficiency is still defined as the experimental temperature drop compared to the theoretical temperature drop.

$$
\eta_{\Delta T}=\frac{T_{G G_{e x p}}-T_{e x p}}{T_{G G_{\text {theory }}}-T_{\text {theory }}}
$$

The theoretical warm gas temperature $\left(\mathrm{T}_{G G_{\text {theory }}}\right)$ and the theoretical mixing temperature $\left(\mathrm{T}_{\text {theory }}\right)$ were calculated with chemical equilibrium analysis $(\mathrm{CEA})$, presented in Section 2.4.3. Measurements were made in the post combustion chamber for $\mathrm{T}_{\text {exp }}$, and are shown in Table 5.6. Measurements of the GG propellant temperature $\left(\mathrm{T}_{G G_{\text {exp }}}\right)$ when conducting each injector test could not be obtained for obvious logistical reasons. However a separate test was conducted using the full AIH motor with combustion of only the GG propellant (i.e. no water introduced in the post combustion chamber) to gather experimental temperature measurements. Since the propellant grains used for all test came from the same batch of propellant 
there is no deviation in the flame temperature. The results from this individual GG propellant test are shown in Figure 5.23.

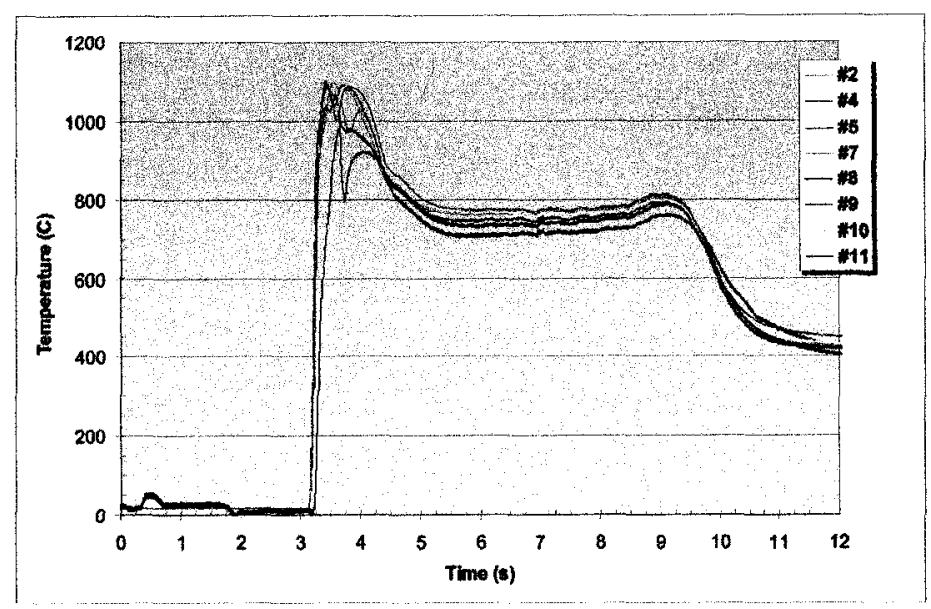

Figure 5.23: Temperature measurements in post combustion chamber when just GG propellant is ignited i.e. no water injection (for thermocouple \# locations refer to Figure 5.9)

With this, it was found that under steady state, the experimentally measured average temperature of the decomposed GG propellant was $754^{\circ} \mathrm{C}$. The high startup temperature over the first second is due to the solid propellant starter grain discussed previously. It should be noted that this temperature is significantly lower than the theoretical flame temperature from CEA $\left(896^{\circ} \mathrm{C}\right)$. Both the individual GG propellant test and all injector test using water (Table 5.6) exhibited lower temperatures then theoretically predicted $\left(263^{\circ} \mathrm{C}\right)$. 
The reason for these lower temperatures can be attributed to the high percentage of soot associated with the combustion of the solid GG propellant. This soot builds up on the thermocouple probes and acts as an insulator. The soot buildup is unavoidable and even with the first test that had brand new thermocouples, the soot accumulation occurs almost instantaneous. However this insulating effect of the soot will be representative in all tests conducted. Since the efficiency is dependent on the experimental drop in temperature, and the lower temperature will be exhibited in both the individual GG temperature test and the GG / Water injector tests, the temperature change should not be drastically effected.

\section{Injector Efficiency}

As mentioned previously, the $\eta_{c^{*}}$ is not always that accurate, however it was still determined for all six injectors for completeness. The problem with the using $\eta_{c^{*}}$ to evaluate the injectors is that in this particular case the mass flow is based on the contribution of both the water and GG propellant mass flow. To complicate matter the startup process for the GG propellant must use the small Pro-38 propellant. For the water mass flow, it is measured at each point with the hanging load cell and the venturi so this is well defined. However the GG propellant mass flow is not measured instantaneous but instead has to be estimated by the total mass of the dry GG propellant (weighed before and after) divided by the burn time. The 
problem that arises is that there is still a long tail off at the end of the burn from the large amount of residual propellant that continues to smolder. This is clearly seen in Figure 5.18 where the tail off (drop in pressure) extends almost 1.5 seconds. To complicate matters, water is still injected at its constant rate during this tail off time so the pressure does not drop right off. Therefore defining exactly when burn out occurs is difficult and can result in erroneous estimates for the mass flow which translated directly into errors in the $\mathrm{c}^{*}$ value . However as long as a consistent method is used for determining the burn out time with all injectors it will show a good comparison relative to each other. The results from this are shown in Figure 5.24 .

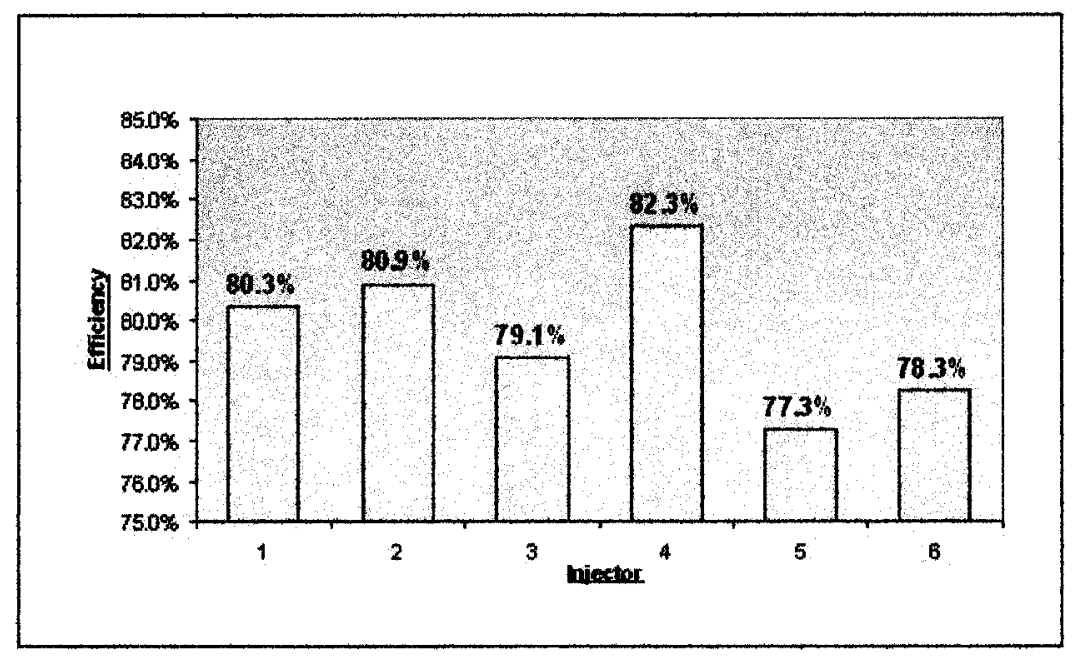

Figure 5.24: Comparison of injectors using $\eta_{c^{*}}$ 
The better method of evaluating the injector efficiency was with measurement of the temperature drop. The experimental temperature measurements $\left(\mathrm{T}_{G G}\right)$ were taken at the farthest axial location, $140 \mathrm{~mm}$ from the faceplate. Two different thermocouples (\#10 and \#11) at two separate radial locations ( $r=15 \mathrm{~mm}$ and $r=34 \mathrm{~mm}$ respecively) were used to calculate the injector efficiencies. The results are shown in Figure 5.25

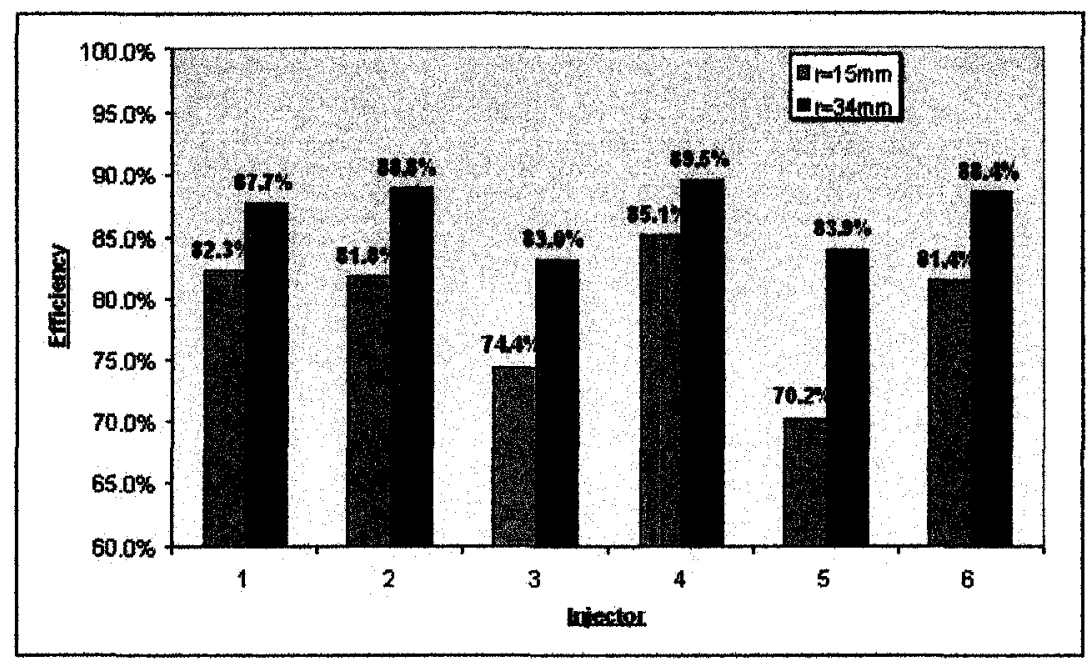

Figure 5.25: Comparison of injectors using $\eta_{\Delta T}$

Looking at Figure 5.25 its noticed that the efficiency of the injector is greater further away from the centerline $(\mathrm{r}=34 \mathrm{~mm})$. A possible explanation for this is due to recirculation effects. With the injector dimensions relative to the diameter of the combustion chamber $(84 \mathrm{~mm})$ the gas and liquid stream effectively flow into a sudden expansion. This causes a recirculation zone around the injection streams. 
This recirculation zone would aid in mixing and reducing the temperature of the GG/Water mixture. This type of recirculation zone was also observed in ramjet research [15. In comparing the injector, both the efficiency closer to and further away to the centerline showed the same pattern. Therefore injector comparison is done using thermocouple \#10 ( $\mathrm{r}=15 \mathrm{~mm})$.

From both Figures 5.24 and 5.25 injectors RC3 and RC5 appear to be less efficient. As mentioned previously the objective was to characterize the injectors and specifically look at the effects of the velocity ratio. Injectors RC3 and RC5 had the lowest velocity ratios, 5.8 and 3.9 respectively, out of all six injectors tested. Looking at Figure 5.26 one sees that there is a trend, indicating the higher the velocity ratio the better the injector efficiency. Obviously there would be an upper limit to this trend. Furthermore to operate at the optimum $\mathrm{O} / \mathrm{F}$ ratio there is a upper limit on how fast the GG propellant can be injected at while still remaining unchoked.

To further support the argument that the velocity ratio (momentum ratio) plays the significant role in defining injector efficiency, a comparison between injectors RC4 and RC6 was done. These two have approximately the same velocity ratio ( 6.9 and 7.0 respectively) but differ in there absolute velocities of the water and GG 


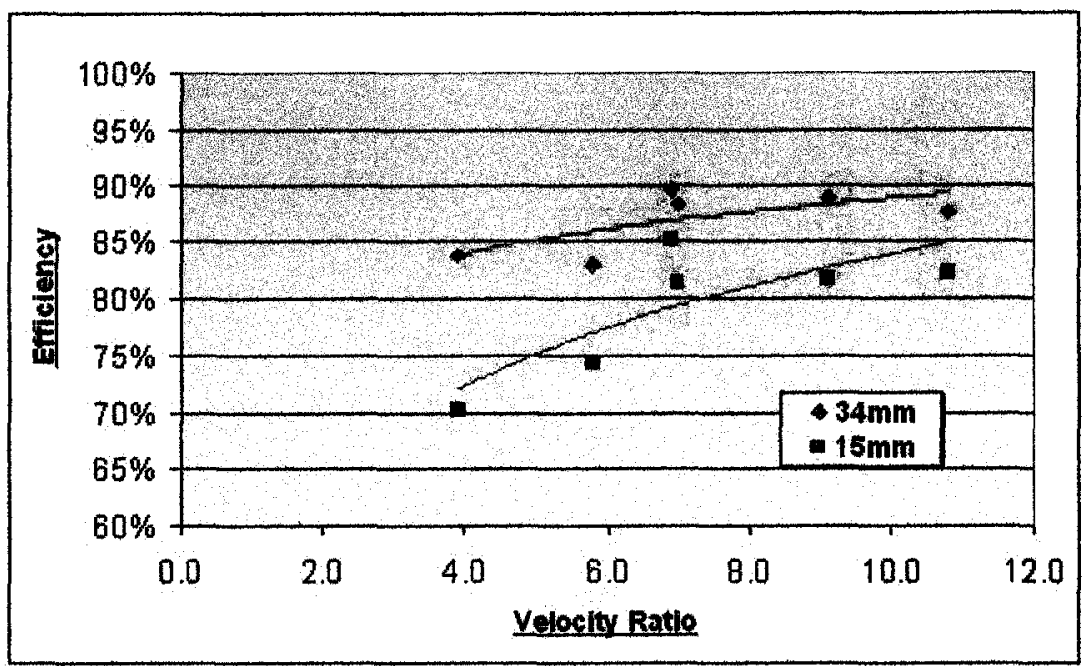

Figure 5.26: Effect of velocity ratio on injector efficiency

streams. Both the liquid and gas velocities for $\mathrm{RC} 6$ are approximately $60 \%$ higher than RC4.

From all this it was concluded that the velocity ratio appears to play a significant roll in defining how well a coaxial injector mixes its low speed liquid and high speed gas. 


\section{Chapter 6}

\section{CFD Injector Modeling}

The injector of any rocket motor plays a significant role in the efficiency of the overall system. Since combustion efficiency and motor operation stability is highly dependent on the injector system, much care and work goes into its design. However the construction of the injector and the subsequent experimental testing is very costly. Another problem associated with only using experimental testing is that there are limitations in the understanding of particular aspects of the flow since certain parameter, simply cannot be measured due to the complex nature of a rocket. In addition to this problem some of the tools used to take data measurements effect the flow characteristics and can slightly skew results. One tool that has recently been made available with the advancement in current computer technology is computational fluid dynamics model (CFD). 
What CFD allows in this application is a complete understanding of the entire injector process and can display the inner working within the combustion chamber that cannot be seen with real motors. However there are limitations using CFD because of the assumptions that have to be made. Furthermore the only real way to have confidence in a numerical model is to validate the results with actual experimental testing.

To better understand the injector, a numerical model was developed for the mixture of the warm gas generator and water injector. Modeling of the GG/water injector was done which can be compared to the experimental results discussed in Section 5.8. Although the final AIH motor is to use LOX instead of water, the use of the GG/water model will allow for confidence to be gained with applying these numerical modeling techniques to this particular problem. Furthermore this model will capture the bulk of the physical situation that will be present with the exception of combustion effects. The phase change that occurs with the water \& LOX, as well as the momentum transfer between the high speed gas flow and low speed liquid would still be representative. These are the major factors that influence the injector efficiency, and this model will still capture these effects. In terms of validating the model, obtaining experimental injector data with LOX would be extremely difficult and would require very expensive test hardware as discussed previous. This was the 
reason for initially testing using water as a substitute for the oxidizer, and this data can be used for validation.

One of the key parameters effecting overall combustion efficiency is the combustion residence time (time required for complete combustion of the propellant). This is highly dependent on the injectors geometry and flow parameters. The CFD analysis was done in order to characterize the mixing (combustion) length scales. It will also help to understand the efficiency of the injectors with a temperature drop as was performed in Section 5.8.4q. The obvious goal is to reduce the length (volume) of the combustion chamber as much as possible to save weight, without adversely effecting the mixing/atomization process.

This model will demonstrate the effect the velocity ratio has on the atomization process and on the achievable flame temperature. The actual mixing and atomization phenomenon was not the goal of this model, and has been studied extensively in other research and literature $[5],[29,[39]]$. This model is developed to determine the length required to achieve near complete mixing. With this model the geometric and flow variables will be examined in order to determine which combination results in shortest mixing (combustion) residence time. 


\subsection{CFD Software}

The software package used for the computational fluid dynamics model was CFX 5.7. The software solves the set of three-dimensional, unsteady, Navier-Stokes equations in their conservative form. Simplifying assumptions are taken based on the specific problem in order to solve the Navier-Stokes equations, which is discussed in the following sections.

\subsection{Numerical Discretization}

Solving the full Navier Stokes equations analytically can only be done for simplified cases. To solve more complex type of flow problems, numerical methods are used to solve algebraic approximations which are substituted for the Navier Stokes equations. This is accomplished in CFX by discretising the spatial domain into finite control volumes based on a mesh created for the specific problem being looked at. It then integrates the governing equations (discussed in Sections 6.5) over each control volume ensuring that mass, momentum, energy, are conserved. Linar shape functions with respect to parametric coordinates are used to account for solution variations within the finite volume. A First Order Backward Euler scheme is used to step the governing equations in time to a steady state solution. For more information on CFX 5.7 numerical discretization method see reference [7]. 


\subsection{Modeling Geometry Simplification}

For the model the goal was to examine the effects of the injection process of a liquid and gas into a cornbustion chamber. Therefore the models consisted of a single coaxial injector element and a combustion chamber. The nozzle was not included due to the complexity of the associated flow regime (shocks) within a nozzle. The details of this were beyond the scope of this specific research. Instead, the combustion chamber had a simple outlet condition with the pressure set to that of the combustion chamber pressure for the desired simulation. This same simplifying assumption is commonly made with CFD modeling of injectors [4], [9], [43].

The upstream effects of the injector for both the LOX manifold and the warm fuel-rich gas ducting were all neglected. The inlet conditions for the injector were assumed to be uniform with a turbulence intensity factor of $5 \%$ set.

\subsection{GG/Water Domain}

As mentioned in Section 6.3 the domain only looked at the combustion chamber and entrance of the injector, neglecting the downstream nozzle and upstream injector manifold. 
For the analysis, the combustion chamber was selected to be the same as the Pro-98 hobby solid motor series in order to replicate the sub-scale test motor. This allowed the test results to be compared to the numerical results. It is, however, expected that the injection and combustion process will actually require less crosssectional area, which will be demonstrated with the CFD simulation.

As the combustion chamber and associated injector will be axi-symmetrical, this can be utilized in order to reduce computational requirements. However, since CFX can only except models in $3 \mathrm{D}$, the geometry for the model selected was a $45^{\circ}$ slice of the actual injector (see Figure 6.1). A $45^{\circ}$ slice was selected because slices less then this $\left(2^{\circ}, 5^{\circ}, 10^{\circ}, 22.5^{\circ}\right)$ resulted in very large aspect ratios with the tetrahedral elements which may cause solver errors and poor convergence.

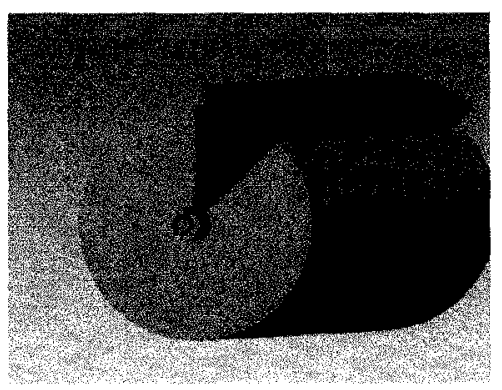

Figure 6.1: GG/LOX domain dimensions

Figure 6.2 shows the domain that was used. The origin $(0,0,0)$ is taken at 
the injector/combustion chamber interface, along the axis of revolution. The $\mathrm{x}$-axis is coincident with the axis of revolution. The combustion chamber extends 150 $\mathrm{mm}$ in the positive $\mathrm{x}$-direction, while the injector extends $25 \mathrm{~mm}$ in the negative $\mathrm{x}$-direction. The radius of the combustion chamber was set to $43 \mathrm{~mm}$ (Pro98 hobby motor case). The injector dimensions (referenced on the top of Figure 6.2) for each CFD case investigated are shown in Table 6.1. These dimension are the same dimensions used in the experimental testing outlined in Section 5.2.

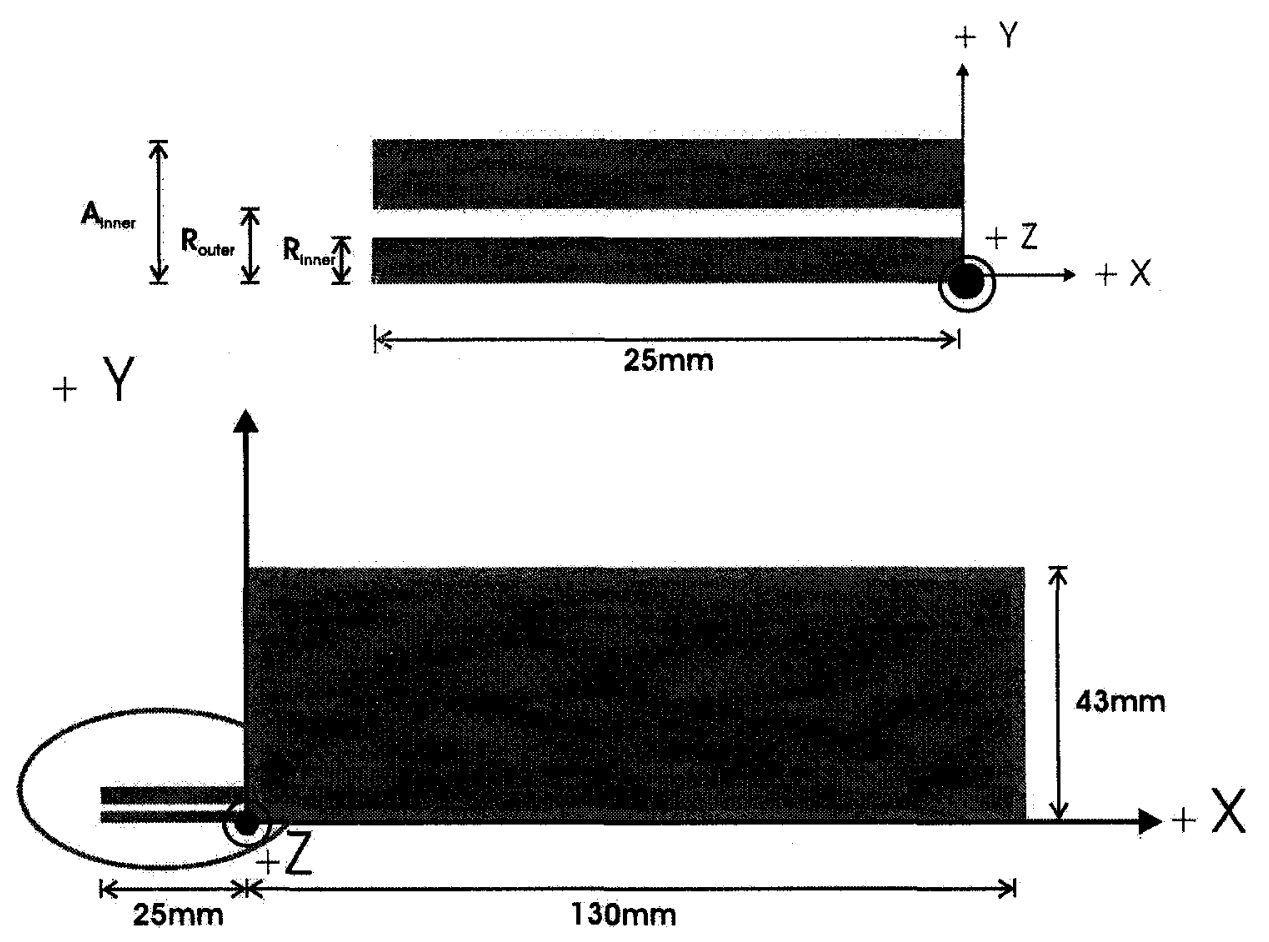

Figure 6.2: (TOP) Reference dimensions for the injectors investigated (BOTTOM) Modeling domain dimensions. 
Table 6.1: Gas Generator/Water Injector Dimensions

\begin{tabular}{|c|c|c|c|c|c|}
\hline $\begin{array}{c}\text { Reference } \\
\text { Dimensions }\end{array}$ & $\begin{array}{c}\text { RC1 } \\
{[\mathbf{m m}]}\end{array}$ & $\begin{array}{c}\text { RC2 } \\
{[\mathbf{m m}]}\end{array}$ & $\begin{array}{c}\text { RC3 } \\
{[\mathbf{m m}]}\end{array}$ & $\begin{array}{c}\mathbf{R C 4} \\
{[\mathbf{m m}]}\end{array}$ & $\begin{array}{c}\text { RC5 } \\
{[\mathbf{m m}]}\end{array}$ \\
\hline $\mathrm{R}_{\text {inner }}$ & 2.50 & 1.98 & 1.98 & 2.50 & 2.50 \\
\hline $\mathrm{R}_{\text {outer }}$ & 4.50 & 3.98 & 3.98 & 4.50 & 4.50 \\
\hline $\mathrm{A}_{\text {inner }}$ & 6.75 & 6.35 & 5.56 & 5.56 & 7.14 \\
\hline
\end{tabular}

\subsubsection{Working Fluid}

Since the injector is mixing water and the GG products this CFD model will obviously involve more then one working fluid. To account for multiple fluids CFX implies a "multi-phase" Eulerian-Eulerian model. This model also allows interphase transfer terms to be used to account for the phase change of water.

For this model three separate working fluids were used; liquid water, vapour water, and GG products. Both liquid water and water vapour were required due to the phase change that occurs from the heat transfer of the warm gas. The warm gas from the product of combustion of the solid GG propellant is treated as a multicomponent mixture with fixed properties. This means the mixture is treated as chemical species mixed at the molecular level, so that they share the same velocity, temperature, turbulence, etc. fields. This composition mixture contains all of the major products of combustion of the solid propellant gas generator. The products and their quantities were obtained from the output of CEA (Section 2.2). The rel- 
evant products were defined as ones with a mole fraction larger than 0.0005 . The products and important thermodynamic parameters from CEA used are shown in Table 1. 
Table 6.2: CEA Output For Gas Generator

\begin{tabular}{|l|c|}
\hline Products & Mole Fraction \\
\hline $\mathrm{CH} 4$ & 0.133 \\
\hline $\mathrm{CO}$ & 0.077 \\
\hline $\mathrm{CO} 2$ & 0.019 \\
\hline $\mathrm{HCL}$ & 0.047 \\
\hline $\mathrm{H} 2$ & 0.245 \\
\hline $\mathrm{H} 2 \mathrm{O}$ & 0.077 \\
\hline $\mathrm{N} 2$ & 0.024 \\
\hline C(graphite) & 0.377 \\
\hline \hline Property & Value \\
\hline \hline Temperature $[\mathrm{K}]$ & 1169 \\
\hline Pressure $[\mathrm{bar}]$ & 68.94 \\
\hline Density, $\left[\mathrm{kg} / \mathrm{m}^{3}\right]$ & 15.88 \\
\hline Enthalpy, $[\mathrm{KJ} / \mathrm{kg}]$ & -1620.62 \\
\hline Entropy, $[\mathrm{KJ} / \mathrm{kg}]$ & 9.4848 \\
\hline Molecular Weight $[\mathrm{mol} / \mathrm{kg}]$ & 13.971 \\
\hline Cp $[\mathrm{KJ} / \mathrm{kg} \cdot \mathrm{K}]$ & 8.1568 \\
\hline
\end{tabular}




\subsection{Governing Equations}

When using CFX for the injector modeling, the governing equations used are the unsteady, Navier-Stokes mass, momentum, and energy equations in their conservative form. Details of the equations used were obtained from references [6], [8]. The governing equations are modified in the form of the Reynolds Averaged Navier-Stokes (RANS) equations to account for turbulence (discussed in detail in Section 6.5.1).

As outline in Section 6.2, the general form of governing equations are written based on infinitesimally small element fixed in space as,

\section{Continuity Equation:}

$$
\frac{\partial \rho}{\partial t}+\nabla \cdot(\rho U)=0
$$

Momentum Equation:

$$
\frac{\partial \rho U}{\partial t}+\nabla \cdot(\rho U \otimes U)=\nabla \cdot\left(-\rho \delta+\mu\left(\nabla U+(\nabla U)^{T}\right)\right)+S_{m}
$$

\section{Energy Equation:}

$$
\frac{\partial \rho h_{t o t}}{\partial t}-\frac{\partial P}{\partial t}+\nabla \cdot\left(\rho U h_{t o t}\right)=\nabla \cdot(\lambda \nabla T)+S_{e}
$$


Since the GG/Water model uses three separate working fluids the governing equations must be rearranged for multiple fluids. This requires the volume fraction of each fluid $(\alpha)$ to be defined as,

$$
r_{\alpha}=\frac{V_{\alpha}}{V}
$$

Then the governing equations take on the form,

\section{Continuity Equation:}

$$
\frac{\partial}{\partial t}\left(r_{\alpha} \rho_{\alpha}\right)+\nabla \bullet\left(r_{\alpha} \rho_{\alpha} U_{\alpha}\right)=+\sum_{\beta=1}^{N_{p}} \Gamma_{\alpha \beta}
$$

\section{Momentum Equation:}

$$
\begin{aligned}
\frac{\partial}{\partial t}\left(r_{\alpha} \rho_{\alpha} U_{\alpha}\right)+\nabla \bullet\left(r_{\alpha}\left(\rho_{\alpha} U_{\alpha} \otimes U_{\alpha}\right)=\right. & -r_{\alpha} \nabla P_{\alpha}+\underbrace{M_{\alpha}}_{\text {I }} \\
& +\nabla \bullet\left(r_{\alpha} \mu_{\alpha}\left(\nabla U_{\alpha}+\left(\nabla U_{\alpha}\right)^{T}\right)\right. \\
& +\underbrace{\sum_{\beta=1}^{N_{p}}\left(\Gamma_{\alpha \beta}^{+} U_{b e t a}-\Gamma_{\beta \alpha}^{+} U_{\alpha}\right.}_{\text {II }}
\end{aligned}
$$

Where term I is due to the momentum transfer between all fluids and term

II is due to the mass transfer caused by the phase change between water and steam. 


\section{Energy Equation:}

$$
\begin{gathered}
\frac{\partial}{\partial t}\left(r_{\alpha} \rho_{\alpha} h_{\alpha, t o t}\right)-r_{\alpha} \frac{\partial P}{\partial t} \\
+\nabla \bullet\left(r_{\alpha} \rho_{\alpha} U_{\alpha} h_{\alpha, t o t}-r_{\alpha} \lambda_{\alpha} \nabla T_{\alpha}\right) \\
-\nabla \bullet\left(r_{\alpha} \mu_{\alpha}\left(\nabla U_{\alpha}+\left(\nabla U_{\alpha}\right)^{T}-\frac{2}{3} \nabla U_{\alpha} \delta\right) U_{\alpha}\right)=\underbrace{\sum_{\text {beta }=1}^{N_{p}}\left(\Gamma_{\alpha \beta}^{+}-h_{\beta, t o t}-\Gamma_{\alpha \beta}^{+}\right)}_{\text {III }} \\
\underbrace{+Q_{\alpha}}_{\text {IV }}
\end{gathered}
$$

The source terms within these governing equations has been omitted since there are no external mass sources for this particular numerical model. Term III is the heat transfer induced by the phase change. Term IV represents the heat transfer between the two fluids at the interface, which is defined by the a two resistance model (discussed later in Section 6.5.2).

In addition, since the GG fluid is modeled as a mulit-component fluid to account for all the product species an additional transport equation must be solved for each component. This is required in order to determine how the component moves within the fluid. The main motion of the fluid is accomplished using single velocity, pressure, temperature and turbulence fields, with the effects that each component 
has on the mean fluid field only being felt by virtue of their differing properties. As density difference between components is the most significant, equation 6.5 is modified,

$$
\frac{\partial}{\partial t}\left(r_{\alpha} \rho_{\alpha} Y_{\alpha}\right)+\nabla \bullet\left(r_{\alpha}\left(\rho_{\alpha} U_{\alpha} Y_{A \alpha}-\rho_{\alpha} D_{A \alpha}\left(\nabla Y_{A \alpha}\right)\right)\right)=\sum_{\beta=1}^{N_{p}} \Gamma_{\alpha \beta}
$$

Where $\mathrm{D}_{A \alpha}$ is the kinematic diffusivity and $\mathrm{Y}$ is the mass fraction of the component within the multi-component fluid (i.e. GG fluid).

For the equations of state, water is an incompressible fluid and uses equation 6.9. The vapour H20 and the gas component of the GG fluid are treated as ideal gases and use equation 6.10

$$
\begin{gathered}
P_{\text {tot }}=P_{\text {stat }}+12 \rho(U \cdot U) \\
\rho=\frac{\left(P+P_{r e f}\right)}{R T}
\end{gathered}
$$

The last equation required to close out the entire system is the constitutive relation. For the case of water with a constant specific heat, 


$$
h_{s t a t}-h r e f=c_{p}\left(T_{s t a t}-T_{r e f}\right)
$$

For the water vapour and the components of the GG mixture the enthalpy as a function of temperature is related by

$$
h_{s t a t}-h_{r e f}=\int_{T_{r e f}}^{T_{s t a t}} C_{p}(T) d T
$$

Equation 6.12 was evaluated using a polynomial fit function based on a widely excepted NASA format.

$$
\begin{array}{r}
C_{p}=\left(a_{1}+a_{2} T+a_{3} T^{2}+a_{4} T^{3}+a_{5} T^{5}\right) \\
H=\left(a_{1} T+\frac{a_{2}}{2} T^{2}+\frac{a_{3}}{3} T^{3}+\frac{a_{4}}{4} T^{4}+\frac{a_{5}}{5} T^{4}+a_{6}\right) R
\end{array}
$$

The coefficients for water vapour and all components of the GG mixture can be found in Appendix 7.1.3.

The entropy is defined in a similar manner with

$$
s-s_{r e f}=c_{p} \log \left(\frac{T}{T_{r e f}}\right)
$$




$$
s=\left(a_{1} \ln T+a_{2} T+\frac{a_{3}}{2} T^{2}+\frac{a_{4}}{3} T^{3}+\frac{a_{5}}{4} T^{4}+a_{7}\right) R
$$

\subsubsection{Turbulence Model}

Looking at the Reynolds numbers for both the water post and gas generator annulus (Table 6.5) of the coaxial injector, both conditions fall in the turbulent regime. For real life problems turbulent flows would have length scales drastically smaller then the smallest possible finite volume mesh that could be applied given current computational power. As such, turbulence models, which are based on a statistical approach, have been developed to predict these flows without having to evaluate the total turbulent fluctuations.

As mentioned above, the governing equations are transformed into the RANS equations to predict turbulence. This is done by decomposing the instantaneous component into two parts; the averaged component $(\bar{U})$ and the fluctuating component $\left(u^{\prime}\right)$. For example the velocity is broken down into;

$$
\mathbf{U}=\bar{U}+u^{\prime}
$$

When adding these time averaged components into the governing equations, the momentum equation (6.6) and the transport equation (6.8) have new terms 
introduced. Although a random fluctuating quantity would be zero when time averaged, the product of two fluctuating quantities is not, and this is were the additional terms $\left(u^{\prime} \times u^{\prime}\right)$ stems from. These term are known as the Reynolds stress (V) in the momentum equation, and the Reynolds flux (VI) in the transport equation.

$$
\begin{gathered}
\frac{\partial \rho U}{\partial t}+\nabla \cdot(\rho U \otimes U)=\nabla \cdot(\tau-\underbrace{\rho \overline{u \otimes u}}_{\mathbf{V}})+S_{M} \\
\frac{\partial \rho \phi}{\partial t}+\nabla \bullet(\rho U \phi)=\nabla \bullet(\Gamma \nabla \phi-\underbrace{\overline{u \phi \phi}}_{\mathbf{V I}})+S_{E}
\end{gathered}
$$

Turbulence models are used to solve for these two additional unknowns (V $\&$ VI) and close out the governing equations. For this the eddy viscosity hypothesis was used which assumes the Reynolds stress can be related to the mean velocity gradient by the Boussinesq approximation [8].

$$
\rho \overline{u \otimes u}=\underbrace{-\frac{2}{3} \rho k \delta}_{\text {VII }}-\underbrace{\frac{2}{3} \mu_{t} \nabla \bullet U \delta}_{\text {VIII }}+\mu_{t}\left(\nabla U+(\nabla U)^{T}\right)
$$

In the implementation of CFX, terms VII and VIII are omitted[16]. For the Reynolds fluxes they are linearly related to the mean scalar gradient.

$$
-\rho \overline{u \phi}=\frac{\mu_{t}}{P r_{t}} \nabla \phi
$$


Using equations 6.21 and 6.22 , the governing equations become,

\section{Momentum:}

$\frac{\partial \rho U}{\partial t}+\nabla \cdot(\rho U \otimes U)=\nabla \cdot\left(\mu_{e f f}\left(\nabla U+(\nabla U)^{T}\right)\right)-\nabla[P+\frac{2}{3} \rho k+\underbrace{\nabla \bullet\left(\frac{2}{3} \mu_{e f f}-\zeta\right)}_{\mathbf{V}}]+B$

Scalar Transport:

$$
\frac{\partial \rho \phi}{\partial t}+\nabla \bullet(\rho U \phi)=-\nabla \cdot\left(\Gamma_{\Phi}+\frac{\mu_{t}}{\sigma_{\Phi}}\right) \nabla \Phi+S
$$

Energy:

$$
\frac{\partial \rho h_{t o t}}{\partial t}+\frac{\partial P}{\partial t}+\nabla \bullet\left(\rho U h_{t o t}\right)=\nabla \bullet\left(\lambda \nabla T+\frac{m u_{t}}{P r_{t}} \nabla h\right)+S_{e}
$$

Term V was excluded as the temperature flow field was heterogenous (not isothermal) due to the phase change of the water, and the water and gas are at relatively slow speeds.

The eddy viscosity model was selected over the Reynolds stress model since the added complexity of having to solve seven additional transport equations for each Reynolds stress did not warrant the improvements in the turbulence prediction [41]. The eddy viscosity turbulence model used for the CFD simulation was the 
Shear Stress Transport (SST) because it combines the advantages of both $k-\epsilon$ and the Wilcox $(k-\omega)$ models, and gives proper prediction of flow separation. The way it offers the advantage of both models is that it uses the Wilcox model in the near wall region, and then switches to the $k-\epsilon$ model outside the boundary layer. It does this with use of a blending function, F. Both these models use one transport equations for the turbulent kinetic energy to solve for the velocity scale. They each use a second transport equation to solve for the length scale, but differ in that the $k-\epsilon$ model uses the turbulence dissipation rate, while the Wilcox model uses turbulent frequency.

For the $k-\epsilon$ model it relates the turbulence viscosity to the turbulence energy and dissipation by,

$$
\mu_{t}=C_{\mu} \rho \frac{k^{2}}{\epsilon}
$$

where $\mathrm{k}$ and $\epsilon$ are determined from the following transport equations,

$$
\begin{array}{r}
\frac{\partial(\rho k)}{\partial t}+\nabla \bullet(\rho U k)=\nabla \cdot\left[\left(\mu+\frac{\mu_{t}}{\sigma_{k} 2}\right) \nabla k\right]+P_{k}-\beta^{\prime} \rho \epsilon \\
\frac{\partial(\rho \epsilon)}{\partial t}+\nabla \bullet(\rho U \epsilon)=\nabla \bullet\left[\left(\mu+\frac{\mu_{t}}{\sigma_{\epsilon}}\right) \nabla \epsilon\right]+\frac{\epsilon}{k}\left(C_{\epsilon 1} P_{k}-C_{\epsilon 2} \rho \epsilon\right)
\end{array}
$$


For the Wilcox model it assumes that the turbulence viscosity is linked to the turbulence kinetic energy and frequency by the following,

$$
\mu_{t}=\rho \frac{k}{\omega}
$$

where $\mathrm{k}$ and $\omega$ are determined from the following transport equations,

$$
\begin{array}{r}
\frac{\partial(\rho k)}{\partial t}+\nabla \bullet(\rho U k)=\nabla \bullet\left[\left(\mu+\frac{\mu_{t}}{\sigma_{k}}\right) \nabla k\right]+P_{k}-\beta^{\prime} \rho k \omega \\
\frac{\partial(\rho \omega)}{\partial t}+\nabla \bullet(\rho U \omega)=\nabla \bullet\left[\left(\mu+\frac{\mu_{t}}{\sigma_{\omega}}\right) \nabla \omega\right]+\alpha \frac{\omega}{k} P_{k}-\beta \rho \omega^{2}
\end{array}
$$

Table 6.3: Values For Constants Used In Turbulence Models

\begin{tabular}{|l|c|}
\hline Constants & Value \\
\hline $\mathrm{C}_{\epsilon 1}$ & 1.44 \\
\hline $\mathrm{C}_{\epsilon 2}$ & 1.92 \\
\hline$\sigma_{\epsilon}$ & 1.3 \\
\hline$\sigma_{k 1}$ & 2 \\
\hline$\sigma_{\omega 1}$ & 2 \\
\hline$\sigma_{k 2}$ & 1 \\
\hline$\sigma_{\omega 2}$ & $1 / 0.856$ \\
\hline$\alpha 1$ & $5 / 9$ \\
\hline$\alpha 2$ & 0.44 \\
\hline$\beta 1$ & 0.075 \\
\hline$\beta 2$ & 0.0828 \\
\hline$\beta^{\prime}$ & 0.09 \\
\hline
\end{tabular}




\subsubsection{Phase Change Model}

To account for the phase change of liquid water into gaseous H20 vapour (steam) a phase change model was utilized. As mentioned previously a two resistance model is used to account for heat transfer on either side of the fluid interface.

$$
\begin{array}{r}
q_{\alpha}=h_{\alpha}\left(T_{s}-T_{\alpha}\right) \\
q_{\beta}=h_{\beta}\left(T_{s}-T_{\beta}\right) \\
h_{\alpha}=\frac{N u_{\alpha} \lambda_{\alpha}}{d_{\alpha \beta}} \\
h_{\beta}=\frac{N u_{\beta} \lambda_{\beta}}{d_{\beta \alpha}}
\end{array}
$$

where $T_{s}$ is the interfacial temperature, $\lambda_{\alpha}$ is the thermal conductivity of the fluid $\alpha$ and $\mathrm{d}_{\alpha \beta}$ is the interfacial length scale defined as the mean particle diameter. For the interaction of the GG mixture/H20 Vapour and with the GG mixture/Water this two resistance model is sufficient to define the heat transfer since no phase change occurs. With the interaction of water and H20 vapour where there is a phase change, $\mathrm{T}_{s}$ is taken as the saturation temperature with the assumption that surface tension can be ignored. The total heat flux is defined as,

$$
Q_{\alpha}=q_{\alpha}+m_{\alpha \beta} H_{\alpha S}
$$




$$
Q_{\beta}=q_{\beta}+m_{\alpha \beta} H_{\beta S}
$$

where $\mathrm{H}_{\alpha S}$ and $\mathrm{H}_{\beta S}$ are the interfacial enthalpy carried in/out of fluids $\alpha$ and $\beta$. Since the total heat balance must follow,

$$
Q_{\alpha}+Q_{\beta}=0
$$

the mass flux can be determined by,

$$
m_{\alpha \beta}=\frac{q_{\alpha \beta}+q_{\beta \alpha}}{H_{\beta S}-H_{\alpha S}}
$$




\subsection{Boundary Conditions}

For this injector numerical model there were two inlet boundary condition located at $\mathrm{x}=-25 \mathrm{~mm}$ axially (Figure 6.3). They are located at the cross section of the injector (parallel to the $\mathrm{YZ}$ plane). One inlet boundary condition was for the water inlet port (yellow) and a second inlet for the gas generator inlet annulus (green). Both of these inlet boundary conditions were given velocity and temperature values for each injector as shown in Table 6.4. Both the water and the GG inlet conditions were set with a turbulence intensity of $10 \%$ as was done in other research [41]. This allows the inlet turbulence energy and dissipation to be calculated by,

$$
\begin{aligned}
& \kappa_{\text {inlet }}=\frac{3}{2} I^{2} U^{2} \\
& \epsilon_{\text {inlet }}=\rho C_{\mu} \frac{\kappa^{2}}{\mu_{t}}
\end{aligned}
$$

where $\mu_{t}=1000 I \mu$

A single outlet boundary condition was used for the exit of the combustion chamber. This is shown on the right side of Figure 6.3 in blue located at $x=150$ $\mathrm{mm}$. To capture the effects of the flow recirculation the radius of the outlet extended $10 \mathrm{~mm}$. This allowed the effects of the nozzle to be eliminated, but still allow the 
effects of the recirculation zone to occur. The chamber pressure of this AIH is $\mathbf{8 0 0}$ psi, which is what the static pressure of the outlet boundary condition was set to.

Two symmetrical boundary conditions were used for the faces of the $45^{\circ}$ slice in order to represent the entire combustion chamber/injector. All other surfaces were set to no slip, smooth, adiabatic walls. The assumption of using an adiabatic wall was made since the combustion chamber wall has a full insulator and the duration of the actual injector tests was short enough $(\approx 4 \mathrm{sec}$.) that no significant interaction would occur.
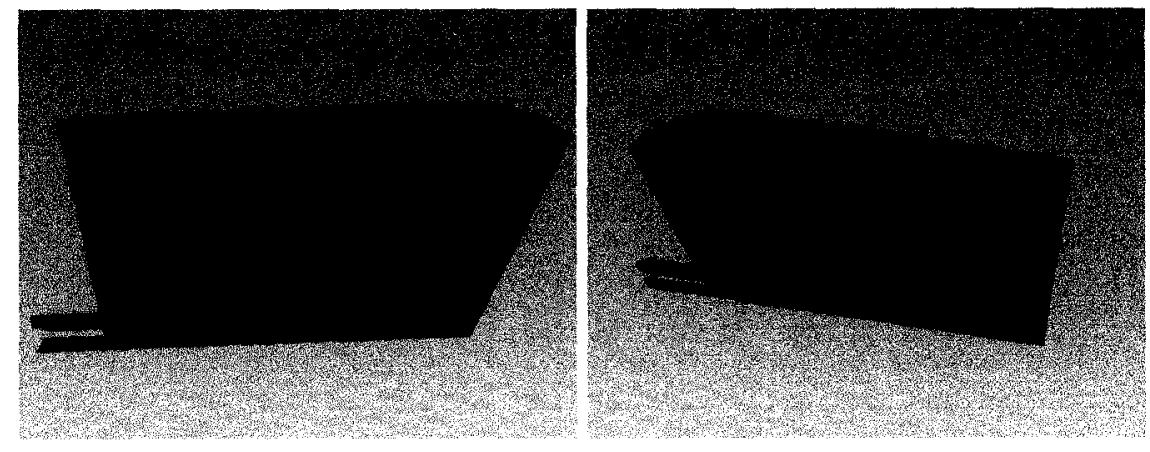

Figure 6.3: Location of inlet (left) and outlet (right) boundary conditions 
Table 6.4: CFD boundary conditions

\begin{tabular}{|l|c|c|c|c|c|c|}
\hline & RC1 & RC2 & RC3 & RC4 & RC5 & RC6 \\
\hline \hline Water Post Inlet & & & & & & \\
\hline \hline Velocity (m/s) & 18.4 & 24.1 & 29.2 & 18.4 & 29.2 & 29.2 \\
\hline Temperature (K) & 1169 & 1169 & 1169 & 1169 & 1169 & 1169 \\
\hline Turbulence Intensity & $10 \%$ & $10 \%$ & $10 \%$ & $10 \%$ & $10 \%$ & $10 \%$ \\
\hline \hline GG Annulus Inlet & & & & & & \\
\hline \hline Velocity (m/s) & 198.1 & 219.6 & 168.8 & 126.4 & 113.5 & 205 \\
\hline Temperature (K) & 298 & 298 & 298 & 298 & 298 & 298 \\
\hline Turbulence Intensity & $10 \%$ & $10 \%$ & $10 \%$ & $10 \%$ & $10 \%$ & $10 \%$ \\
\hline \hline Outlet & & & & & & \\
\hline \hline Pressure (psi) & 800 & 800 & 800 & 800 & 800 & 800 \\
\hline
\end{tabular}

\subsection{Wall Functions}

In dealing with solid surfaces and the associated logarithmic velocity profile of the boundary layer, CFX uses wall functions to account for viscous effects of the wall. Near the wall, the shear stress is related to the tangential velocity by logarithmic relation $[8]$;

$$
U_{t}=\sqrt{\frac{\tau_{w}}{\rho}} \frac{1}{\kappa} \ln \left(Y^{+}\right)+C
$$

where $\mathrm{U}_{t}$ is the tangential velocity, $\tau_{w}$ is the wall shear stress, $\rho$ is the density, $\kappa=0.41$ is the von Karman constant, $\mathrm{C}=5.2$ is the log-layer constant (dependent on wall roughness). $\mathrm{Y}^{+}$is the non-dimensional distance from the wall. 


$$
Y^{+}=\frac{\rho \triangle Y u_{\tau}}{\mu}
$$

Defining $\mathrm{y}^{+}$as the non-dimensional distance of the first node, then $\Delta y$ is the actual distance from the wall to the first node. In order to properly resolve the boundary layer 15 nodes would be required, with the first node spaced at $\mathrm{y}^{+} \leq 2$. The distance of the first node is based on the correlation of the Reynolds number for a flat plate [45].

$$
\operatorname{Re}_{L}=\frac{\rho U L}{\mu}
$$

The correlation for the wall shear stress coefficient is,

$$
c_{f}=0.025 R e_{x}\left(\frac{-1}{7}\right)
$$

Using equation $6.43,6.44,6.45$, and $\operatorname{Re}_{x}=\mathrm{C} \operatorname{Re}_{L}$ with the assumption $\mathrm{C}^{1 / 14} \approx 1$, the actual distance spacing of the first node can be determined as follows (for details see [8]),

$$
\triangle y=L y^{+} \sqrt{80} R e_{L}^{\frac{-13}{14}}
$$

Using equation 6.46 and the injection and physical properties for water and GG products within the boundary layer was defined. 
Table 6.5: First Node Spacing

\begin{tabular}{|l|c|c|c|}
\hline & Water Post Wall & GG Post Wall & CC Wall \\
\hline Velocity $(\mathrm{m} / \mathrm{s})$ & 30 & 300 & 100 \\
\hline Reynolds Number & 746000 & 2890000 & 24100000 \\
\hline Density $\left(\frac{\mathrm{kg}}{\mathrm{m}^{3}}\right)$ & 998 & 15.88 & 21.03 \\
\hline Viscosity $\left(\frac{\mathrm{Ns}}{\mathrm{m}^{2}}\right)$ & 0.001003 & 0.000041218 & 0.000034895 \\
\hline Length $(\mathrm{mm})$ & 25 & 25 & 150 \\
\hline Temperature $\left({ }^{\circ} \mathrm{C}\right)$ & 20 & 896 & 264 \\
\hline $\mathrm{y}+$ & 1.5 & 1.5 & 1.5 \\
\hline$\triangle \mathrm{y}(\mathrm{mm})$ & 0.0012 & 0.0003 & 0.0003 \\
\hline boundary layer thickness $(\mathrm{mm})$ & 0.127 & 0.104 & 0.463 \\
\hline
\end{tabular}

\subsection{Mesh}

For the domain discussed in Section 6.4 an unstructured mesh was used. This was created using the program ANSYS Workbench 8.1 which is the mesh generator associated with CFX 5.7. An unstructured mesh was required due to the curvature of the combustion chamber and injector walls. Figure 6.4 shows the final mesh that was used for $\mathrm{RC} 1$. As can be seen, the mesh was refined in the injector region since the geometry is significantly smaller. Within the injector region the tetrahedral elements were made be $0.2 \mathrm{~mm}$ providing a minimum of 12 nodes in the radial direction on the smallest injector. 


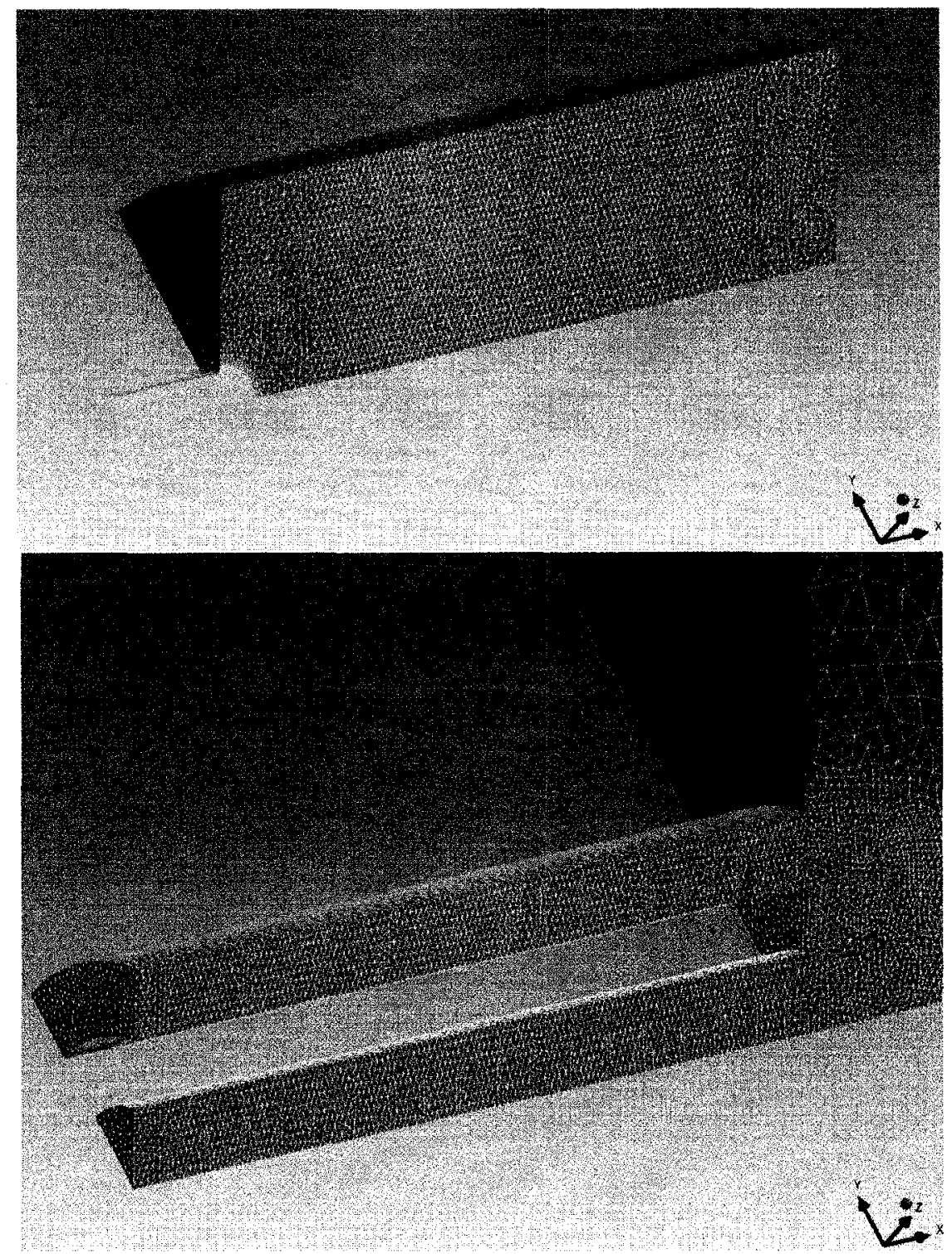

Figure 6.4: Unstructured mesh geometry for injector RC1 (Top) full domain view (Bottom) refined nodes in injector region 
Additional to the tetrahedral elements, in the near wall region the mesh is transformed into a semi-structured mesh with the use of inflation layers. This is used to allow a fine mesh in the boundary layer and allow the precise control of the first node location as discussed above (Section 6.7). This option allows the height of the prisms (inflated layers) to be controlled, while the length of each element is still defined by the length of the tetrahedral element in the unstructed mesh (see Figure 6.5). These inflation layers were specifically used for the water injection post and the GG annulus, but were also implement on the combustion chamber walls.

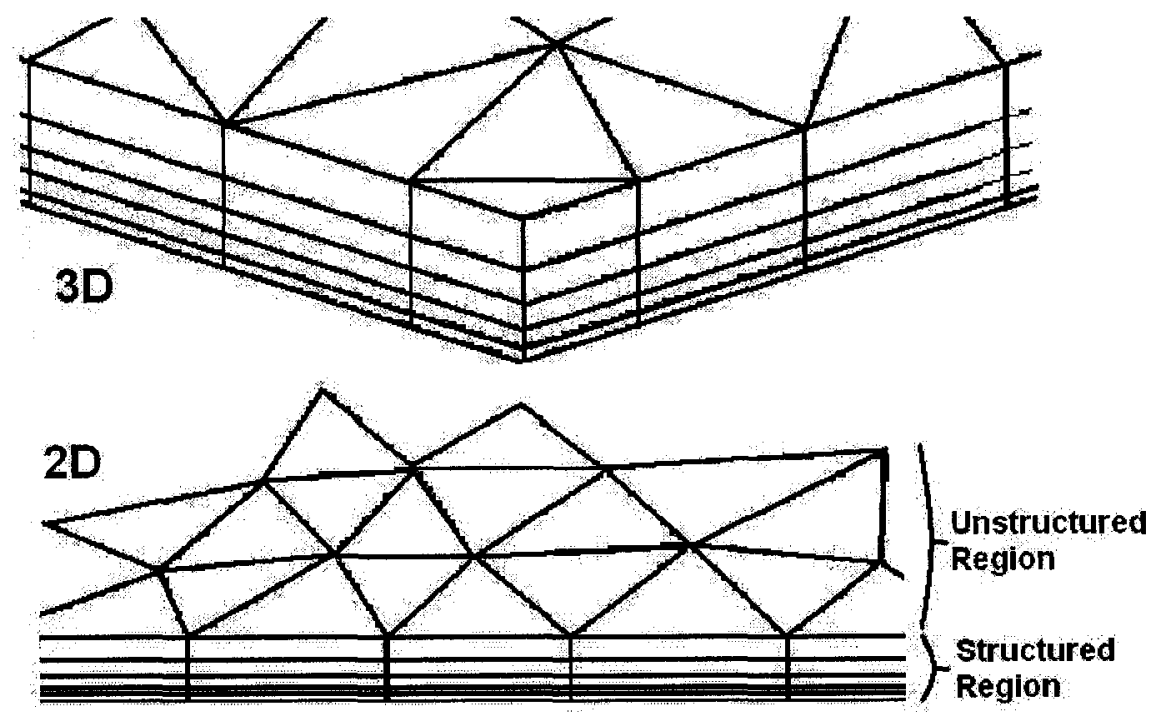

Figure 6.5: Depiction of how inflated layers are used in the near wall region to allow a semi-structured mesh 
Table 6.6: GG/Water model specifications used For ANSYS mesh generator

\begin{tabular}{|l|c|}
\hline Tetrahedral Elements & \\
\hline \hline Body Spacing & $1 \mathrm{~mm}$ \\
\hline Injector Region Spacing & $0.4 \mathrm{~mm}$ \\
\hline Axial Location & $-25 \mathrm{~mm}$ to $25 \mathrm{~mm}$ \\
\hline Radius of Influence & $8 \mathrm{~mm}$ \\
\hline Near Wall Elements & \\
\hline \hline \# of nodes & 15 \\
\hline Expansion Factor & $35 \%$ \\
\hline GG Walls Inflation Layer & $0.086 \mathrm{~mm}$ \\
\hline Water Walls Inflation Layer & $0.301 \mathrm{~mm}$ \\
\hline CC Walls Inflation Layer & $0.100 \mathrm{~mm}$ \\
\hline
\end{tabular}

\subsubsection{Mesh Analysis}

In defining the mesh that is required for the model a mesh analysis was performed. A coarse mesh was looked at, and finer meshes were then compared to see at what point more refinement was no longer necessary to obtain the same results. This allows a mesh with the least amount of nodes to be used without sacrificing any accuracy in the results. Obviously with less nodes there is a reduction in the CPU requirements which translates into faster solver time to reach complete convergence.

The mesh analysis was performed for only the $\mathrm{RC} 1$ injector. The final mesh spacing required for $\mathrm{RC} 1$ was assumed to be representative of the other injectors (RC2-RC5). This assumption was made since although the flow conditions vary between the cases, they do not change significantly enough to effect the grid re- 
finement. It should be clarified that in defining the grids for injectors RC2-RC6 the total number of nodes was different for each case, since the injector geometry changed. What was kept constant was the grid resolution within the combustion chamber (i.e from $\mathrm{x}=0 \mathrm{~mm}$ to $\mathrm{x}=150 \mathrm{~mm}$ ).

The different meshes were compared based on resultant GG volume fraction as this is one of the key parameter of interest in the numerical model and it also exhibits some of the largest changes. The GG volume fraction was plotted at a radius of $6 \mathrm{~mm}$ from the center line. This location was selected since this is where the largest changes occur with the steepest gradients. Figure 6.6 show the results of the mesh analysis. As can be seen the difference between the mesh with 157,000 nodes and 192,000 node is very minimal. 


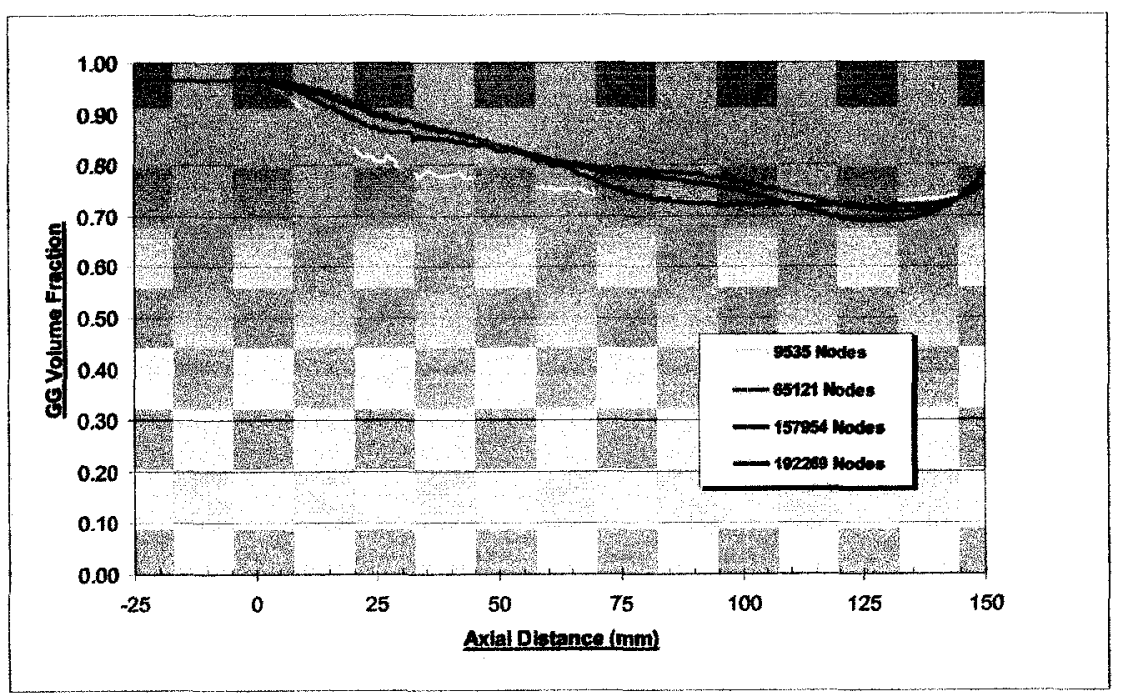

Figure 6.6: $\mathrm{RC1}$ GG volume fraction profile at $\mathrm{r}=6 \mathrm{~mm}$ for different mesh densities

To better quantify the effect that the mesh refinement has on the final results, the grids were compared based on the percentage difference from the finest mesh (taken as the baseline) and is shown in Figure 6.7.

Therefore based on these two plots using a mesh with 150,000 nodes was deemed sufficient for accurate prediction of the injector flow without wasting valuable CPU time. 


\subsection{Results}

The results for the numerical simulation of the six injectors are presented here. For clarity the results are presented with the plane reflected along the $\mathrm{x}$-axis to show the full cross section of the combustion chamber.

As mentioned previously, the goal was to investigate which injector would be the most efficient at mixing the liquid and gas flow so that the combustion chamber length can be set to the shortest possible length. This will also be critical when LOX is used instead of water as the oxidizer in order to obtain the greatest combustion

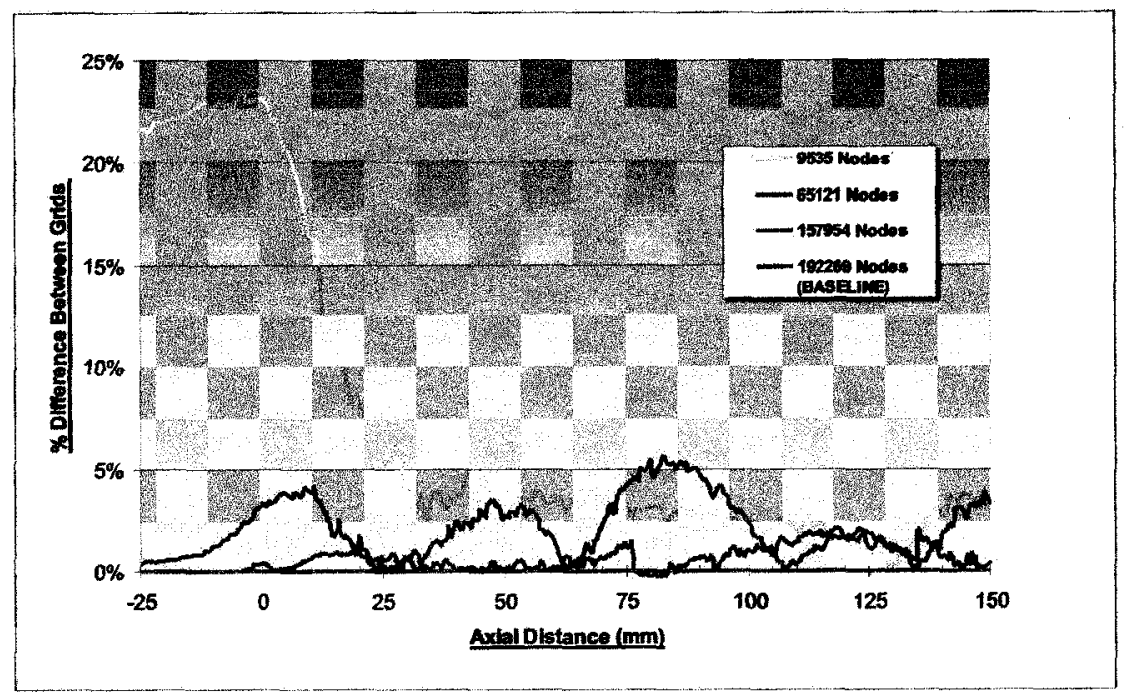

Figure 6.7: Comparison of mesh density based on \% difference from finest mesh for injector RC1 using GG volume fraction profile at $\mathrm{r}=6 \mathbf{~ m m}$ 
efficiency which ultimately translates into improved performance. To characterize which injector was the most efficient both the volume fractions and the temperature profile were investigated. The effect that the momentum ratio plays based on the six different injectors was also looked at. 


\subsubsection{Velocity Profile}

For completeness, the velocity profile is first presented. One aspect that was noticed and speculated with the experimental results is the presence of a recirculation zone. To examine this, the velocity profile and associated vector plot for RC1 is shown in Figure 6.8. As can be seen by this the numerical model also indicates a recircularization zone.

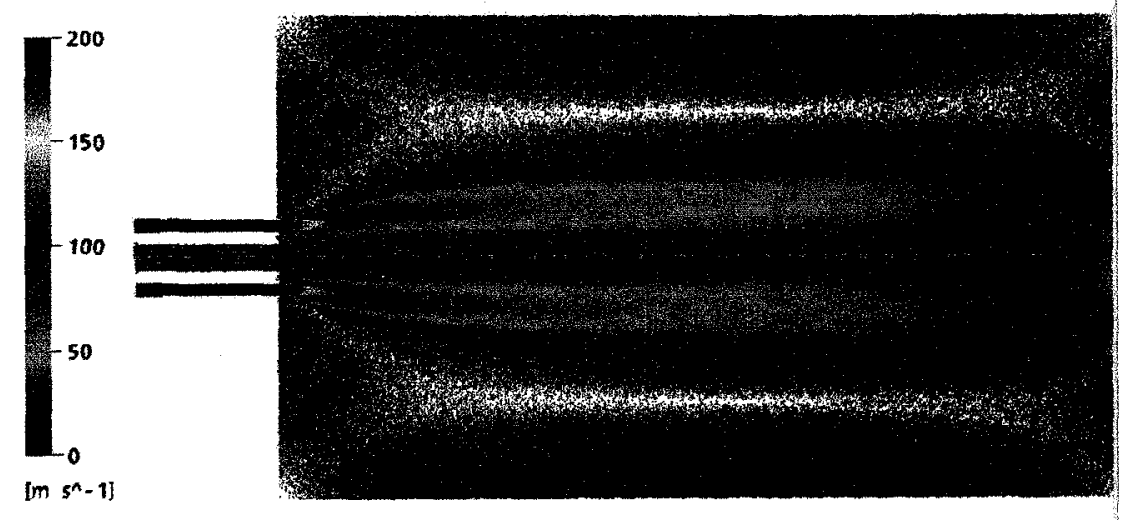

Figure 6.8: Velocity vector plot for injector RC1

\subsubsection{Volume Fraction}

Looking at the volume fraction of the three fluids present (water, vapour water, and GG mixture), gives a direct representation of how well the injectors are mixing the liquid and gas. This is one of the benefits of using a numerical model since experimental testing would not be able to distinguish and quantify between the different components in the mixture. 

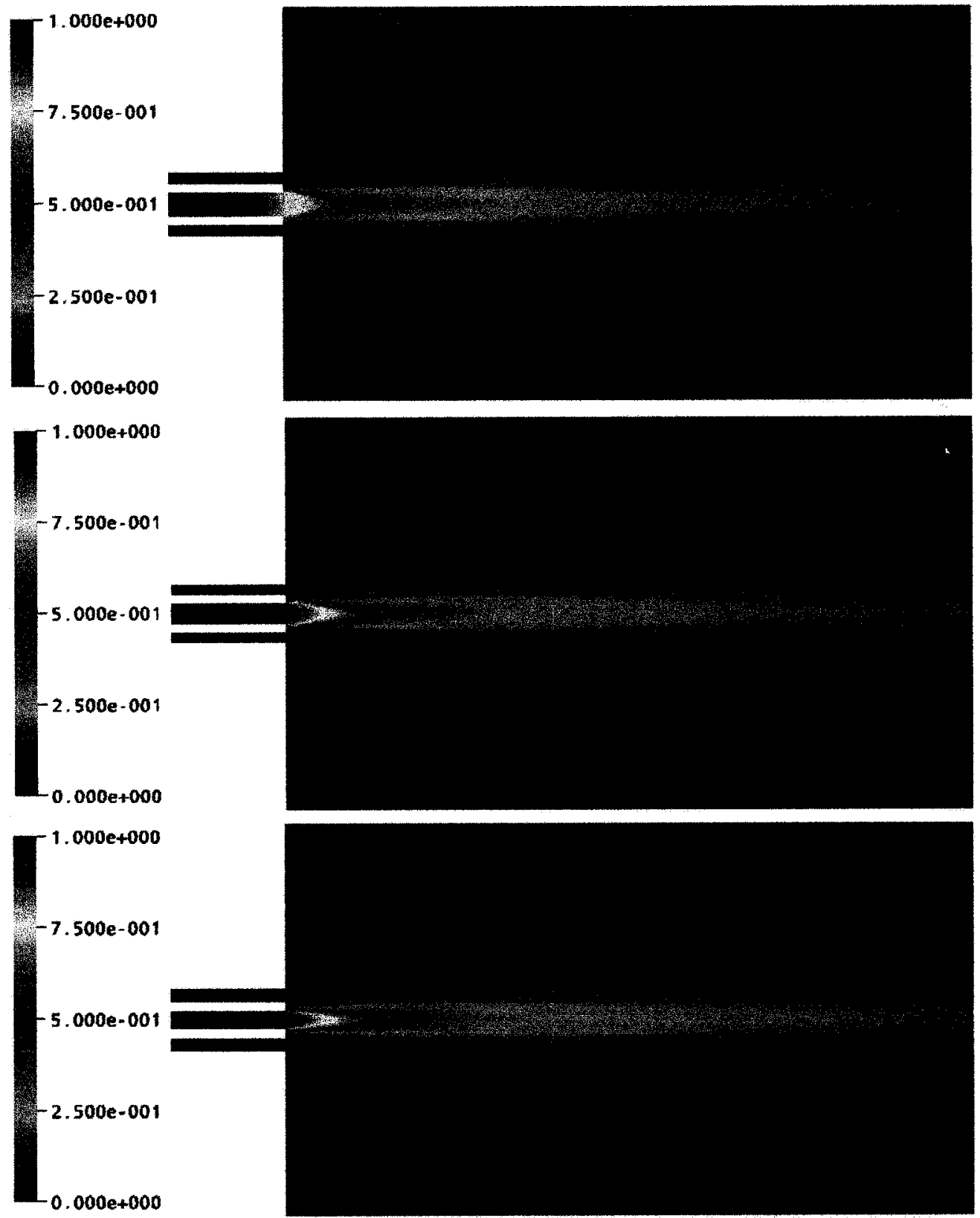

Figure 6.9: Water volume fraction: (TOP) RC1 injector (MIDDLE) RC2 injector (BOTTOM) RC3 injector 


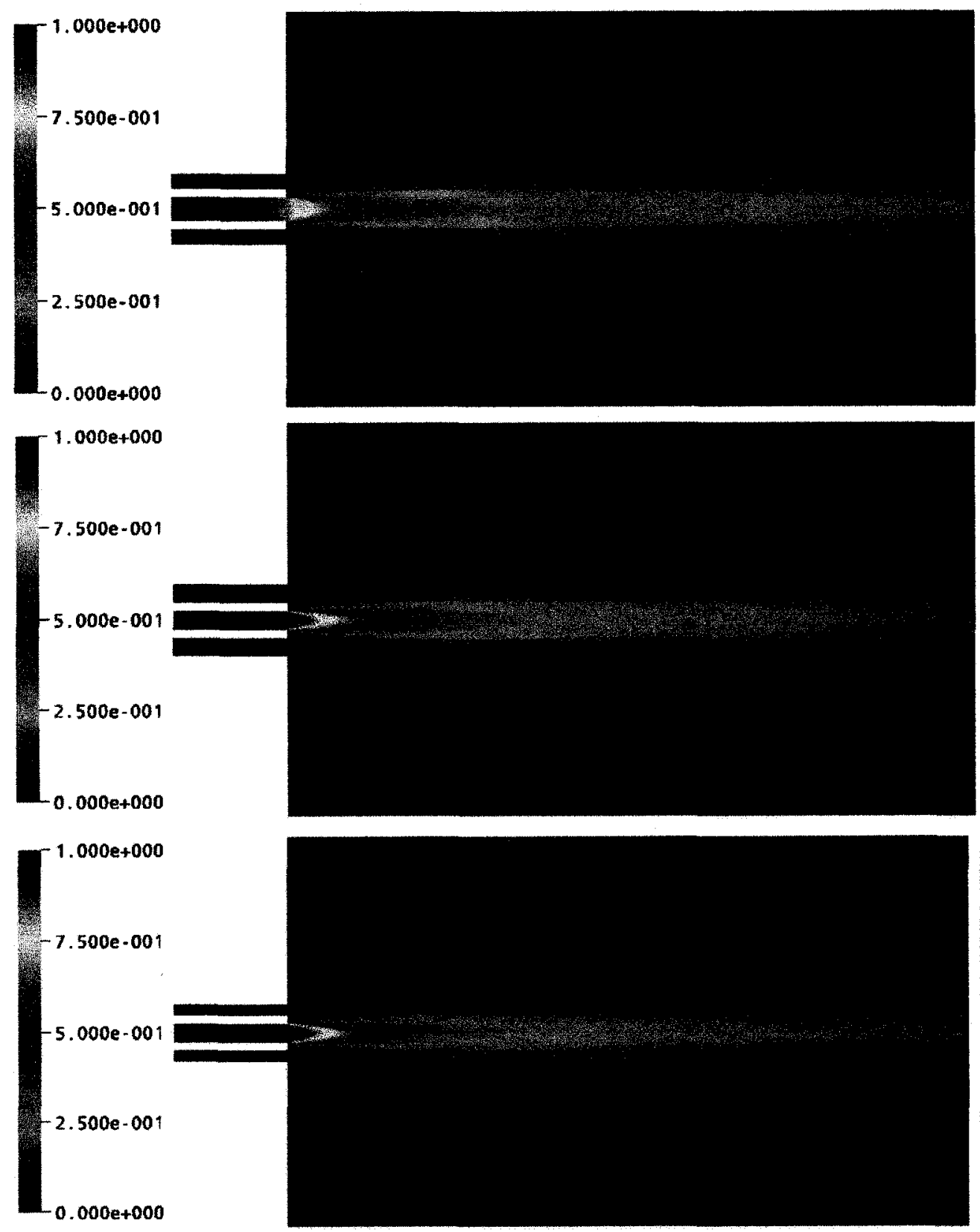

Figure 6.10: Water volume fraction: (TOP) RC4 injector (MIDDLE) RC5 injector (BOTTOM) RC6 injector 


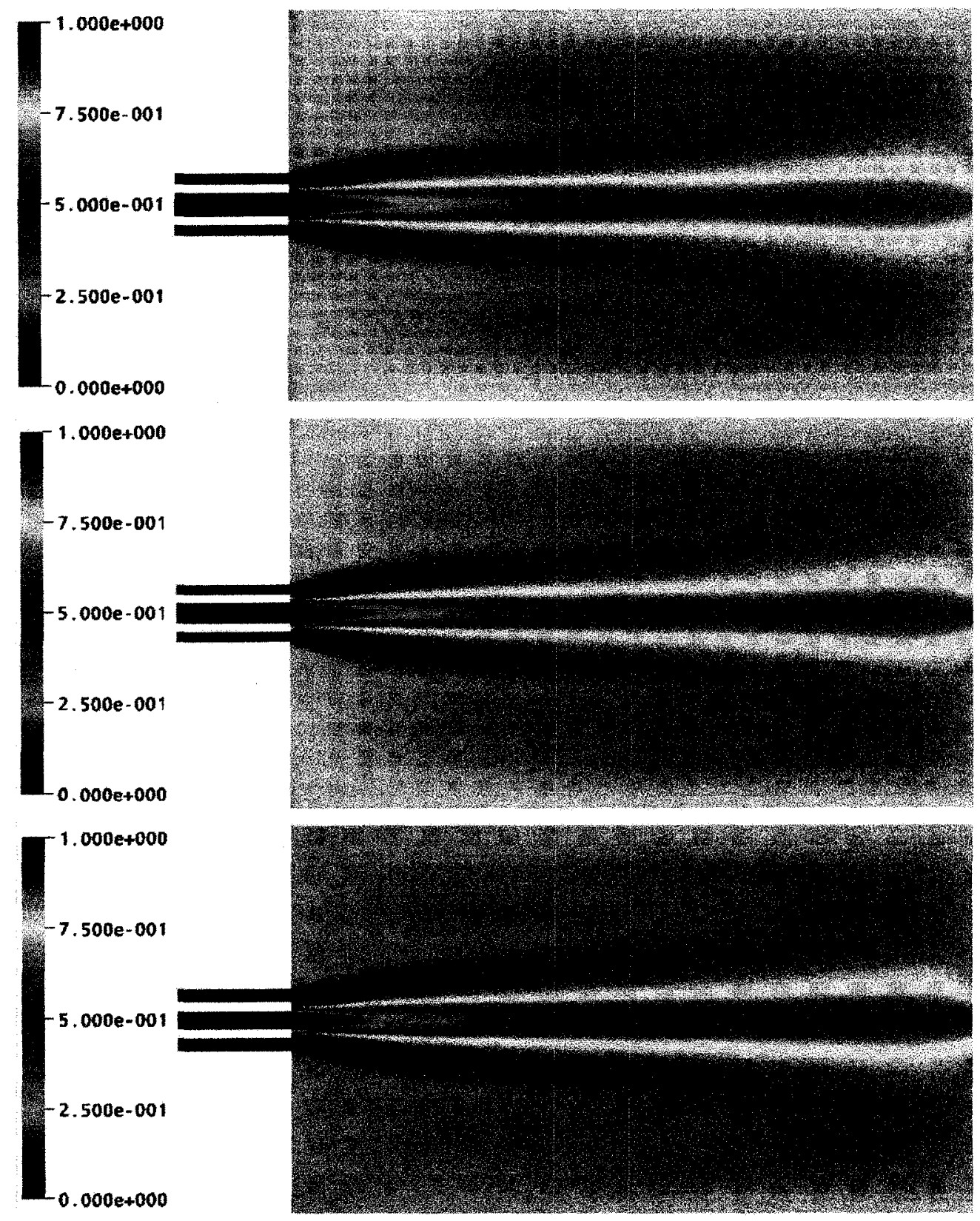

Figure 6.11: Water volume fraction: (TOP) RC1 injector (MIDDLE) RC2 injector (BOTTOM) RC3 injector 

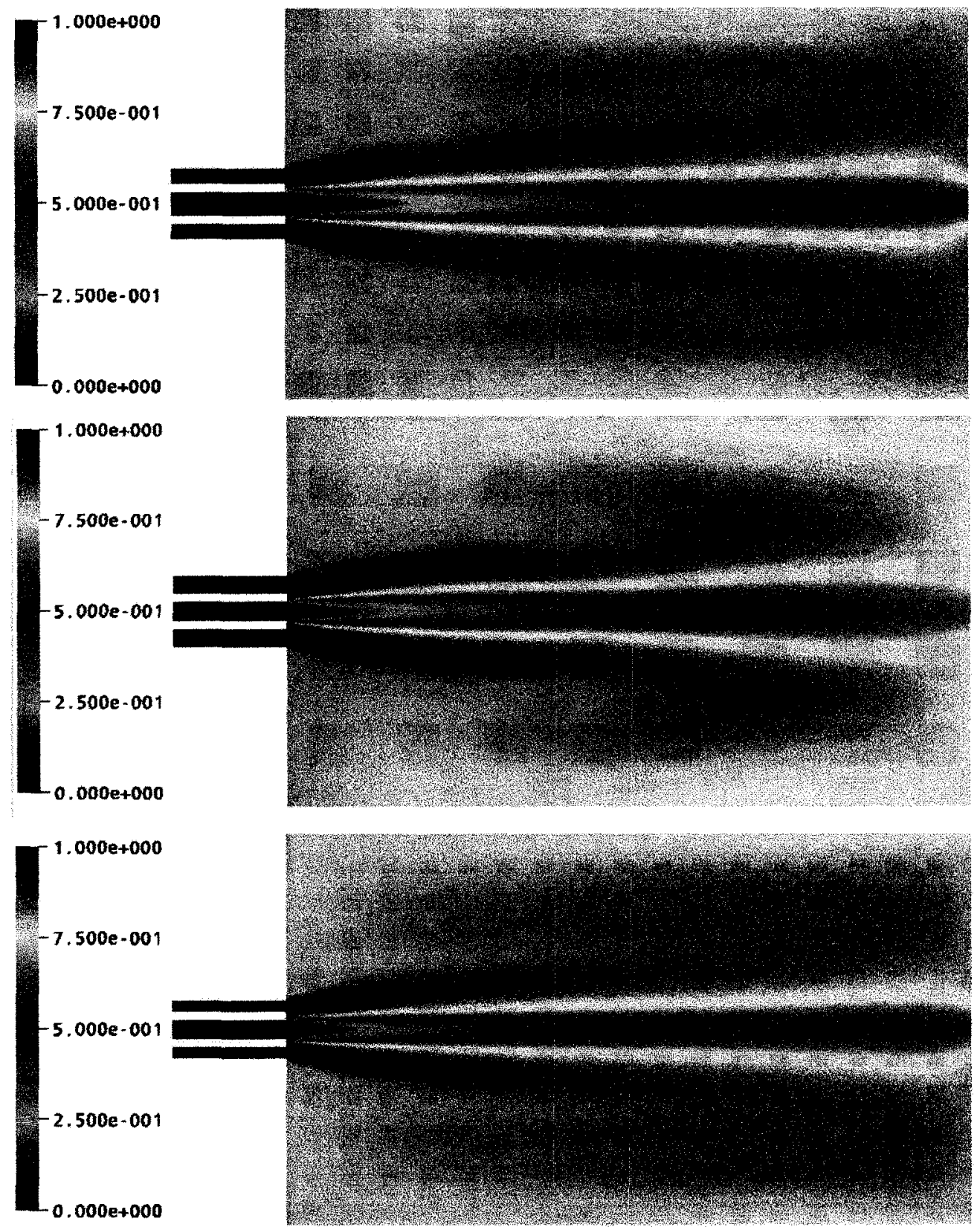

Figure 6.12: Water volume fraction: (TOP) RC4 injector (MIDDLE) RC5 injector (BOTTOM) RC6 injector 
As can be seen in Figures $6.9-6.14$ it is hard to notice any major differences to determine which injector was the best at mixing the gas and liquid. To quantify this, the water volume fraction was plotted along the center axis of revolution (i.e. $r=0 \mathrm{~mm}$ ) for all injectors. An injector that provides better efficient mixing is characterized with a reduced water volume fraction, specifically over a short length scale. As seen in Figure 6.13, there is a notable difference between injectors.
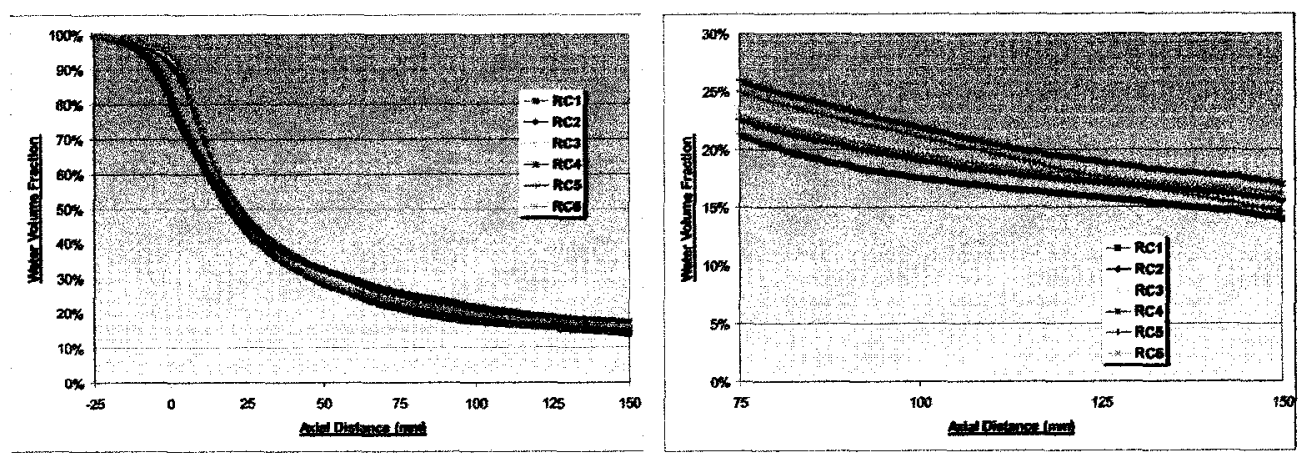

Figure 6.13: Water volume fraction of all six injectors along center axis (TOP LEFT) full length plot (TOP RIGHT) Zoomed view

Specifically looking at a location $100 \mathrm{~mm}$ down stream, it appears that injectors RC4 and RC5 show the worst mixing. There is also a general trend which is present on the right side of Figure 6.14. As the momentum ratio increases, the less water volume is present which indicates that better mixing is occurring. This correlates nicely with what was also shown experimentally in Section 5.8.4 where we say a better injector efficiency with a high momentum ratio. 

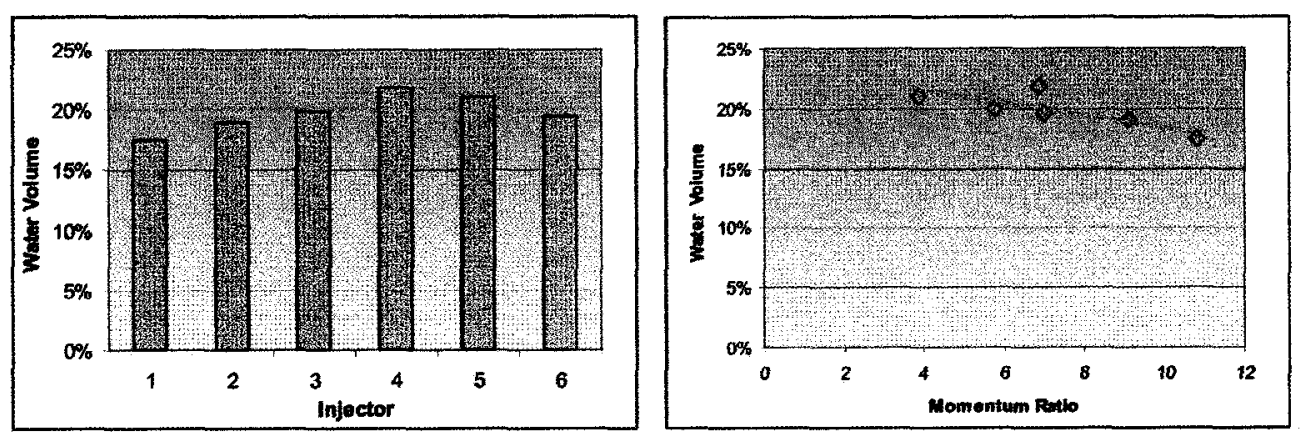

Figure 6.14: Resultant water volume $\%$ at $100 \mathrm{~mm}$ axial location

\subsubsection{Temperature Profile}

With this particular CFD simulation a Eulerian-Eulerian model with a heterogenous heat transfer was used. This is pre-requisite in order to accurately simulate the phase change of water. A minor drawback in using this model is that the temperature field for each fluid is calculated individually so that the mass flux can be determined as discussed in Section 6.5.2. The global temperature field is of primary importance so it will allow the efficiency of the injector to be determine by the temperature drop. This is also necessary so it can be compared and validated against the experimental results from Section 5.8. In order to obtain the global temperature field, the temperature of the individual fluid were weighted based on there enthalpy and mass fraction. 


$$
T_{\text {gloabl }}=\frac{\Upsilon_{\text {water }} h_{\text {water }} T_{\text {water }}+\Upsilon_{H 20} h_{H 20} T_{H 20}+\Upsilon_{G G} h_{G G} T_{G G}}{\Upsilon_{\text {water }} h_{\text {water }}+\Upsilon_{H 20} h_{H 20}+\Upsilon_{G G} h_{G G}}
$$

A temperature profile along a longitudinal polyline at a radius of $8 \mathrm{~mm}$ from the center-line was calculate for each injector. The location of this polyline was selected so it would mimic the axial location of the thermocouple from the experimental results. The results from this for each injector is shown in Figures $6.15-6.20$ and the experimental data points are also shown. 


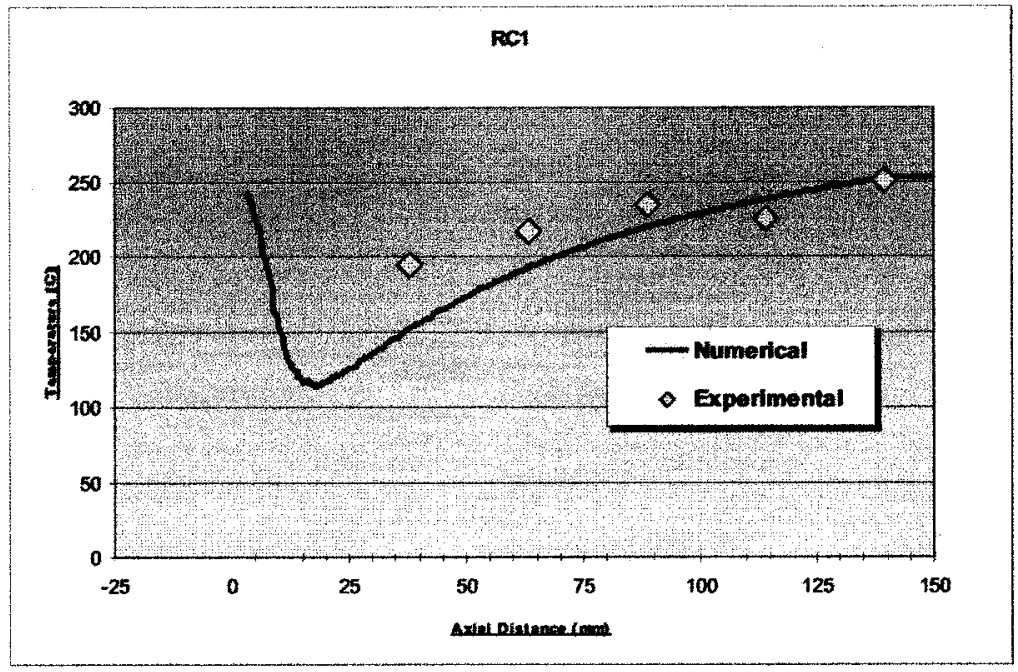

Figure 6.15: RC1 injector numerical results for global temperature profile at $r=8 \mathrm{~mm}$

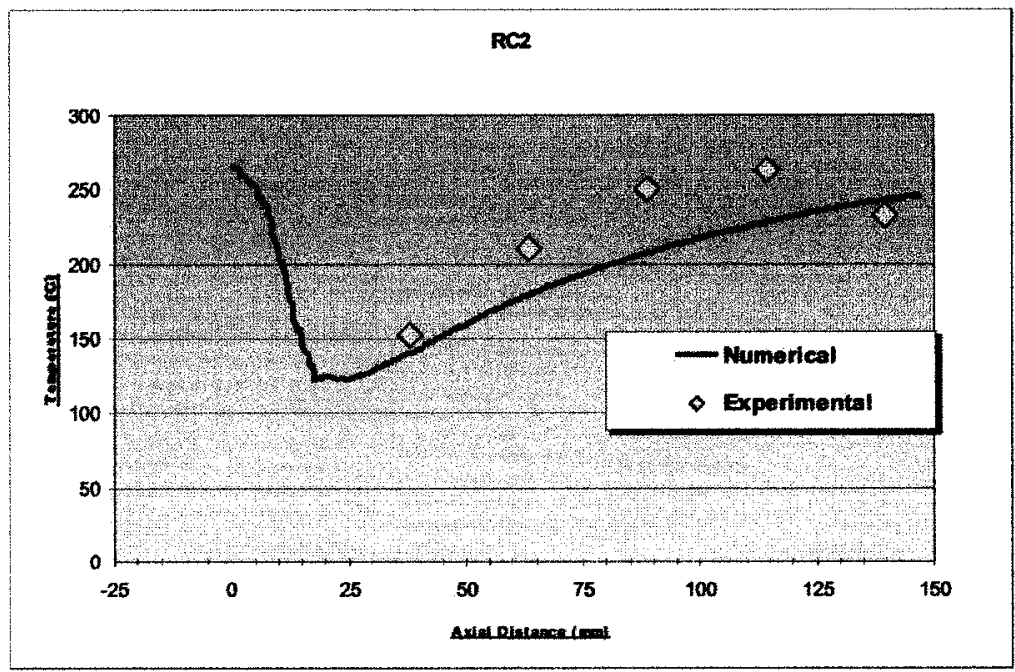

Figure 6.16: $\mathrm{RC} 2$ injector numerical results for global temperature profile at $\mathrm{r}=\mathbf{8} \mathrm{mm}$ 


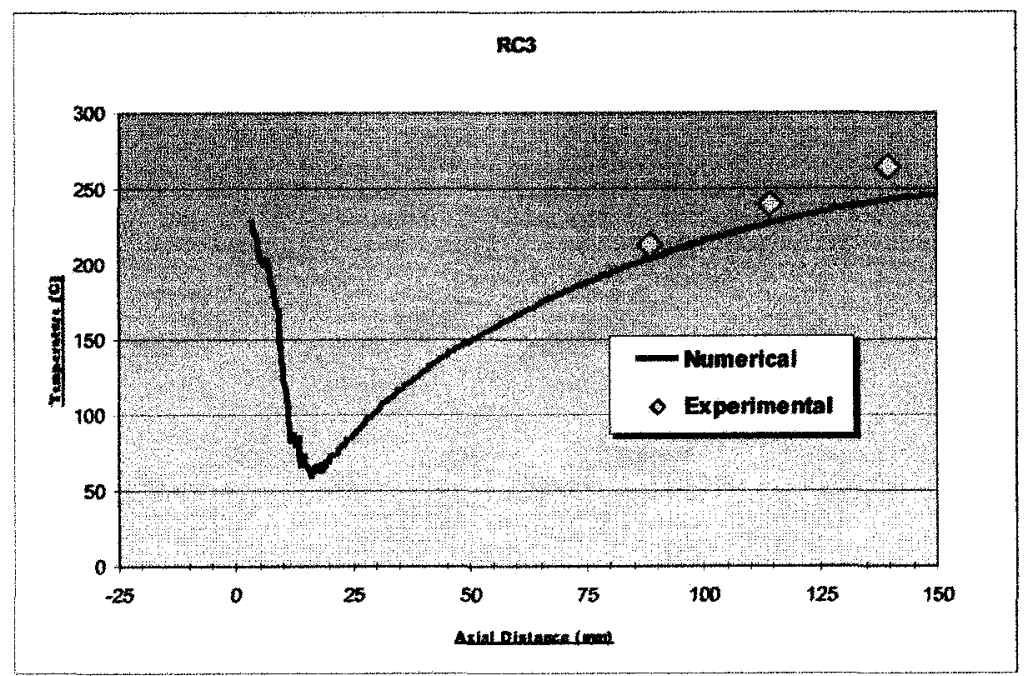

Figure 6.17: RC3 injector numerical results for global temperature profile at $\mathrm{r}=8 \mathrm{~mm}$

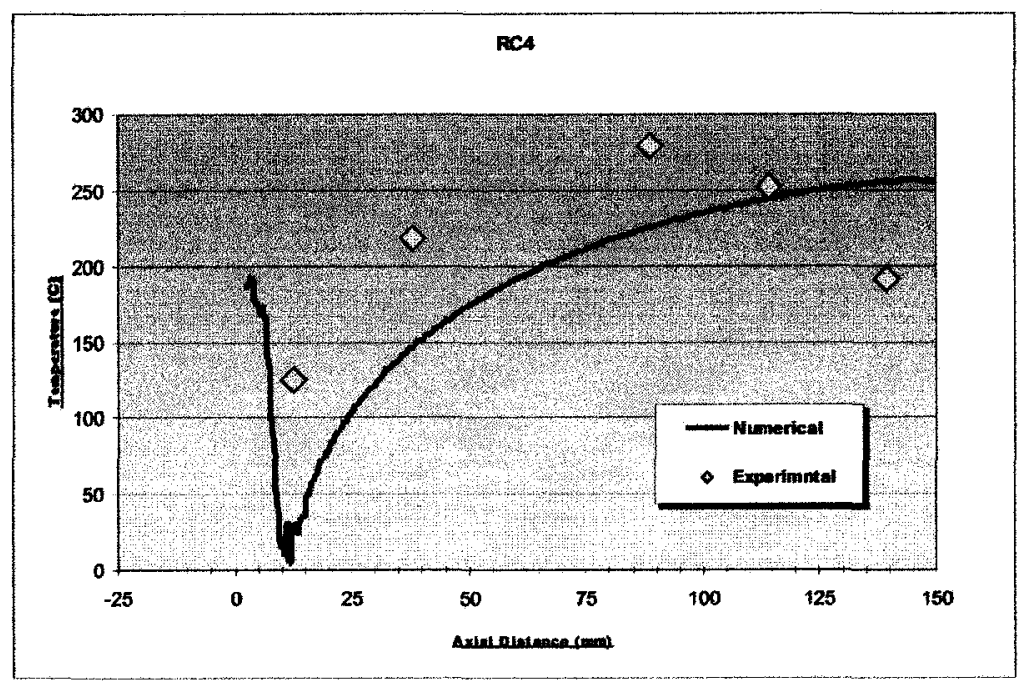

Figure 6.18: $\mathrm{RC} 4$ injector numerical results for global temperature profile at $r=8 \mathrm{~mm}$ 


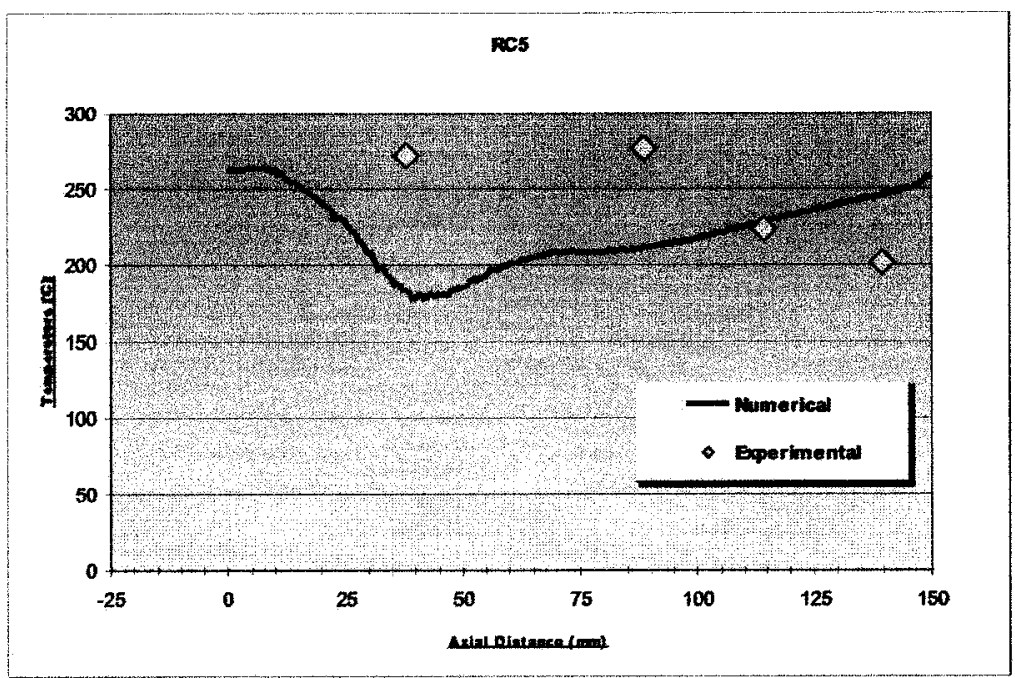

Figure 6.19: RC5 injector numerical results for global temperature profile at $r=8 \mathrm{~mm}$

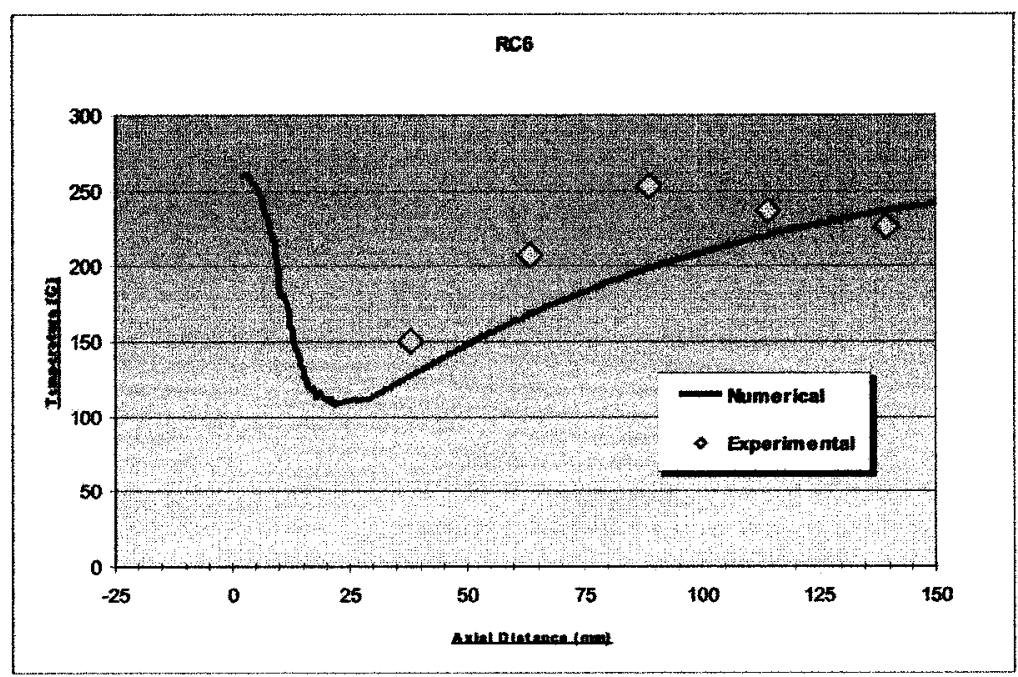

Figure 6.20: $\mathrm{RC6}$ injector numerical results for global temperature profile at $\mathrm{r}=8 \mathrm{~mm}$ 
As can be seen there is some slight differences between the numerical and experimental data. The majority of the data points are within the experimental uncertainty outlined in Section 5.8.3. Although there is experimental error with the sub-scale testing, there are also some possibilities for the discrepancies based on the numerical model as well. As was previously mentioned there is a lot of soot produced from the decomposed solid propellant gas generator. The mass and density of this soot was not independently modeled, and could contribute to the discrepancy. However as can be seen in the results the numerical model does follow the same general trends that the experimental results exhibit, with the exception of injector RC5. Injector RC5 shows a different trend all together both experimentally and numerically. A possible explanation for this is due to its low momentum ratio of 3.9 (the lowest out of all injectors). There are two side effects to having such a low momentum ratio. The first is that fact that the is very poor atomization and mixing occurring due to such a low speed gas relative to the liquid so the shearing stress at the interface is significantly lower. In addition to this in order to have the gas at a lower velocity the diameter of the gas annulus must be larger than the other injectors. Since the temperature is taken at a radial distance of $8 \mathrm{~mm}$ both numerically and experimentally (where the thermocouple probes where located) the warm gas stream flow was directly on this location given such a large diameter of the annulus. 


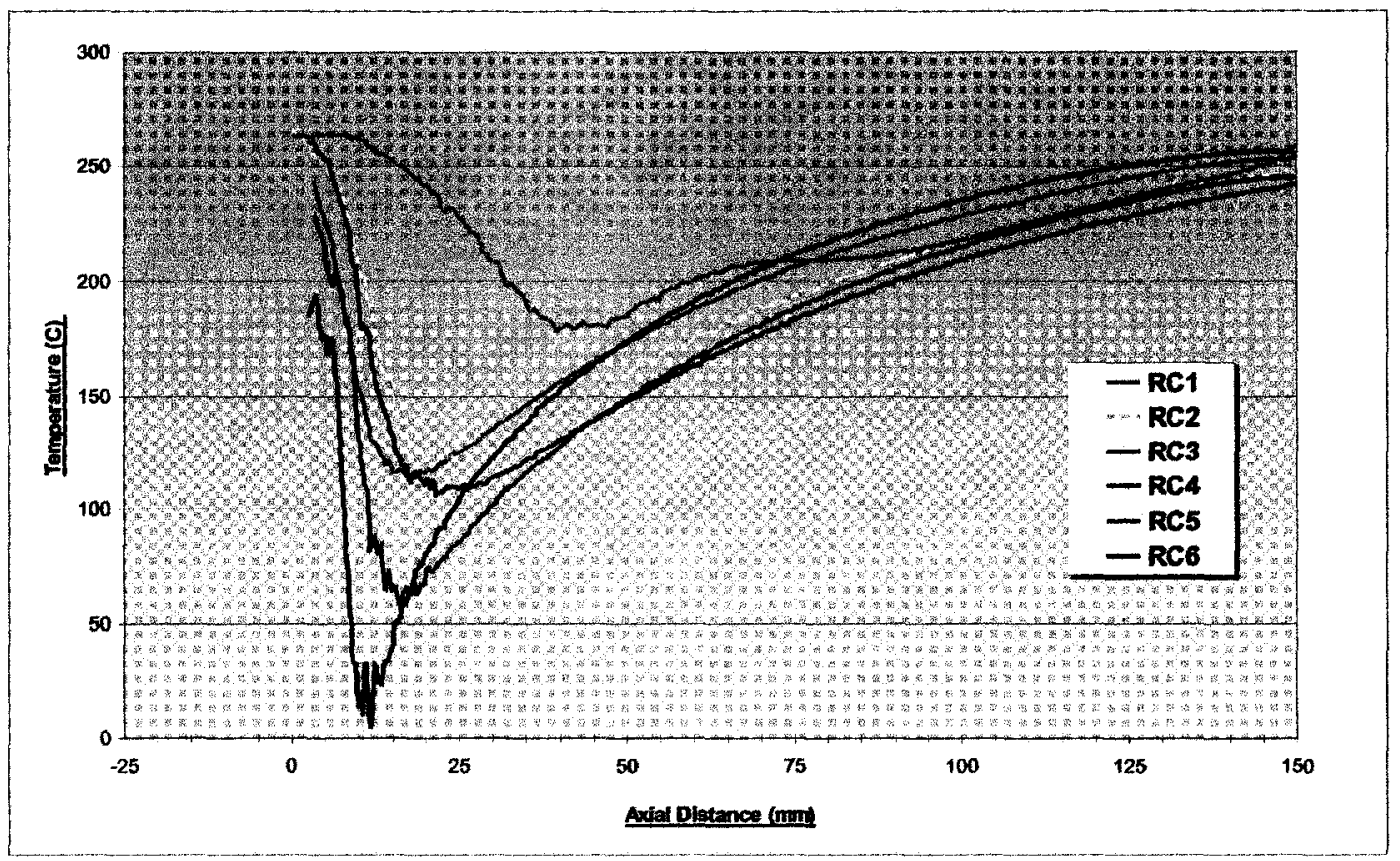

Figure 6.21: Comparison of temperature profile of all six injectors

This also explains the dip in the temperature profile within the numerical model over the first $50 \mathrm{~mm}$ which is due to the dispersion of the liquid water. As shown in the volume fraction contour plots (Figures 6.9-6.12) the water spreads radially outward as it exits the injector into the combustion chamber as would be expected. This conversely forces the GG mixture outwards as well. This shear interaction is actually part of the principle that makes the coaxial injector successful. How this effects the temperature dip is again due to the radial location (8mm) where the temperature profile is evaluated and the experimental thermocouples are 
located. When looking at the numerical temperature polyline, in the region closest to the injector faceplate (axially $0-10 \mathrm{~mm}$ ) it experience all the warm gas generator. In the region $10-50 \mathrm{~mm}$ where the dip occurs, this is causes by the water dispersing the gas outward, so the cooler water is playing a more dominate effect. As it progresses further downstream from $50 \mathrm{~mm}$ onward the temperature slower climbs up to the thermodynamic equilibrium of mixing the water and gas generator. Its for this reason why in Figure 6.21 within the region close to the injector face the temperature dip is more apparent for certain injectors that have a smaller diameter gas annulus and a larger liquid post diameter.

It was for this reason why this radial location was selected for the thermocouples and numerical polyline results. This flow condition that are exhibited which the experimental results have indicated shows that the numerical model is capturing the physics of the situation. The fact that these trends are being captured by the numerical model give confidence in verifying that the model is working correctly. 


\section{Chapter 7}

\section{Conclusions}

The AIH motor system has been shown to be a feasible propulsion system that can offer many advantages. The utilization of a fuel-rich gas generator propellant allows the safety aspect of a conventional hybrid to be maintained but differs in that it is not restricted through turbulent boundary layer heat feedback and mixing. Therefore it doesn't suffer from low burn rates and poor volumetric loading like conventional hybrids. The gas generator propellant developed for this, demonstrated that it would sustain combustion at an elevated pressure level but at ambient conditions would self-extinguish. Therefore the propellant essentially acted as an inert grain under normal handling conditions at ambient pressure. This provides it with the safety advantages that conventional hybrid offer. This safety advantage which hybrids offer translates into major cost saving and improves safety concerns associated with handling, storage, and transportation of the propellant both during 
developing of this system and later in production of the propellant.

Overall, the gas generator propellant that was developed, proved to be very successful. Using this precise propellant formulation when mixed with liquid oxygen would provide a high level of performance (Isp $=291 \mathrm{~s}$ ) as indicated theoretically using CEA. Obviously the delivered specific impulse would be less then this, but even at $90 \%$ efficiency, which would be considered conservative, this system would still provide significantly more than conventional solid propellant motors. The actual delivered specific impulse could be measured with the sub-scale motor and is discussed further in Section 7.1.2. In addition, the flame temperature was also much cooler (1200K) than typically seen from solid propellants which offers several advantages in a propulsion system such as this (i.e. low cost thrust vectoring, higher reliable, cheaper materials, etc.). Based on the hot-fire experimental testing conducted with this propellant, it was shown that a high burn rate of $6.5 \mathrm{~mm} / \mathrm{s}$ was achievable. This is well above the requirements set forth by the trajectory simulations.

The launch vehicle trajectory model was conducted to show this system is a viable option that would be capable of placing a useful payload into a realistic trajectory using this new aft-injected hybrid propulsion system. The resultant simulation showed a vehicle with a reasonable gross lift-off weight was capable of placing 
a $100 \mathrm{~kg}$ payload into a $680 \mathrm{~km}$ circular orbit at $60.4^{\circ}$ inclination.

Looking at the injector research conducted, a coaxial injector was selected and a sub-scale aft-injected hybrid motor was developed to test these injectors. This sub-scale motor used the gas generator propellant developed earlier and utilized a BATES grain to provide a neutral burn profile. The testing of the injectors was done using water which provided cooler temperatures of $\approx 250^{\circ} \mathrm{C}$, so thermocouples could be used in the post combustion chamber. The injector efficiency was evaluated both on $\eta_{c^{*}}$ and $\eta_{\Delta T}$, however due to the error in estimating the water and GG mass contribution over the action time $\eta_{\Delta T}$ proved to be a better method. The effect that the momentum ratio plays on the injector efficiencies was investigated. It was seen that there is a relationship between these two and that the higher the momentum ratio, the better the injection efficiency.

A CFD model of the injector \& combustion chamber was developed and proved a useful tool. It provided insight into the flow regime which could not be analyzed or experimentally measured. The results from this numerical model showed similar trends which the experimental tested demonstrated. Again, there appeared to be a relationship between the momentum ratio and how well the injector mixes the gas and liquid streams. Looking at the volume fraction of water downstream 
$(100 \mathrm{~mm})$ it was shown that with a higher momentum ratio there was less water present at the center line, indicating that better mixing and atomization had occurred. Overall the numerical and experimental results were relatively close to one another. They both showed the same general trend demonstrating a temperature drop near the injector faceplate due to the expansion of the water jet stream. With the success of this CFD model the advantage offered is two fold. First as the numerical model appears to represent the real life injector reasonably well, it gives significant confidence to use CFD for sizing and designing the next version injector that will utilize liquid oxygen. Secondly this model can be used to further investigate additional aspects to improve the injector efficiency such as varying the splitter plate thickness, or the effect the magnitude of the injection velocities of the two streams have. This can now be done numerically so expensive and time consuming experimental tests do not have to be conducted.

\subsection{Recommendations}

The AIH motor system is a novel system which has promise to offer several advantages. The research conducted here focused in on the gas generator propellant development and the injector. Further work and research is required on the system and its many components before it can be fully proven for a launch vehicle application. 


\subsubsection{Gas Generator Propellant}

To be used in a launch vehicle application, the gas generator propellant would need to undergo more scrutiny in terms of evaluating its mechanical properties as well as refining the burn rate to the precise level desired for the particular application. Further testing and government licensing would have to be done in order give the gas generator its hazardous classification, specifically a 1.4. Research into identifying the startup transient with the gas generator propellant should be conducted.

\subsubsection{Sub-Scale Motor}

Examining more injectors with a larger matrix of momentum ratio is need to fully understand its effect on atomization and mixing. Also repeating the same injector tests to ensure there is minimal fluctuations in the results would also be required. In addition to just examining the momentum ratio, other variable should be isolated to verify their effect on the injection efficiency. Some of these key variable include;

1. mass flow rated of both liquid and gas

2. injection velocities magnitude (both liquid \& gas)

3. splitter plate thickness (kept constant at $2 \mathrm{~mm}$ in this research) 
4. heat flux though injector walls

5. pressure drops and turbulence intensity (examine fully developed flow vs. short inlet)

There are multitudes of minor variable that may be at play with the injector efficiency, but as a whole, a wide matrix of injectors is required in order to fully isolate these variables, and understand their effects. Obviously cost and time was the key deciding factor in only testing six injectors, but additional tests are required to definitively draw conclusion.

With the actual sub-scale motor, the next step would be to conduct the injector testing using a real oxidizer instead of water. If LOX is to be used the tank and plumbing system would have to be adapted for cryogenics. The next evolution of the sub-scale test motor should be conducted using hydrogen peroxide (90-95\%) as the oxidizer. This would allow the complexity of the motor to be advanced without involving cryogenics, and would also serve as a method of comparing LOX against hydrogen peroxide in terms of performance penalty vs simplicity. Since the properties of water are very close to hydrogen peroxide it would require very minimal modifications in the current sub-scale setup to conduct these tests. This would also be very valuable in obtaining actual performance data to compare to 
CEA estimations.

\subsubsection{CFD}

The CFD model developed here in this research acts as a foundation to advancing the model further for real injector applications. With further additions to the model it can provide predictable flows for future injectors to reduce cost and time in design. It is suggested that the next step with this model is to factor in the large amounts of soot present. The soot in the gaseous flame can enhance radiative heat transfer, so modeling this could aid in predicting the overall heat transfer. Along the same lines, the heat transfer through the splitter plate wall in the injector element due to the warm gas should also be investigated further and applied to the CFD model. For completeness and to asses the symmetry assumption made, the model should be completed with a full 3-dimensional domain to verify there are no abnormal effects. This will obviously require more computational power than what was available for the current model.

In conjungation with the recommendation for the sub-scale motor to use a real oxidizer, a CFD model should be developed in parallel. This would introduce the combustion process into the model and establish its effect. Applying the eddy dissipation combustion model in CFX would allow the reaction between the GG 
products and LOX or hydrogen peroxide to be evaluated. This would provide a global model that would result in a valuable tool for injector modeling in the future. 


\section{Bibliography}

[1] Atlantic Research Corportation Virginia Propulsion Division, 'Hybrid Propulsion Technology Program Final Report Contract: NAS8-37776," Virginia, January $31,1990$.

[2] AED Electronics, "K-type Thermocouple Amplifier User Manual," Waalre, Netherlands, 2001.

[3] ASTOS 5.1.1, "ASTOS Software User Manual" Institute of Flight Mechanics and Control, University of Stuttgart, Germany, Feburary 2005.

[4] Barbeau, B., Lacas, F., Rymer, G., and Candel S., "Cryogenic Flame Modelling in a Coaxial Configuration," AIAA-1999-207, 37th AIAA Aerospace Sciences Meeting and Exhibit, Reno, Nevada, Jan 11-14, 1999.

[5] Bodele, E., Gokalp, I., Zurback, S., Saucereau, D., "Modeling Of The Break-up Of Liquid Oxygen Dropelts For Application In A Cryogenic Rocket Engine Sim- 
ulation Code," AIAA-2000-3496, 36th AIAA/ASME/SAE/ASEE Joint Propulsion Conference and Exhibit, Huntsville, AL, July 16-19, 2000.

[6] CFX 5.7.1, "Basic Solver Capability Theory," CFX 5.7.1 Reference Guide, Ansys Inc., 2004.

[7] CFX 5.7.1, "Discretisation and Solution Theory," CFX 5.7.1 Reference Guide, Ansys Inc., 2004.

[8] CFX 5.7.1, "Turbulance And Near Wall Theory," CFX 5.7.1 Reference Guide, Ansys Inc., 2004.

[9] Cheng, G.C., Farmer, R.C., "CFD Spray Combustion Model for Liquid Rocket Engine Injector Analysis, " AIAA-2002-0785, 40th AIAA Aerospace Sciences \& Exhibit , Reno, NV, July 14-17, 2002.

[10] Cho, N., Kim, S., Kim, Y.,Jeong, S., Jeong, J. "Two-Phase Flow Characteristics of Liquid Oxygen Flow In Low Pressure Liquid Rocket Engine," Cryogenics, Vol 44., pp. 493-500, 2004.

[11] Cohen, N.S., Strand, L.D., "Hybrid propulsion based on fluid controlled Solid Gas Genrator," . 
[12] Cohen, J., Landers, L.C. and Lou, R.L., "Minium Response Delay Controllable Solid Propellant Gas Generators," Journal of Spacecraft and Rockets,Vol. 14, No. 5, pp. 310-314, May-June 1997.

[13] Culver, D.W., "Comparison of Forward and Aft Injected Hybrid Rocket Boosters," AIAA 91-2586, 27th AIAA/SAE/ASME Joint Propulsion Conference, Sacrameto, CA, June 24-26, 1991.

[14] Culver, D.W. and Muenggenburg, H.H. "Aft Mounted Gas-Liquid Injector Technology For Gas Generator Cycle Hybrid Rockets," AIAA 91-2586, 27th AIAA/SAE/ASME Joint Propulsion Conference, Sacrameto, CA, June 24-26, 1991.

[15] Elands, P.J., Korting, P., Wijchers, T., "Comparison of Combustion Experiments and Theory in Polyethylene Solid Fuel Ramjets," Journal of Propulsion and Power, Vol. 6, No. 6, pp. 732-739, Nov-Dec 1990.

[16] Farbar, E., "Experimental and Numerical Study of a Hydrogen Peroxide / Hydroxyl Terminated Polybutadiene Hybrid," Thesis Carleton University, Department of Mechanical and Aerospace Engineering, November 25, 2004.

[17] Ferraro, M. Kujala, M., Thomas, J.L., and Micci, M.M., "Measurements of shear coaxial injector sprays - Cold flow and hot fire experiments," AIAA- 
1996-3028 , 32nd AIAA/ASME/SAE/ASEE Joint Propulsion Conference and Exhibit, Lake Buena Vista, Florida, July 1-3, 1996.

[18] Gurliat, O., Schmidt, V., Haidn, O.J., Oschwald, M., "Ignition of Cryogenic H2/LOX Sprays," Aerospace Science and Technology," Vol. 7, pp 517-531, 2003.

[19] Haridwar S. and Himanshu S., "Science and Technology of Solid rocket Propellants", Printwell Inc., Darbhanga, India, 2005.

[20] Huang, D.H, and Huzel, D.K, "Modern Engineering For Design of Liquid Propellant Rocket Engines," Progess in Astronautics and Aeronautics Vol. 147. AIAA. 1992.

[21] Korting, P.A.O.G, Zee, F.W.M., and Meulenbrugge, J.J., "Combustion Characteristics of Low Flame Temperature Cholorine-Free Composite Solid Propellants," Journal of Propulsion and Power, Vol. 6, No. 3, pp. 250-255, May-June 1990.

[22] Kuo, K.K and Summerfield, M., "Fundamentals of Solid Propellant Combustion," Progess in Astronautics and Aeronautics Vol. 90. AIAA. 1984.

[23] Kim, B. and Heistery, S.D.,"Two-phase Modeling and Hydrodynamic Instability Study of Shear Coaxial Injector Flow," AIAA 2002-3696, 38th 
AIAA/ASME/SAE/ASEE Joint Propulsion Conference and Exhibit, Indianapolis, Indiana, July 7-10, 2002.

[24] Lauwers, J., Step Motor CAD Drawing, Cesaroni Technologies Inc.

[25] Lonchard, J., Thomas, J., and Fournet, A., "Technology Demonstration for Low Cost Gas Generator, " AIAA-2004-4006 , 40th AIAA/ASME/SAE/ASEE Joint Propulsion Conference and Exhibit, Lauderdale, Florida, July 11-14, 2004

[26] Lund, G.K., Starrett, D., and Jensen, K.C., "Development and Lab Scale Testing of a Gas Generator Hybrid Fuel in Support of the Hydrogen Peroxide Hybrid upper Stage Program, " AIAA-1997-3095, 37th AIAA/ASME/SAE/ASEE Joint Propulsion Conference and Exhibit, Salt Lake, Utah, July 8-11, 2001.

[27] Mah, C.S., "Evaluating The Operational Limits of a Gas Generator, " AIAA2001-3990, 37th AIAA/ASME/SAE/ASEE Joint Propulsion Conference and Exhibit, Salt Lake, Utah, July 8-11, 2001.

[28] Markopoulos, P. and Abel, T., "Developement and Testing of a Hydrogen Peroxide Hybrid Upper Stage Propulsion System " AIAA-2001-3243, 37th AIAA/ASME/SAE/ASEE Joint Propulsion Conference and Exhibit, Salt Lake, Utah, July 8-11, 2001. 
[29] Mayer, W. and Krulle, G., "Rocket Engine Coaxial Injector Liquid/Gas Interface Flow Phenomena," Journal of Propulsion and Power, Vol. 11, No. 3, pp. 513-518, May-June 1995.

[30] McBride, B.J., and Sanford, G., "Computer Program For Calculation of Complex Chemcial Equilibrium Compositions and Applications PartI-Analysis" NASA Reference Publication 1311, Cleveland, Ohio 1994.

[31] McBride, B.J., and Sanford, G., "Computer Program For Calculation of Complex Chemcial Equilibrium Compositions and Applications PartI-Users Manual and Program Describtion" NASA Reference Publication 1311, Cleveland, Ohio, June 1996.

[32] Miyata, K. and Fredrick, R.A., "Ammonium Nitrate-Based Solid Fuel Gas Generator For Gas Hybrid Rockets," AIAA-1996-3254 , 32nd AIAA/ASME/SAE/ASEE Joint Propulsion Conference and Exhibit, Lake Buena Vista, Florida, July 1-3, 1996.

[33] Moon, L.F., "Pressure And Velocity In A Developing Coaxial Jet," AIAA Journal, Vol. 14, No. 1, pp. 43-49, January 1976.

[34] Obermaier, G., Taubenberger, G., and Feyhl, D., "Coaxial injector development for storable propellant upper stage turbopump engines," AIAA-1997-3095, 32nd 
AIAA/ASME/SAE/ASEE Joint Propulsion Conference and Exhibit, Seattle, WA, July 6-9, 1997.

[35] Omega Engineering; "Product Catalog - Comparison of Time Constant vs. Overall Outside Diameter of Bare Thermocouple Wires or Grounded Junction Thermocouples In Air," Omega Engineering Inc., pg Z-51, Stamford, CT, 2005.

[36] Osherov, A., and Benveniste, N., "The Starting Transient In A Gas Generator Hybrid Rocket Motor," Journal of Propellants, Explosives, Pyrotechnics, Vol. 25, No. 3, pp. 260-270, 2000.

[37] Price, C.F., and Smoot, L.D., "Regression rates of nonmetalized hybrid fuel systems ," AIAA Journal, Vol. 3, No. 8, pp. 1408-1413, 1965.

[38] Smith, T.D., Klem, Breisacher, K.J, Farhangi, S. and Sutton, R. "Experimental Evaluation of a Subscale Gaseous Hydrogen/Gaseous Oxygen Coaxial Rocket Injector," NASA/TM2002-211982, Glenn Research Center, November 2002.

[39] Schmidt, V., Wepler, U., Haidn, O.J., and Oschwald, M., "Characterization Of The Primary Ignition Process Of A Coaxial GH2/LOX Spray," AIAA-1997. 3095, 42nd AIAA Aerospace Sciences Meeting and Exhibit, Reno, Nevada, Jan $5-8,2004$. 
[40] Stern, F., Muste, M., Beninati, M.L., and Eichinger, W.E., "SUMMARY OF EXPERIMENTAL UNCERTAINTY ASSESSMENT METHODOLOGY WITH EXAMPLE," IIHR Technical Report No. 406,Institute of Hydraulic Research College of Engineering, Universtiy of Iowa, Iowa City, Iowa, July 1999.

[41] Stowe, R.A., "Performance Prediction of a Ducted Rocket Combustor," Thesis DREV TR 2001-200, Laval University,Faculte Des Sciences Et De Genie, Quebec, August 2001.

[42] Sutton, P.G. and Biblarz, O., "Rocket Propulsion Elements," 7th Ed., John Wiley \& Sons Inc., New York, 2001.

[43] Vaidyanathan, R., Tucker, K., Papila, N. and Shyy, W.(, "CFDBASED DESIGN OPTIMIZATION FOR A SINGLE ELEMENT ROCKET INJECTOR," AIAA-1997-3095, 41st AIAA Aerospace Sciences Meeting and Exhibit, Reno, Nevada, Jan 6-9, 2003.

[44] Wernimont E.J. and S. D. Heistert, S.D., "Reconstruction Technique for Reducing Hybrid-Rocket Combustion Test Data," Journal of Propulsion and Power,Vol. 15, No. 1, pp. 128-136, Jan-Feb 1999.

[45] White, F., "Fluid Mechanics," 4th Ed., McGraw-Hill Inc., New York, 1999. 
[46] XiaoPing $\mathrm{Hu}$, Jin Zhou, YuLin Zhang, and ZhenGuo Wang, "A Simplified Design Methodology For Coaxial Swirl Injector," AIAA-1997-2971, 33rd AIAA/ASME/SAE/ASEE Joint Propulsion Conference and Exhibit, Seattle, WA, July 6-9, 1997.

[47] Xiaoping $\mathrm{Hu}$, Jin Zhou, Zhenguo Wang, and Liangsheng Zhong, "Experimental Studies on Atomization and Flux Distributions of Gas-Liquid Coaxial Injectorsr," AIAA-1996-3023, 32nd AIAA/ASME/SAE/ASEE Joint Propulsion Conference and Exhibit, 32nd, Lake Buena Vista, FL, July 1-3, 1996. 


\section{Appendix A \\ Chemical Equilibrium Analysis (CEA) Output}

CEA was used extensively with the gas generator propellant development therefore an example is presented here. The output file is shown, which contains the input file in the first 15 lines. Due to proprietary restrictions of Cesaroni Technology Inc the precise propellant formulations can not be distributed. The exact weight percentages $(w t \%=)$ for the gas generator ingredients has been omitted in the input file and all weight percentages have been replaces with XX.X. The rest of the output file remains unaltered. 


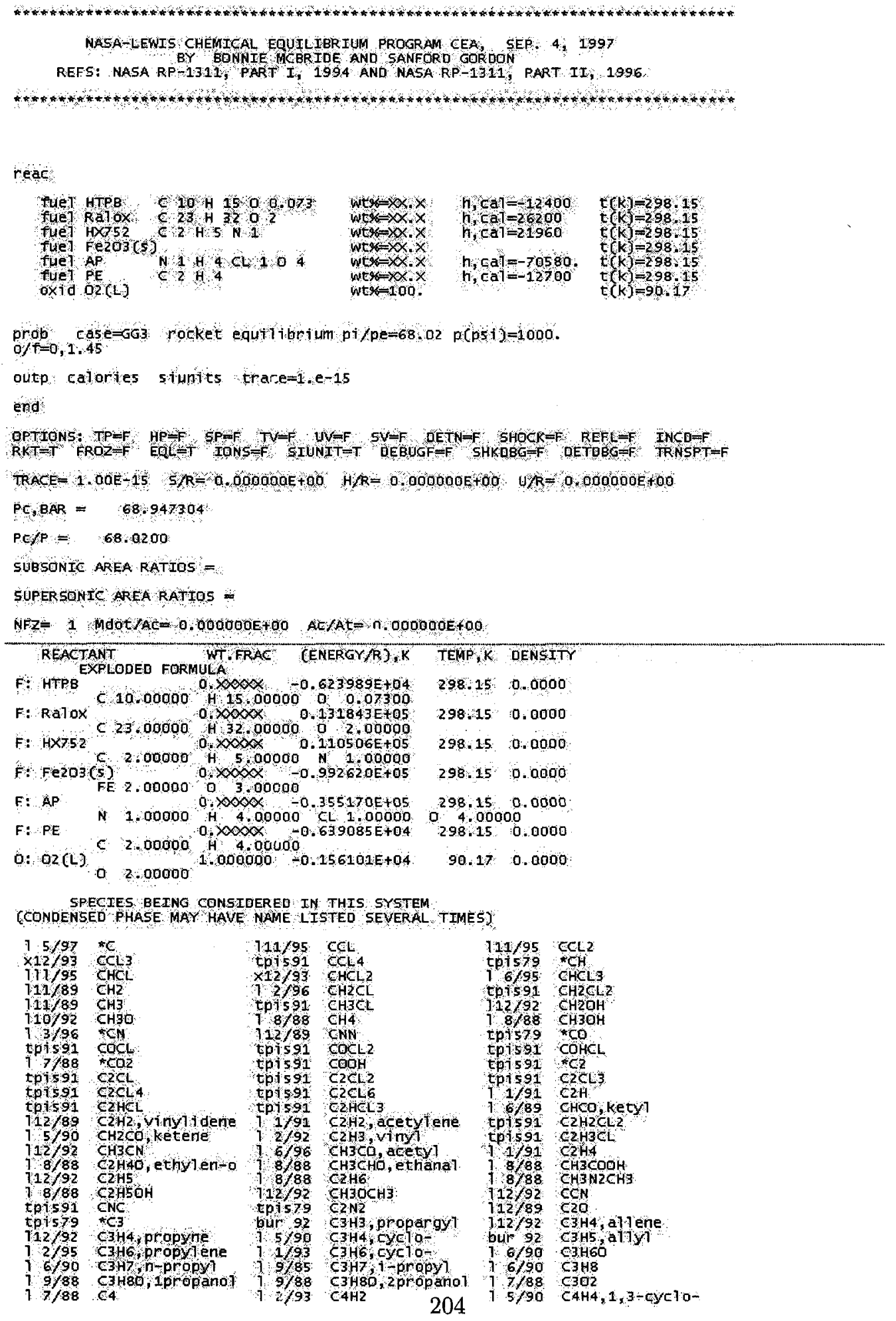




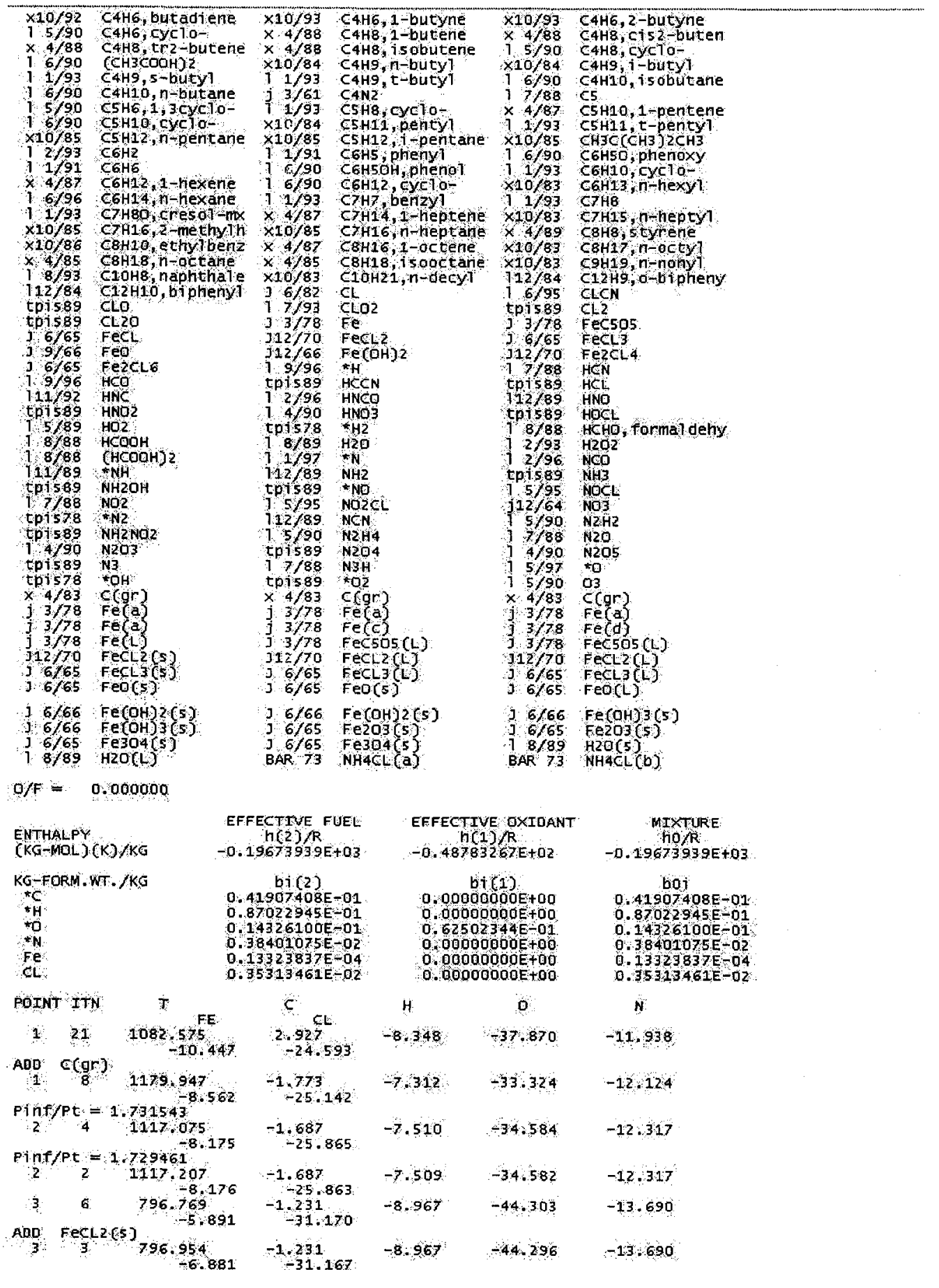


THEORETICAL ROCKET PERFORMANCE ASSUMING EQUILIBRIUM

COMPOSITION DURING EXPANSION FROM INFINTTE AREA COMBUSTOR

RANJ $=1000$. $=$ PGI
CAS

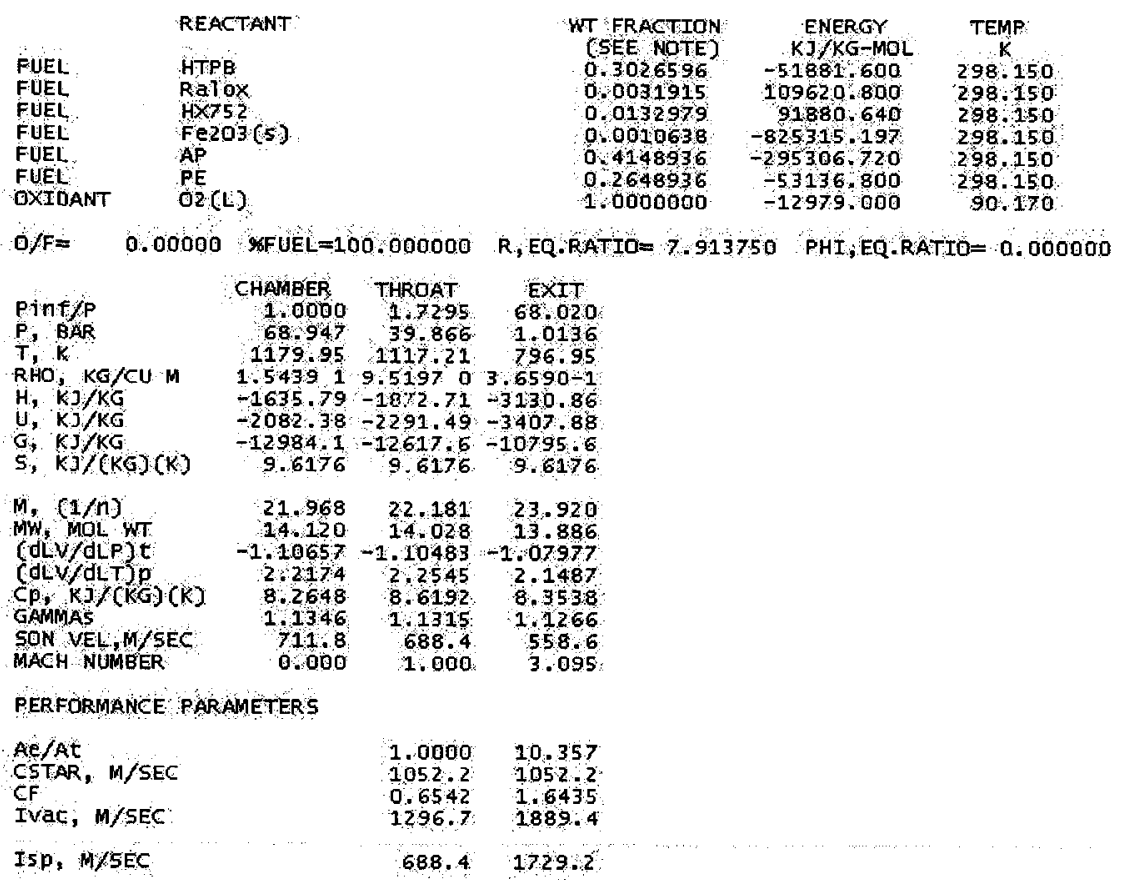

MOLE FRACTIONS

\begin{tabular}{|c|c|c|c|}
\hline 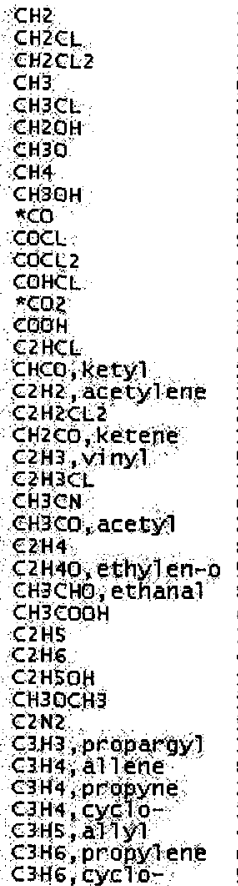 & 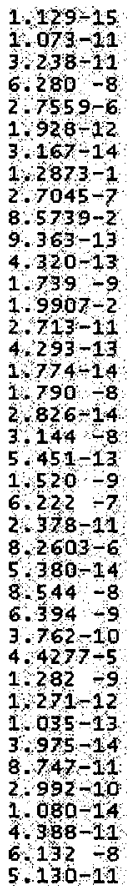 & 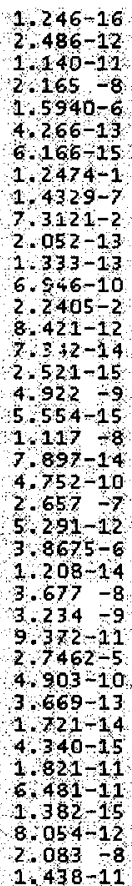 & 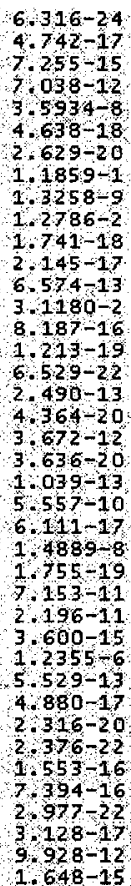 \\
\hline
\end{tabular}




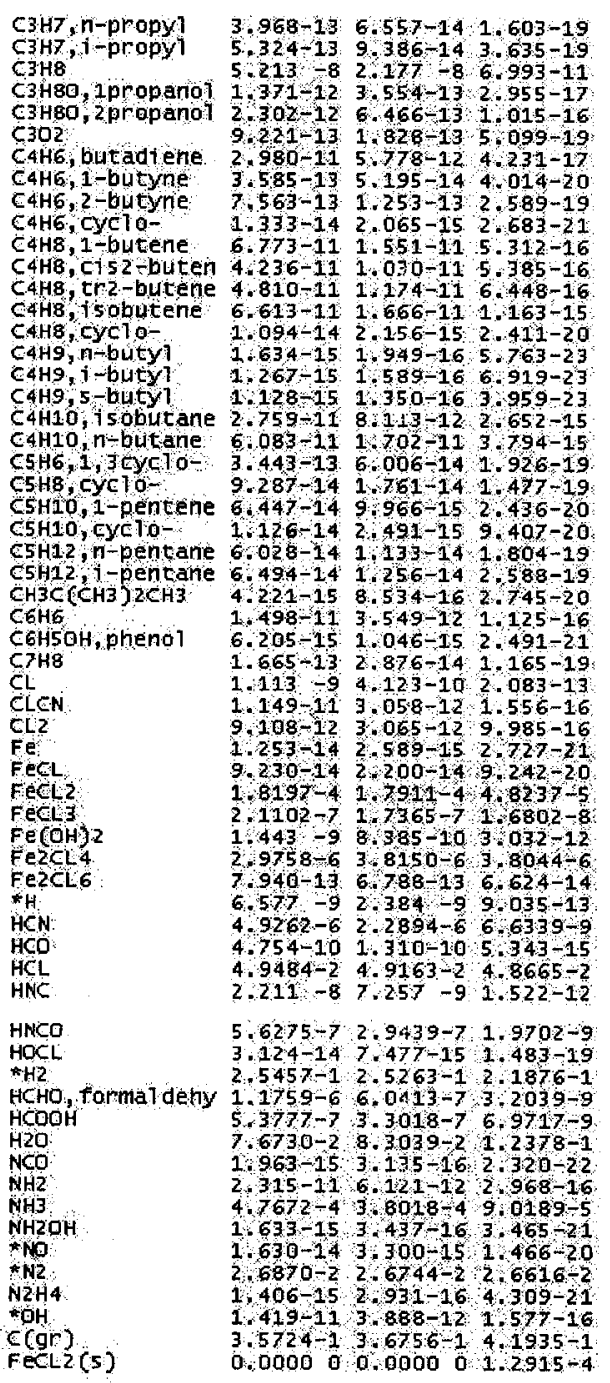

* THERMODMAMIC PROPERTIES FITTED TO 20000,K

PROQUCTS WHICH WERE CONS IDERED BUT WHOSE MOLE FRACTIONS WERE LESS THAN 1.000000 - 15 FOR ALL ASSIGNED CONOTTIONS

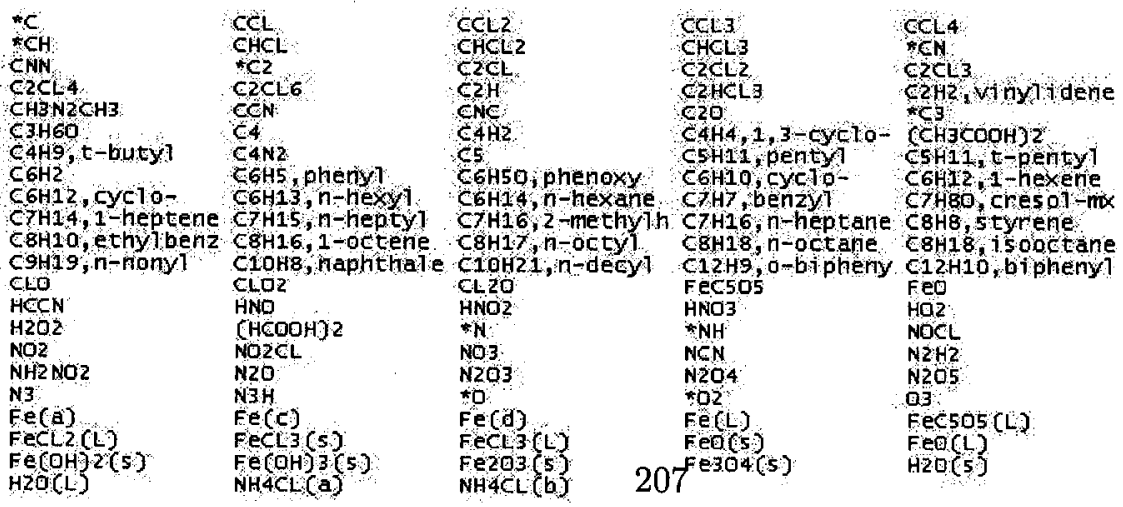


NOTE. WEIGHT FRACTION OF FUEL IN TOTAL FUELS AND OF OXIDANT IN TOTAL OXIDANTS

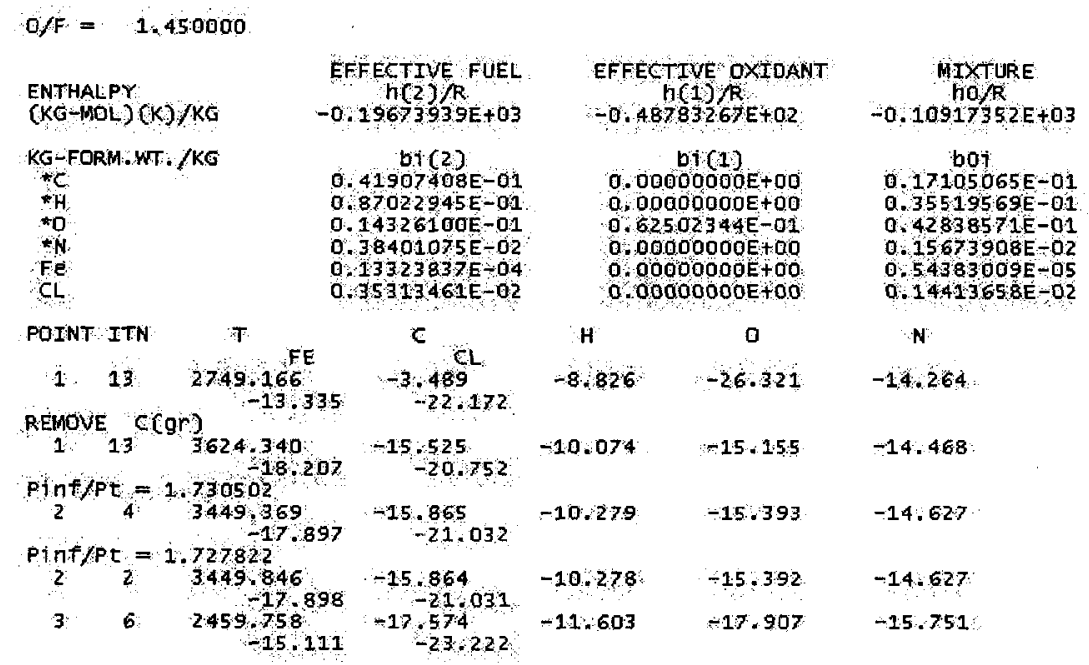

THEORETICAL ROCKET PERFORMANCE ASSUMING EQUTL IBRIUM

COMPOSITION QUR ING EXPANSION FROM TNFINTTE AREA COMBUSTOR

Pin $y=1000$. D PSIA

\begin{tabular}{|c|c|c|c|c|}
\hline & REACTANT & WTFAACTION: & ENERGY & $\begin{array}{l}\text { TEMP } \\
K\end{array}$ \\
\hline & HTPB & 0,3026596 & $-51881 \cdot 600$ & 298.1 \\
\hline FUEL & Ralox & 0.0031915 & 109620.800 & 298.15 \\
\hline FUEL & $4 \times \bigcirc 52$ & 0,0132979 & 91880.640 & 298.15 \\
\hline FUEL: & $F e 203(5)$ & 0.0010638 & $-825315,197$ & 298.15 \\
\hline FUEL & $A P$ & 0.4148936 & -295306720 & 29 \\
\hline FUEL: & $P E$ & 0.2648936 : & $-53136,800$ & 29 \\
\hline DXTDAN & $02(4)$ & 1,0000000 & -12979.000 & \\
\hline
\end{tabular}

$O / F=1,45000$ \%FUEL $=40,81632 \mathrm{~T}$ R,EQ.RATIO-1.193273 PHT, EQ.RATIO=1.227590

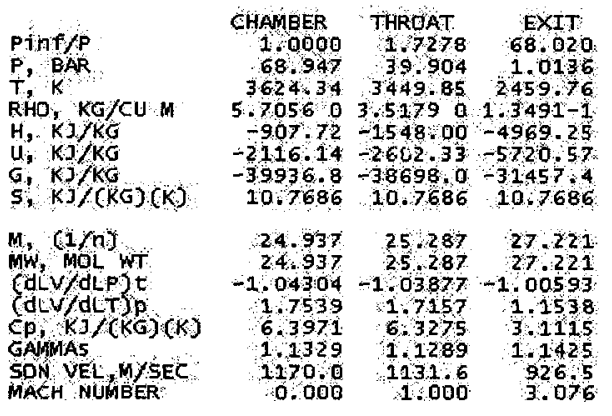

PERFORMAXCE PARAMETERS

\begin{tabular}{|c|c|c|}
\hline $\begin{array}{l}\mathrm{AE} / \mathrm{At} \\
\mathrm{CF} \text { AR, } \mathrm{M} / \mathrm{SEC} \\
\text { IVaC, M/SEC }\end{array}$ & $\begin{array}{r}1,0000 \\
17320 \\
0.6534 \\
21340\end{array}$ & $\begin{array}{l}10,353 \\
1732.0 \\
1.5456 \\
13.7\end{array}$ \\
\hline $\mathrm{Isp}, \mathrm{M} / \mathrm{sEC}$ & 1131.6 & 2850.1 \\
\hline
\end{tabular}


MOLE FRACTIONS

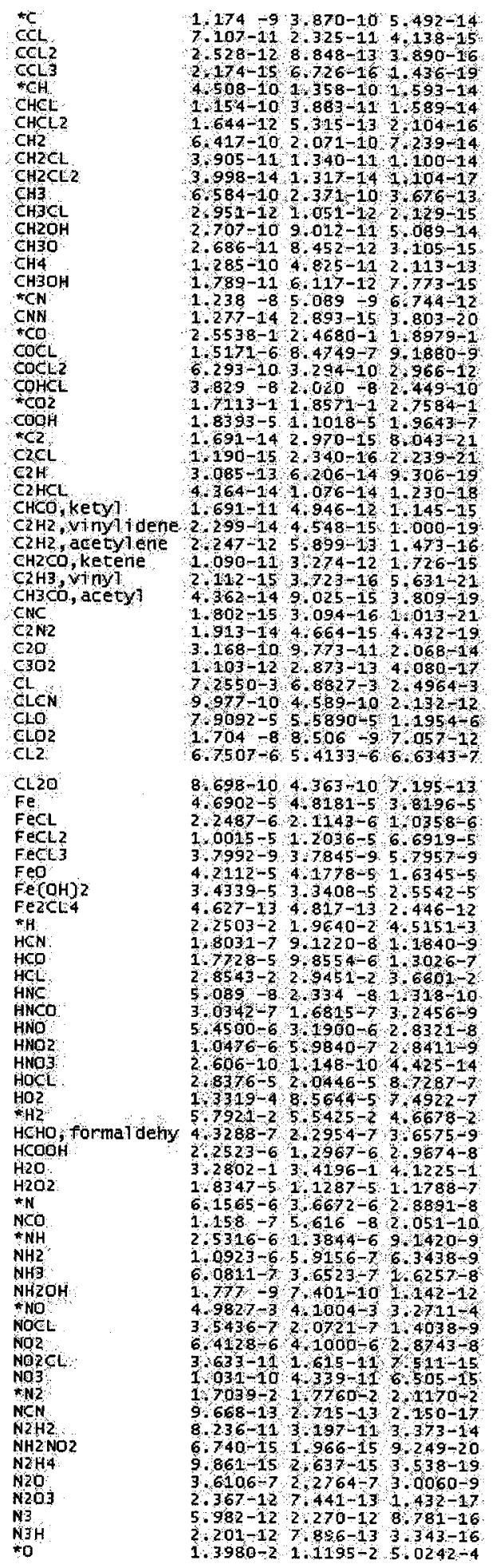




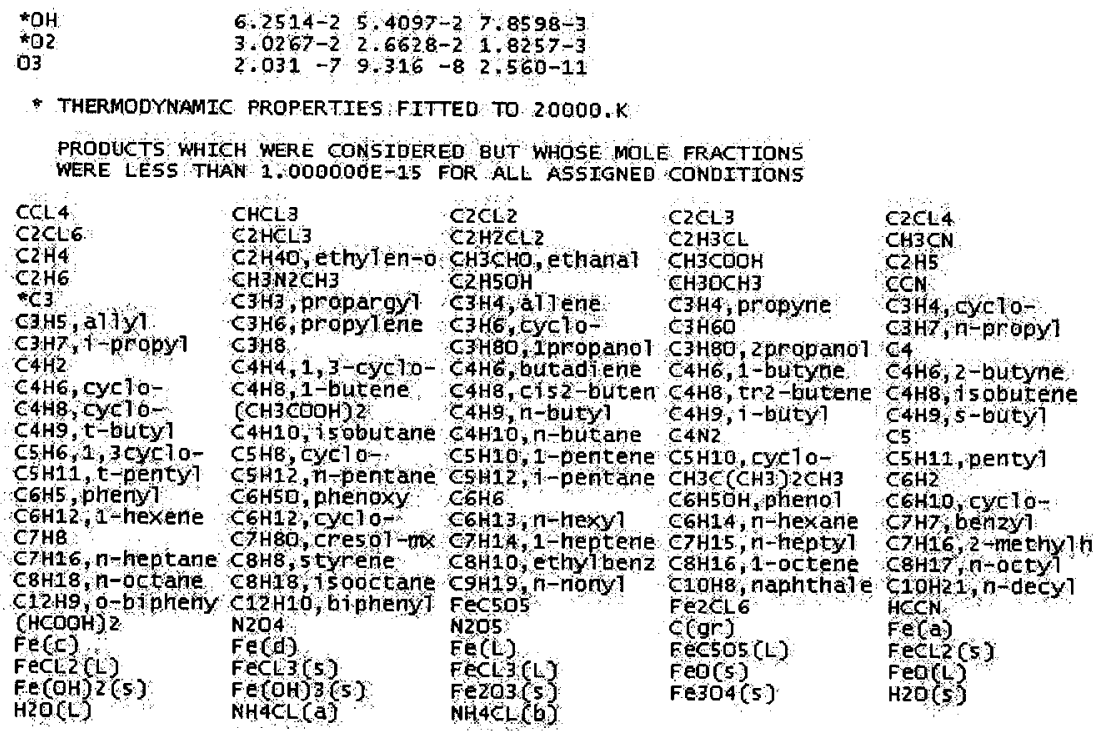

NOTE, WEIGHT FRACTION OF FUEL IN TOTAL FUELS ANO OF OXIDANT IN TOTAL OXIOANTS 


\section{Appendix B}

\section{Polynomial Coefficients In NASA Format}

Table 1: CEA Output For Gas Generator

\begin{tabular}{|c|c|c|c|c|c|c|}
\hline & \multicolumn{2}{|c|}{$\overline{\mathrm{CH} 4}$} & \multicolumn{2}{|c|}{$\mathrm{CO}$} & \multicolumn{2}{|c|}{$\mathrm{CO} 2$} \\
\hline & Lower & Upper & Lower & Upper & Lower & Upper \\
\hline a1 & $7.79 \mathrm{E}-01$ & $1.68 \mathrm{E}+00$ & $3.26 \mathrm{E}+00$ & $3.03 \mathrm{E}+00$ & $2.28 \mathrm{E}+00$ & $4.45 \mathrm{E}+00$ \\
\hline$a 2$ & $1.75 \mathrm{E}-02$ & $1.02 \mathrm{~F}_{r}-02$ & $1.51 \mathrm{E}-03$ & $1.44 \mathrm{E}-03$ & $9.92 \mathrm{E}-03$ & $3.14 \mathrm{E}-03$ \\
\hline a3 & $-2.78 \mathrm{E}-05$ & $-3.88 \mathrm{E}-06$ & $-3.88 \mathrm{E}-06$ & $-5.63 \mathrm{E}-07$ & $-1.04 \mathrm{E}-05$ & $-1.28 \mathrm{E}-06$ \\
\hline $\mathrm{a} 4$ & $3.05 \mathrm{E}-08$ & $6.79 \mathrm{E}-10$ & $5.58 \mathrm{E}-09$ & $1.02 \mathrm{E}-10$ & $6.87 \mathrm{E}-09$ & $2.39 \mathrm{E}-10$ \\
\hline$a 5$ & $-1.22 \mathrm{E}-11$ & $-4.50 \mathrm{E}-14$ & $-2.47 \mathrm{E}-12$ & $-6.91 \mathrm{E}-15$ & $-2.12 \mathrm{E}-12$ & $-1.67 \mathrm{E}-14$ \\
\hline$a 6$ & $-9.83 E+03$ & $-1.01 \mathrm{E}+04$ & $-1.43 \mathrm{E}+04$ & $-1.43 \mathrm{E}+04$ & $-4.84 \mathrm{E}+04$ & $-4.90 \mathrm{E}+04$ \\
\hline \multirow[t]{3}{*}{ a7 } & $1.37 \mathrm{E}+01$ & $9.62 \mathrm{E}+00$ & $4.85 \mathrm{E}+00$ & $6.11 \mathrm{E}+00$ & $1.02 \mathrm{E}+01$ & $-9.55 \mathrm{E}-01$ \\
\hline & \multicolumn{2}{|c|}{ HCL } & \multicolumn{2}{|c|}{$\mathrm{H2}$} & \multicolumn{2}{|c|}{ H20 } \\
\hline & Lower & Upper & Lower & Upper & Lower & Upper \\
\hline a1 & $3.34 \mathrm{E}+00$ & $2.76 \mathrm{E}+00$ & $3.30 \mathrm{E}+00$ & $2.99 \mathrm{E}+00$ & $3.39 \mathrm{E}+00$ & $2.67 \mathrm{E}+00$ \\
\hline $\mathrm{a} 2$ & $1.27 \mathrm{E}-03$ & $1.47 \mathrm{E}-03$ & $8.25 \mathrm{E}-04$ & $7.00 \mathrm{E}-04$ & $3.47 \mathrm{E}-03$ & $3.06 \mathrm{E}-03$ \\
\hline a3 & $-3.67 \mathrm{E}-06$ & $-4.97 \mathrm{E}-07$ & $-8.14 \mathrm{E}-07$ & $-5.63 \mathrm{E}-08$ & $-6.35 \mathrm{E}-06$ & $-8.73 \mathrm{E}-07$ \\
\hline $\mathrm{a4}$ & $4.70 \mathrm{E}-09$ & $8.11 \mathrm{E}-11$ & $-9.48 \mathrm{E}-11$ & $-9.23 \mathrm{E}-12$ & $6.97 \mathrm{E}-09$ & $1.20 \mathrm{E}-10$ \\
\hline $\mathrm{a} 5$ & $-1.84 \mathrm{E}-12$ & $-5.07 \mathrm{E}-15$ & $4.13 \mathrm{E}-13$ & $1.58 \mathrm{E}-15$ & $-2.51 \mathrm{E}-12$ & $-6.39 \mathrm{E}-15$ \\
\hline a6 & $-1.21 \mathrm{E}+04$ & $-1.19 \mathrm{E}+04$ & $-1.01 \mathrm{E}+03$ & $-8.35 \mathrm{E}+02$ & $-3.02 \mathrm{E}+04$ & $-2.99 \mathrm{E}+04$ \\
\hline \multirow[t]{3}{*}{$a 7$} & $3.19 \mathrm{E}+00$ & $6.52 \mathrm{E}+00$ & $-3.29 \mathrm{E}+00$ & $-1.36 \mathrm{E}+00$ & $2.59 \mathrm{E}+00$ & $6.86 \mathrm{E}+00$ \\
\hline & \multicolumn{2}{|c|}{ H20 } & \multicolumn{2}{|c|}{ N2 } & \\
\hline & Lower & Upper & Lower & Upper & Lower & Upper \\
\hline a1 & $3.39 \mathrm{E}+00$ & $2.67 \mathrm{E}+00$ & $3.30 \mathrm{E}+00$ & $2.93 \mathrm{E}+00$ & $-6.71 \mathrm{E}-01$ & $1.49 \mathrm{E}+00$ \\
\hline a2 & $3.47 \mathrm{E}-03$ & $3.06 \mathrm{E}-03$ & $1.41 \mathrm{E}-03$ & $1.49 \mathrm{E}-03$ & $7.18 \mathrm{E}-03$ & $1.66 \mathrm{E}-03$ \\
\hline a3 & $-6.35 \mathrm{E}-06$ & $-8.73 \mathrm{E}_{-}-07$ & $-3.96 \mathrm{E}-06$ & $-5.68 \mathrm{E}-07$ & $-5.63 \mathrm{E}-06$ & $-6.69 \mathrm{E}-07$ \\
\hline a4 & $6.97 \mathrm{E}-09$ & $1.20 \mathrm{E}-10$ & $5.64 \mathrm{E}-09$ & $1.01 \mathrm{E}-10$ & $2.14 \mathrm{E}-09$ & $1.29 \mathrm{E}-10$ \\
\hline $\mathrm{a5}$ & $-2.51 \mathrm{E}-12$ & $-6.39 \mathrm{E}-15$ & $-2.44 \mathrm{E}-12$ & $-6.75 \mathrm{E}-15$ & $-4.17 \mathrm{E}-13$ & $-9.21 \mathrm{E}-15$ \\
\hline $\mathrm{a} 6$ & $-3.02 \mathrm{E}+04$ & $-2.99 \mathrm{E}+04$ & $-1.02 \mathrm{E}+03$ & $-9.23 \mathrm{E}+02$ & $-7.34 \mathrm{E}+01$ & $-7.07 \mathrm{E}+02$ \\
\hline a7 & $2.59 \mathrm{E}+00$ & $6.86 \mathrm{E}+00$ & $3.95 \mathrm{E}+00$ & $5.98 \mathrm{E}+00$ & $2.60 \mathrm{E}+00$ & $-8.72 \mathrm{E}+00$ \\
\hline
\end{tabular}

